(x) d

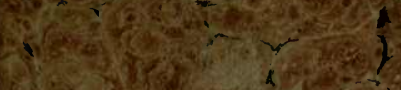

$$
\text { 3. }
$$

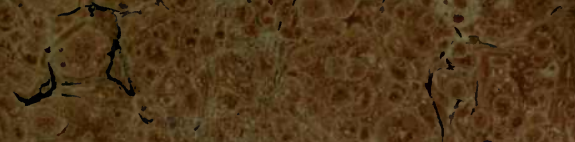

(3)

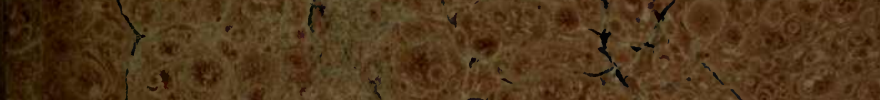

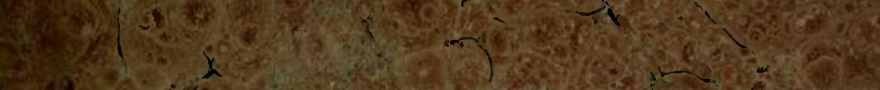

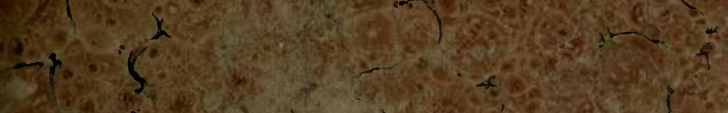

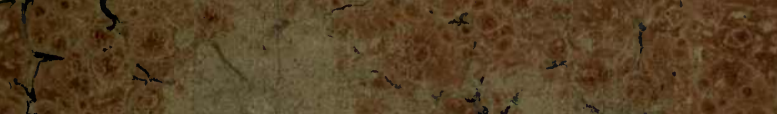

the The

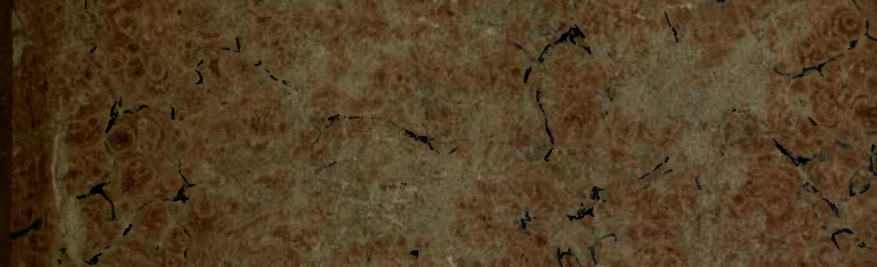

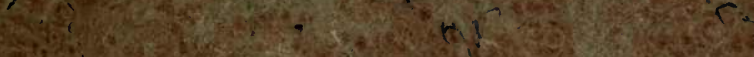

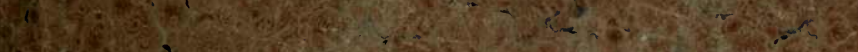

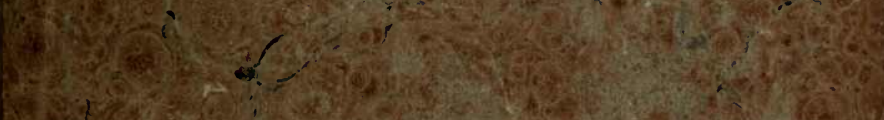


CASE
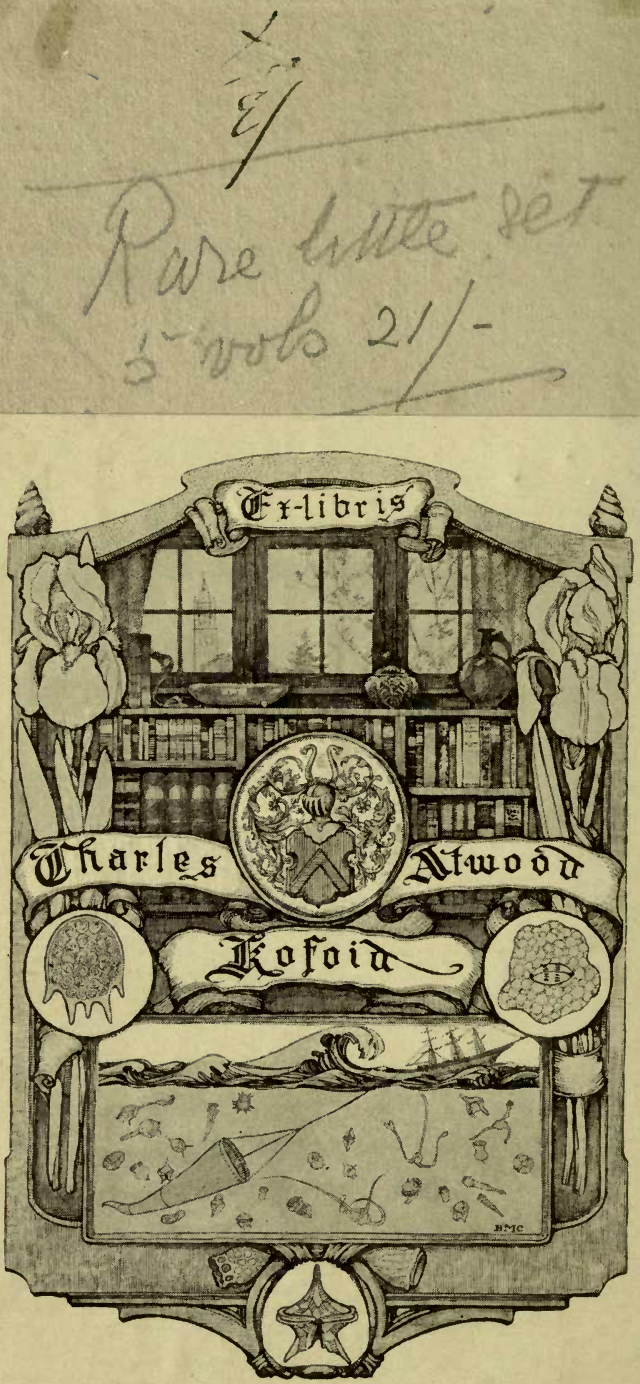


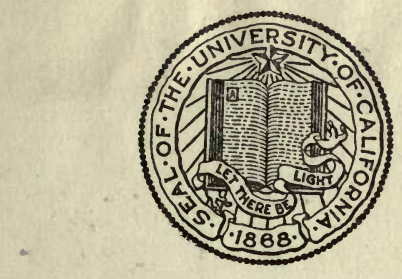

THE LIBRARY OF

THE UNIVERSITY OF CALIFORNIA

\author{
PRESENTED BY
}

PROF. CHARLES A. KOFOID AND MRS. PRUDENCE W. KOFOID 

A

$S \mathbb{U} \mathbb{V} \mathbb{E}$

OP THE

\section{WISDOM OF GOD}

IN THE

\section{CREATION :}

OR,

A COMPENDIUM

of

Patural Đyilosouby.

IN FIVE VOLUMES.

\section{BY JOHN W ESLEY, A. M.}

A. NEW EDITION, REVISED AND CORPECTED.

\section{VOL. I. :}

The se are thy glorious Works, Parent of Golod,

Almighty! Thine this universal Frame,

'Thus wond'rous fair : Thygelf how wond'rous then'?

MILTON.

LONDON :

Printed by W. Flint, Old Bailey,

FOR MAXWELX AND WILSON, 17, SKINNER STREET, SNOW-RILR,

ALD WILLIAMS AND SMITH, STATIONIR'S COURT. -

1809. 

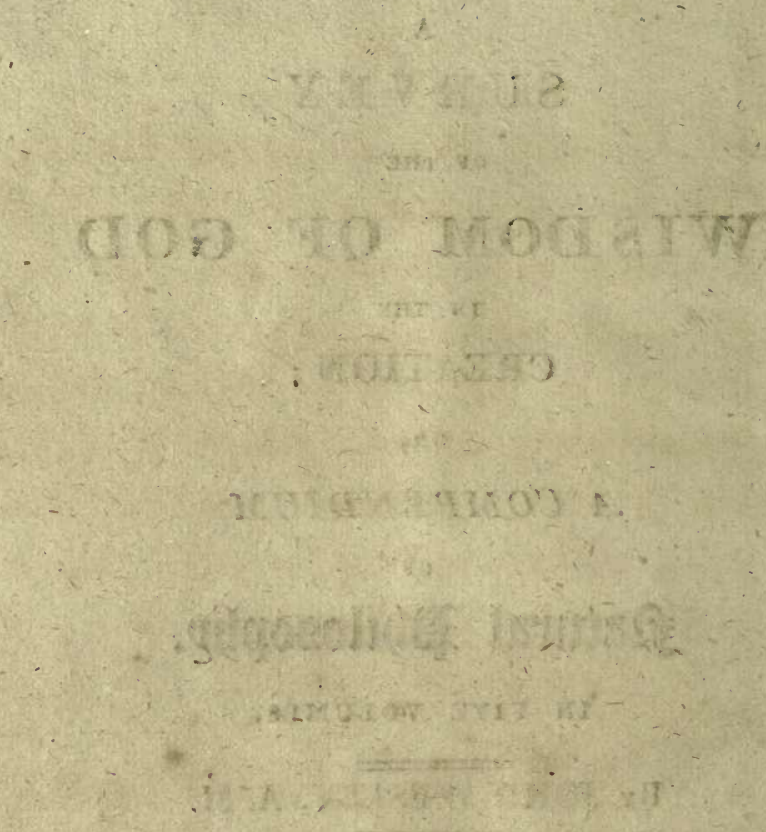

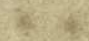

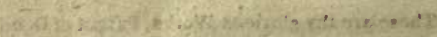

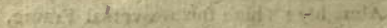

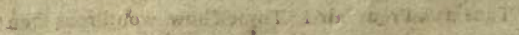
Peis in $+5$

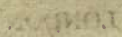

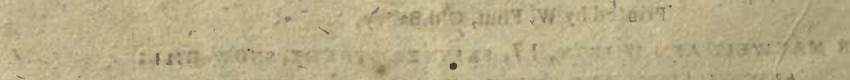

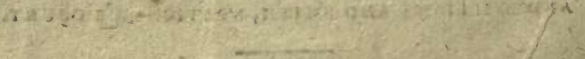

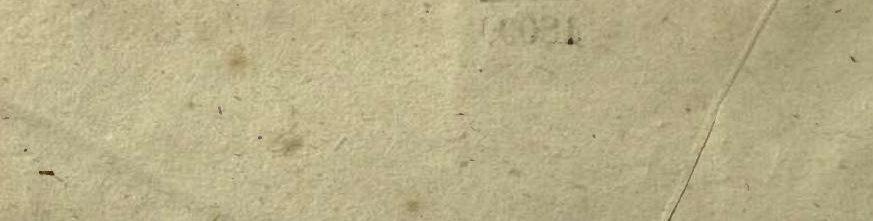




\section{$K-Q 157$ \\ w4. \\ 1809 \\ U. 1 \\ Biology \\ PREFACE: hibiary}

1. I Have long desired to see such a $C o m$ pendium of Natural Philosophy, as was, 1. Not too diffuse, not expressed in many words, but comprised in so moderate a compass, as not to require any large expence, either of time or money. 2. Not maimed or imperfect; but containing the heads of whatever (after all our discoveries) is known with any degree of certainty, either with regard to the earth or the heavens. And this I wanted to see, 3. In . the plainest dress, simply and nakedly expressed, in the most clear, easy, and in: VOL. 1 . 
telligible manner, that the nature of the things would allow; particularly free from all the jargon of mathematics, which is mere heathen Greek to common readers. At the same time I wished to see this short, full, plain account of the visible creation, directed to its right end: not barely to entertain an idle barren curiosity, but to display the invisible things of God, his power, wislom, and goodness.

2. But I cannot find such a treatise as this in any molern, any more than ancient language; and I am certain there is none such in the English tongue. What comes nearest to it of any thing I have seen, is Mr. Ray's Wisdom of God in the Creation; Dr. Derham's Physico and Astro-Theology; Niewentyt's Retigious Philosopher; Mather's Christian Philosopher, and $\mathrm{Na}$ ture delineated. But none of these, single, auswers the design; and who will be at the 
pains to extract the substance of them all, and add the later discoveries, of which they had little knowledge, and therefore could take but little notice. This is a desideratum still, and one that a lover of. mankind would rejoice to see even tolerably supplied.

3. I am thoroughly sensible there are many who have far more ability, as well as leisure, for such a work than me; but as none of them undertake it, I have myself made some little attempt in the ensuing volumes. Herein following Mr. Derham's plan, I divide the work into text and notes.* The text is in great measure translated from the Latin work of John Francis Buddceus, the late celebrated professor of philosophy in the University of Jena, in Germany. But I have found oc-

- So it was in the first edition. Many of these are, now taken into the text. 


\section{vi}

casion to retrench, enlarge, or alter every chapter, and almost every section, so that it is now, I believe, not only pure, containing nothing false or uncertain, but as full as any tract can be expected to be, which is comprised in so narrow a compass; and likewise plain, clear, and intelligible, to one of a tolerable understanding. The notes contain the sum of what is most valuable in the above-named writers; to which, are added the choicest discoveries both of our own and of the foreign societies. These likewise, I trust, are as plain and clear as the nature of the things spoken will allow; although some of them, I know, will not be understood by an unlearned or inattentive reader.

4. Mean time I must apprize the reader that I have sometimes a little digressed, by reciting both uncommon appearances of 2ature, and uncommon instances of art: 


\section{vii}

and yet this is not properly a digression from the main design I lave in view. For surely in these appearances also the wisdom of God is displayed ; even that manifold wisdom which is able to answer the same ends by so various means. And those surprising instances of art do likewise reflect glory upon him, whose spirit in man giveth that wisdom, whose inspiration teacheth understanding.

5. It will be easily observed, that I endeavour throughout not to account for things, but only to describe them. I undertake barely to set down what appears in nature, not the cause of those appearances. The facts lie within the reach of our senses and understanding; the causes are more remote. That things are so, we know with certainty; but why they are so, we know not. In many cases we cannot know; and the more we enquire, the morewe are 


$$
\text { March 25, } 1775
$$

1. I BAD finished the additions which I designed to make to the System of Natural Philosophy, before I saw Dr. Goldsmith's "History of the Earth and Animated Nature." I had not read over the first volume of this, when I almost repented of having wrote any thing on the head. It seemed to me, that had he published this but a few years sooner, my design would have been quite superseded, since the subject had fallen into the hands of one who had both greater abilities and more leisure for the work. It cannot be denied that he is a fine writer. He was a person of strong judgment, of a lively imagination, and a master of language, both of the beauty and strength of the English tongue.

2. Yet I could not altogether approve of this, that it seemed the design of the au- 
thor to say all he could upon every article, rather than all he should say. Hence arose his numerous and large digressions, making . no inconsiderable part of his work. Hence his minute description of cows, horses, logs; of cocks, hens, and pigeons, and of abundance of animals equally known to every man, woman, and child; descrip. tions that are of little or no use, and no more entertaining than useful; at least useful only to the bookseller, by swelling: the bulk, and consequently the price of his book.

3. Indeed this, the price of it, must ever remain a weighty objection to many readers: they cannot afford to purchase eight volumes at six or seven shillings a volume : ten or fifteen shillings they may possibly afford for five or six smaller volumes, especially when they contain all that is curious or useful in the far more a 5 . 
costly work. Nay, I hope, considerably mure than all; as I have consulted abundance of authors, and taken abundance of passages from them, whom I apprebend the Doctor had notseen.

4. I have another objection to this ingenious book; I doubt some parts of it are not true. The anthor, indeed, has correcied many vulgar errors, but has, I fear, adopted others in their place. Many times he exposes the credulity of other writers, but does he not sometimes fall under the same imputation? As where he terms presumption, to deny the existence of Bishop Pontoppidan's Kraken, and the Sea-serpent; the one a mile across, the other raising himself out of the water, higher than the main mast of a man of war! Could one who made the least scruple of rejecting these gross absurdities, accuse other writers of credulity? 
5. Mean time, the accounts which he has given of many animals, being taken from the best and latest authorities, are both more accurate, and more to be depended on, than any which had been published before. Many of these I have inserted in their places, (only contracting thirty or forty pages into four or five) often in the room of those which were less accurate, and probably less authentic; as also several of his beautiful remarks, such as directly tended to illustrate that great truth, OLord, how manifold are thy works ! In wisdom hast thou made them all! 


\section{Wilice}

की

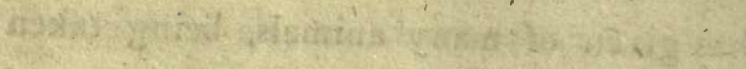

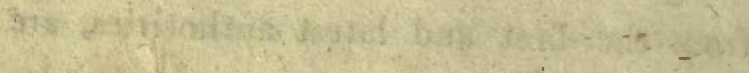

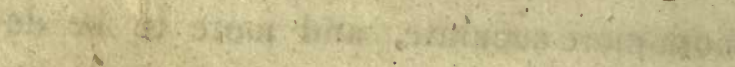

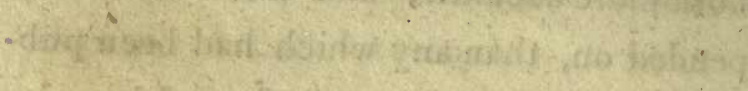

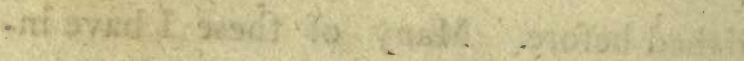
-

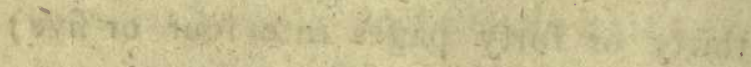

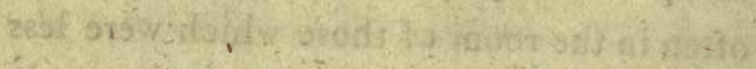

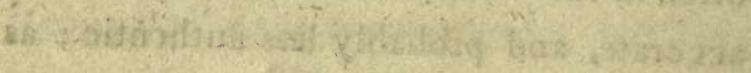

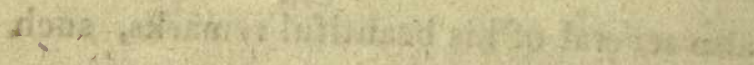

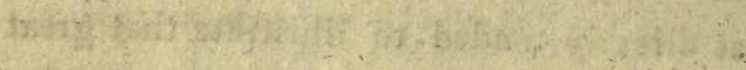
tekt(2. Y) 


\section{ar}

\section{CONTENTS}

OT THE

\section{FIRST VOLUME.}

\section{The IN'TRODUCTION.}

Of the gradual Improvement of Nutural Philosophy.

PAGE.

1. The Order observed in this Treatise

2

2. The Method of philosophizing among the Hebrews and Egyptians

3. Among the Greeks. - The philosophy of Pythagoras, Plato, Aristotle - - $\quad$ - $\quad$ ib.

4. The different Method plirsued by the four Greek Sects \&

5. The Philosophy of the Schoolmen - ib.

6. The revival of philosophy by Lord Bacon - ib.

7. Greatly promoted by philosophical societies ib.

8. The Improvement made in every Branch of it: in anatomy; the discovery of the circulation of the blood, of the lacteal veins; and the thoracic duct 


\section{xvi}

9. Of the generation of all animals from eggs

PAGF.

10. Of the transfusion of blood

11. Diseases themselves, and the operations of medicines, give occasion for farther discoveries

12. Many anatomical discoveries have been made by microscopes

ib.

13. Many with regard to brutes, particularly fishes and insects

14. Many likewise, with regard to plants, stones, metals and minerals

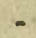

15. Great improvements from the art of chemistry

ib.

16. Discoveries concerning the loadstone

ib.

17. Concerning glass an

ib.

18. The nature of the air is more accurately discovered by means of the barometer, the thermometer, and the air-pump

19. Discoreries relating to water

20. Discoveries which shew the nature of fire: of gunpowder, phosphorus, aurum fulminans

21. Of the earth, and the chief systems of the umiverse

ib.

22. Of the sun, the planets, and their satellites

23. Of the causes of natural bodies

ib.

24. Of spirits and divine things

ib.

\section{PART the FIRST.}

\section{OF MAN.}

Crap. I. - Of the Structure of the Human Body. ?

1. The sinilar solid parts

2. A fibre 


\section{xrii}

PAGE.

3. The cellular membrane -

4. A bone

5. A cartilage

6. A membrane

19

7. An artery

8. A vein

their use

ib.

9. The lymphatic vessels, and their use

22

10. A nerve
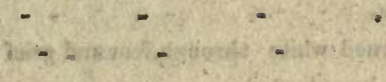

ib.

11. The flesh

12. A gland

13. A miscle

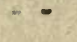

14. The cuticula and skin -

A boy with a dappled skin

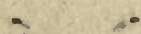

23

ib.

b.

ib.

A boy with a dappled skin

15. The fat

16. The panniculus carnosus

17. The dissimilar parts : in particular, the head, cerebrum, cerebellum, medu!la oblongata

ib.

18. The meninges

19. The brain

$-$

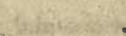

ib.

20. The origin of the nerves

21. The pineal gland

22. The guards of the eyes

23. The muscles of the eye : the tunica adnata, the structure of the eye

24. The coats of the eye -

ib.

25. The humours of the eye

26. Peculiarities relative to the eyes; help for decayed sight; account of a person couched

27. Queries concerning the eyes

28. The external parts of the ear

The internal : particularly the drum

ib.

29. The bones, passages, windows, labyrinth 


\section{sviii}

31. Of the tongue :

A person speaking without a tongue

ib.

Persons deaf and dumb taught to speak

Dumbness suddenly removed

Of the teeth

52. The palate

ib.

33. The uvula, tonsils, and wind-pipe

34. The hair

Hair turned white through fear and grief White triangular hairs.

35. The heart

36. The pericardium

37. The lungs

38. The thorax, intercostal muscles, diaphragm

59. The pleura and mediastinum

61

40. The external parts of the middie cavity

An old woman giving suck

ib.

41. The stomach

42. The intestines and mesentery

ib.

43. The lacteal veins

44. The omentum, peritoneum, - pancreas

45. The liver, gall, bladder, and dacts

46. The spleen

it.

17. The kidneys, ureters, bladder

ib.

48. The hands

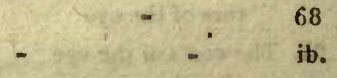

Account of a man without arms - - ib.

49. The thighs, feet, and legs _ _ _ $\quad 69$

50. The animalospirits - - - ib.

51. Secretion of the other fluids

52. The blood - - 71

53. What are the first elements of the body :

54. Reflections _.. 


\section{xix}

\section{CHAP. II.}

Of the Natural State of the Human Body.

PAGs.

1. What the natural state of the body means - - $\quad 98$

2. Of the circulation of the blood - - ib.

\$. Of Respiration - - , - - 102

4. Of chylification - 104

5. Of autrition - . . ib.

Uncommon instances of the utility of abstinence $\quad 105$

6. Of the senses $\quad \ldots \quad 107$

7. Of the sight - _ _ ib.

8. The hearing - 108

9. The smelling _ _ _ ib.

10. The tasting - _ ib.

11. The feeling - 109

12. Of hunger and thirst - .

13. Of sleep _. _ _ $\quad$ ib.

14. Of local motion - - $\quad 113$

15. Of the voluntary and involuntary motions ib.

16. Of the stature of man ib.

17. Of the age of man $\quad \ldots \ldots+\ldots 15$

\section{CHAP. III.}

Of the preternatural State of the IIuman Body.

1. What the preternatural state of the body is

2. The variety of diseases

ib: 


\section{$\mathbf{x}$}

PAGE.

3. Reduced to three classes: those of the solids

4. Those of the fluids, particularly the blood

5. Those of the animal spirits

ib.

6. The remote, causes of diseases

7. Of fevers

ib.

8. The way to preserve health

9. Of life and death

\section{CHAP. IV.}

\section{Of the Soul, and of the Origin of Man.}

1. There is something in man, which perceives the various motions of the body

2. The perception is sometimes continued and recalled

ib.

3. We know some things in a more sublime manner

4. There is something in us which has an appetite to sen. sual things

5. And another appetite which is often contrary to this ib.

6. How philosophers account for the direction of our bodily inotions

7. For the external senses

ib.

8. The imagination and memory

ib.

9. The understanding, will, and affections

136

10. This may be so, or not

11. Of the immortality of the soul

12. Of the union of the soul and body ib.

13. Reason cannot discover the origin of man ib.

14. The scriptural account of it ib. 


\section{xxi}

15. Of the production of the soul

16. Of the generation of the budy

\section{PART the SECOND.}

\section{OF BRUTES.}

Chap. I. Of Beasts.

1. The general difference of men and beasts as to the structure and posture of the body $\quad-\quad 148$

2. Their agreement

3. Their agreement and dicagreement as to the head and brain

4. The heart and lungs -

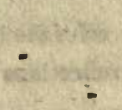

ib.

5. The eyes

-

151

6. The ears, nose, and teeth

152

7. The wind-pipe

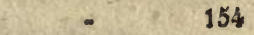

8. The vegetative and sensitive motions in brutes

156

9. Of the soul of brutes

ib.

10. Of some particular sorts of beasts

157

Of the elephant

of the rhinoceros

ib.

Of the camel

Of the dromedary

Of the lamas of Peru

Of the castor or beaver

Of the shammoy

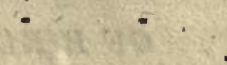

1.58

Of the roe.buek

162

163

164

ib. 


\section{xxii}

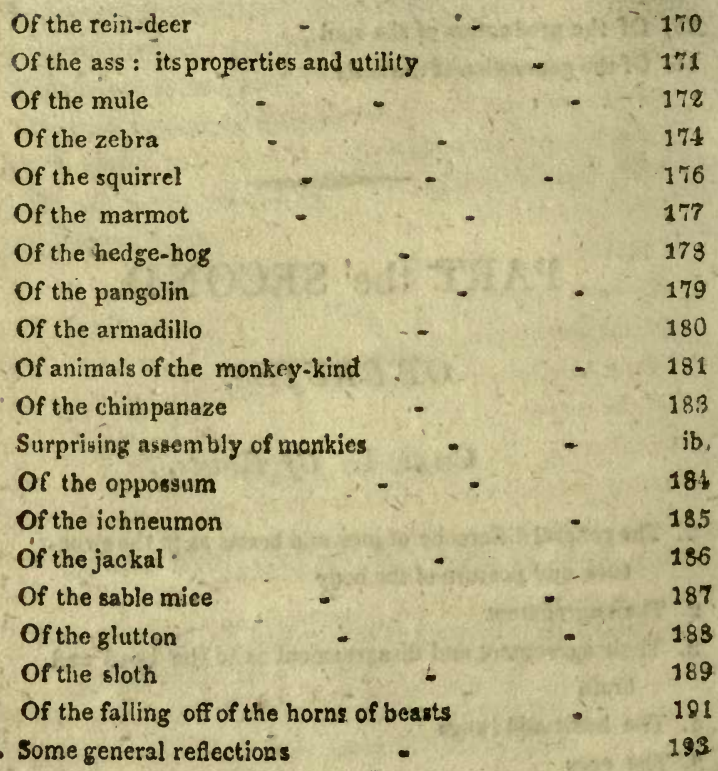

\section{CHAP. II.}

\section{OF BIRDS.}

y. Same general remarks

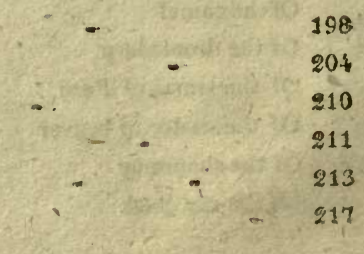

2. Of their motion

3. Of their brain

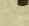

4. Of their organs of sen se

5. Of their lungs

6. Of their stomach and bladdet 


\section{xxiii}

\%. Of the generation of birds

PAGE,

8. Of some particular sorts of birds * - 227

Of the largest of birds, the Cuntor of Peru - . ib.

Of the smallest, the humming bird - - ib.

Of vultures : the singular service they are of in Egypt 229

Their uses in America $\quad$ - 230

Of rooks : their peculiar modes, or systems - $\quad$ ib.

Of the magpie : its peculiar degrees of instinct 231

Of the wood-pecker $\quad 232$

Of the bird of paradise - 234

Uf the American mock-bird : its uncominon properties 235

Of the crane - _ - _ ib.

Of the stork $\quad 236$

Remarkable adventure of a tame stork at the university of Tubingen - - $\quad 237$

Of the pelican : its singular construction and properties ib.

Of the aibatruss one of the largest and most formidable

birds in America - - $\quad 239$

Of the swan: its peculiarities and longerity 240

Of the goose, and wild-goose - _ $\quad 241$

Of the Soland goose - $\quad 242$

Of a couple of remarkable eagles, and a couple of ravens, in the isle of Rona, one of the Scotch Western isles

Of the down-bird in Iceland. $\quad$ _ ib.

Of the bat _ - .

Of the king-fisher $\quad=\quad-i b$ ib.

9. General reflections - 245 


\section{CHAP. III.}

\section{OF FISHES.}

1. The number of fish

2. Their covering

3. Their brain

4. Their organs of sense

5. Gills, or lungs

6. The heart

7. The air-bladder

8. The stomach

9. The fins

10. Experiments on fish

11. Of shell fish

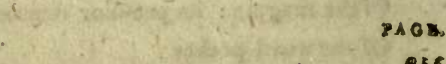

Of the reproduction of the shells of some fish

256

ib.

ib.

ib.

338

260

ib.

ib.

Of the extraordinary manner in which lobsters and crabs change their shells

-

ib.

The rf markable difference of the land crabs on the $\mathrm{Ca}$ ribbee Islands

The surprising regularity of their descent from the mountains to the sea

271

Of the soldier crab

-

278

Of crabs eyes

273

Of turbinated fish, of the snail-kind : .

Of theoyster $\quad 276$

The remarkable movings and operations of the scallop $27 \%$

Of the razor shell _ _ _ _ _

Of multivalve shell-fish $\quad$ - $\quad 278$ 


\section{$x \times r$}

PACs.

Of the sea-urchin

-

278

Of the acoin shell-fish, the thumb-footed shell-fish, and the imaginary barnacle

279

Of the murex, which gives the Tyrian purple 280

Of pearl muscles 281

The peculiarities of mascles in general

In Port Mahon harbour muscles are found in stones of immense magnitude

288

Of the bollani, which are found to live in large stones in the Adriatic sea

ib.

Of other shell fish, found in Toulon harbour, and on the coast of Ancona

Of the pholades bollani, who buries itself in the hardest rock

Of the animal flower in Barbadoes : itg: peculiarities, as it seems an aquatic sensitive plaot 


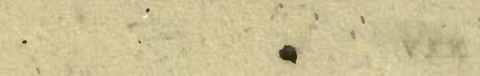

$2 x^{2}+2 x^{2}-$

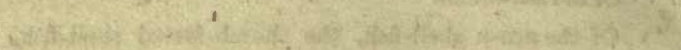

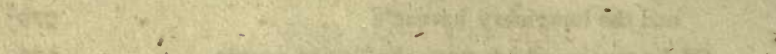

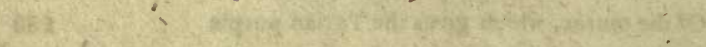

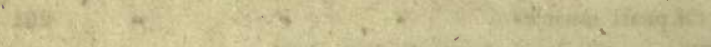

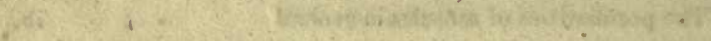

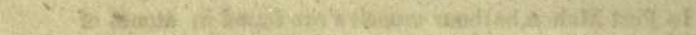
896

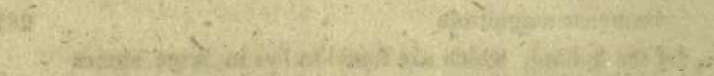

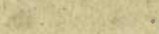

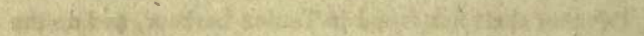

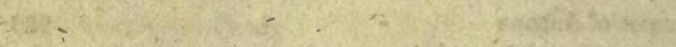

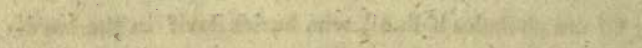

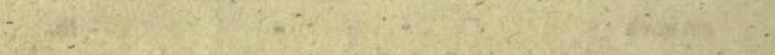

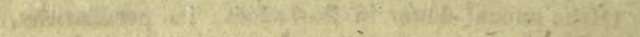

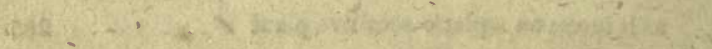

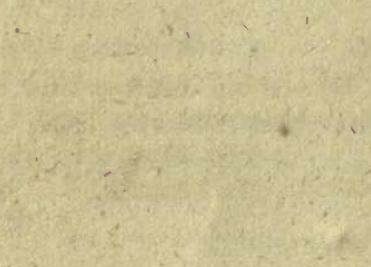




\section{COMPENDIUM}

\section{oE}

\section{NATURAL PHILOSOPHY.}

\section{INTRODUCTION.}

Of the gradual Improvement of Nuturat Philosophy.

1. The Order observed in this Treatise.

2. The Method of philosophizing among the Hebrews and Egyptians.

3. - Among the Greeks. - The Philosophy of Pythagoras, Plato. and Aristotle.

4. The different Methods pursued by the four Greek Sects.

5. The Philosophy of the Schuolmen.

6. The Revival of Philosophy by Lord Bacon.

7. - Greatly promoted by Philosophical Societies.

8. The Improvement made in every Branch of it: in Anatomy; the Discovery of the Circulation of the Blood; of the Lacteal Veins; and the Thoracic Duct.

9. Of the Generation of all Animals from Egys.

10. Of the Transfusion of Blood.

11. Diseases themselves, and the Operations of Medicines, give occasion for farther Discoveries.

12. Many Anatomical Discoveries have been made by Microscopes.

13. Many with regard to Brutes, particularly Fishes and Insects. 14. Many likewise with regard to Plants, Stones, Metals, and Minerals. 
15. Great Impruvements from the Art of Chymistry.

16. Discoveries concerning the Loadstone.

17. Concerning Glass and Burnino-Glasses.

18. The Nature of the Air is more accurately discovered by means of the Barometer, the Thermometer, and the Air-Pump.

19. Discoveries relating to Water.

20. Diseoveries which shew the Nature of Fire, Gunpowder, Aurum Fulminans, Phosphorus.

21. Of the Earth, and the chief Systems of the Universe.

22. Of the Sun, the Planets, and their Satellites.

23. Of the Causes of Natural Bodies.

24. Of Spirits and Divine Things.

1. N ATURAL PHILOSOPHY treats both of Gov himself, and of his creatures, visible and invisible. Of these $I$ purpose to speak in such a manner as to as. cend from the consideration of man, through all the orders of things as they are farther aud farther removed from us, to Gov the centre of all knowledge. (I mean of visible things; of the invisible world we cannot know much, while we dwell in houses of clay.) 'Thus speculative philosophy ascends from man to GoD; practical, desceuds from Gop to man.

2. The most ancient nations, the Egyptians and Hebrews, in particular, philosophized much concern. ing Gon, and concerning Genii, good or evil spirits, of an order superior to man. What they taught concerning the visible world, related chiefly to its origin, the changes it was to undergo, and its final dissolution. But on all these heads they only delivered to their posterity what they had reccived from their forefathers.

3. Among the Greeks, Thales Milesius and his followers, applied themselves with great industry to discover, with the best helps they had, the material causes of natural things. They were succeeded by others who more curiously searched into the structure of natural bodics. Here the foundation of natural history was laid, in various observations on plants, animals, and other things. Aud herein the endeavours of A ristotle and Theophrastus, in particular, are to be 
commended. Yet, in other respects, Aristotle did not promote, but rather obstruct the knowledge of nature : for he made philosophy as unintelligible by his abstract and metaphysical notions, as Plato, Pythagoras, and others did, by their ideas, numbers, and symbols.

4. In succeeding times, when the four Greek sects, the Platonic, Peripatetic, Epicurean, and Stoic, divided the Western world betweeu them, the Platonists almost confined themselves and their opinions to the subject of divinity; the Peripatetics regarded little but logick; the Stoics little but moral philosophy; and the Epicureans had small concern about any, being immersed in sensual pleasures : so that none of them made any considerable improvement in any brauch of natural philosophy.

5. When the utter barbarism which followed was a little dispelled, Aristotle began to reign. His followers (the School-men, as they were called) might have improved natural philosophy, if (like their master) they had diligently cultivated the knowledge of nature, and searched out the properties of particular things ; but it was their misfortune to neglect what was com. niendable in him, and to follow only what was blameworthy, so as to obsciure and pollute all philosophy with abstract, idle, vain speculations. Yet some of them, after the Arabians had introduced t' $\mathrm{k}$ know-). ledge of chymistry into Surope, were wise above the age they lived in ; and penetrated so far into the secret ricesses of nature, as scarce to escape the suspicion of magic. Such were Roger Bacon and Albertus Magnus.

6. After the revival of learning, as all other branches. of philosophy, so this in particular received new light. And none was moro serviccable herein than Iiord Bacon, who, well understanding the defects of the schuol-philosophy, incited all luvers of natural philosophy to a diligent search into natural history; and he himself Jed them the way by many experiments and ob. servations.

7. After this, not single persons only, but whole sucieties applied themselves carefully to make experi- 
ments; that haring accurately observed the structure and properties of each body, they might the more safely judge of its nature. And the advantages which have arisen from hence, manifestly appear from the memoirs of the royal society at London, of the academy of sciences at Paris, and those of the same kind in Gernany, as well as several other parts of Europe.

8. To mention but a few of the late discoveries in each branch of natural philosophy, with regard to the structure of a human body, how many things have modern anatomists discovered, which were either little understood by the ancients, or whally unknown to them? Such, for instance, is the circulation of the blood discovered by Dr. William Harvey, whose "Anatomic Exercitations," concerning it, were first published in the year 1628 . Such were the lacteal veins discovered first in brutes by Casper Asellius, of Cremona, and soon after in men. Such the thoracic duct, and receptacle of the chyle, observed first by Dr. John Pecquet, of Paris, whereby the whole course of the blsod is now clearly understood.

9. Dr. Harvey improved natural philosophy by another no less eminent discovery : for he was the first of the moderns that shewed all animals to be generated from eggs. That the ancients knew and taught this, (Orpheus in particular) cannot reasonably be doubted. But as the knowledge of it was entirely lost, to revire was the same thing as to invent it. It is obvious how great a light this pours upon that dark subject with regard to the generation of men, as well as of other animals.

10. Another remarkable discovery in the last century was that of the transfusion of the blood. The blood of a young, lively, healthy animal, was transfused by means of a small silver tuhe, properly adjusted in to the veins of another which was old, weak, and sickly, and the effect amazed all the beholders. When the experiment was tried before several of the royal society, feeble worn-out dog, ready to die with age, and hardly able to trail his legs after him, was no sooner 
filled with young blood, than he leaped up as from sleep, shook himself, and ran up and down as tively and active as a puppy. In France the experiment has been made upon men, and with as surjprising success. What pity, that so important an experiment should ever fall into disuse; that it is not still repeated upon proper occasions; especially where all other means fail.

11. It cannot be denied that physicians hare signally improved this branch of philosophy, as they have contimual opportunities of making new discoveries in the human body. In diseases themselves, the wonderful wisdom of the Author of Nature appears; and by means of them many hidden recesses of the human frame are unexpectedly discovered. The powers of medicines also variously exerting themselves, lay open many seerets of nature.

12. And how many things in all bodies, as well as in the human, which eluded all the art and industry of the ancients, have the moderns discovered by the help of microscopes? Although these are not properly a modern invention, it being certain something of this kind was in use many hundred years ago. There are several works of great antiquity still extant ; the beauties of which cannot even be discerned, much less could they have been wrought by the finest naked eye which ever was in the world. Such is that seal which was formerly in the cabinet of the late King of France, allowed to be at least 1500 years old, six-tenths of an incle long, and four bruad, which to the naked eye presents only a confused groupe, but surveyed with a micros. cope, distinctly exhibits trees, a river, a boat, and sixteen or seventeen persons.

13. Now whatever assists us in searching out the structure of a human body, equally helps is to find out the nature and properties of other animals. Hence in these likewise we have, received great light, from anatomical and microscopical observations. Those especially who have bestowed their whole time and thoughts on one kind of animal;, (as Dr. Willoughby, on fishes, 
Dr. Swammeriam, of Ansterdam, on insects) have itlustrated to a surprising degree the subjects on which they wrote.

14. Many have diligently searched into the nature of plants; particularly Mr. Ray, who has not only ranged them in a new method, but also wrote an ela. borate history of them. Others have described, with equal diligence, either plants in general or those of a particular country; and others have shewn the like industry in finding out and explaining the nature of stones, metals, minerals, and other fossils.

15. Nor is it strange that the moderns have penetrated farther into the recesses of nature than the ancients, considering the advantages they have received from the art of chymistry. Not that this is an inven. tion of later ages: it was in some mcasure known long ago. But as this art has been cultivated in our age, with far greater accuracy than ever, so by this means many properties of natural bodies have been discovered, of fossils in particular.

16. But none of these hare so much engaged the study of the learned, or so well deserved it, as the load-stone. Its attractive force was known to the ancients, and the origin of that discovery is recorded by Pliny. But it does not appear that they knew of is pointing to the pole, or of the use of the compass. This (the compass) was invented by John Goia, in the year 1300: but it has since been observed, that the magnetic needle seidom points exactly to the pole, but varies from it some degrees to the liast or West in a fixed and regular order.

17. Nearly related to the nature of fossils is glass, which was well known to the ancients, being mentioned by Plutarch and Lucian among the Greeks, by Lucretius, Pliny, and others, among the Latins. Yet the art of making glass has been since their times abundantly improved. One branch of this is, the art of making burning-glasses, which are now brought to so) great perfection, as either to melt or reduce to ashes the most solid bodies in a few moments. If these were 
known to the ancients at all (which may reasonably be (loubted) yet the art was wholly lost for many ages, and not recovered till of late years.

18. Later ages have likewise made many discoveries with regard to earth, water, fire, and air: the last of which, air, though it be of so fine a texture as to be wholly invisible, yet producing such amazing effects, has excited the most diligent enquiries of the curious. Nor does any part of philosophy afford a wider field for experiments and discoveries. The weight of it we can ascertain by that curious instrument the barometer, invented by Torricellius; the degrees of heat and cold by the thermometer. By the air-pump (invented by Otto Guerick, Mayor of Magdeburgh) the air is drawn out of any bodies, or more largely thrown into them, and hereby many effects are produced which deserve our diligent consideration.

19. With regard to water, the discoveries of later times are numerous and important. Such are the diving-bell, invented by George Sinclair : the divingmachine of Alphouso Borelli, a kind of buat which is so contrived as to be navigated under water: and the art of making salt-water fresh, which is now done with little expence, so far that the saltness is taken away, and it is fit for almost all uses.

20. The nature and propertics of fire also have been accurately traced in late ages: for which new occasion was given by the invention of gunpowder, by Berthold Schwartz, in the fourteenth century. Aurum Fulminans, a yet later invention, goes off with a louder ex. - plosion than gunpowder. Other bodies there are, which do not burn, yet emit light; such is the Bu. nonian sione, which placed in the dark, diffuses light like a burning coal. It is wcll known that the preparation called phosphorus hias the same property.

21. Various theories of the earth have lately appeared, but they are no more than ingenions conjectures. The same may be said of the systems of the Universe, a lew particulars excepted. The Ptolemaic system, which supposes the earth to be the centre of the Uni. 
verse, is now deservedly cxploded ; since Copernicus has revired that of Pythagoras, which was probably received by most of the ancients. Tycho Brahe's, which jumbles both together, is too complex and in. tricate, and contrary to that beautiful simplicity, con. spicuous in all the works of nature.

22. The telescope (invented by Galileo) has discovered many stars unknown to the ancients, together with the nature and motion of the platets, both primary and secondary. By this also have been discovered the spots of the sun, the inequality of the sur. face of the moon, the nature of the galaxy or milkyway, and piany other particulars relating to the heavens.

23. With regard to body in general, it is common. ly supposed that our age has a vast adrantage over antiquity, by having found out new principles and new hypotheses, whereby we can account for all the secrets of nature; but this will bear a clispute. For beside that the chief of our hypotheses are nut new, but known long ago, the learned have hitherto very little profited by all their hypotheses. And in truth, all their dis. quisitions touching the causes of natural bodies, ter. minate in mere conjectures: one whereof is often more probable than another, but none admits of any solid proof.

24. What remains of natural philosephy is, the doctrine concerning God and spirits. But in the tracing of this we can neither depend upon reason nor experiment. Whatsoever men know or can know concerning them must be drawn from the oracles of God. Here therefore we are to look for no new improvements, but to stand in the good old paths; tos content ourselves with what Gorl has been pleased to reveal, with the faith once delivered to the saiuts. 


\section{PART the FIRST.}

\section{OF MAN.}

\section{CHAP. I.}

\section{Of the Structure of the IIuman Body.}

1. The sinilar solid parts.

2. A fibre.

3. The Celluiar Membrane.

4. A Bone.

5. A Cartilage.

6. A Membrane.

7. An Artery.

8. A Vein.

9. The Lymphatic Vessels, and their use.

10. A Nerve.

11. The Flesh.

12. A Gland.

13. A Misscle.

14. The Citicula and Skin.

A Boy with a dappled Skin.

15. The Fat.

16. The Panniculus carnosus.

17. The dissimilar Parts : in particular, the Head, Cerebrum, Cerebelluin, Medulla oblongata.

18. The Meninges.

19. The Erain.

20. The Origin of the Nerves.

21. The Pineal Gland.

23. The guards of the Eye.

23. The Muscles of the Eye.

The Tunica adnata.
The Structure of theEye.

24. The Coats of the Eye.

25. The Humours of the Eye.

26. Peculiarities relative to them.

27. Queries concerning the Eyes.

- Help for decayed Sight. Account of a person couch. ed.

28. The External parts of the Ear.

The internal: particularly the Drum.

29. The Bones, Passages, Windows, Labyrinth.

30. The Nostrils.

31. The Tongue, and Teeth,

A person speaking without a Tongue.

Persons deaf and dumb tanght to speak.

- Dumbness suddenly removed.

32. The Palate.

33. The Uvula and Tonsils.

34. The Hair.

Hair turned white through fear: 
Throngh grief.

White Hairs triangular.

35. The Heart.

36. The Pericardium.

37. The Lungs.

38. The Thorax, intercostal Mus. cles.

Diaphragm.

9. The Pleura and Mediastinum.

40. The external parts of the Middle Cavity.

An old woman giving suck.

41. The Stomach.

42. The Intestines and Mesen-. tery.

43. The Lacleal Veins.
44. TheOmentum, Peritoneum, Pancreas.

45. The Liver, Gall, Bladder and Ducts.

46. The Spleen.

47. The Kidneys, Ureters, Bladder.

48. The Hands. Account of a Man without arms.

49. The Feet.

50. The Animal Spirits.

51. Secretion of the other fluids. 52 The Blood.

53. What are the first Element: of the body.

54. Reflections.

\section{OF MAN.}

1. A $\mathrm{S}$ man ought to know himself best, we begin our treatise here. And first, let us contemplate the Human Body. The parts of this are either solid or fluid. 'Those of the solid, of which the rest are formed, are termed similar parts. Such are fibres, bones, membranes, ligaments, arteries, veins, lymphatic vessels, nerves, flesh, muscles, tendons : and those general coverings of the body, the cuticle, the skin, fat, and the pauticulus carnosus.

2. A fibre is a kind of slender thread, of which all the other parts of the body are woven: according to the difference of which, the substance of the fibres is different also.

Earth, as an element, is a solid, opaque, angular, friable substance, of such small volatile partictes, that 
it readily diffuses itself through air and water, and re. sides invisibly in them. And earth eagerly inbibing both air and water, by their means forms the permanent basis and growth of all mincral, vegetable, and auimal bodies.

These carthly particles have their connexion and power of cohesion, not from themselves or 2 mere contact; but from the intermediate glue placed betwixt them.

That this glue is composed of oil, combined with water, by the vital attrition in animals, appears from the chymical analysis of bones and hair; from the jellyof bones, ivory, and horns; and from the nature of our aliments themselves. Nor is there any kind

- of glue that could more powerfully join the parts of aninals, as we experience in fish glue, and that of joiners or cabinet-makers.

Larthy particles then cohering longitudinajly, and tied together by an interveniug cohesive glue, compose first one of the least or most simple fibres; such as we hare a knowledge of rather from reason than sense.

The finest microscopes have been hitherto insuff. cient to lead us to a sight of the smallest moving and nerrous fibrils, and still less can we ever expect from them, to get any sensible idea of the mechanism by which sensation and motion are effected.

But the least fibres which appear to the sight are of two kinds.

Of these two kinds of fibres, as we shall presently see, we may distinguish the furmer by the title of filamentary, and the latter of membranous.

The first kind of these fibres is lineal, namely, such a form as makes their Iength considerably large in proportion to their breadth; and which, by disposing of the elementary particles in a right line, must of course lay them generally parallel with the neighbouring or contiguous fibres. Examples of such fibres we see in the b jaes, and most easily in those of a fotus ; and likewise in the tudons, ligaments, and muscles; B 6 . 
only we nust here always remember, that the eyc never reaches to the smallest fibres, but to larger ones made up of the smallest, and like to them in slender. ness, placed together in a rectilineal course. That these are not different from the smallest fibres, we are persuaded by the most accurate microscopes of Muyse and Lewenhoeck; hy which the muscular fibres divided even to the last, appear similar to the larger, till, at length, they seem mere lines, like spiders threads.

The second kind of fibres are those which are conjoined with a breadth frequently larger than their length.

From what has been said, we may admire nature no less for her wise economy than simplicity, in thus forming all that variety of parts we see in an animal, from one simple mass of clay or slimy matter, com. pounded of earth and glue ; from whence the body is not only augmented from a single point in the ovum to its full growth and stature; but like the timbers of a ship, is also every day repaired during life, till at length not two jots of the old or first materials remain. This renovation of parts is made slower in some constitutiuns, and in some organs than in others. How quickly the animal humours, with the hair, nails, \&c. are renewed, every one knows : and we may venture to say, that once in three years the change is universal; at the end of which time, though a man remains the same identical person he is not the same matter.

3. But we proceed from these simple fibres to the next least compounded solid which they compose; viz. the cellular web-like substance.

This is made up partly of the simple fibrils, and partly by an infinite number of little plates or scales, which, joined in various directions, intercept small cells and web-like spaces; and by extending round every, even the least moving solid parts of the body, conjuins them all together in such a manner as not only sustains, but allows them a free and ample motion. 
The extension of this substance, not only with the skin round the whole body, but also round every vis. cus or organ, and round every individual moving fibrc or vessel of them, into the carities of the bones, and cren the substance of the brain and its medulla, is a modern and wonderful discorery. This substance in its ultimate state being composed of simple membranes, when compacted and convoluted, gives birth to the least or most simple vessels, which again reflected through plates of the samesubstance compacted together, make compound and vascular membranes: to theconsideration of which we next proceed.

Out of this cellular substance compacted by a coni cretion of the membranous plates or partitions, and pressed together by the force of the incumbent muscles, and distending fluids, arise other broad and flat plates or skins in various parts of the body; which being generally disposed in one and the same direction, seem to have a better right to the name of membrane than the former; and these being convoluted into coues and cylinders, pervaded by a tlux of some juice or liquors brought to them, put on the name of ves. sels, or else being extended round some space that is in a plane, parallel to itself, we call it a tunic or coat.

This cellular substance in the human body, is found throughout the whole; wherever any ressel or move ing muscular fibre can be traced, and this without the least exception, that I know of, in any part whatever. But so far as ever we can trace, it hardly ever admits of any iat into the cells; which are rather moistene? by a watry vapour, somewhat oily, exhaled out of the arteries and received again into the veins.

Its plates or scales are still more loose and open where it divides the muscles and all their fibres (even to the ultimate fibre; and likewise where it surrounds and sustains the least vessels with their free motion. 'That within the cavities of the bones is also made up of bony plates, with membranous ones intermixed ; and lastly, it is the most loose and open of all, round 


\section{4}

the surface of the body on all sides betwixt the muscles and the skin.

'Ihrough this cellular substance the small ressels are spread, and ramified in all parts of the body ; from whose arterial extremities the fat is deposited in to the cells, and afterwards absorbed by the venal orifices. 'This passage from the arteries, into the adipose cells, is so free and short, that there must needs be very large mouths by which they opell, and by which they give admittance to injected mercury, air, or water. The oily fat, in this substance, is separated and expelled from the artery; not by any long ducts, but by transuding on all sides through the whole extent of the ressel. How quickly it is collected from the arteries, appears from the speedy renovation of it, by a returning fatness after acute diseases.

With regard to the sponge-like communications of this substance, it is remarkable, the interrals or spaces betwixt the plates or scales that make up their sides in the cellular membrane, are every where open, and form one continuous cavity throughout the whole body.

That out of this substance joined with ressels, meries, museular and tendinous fibres, (a great part of all which are before formed of this substance only) all the viscera; all the muscles and glands, with their ligaments and capsules, are entirely composed; and that only frou the different length, tension, quantity or pronortion of this, the diversity of our glands and viscera arises; and lastly that this alone makes up by far the greatest part of the whole body, we are certain, if the whole be not formed out of the cellular filaments of this knd.

4. The hardest part of the body, white and roid of sense, is termed a bone. The bones are covered with a thin skin, called the periusteum, extremely sensible.

The bones consist of thin plates, lying one upon 


\section{5}

another; aud these again, of fibres running lengthways; some to the extremity of the bone, some not so far. Yet none of them terminate there; but are continued transversely, and as it were arched, the fibres of one side mecting and uniting with those of the other, and this at each extremity.

These plates are differently disposed in different bones: in those that have a large cavity, they are contiguous on each side, and very closely united. In those whose cavities are small, many of the inner plates are distant from each other; having little long cells between them. In bones whose plates are contiguous, there are pores through and between them, (beside those for the blood-vessels.) The first pierce them transversely, from the cavity to the external surface of each plate. The second run lengthways between the plates, and diffuse an oil with which they are sup. plied by the transierse pores.

The bones are generally bigger at each end than in the middle, that the joints may be firm, and the bones not so easily dilocated. But to strengthen the micldle of the bone, the fibres there are more closely compacted. Likewise the bone, being large and hollow, is not so easily broke as if it had been solid and smaller; for of two bones of equal length and equal number of ubres, that is stronger which has the larger diameter.

'The blood-ressels usually enter the ends of the bones; the arteries at one end, the veins at the other. I he medullary vessels commonly enter the sides of the bone, and that obliquely.

The marrow is covered with a membrane, wherein are inclosed little bags. In these bags are glandulous bladders, serving botin to secern the marrow from the blood, and to receive it. Both these and the bags have jassages into each other, whereby the marrow has free course. It passes first through the transverse pores of the first internal plate into the longitudinal ones. Thence it proceeds into other transverse pores, wben it alters its course igain, and exudes farther. 
Thus it passes alternately through and between the plates, till it is diffused throughout. In this manner it is diffused through bones, whose plates are contiguous. But where the plates are at a distance, the small cells contain glands, which directly supply the plates with marrow.

The marrow not only serves to keep the substance of the bone moist, but to lubricate the joints, and to hinder the ends of the bone from being worn or over-heated with motion. It also moistens the Ligaments, which tie them to each other: as do likewise the glands found in all the joints. The backbone hath these two things peculiarly remarkable. 1. Its different articulations from the other joints of the body. For here most of the joints are flat, and withal guarded. with asperities and hollows, made for catching and holding; so as firmly to lock and keep the joints from luxations, but withal to afford them such a mo. tion, as is necessary for the incurrations of the body. 2. The difference of its own joints in the neck, back and loins. In the neck the two upper vetebra are curionsly made, and jointed (different from the rest) for the commodious and easy bending and turning the head every way. In the thorax, and back, the joints are more close and firm; and in the loins more lax and pliant; also the knobs and sockets are turned a quite contrary way, to answer the occasions the body hath to bend more there, than higher in the back. So that its structure is the very bost that can be contrived; for had it been all bone, we could have had no mo. tiun in our body; had it been two or three bones articulated for motion, the medulla spinalis must have been necessarily bruised at every angle or joint; besides, the whole would not have been so pliable, for the several postures we have occasion to put oursclves in. If it had been made of several bones without intervening sartilages, we should have had no. more use of it than if it had been but one bone. If each vertebra had had its own distinct cartilage, it might have been easily dislocated. And lastly, the 
oblique processes of each superior and inferior verte. bra, keep the middle one, that it can neither be thrust backwards nor forwards to compress the medulla spinalis.

The pelvis made in the belly by the illium, ossa coxendicis, and pubis, is larger in a female than in a male skeleton, that there may be more room for the laying of the viscera and foetus. So the cartilage bracing together the two sharebones, is twice thicker and laxer in women than in men. As also is the cartilage that ties the os sacrum to its vertebra ; and all, to give way to the passage of the feetus.

Another considerable difference is, in the cartila. ginous production of the seven long ribs, whereby they are braced to the breast.bonc. These are harder and firmer in women than in men; the better to support the weight of the breasts, the sucking infants, sc.

It is remarkable in the joints, and a manifest act of caution and design, 1. That although the motion of the limbs be circular, yet the centre of that motion is not in a point, but an ample superficits. In a point, the bones would wear and penetrate one another, anil the joints would be exceeding weak. But the joint consisting of two large superficies, concave and convex, some furrowed and ridged, soine like a ball and socket, and all lubricated with an oily substance; they are incomparably prepared both for motion and strength. 2. That the bones next the joints are not spungy, as their extremities commonly are, nor hard and britle; but capped with a strong, tough, smooth, cartilaginous substance, serving both for strength and motion.

For affording this oily matter there are glandules very comnodiously placed near the joints, so as not to suffer too great compression by the motion of the neighbouring bones, and yet to receive a due pressure, to cause a sufficient emission of the oil in to the joints. Another thing considerable is, that the excretory ducts of the mucilaginous glands have some length in 
their passage from the glands to their mouths; which is a good contrivance, to prevent their mouths being oppressed by the mucilage, and also to hinder the too plentiful effusion thereof, but yet to afford a due. expressure of it at all times, and on all occasions; particularly in violent and long-continued motions of - the joints, when there is a greater than ordinary expence of it.

That the nourishment taken in, is continually con. reyed through the bones, as well as the aphears from an easy experiment. Mix red liquor with the food of any animals, and in a short time, their bones are died red. When madder root was mixed with the food of a cock, who died after sixteen days, all his bones were red, the internal parts as well as the external. And the most solid parts were the most deeply tinctured: in swine the teeth above all the rest.

5. Annexed to the bones are the cartitages, white, flexible, and smooth; most of which in process of time become bunes, hard and quite void of sense.

A cartilage is an elastic substance, unifornuly compait and somekhat transparent, harder and more brittle than a ligament, suftur than a bone. It is covered with a fine menibrane, folded over the bone, from where the ligament is inserted. Every joint. is inserted with a membrane, which forms a complete bag, and eovers every thing within the articulation. The blood-ressels are so small, that they clo not admit the red glebules, and are demonstrable only in very young subjects. All round the neck of the bone, there are numerous arteries and veins which spread into smaller branches, and communicate with each other. These divide into still smaller branches on the adjoining surface, as they run toward the centre of the cartilage. We can seldom trace them into its substance, because they end abruptly, at the edge of the cartilage. The larger vessels, plunge in by $11 u \mathrm{~m}$ berless small holes, and clisperse thernselves into brail. 
ches between the cartilage and bune. From these again there arise many short, but small twigs, which shoot toward the outward surface. This distribu. tion of the blood-vessels is very peculiar, and calculated for obviating great inconveniencies. Had they run on the outward surface, the pressure and motion of the two cartilages must have accasioned frequent ob. structions and inflammations. But by creeping round the cartilaginous brim, where there is little friction, or under the cartilage, where there is none, they are perfectly well defended from all such accidents.

Cartilages are admirably contrived for all the purposes of motion. By their uniform surface they move one upon another with ease : by their soft, smooth and slippery surface, mutual abrasion is prevented. By their flexibility, the contiguous surfaces are constantly adapted to each other. By their elasticity the violence of any shock, which might happen in runsing, jumping, or the like, is broken, which must have been extremely pernicious, if the hard surfaces of bones had been imunediately contiguous. The cartilaginous fibres appear calculated chiefly for this last advantage. To conclude, the insensibility of these cartilages is no less wisely designed, that by this means the necessary motions of the body may be performed without paiu.

6. The various parts of the body are cloatherl with Membranes, which are whitish tuniclea, extremely thin and flexible, composed of fibres interwoven with each other, as a piece of cloth is of threads. They are fastencd together by a kind of cartilages, which are termed ligaments.

7. Au artery is a hollow canal, composed of fibres closely twisted together, which conveys the blood from the carity of the heart to all the parts of the body. All the arteries spring from two, the arta or great artery and the pulmonary artery. The latter cunveys the blood from the right rentricle of the heart, 
through the lungs, into the left ventricle. The former conveys it from the left to all other parts of the body.

Thearteries ordinarily consist of three coats or mem.

- branes. The outermost has been generally thought to be composed of fine blood-vessels. The second is muscular, and made of firm and strung circular, or rather spiral fibres: of which there are more or fewer strata, as the artery is larger or smaller. These fibres are extremely clastic. The inmost coat is a fine dense, transparent membrane, containing the blood, which otherwise would easily ooze through the spiral fibre.

On a more accurate examination it has been found, that the outermost coat of all arteries is a cellular substance, composed of fine, pellucid membranes, which may be stretched, even suddenly to a great extent without breaking. And they as suddenly collapse, when thiat stretching force is removed. These cells. contain an oily liquor which their coats secern from the branches of the artery that are spread over them. This cellular substance of the arteries serves to connect them with the surrounding part, without hindering. their actions or motions. It gives a safe passage to the ressels of their ocher coats, and supplies oil for lubricating them. There is also another cellular sub. stance, between the inembranes and the muscular coat.

All the arteries begin with a larger trunk, and grow less and less till they are no longer seen by the naked eye. Hence they are continued till they inosculate with the veins, and so form one uninterrupted channel.

They appear white, because their coats are of so dense a contexture, that the blood is not visible through them. This proceeding from wider to narrower canals is continually obstructed in its passage, but being pushed on from behind, it distends the coats, and causes that leaping motion called the pulse. By this, as well as by their whiteness, arteries are dis. tinguished from veins. 
The pulse of a healthy person, rising in the morn. ing, beats 65 in a minute; but after the fatigne of the day, it will in the evening beat eighty in that time; and again, by the night's rest or sleep, it will become less frequent, till in the morning you will find it return to sixty-five. For the voluitary motions of the muscles, and actions of the exterual a dinternal senses, urge the venal blood on to the heart, which, being thereby oftener stimulated, makes more frequent contractions. This is the cause of those paroxysms or fits of increase observable in all fevers towards the evening; for sleep not on!y retards the motion of the blood, but of all the other humours and actions in the body.

It is one of the curious observations of Dr. Hales, that the pulse is quicker in small animals. He found the pulse of a horse slower by half than in a man, viz. 32 only in a minute; whereas, in a dog, the pulse beat 97 in that time. And this we see is conform. able to the blood's heat, measured by the mercurial thermumeter of Farenheit's scale; for the blood in oxen, horses, and other large animals at rest, being five or six degrees cooler than in us, will not rise to our heat but by labour; whereas dogs, cats, and fowls, are five or six degrees hotter than we, (viz. about 102 ;) and the latter, when sitting or brooding on their egge for young, are still four or five degrees hotter, viz. 107 or 108, which is commonly the heat of our blood in the fit of an ague; where it is ob. servable, that during the greatest sense of cold chill, the blood is three or four degrees hotter than in health, after which it gains four or five degrees more in the height of the hot fit, viz. 104 or 105 degrees; but in ardent fevers, where the pulse beats 140 , the heat of blood will still be four or five degrees higher, viz. 110. i.e. two or three degrees more than equal to a brooding hen.

The pulse is more quick in children, and becomes slower in persons as they grow older. The salient point of an ovum beats 134 in a minute. New born 
infants have their pulse 120, and from thence, down to old age, it grows slower, to 60 in a minute. A feverish pulse begins at $\$ 6$ per minute; it is excessive at 130 or 140 , which is the number of the pulse with which a person dies. The pulse beats slower in winter, and quicker in summer, by about ten strokes per minute; and under the torrid zone, it grows quicker to 120.

8. A vein is a hollow canal, which receires the blood from the artery, and conveys it back to the heart. The chief reins are three, the vena cava, which pours the blood through a wide passage in to the right ven. tricle of the heart; the pulmonary vein, which in like manner pours it into the left ventricle; and the vena portx, which does not, like the two former, end in a large trunk, but spreads itself at each extremity into numerous branches.

In the cavity of the reins there are certain thin tunicles, which are termed valves. These, during the regular motion of the blood, lie close to the side of the inner coat; but in case of any obstruction, recede from it and close the passage, to prevent the bloorl's falling back.

9. The lymphatic ressels are small canals full of valves, consisting of a thin transparent tunic, which convey an extremely clear liquid into the mass of blood. Probably these (as well as the reins) and all the other vessels, are ouly continuations of the arteries.

It has been lately discovered that the lymphatic ves. sels have two coats, betwixt which there are innumerable fine filamcuts containing a nutricious juice, which is conveyed into all parts of the body by a motion from the centre to the circumference, and returns through the inner pipes of the same watry vessels; but this juice, when returning, is no more water or dew, but ferment, and the vessels may be tcrmed ferment-vessels. This ferment is conveyed into the blood by a motion from the circumference to the centre. 


\section{3}

The lymphatics carry their dewy particles through the glandules, which lie between the two coats. In the lowermost end of these glandules, the ferment vessels take their rise. Most of the juice of the lymphatic vessels is discharged between the coats of the veins, arteries, and vessels, in the mesentery, to be conveyed into all parts of the body, both intermal and external. Even in bearing females, the fruit is not nourished by blood, but by this nutricious juice; the remaining part of which is transmitted into the blood through the thoracic duct and jugular veirs.

10. A nerve is a whitish, round, slender body, arising from the brain, which is supposed to conrey the animal spirits to all parts of the body. What these spirits are none can shew; nay, we are not sure they have any being. For none can certainly tell whethe: the nerves are hollow canals or only solid threads en. closed in proper integuments.

11. The fibrous, soft, reddish part of the body is termed flesh. All tleshy fibres are hollow, and divided through their whole length into little caverns, wherein the blood is detained, as occasion requires.

12. A gland is a soft and spungy body, which se. parates some particular liquid from the blood. The larger glands contain arteries, veins, and lymphatic ressels; but the glands of the intestines are only the tops of the arteries.

There is a kind of down in the cavity of every gland, which probably does the office of a filter, and is that whereby a particular bumour is separated from the blood.

The structure of the down-pessel is different according to the different purposes of nature. Sometimes the liquor filtrated through it, falls drop by drop on a membrane, to which one end of the vessel is fastened, as where it is designed only to moisten the part. Sometimes many of these down-vessels spreal over the inner 


\section{4}

surface of a membranous cell, into which they all pour their liquor, which is discharged at a small orifice.

These vessels are often of a great length, though they take up little room, being wound over one another, sometimes in a single knot and sometimes in several, enclosed in a common membrane. And hence is the distiuction of glands into conglobate and conglomerate.

A conglobate gland is a little smooth body, wrapt up in a fine double skin, with only an artery and nerve passing in, and a vein and excretory duct going out.

A conglomerate gland is an irregular assemblage of several simple glands, which are tied together and wrapt under one common membrane.

13. A muscle is a bundle of fibres joined and fasten. ed together, with their proper veins, arteries, and nerves. It is divided into little cells by transverse fibres, parallel to each one, whereby it may be contracted and shortened, or relaxed and lengthened again. Its extreme parts are more closely compacted, which we term tendons; by these the muscles are con. rected with the neighbouring parts. A muscle generally consists of three parts; the upper, termed the head, the middle, termed the belly, and the-lower part or tail.

Every muscle is divisible into smaller muscles, and those into other still smaller, and so on beyond all imagination. The last and smallest parts are muscular fibres, but there is no assignable point in any muscle wherein there is not some nerve, and here all the nerves disappear; (in other parts their extremities expand into membranes.) It is therefore probable that the muscular fibres are only the nervous continued.

14. The cuticle or scarf-skin, is an extremely thin and transparent membrane, void of sense, and covering the skin all over, sticking fast to its surface, to 
which it is also tied by the vessels that feed it ; it consists of several layers of exceeding small scales, which cover one another where it is thick, but in the lips, where it is extremely thin, they little more than touch one another.

In some creaturcs (as fishes) these scales are only the excretory ducts of the glands of theskin; in others, those glands have their proper ducts, opening between the scales.

It is supposed there are in one scale 500 excretory ducts, and that a grain of sand will cover 250 scales. If so, a grain of sand will cover 125,000 of our pores.

The cuticle serves to defend the nerves of the skin, both from the air, which would dry and make them less sensible, and from rough and hard bodies, which would make a painful impression on the naked nerves.

Negroes have a skin between the cuticle and the true skin. They are born white, but the middle skin, in a little time, turns black, and gives that colour to the whole body.

But who can account for the following case? Sir C. Wager had a boy about eleven years old, who was born in Virginia, of negro parents : till he was three years old he was like other black children; he then, without any distemper, began to have little white specks upon his neck and breast; these increased with his years, both in number and bigness, so that from the upper part of his neck, quite down to his knees, he was dappled with white spots, some of them broad: er than the palm of a man's hand. They were won. derfully white, equal to the skin of the fairest lady, only somewhat paler. Hisface, arms, and legs, were perfectly black; he was exceeding active, sprightly, and more ingenious than is common among that generation.

Perhaps the following fact is no less difficult to be accounted for. A negro Woman, cook to Colonel Barnes, in Maryland, about forty years of age, re. markably healthy, had her skin as dark as that of the 


\section{6}

most swarthy African; but that part of it next her finger nails, about fifteen years ago, became white. Her mouth soon underwent the same change, which has since gradually extended over the whole body. $\Lambda t$ present, four parts in five of her skin are white, smooth, and transparent, as in a fair European, elegantly shewing the ramifications of the subjacent blond vessels. The other parts daily lose their blackness, and partake of the prevailing colour. The neck and back retain most of their pristine hue; the head, face, breast, legs, and arms, are all white. Her face and breast, when anger or shame has been excited in her, have been immediately observed to glow with blushes. This is the naked fact; but upon what principles of philosol hy can we account for it?

The skin covers almost all the whole body, and is formed of whitish fibres, intermixed with numberless branches of nerves, veins, and arteries. On its surface are many furrows or inderted lines, having ge. nerally hairs on each side, and pores or little holes of various sizes, serving for the transpiration of superfluous particles. Under the skin lie the subcutaneous glands, which are supposed to transmit through the pores au insensible steam, commonly believed to be of the same kind with what, when sensibly thrown out, is called sweat.

The pores in our hancis and feet are very remark. able. Survey with a glass the palm of your hand, well washed, and you may perceive innumerable little ridges, of equal bigness and distance, cvery where running parallel with each other; these are very ob. servable on the ends and first joints of the fingers and thumb, and near its roct, a little above the wrist. - On these ridges stand the pores, all in even rows. Through a good glass every pore looks like a fountain. The sweat may be. seen to stand therein as clear as rock water: the ridges are so placed that they may better suit with the use and motion of the hand; those on the lower side of each triangle to the bending in of 


\section{7}

the fingers; those on the ottrer two sides, and on the elliptic ridges; to the pressure of the hand or fingers en is against any body, requiring them to yield to the right and left.

The pores are placed on these ridges, not in the furrows between them, that their structure may be less liable to be injured by compression, whereby the furrows only are dilated or contracted : the ridges constantly maintaining themselves; and so the pores are unaltered. For the same reason the pores are very large, that they may be the better preserved; though the skin be never so much compressed and condensed, by the constant labour of the hand : and so those on the feet, that they may be preserved, notwithstanding the compression of the skin, by the weight of the whole body.

Through the pores there continually transudes a subtle vapour from every point of the body, being what redounds of the aliment, comminuted to the highest degrec, and sent to repair every particle of it. And the matter thus evacuated is more than is thrown out by all the other passages together.

A person of mildle age found what he perspired was fire eighths of the food taken in, so that there remained only three eighths for nourishment and all other evacuations. He observed also that so much is perspired in one day, as passes by stool in fourteen; ana? more particularly, that in a night's time about sixteen ounces are usually thrown out by urine, four by stool, and about forty by insensible perspiration.

If a man eats aud drinks eight pounds in a day, five pounc's of it pass by perspiration; namely, about one pound within five hours after eating, (perspiration being least of all soon after cating) from the fifth to the twelfth hour, about three pounds, and from the twelfth to the sixteenth, scarce half a pound. Exercise increases perspiration much; but it is naturally less in women than men.

While this steam flows from our body, it constantly imbibes a supply of moisture from the air, which serve's 


\section{8}

to keep all its parts soft, pliant and fit for motion. Hence, from the greater moisture of the air, we per. spire less in winter than in summer, and in rainy weather than in fair. Live therefore, if possible, in a clean house, and in a pure, dry air.

This inhalation is very considerable. Dr. Keil found his body to have imbibed in one night eighteen ounces of moisture. And on a sudden change of weather from dry to wet, the inspiration, sometimes exceeds the expiration; there being absorbent-veins, which accompany the numberless arteries from which the perspiration is discharged. To the matter thus imbibed (not the obstruction of the pores) he ascribes what we term a cold. Sweating cures this, by throwing out the noxious matter which was imbibed before.

The cutancous vessels both exhaling and inhaling, are capable of contraction and relaxation, by the power of the nerves. This appears from the effects of the passions, which if joyful, increase the circulation, and relax the exhaling ressels. Those passions on the contrary, which are sorrowful, and retard the circulation, contract the exhaling ressels, as appears from the dryness and corrugation of the skin, like a goose-skin after frights; and from a diarrhoa caused by fear. But the same affections seem to open the inhaling vessels; whence the variolous or pestilential contagions are easily contracted by fear.

The benefits of insensible perspiration are so great, that life cannot be preserved without it. And the subtility, equability, and plenty of what we perspire, are the grand symptoms of health.

But how little dowe know even of our own frame! It has hitherto passed as an unquestionable truth, that the same matter which passes by insensible perspiration, passing in great quantities, is sweat. Whereas an in:genious physician, Dr. Rogers, has found by numerous experiments, that a person perspires abundantly less, when he sweats, than when he does not; that one who perspires twenty four-ounces in eeren hours slecp, 
if he sweats, does not perspire above six. This he tried many times, and never found it to fail. Whence he infers, 1. 'That it is not the same matter which is evacuated by insensible perspiration and by sweat; 2. That it is not evacuated through the same pores: 3. That the sweat-pores are abundantly larger and fewer, than those which serve insensible perspiration : 4. That sweat greatly hinders that perspiration, both by covering those pores with a clammy liquor, and by constringing them so that they cannot open, which must be the case, when the sweat pores are dilated. What a field does this open!

Some queries proposed concerning parspiration, by an ingenious writer, seem to deserve a serious conside. ration. 1. "Why do carnivorous animals sweat so little? A fox hunted almost to death neversweats. 2. Why lo those which feed on regetables perspire so much? Horses and cows for example. We may often see them involved in a cloud of their own vapours, yoa, almost covered with froth. 3. How can animals, whose natural food is vegetables, be kept alive, and in health, in very cold climates, by purely animal food? Cows in Iceland and Norway are fed in winter upon fish-bones." I would beg leave to ask 4. Do the sweat-pores only imbibe? Or those also, which serve for insensible perspiration?

15. Fat, a whitish oily substance, roid of sense, is secreted from the blood, and lodged in small oval, membranous bags, which shoot out of the arteries. It is found in various parts, but chiefly under the skin, where (unless a man be emaciated) it runs co-extended with the skin over most parts of the body.

Fat is secerned from the arterial blood by the adipose glands, and transmitted again from the membra. nous cells to the blood through the veins. It seems to be a portion of the blood coagulated by the nitrous air mixed with it in the lungs. Artificial fat is made, by mixing for some days oil of olives with spirit of

$$
c 3
$$


nitrc. Hence divers animals grow fat in frosty weather, the air then abounding with nitre.

The uses of the fat are various, as to facilitate the motions of the muscles in all parts, lessen their attrition against each other, and prevent a stiffness or rigidity, it fills up the intermediate spaces betwcen the muscles, in such a manner, with the cavities about many of the viscera, that it readily yields to their motions, and yet supports them when at rest; it serves as a stratum or bed to conduct and defend the ressels in their course to all parts, it gives an uniform extension to the skin, and serving as a cushion to ease the weight of the body in many parts, at the same time it renders the whole of a comely agrceable shape: it probably by returning and mixing with many of the humours, abates their acrimony; it has a principal share in forming the matter of the bile, and by transuding through the cartilaginous incrustations of the boncs, it mixes with the articular liniment or synovia; also by exhaling in a living person from the mesentery, mesocolon, omentum, and round the kidneys, it lubricales the surfaces of the viscera with an oily emollient vapour, and by interposing betwixt their integuments, prevents their growing one to another.

Yet too much fat is a real disease, which hirders the motion of the lungs, entangles the most actire particles of the blood, and naturally creates dultress and heaviness. You may cure this, by following three plain rules : eat and drink little; sleep little ; work much.

16. The fourth general integument is the panniculus carnosus, which in some parts is of a fleshy substance; in others, a mere membrane, lying just under the fat.

17. The dissimilar parts are composed of the similar. The chief of these is the head. The cavity of the skull is nearly filled with a soft substance, termed in general the brain. But this is properly that part 


\section{1}

of it which lies forward. The hinder part (conside. rably smaller) is called the cerebellum. Under both, but chiefly the latter, and springing from the internal substance of both, is the medulla oblongata.

The skull is divided into two plates, one laid over the other. Between these is a spongeons substance, made of boney fibres detached from each plate. Hereby the skull is made not only lighter, but far less liable to fractures.

The skull is covered with a membrane called the pericranium. This has several holes, which give passage to the spinal marrow, the nerves, arteries, and veins. But these fill them so nicely, that nothing can pass into or out of the head, but through these ressels.

It is round, that it may contain the more; but a little depressed and longish, advancing out behind, and flatted on the sides, which contributes to the enlargement of the sight and hearing.

It is divided into pieces by four sutures. This makes it less liable to break, gives passage to the meinbranes of the pericranium, and vent to the matter of insensible perspiration.

18. All these are involved in two membranes, the inner (called pia mater) extremely thin, the outer (called dura mater) considerably harder and thicker. Where they involve the cerebellum, there is inter. posed between them the arachnoides, a rery sublie and transparent membrane, which descending through the hinder part of the skull, together with them involres the whole spinal marrow.

19. The outer part of the brain (called the cortex or bark) is of an ashy or greyish colour. It is form. ed from the minute branches of the neighbouring ar. teries, which being wove together in the pia mater, enclose the inner part, ordinarily to the thickness of about half an inch.

It consists, therefore, of innumerable little glands, c 4 
contiguous to each other, (supposed to secern the animal spirits) which are of themselves oval, but by their mutual pressure become angular, and run war. ing with each other.

The inver part (called the medulla) is white, and terminates in another medullary substance, very white and hard, called the corpus callosum. The medulla is thought to consist of fine tubes, which when col. lected into litile bundles, and covered with membranes are termed nerves.

20. To trace this a little farther. From every point of the outcr brain arise minute fibres, which in their progress uniting together, are easily perceptible. These constitute the substance of the inner brain, and of the spinal marrow. In their farther progress they are distinguished by coats, detached from the two mem. branes of the brain, into several bundles called nerres, resembling so many horse-tails, each wrapt up in a double tunic.

Several of these part from the rest in the brain itself, of which there are ten pair; one on each side. Frum the spinal marrow there arise thirty pair more. All these, while within the skull or the ispine, are pulpous; but afterwards harden, acquire a coat, and spread through the smallest points of the solid parts of the body. Their coats are every where furnished with blood-ressels, lymphatics, and resicles o: a yery tight texture. which serve to collect, strengthen, and contract their fibres. And if we consider, 1 . The great bulk of the brain, cerebellum and spinal marrow, (whereof the whole substance goes to con. stitute uerves, being continued into, and ending in them:) 2. The great number of nerves distributed hence thronghout the whole body : 3 . That the brain and spinal marrow are the basis of an embryo, whence the other parts are afterwards formed: And lastly, that there is scarce any part of the body, which does not feel or move: it may seem not altogether improbadlc, that all the solid parts of the body, 
-we woven out of nerrous fibres, and wholly consist of them.

21. The brain is diviled into four ventricles. Near the rise of the fourth, there is a roind hole, over which is suspended the pineal gland, so called from its resembling the shape of a pine-apple. It is furnished with reins and arteries, and cnclosed in a thin membrane, derived from the pia mater. Des Cartes imagined this to be the seat of the soul, but without any solid reason. Nor has any one yet been able to discover, what is the use of it.-Is it such a reservoir of blood for extraordinary occasions, as some imagine the spleen to be?

The brain is abundastly bigger in proportion in man than in other animals. In other animals it is com. monly biggest, crteris paribus, in those that hase most sagacity.

There are in the brain multitudes of ressels so extremely small, that if a globule of blood, (a million of which exceed not a grain of sand in bigness) were divided into 500 parts, those parts would be too large to pass throngh them. And these vessels are as large in the brain of a sparrow, as in that of an ox. Nor is there any difference between the brain of $a$ large animal and a small, but that one contains far more of these vessels than the other. But the globules of the fluid passing through them are in all animals of the same size.

'The outer part of a turkey's brain is a véry clear and transparent oily matter. Innumerable fine blood. vessels are spread through every part of this. And if a small part is cut, there flows out a small globule of pellucid Aluid.

The brain is not absolutely necessary to animal life. Infants have been born, and lived some time without any. We have an authentic account from Paris, of a child that survired the birth four days, not only without a brain, but even a head: instead of which it had a mass of tlesh, somewhat like liver. In c 5 
1673 , a child was born alive without any brain, cere. bellum or medulla oblongata; the skull being solid; nor had it any communication with the spinal marrow. Mr. du Verney took out the brain and cere. bellum of a pigeon, yet it lived and walked about. Mons. Chirac took out the brain of a dog; yet he lived. On taking out the cerebellum he seemed dead but revired, when he blew into the lungs, and continued alive an hour. Nay, there are many instances of insects living a long time, after their head is cut off. Hence it appears, that the spinal marrow alone may, for a season, suffice both for life, sensation, and motion.

Are there distinct provisions for the vital or spontaneous, and for the animal or voluntary actions? And does the cerebellum furnish the heart, and other vital organs with nerves, while the brain supplies the nerves, which go out to the organs of sense and voluntary motion? This is an elegant system, but is every where coufuted by anatomy. From the cerebellum, the fifth pair of nerves is manifestly produced, but this goes to the tongue, to the muscles of the outward ear, of the eye, and of the nose, which are parts, all of them either moved by the will, or else destined to sensation. Again, from one and the same nerve there are vital branches sent to the heart and lungs, and others that are animal and voluntary to the larynx, or sensitive in the stumach. Lastly, the repeated accounts of injuries to the cerebellum, being so speedily fatal, are not altogether true, for that both wounds and scirrhosities of this part have fren sustained without any fatality to the patient, may be alfirmed by certain experience.

22. The eyes next offer themselves to our abser. vation, guarded by the eye-lids, eye-lashes, and eyebrows. The eye-lids consist of the cuticle, the skin, a thin expansion of the panniculus carnosus, and an inward coat: A palisade of short, but stiff hairs grows cut of their cartilaginous edge, both to break the too fierce impression of the rays of light, and to prevent 


\section{5}

any thing from getting into the eye, when open. These hairs only grow to a convenient length, and their points stand out of the way, those of the upper eyelids being bent upward, and those of the lower, downward. Mean time the eye-brows hinder sweat, or any thing else which might be hurtful, from falling down from the forehead.

Both the eye-lids are moveable; but chiefly the upper. Animals which have hard eyes, as lobsters, need none, and therefore have no eye-lids. But most brutes have an additional eye-lid (called the nictitating membrane) which draws like a curtain, to wipe off what might incommode the eye. The monkey indeed has it not, as being furnished with hands like a man.

23. The eye can move upward, down ward, to either side, and round, either toward the right or left. For these six motious, six muscles are allotted, which spread their tendous far into the eye. At each inner corner of the eye, there is a gland with two or three ducts, which opening on the inner surface of the eyedid, keep the eye-ball moist, to facilitate its motion. By these glands, tears also are secerned. The eye is con. nected with the surrounding bones by the tunica ad. nata, commonly call the white of the eye, in the midst of which is a large hole for the tunica cornea, through which the iris and pupil appear. The whole ball of the eye rises from the optic nerve, and is formed of thre coats, propaga ed from it, and as many Lumours, two of which, have each a coat of its own also. The eye therefore has five coats in all: three common, and two to contain their several humours.

24. The outermost coat, proceeding from the dura mater, and surro nuling the whole eys, is termed the sclerotica; the, wre part of it being trausparent like horn, is thence styled the cornia. This is more con. vex than the rest of the eye. It is compused of seve. ral parallel piates, wisch are nuurished by many

c 6 


\section{6}

blood-ressels, but so fine, as not to hinder the smallest rays of light. It has an exquisite sense, that on the least touch of any thing, the tears may be expres. sed, to wash off any filth, which by adhering to it might render it dim or cloudy. The rest of the sclesotica is opaque, and of the same colour with the dura mater.

The second coat is called the urea. It is much thinner than the former, though thicker than the pia mater from which it proceeds. In the forepart of it is a round hole, which with the chrystalline humour interposed, constitules the pupil, surrounded by the iris, so named, from its supposed resemblance to the colours of the rainbow. The third and inmost coat is termed the retina. It is extremcly thin and soft, - and darker-coloured than the lower part of the optic oerve, of which it is a continuation.

66 If it be questioned, says Dr. Haller, whether the object is painted upon the retina, or upon the chorcides; we answer, this late supposition is inconsistent with known observation, by which the retina is evidently a most sensible expansion of the nerve, while the choroides has only a few nerves, with small ressels which are certainly blind. It is also opposed by the great variety of the choroides in different animals, while the constant uniformity of the retina is equally remarkable, to which add the black membrane that is interposed betwixt the retina, and choroides, in some kinds of fish. Finally, anatomy demunstrates that the choroides is seated in the blind part of the eye, but is itsulf of a white colour."

25. The Aqueous humour, resembling the colour and consistence of water, lies in the fore part of the eye, just behind the cornea : its interior surface is convex; the other, a little concave. Whence this humour is derived we cannot tell; but its source must be plentiful, for if the coat containing it be so wound. ed, that all the humour runs out, it needs only to keep 


\section{7}

the eye close for a season, and the wound will heal, and the humour recruit.

Indeed an eminent Italian affirms, that he has slit the pupil of divers animals, and squeezed out all the humours, and has afterwards restored them perfectly to sight : nay, that the eyes of many, instead of being damaged thereby, seemed more lively and vigorous than before.

The second humour, termed (improperly enough) the chrystalline, consists of many thousand filaments tending from the circumference to the centre, and closely woven together. It is a little convex before, and more behind. It serves to refract the rays of light so that they may meet and form an image, on the bottom of the eye. It is set in the forepart of the vitreous humour, like a diamond in its collet, and is retained there by a membrane that surrounds it, thence called its capsula. It is toward the outside like a jelly; but toward the centre as hard as salt. The figure of the outer part is varied by a ligament annexed, which can make it either more or less conves, or move it to or from the retina. And this is absolutely necessary, in order to distinct vision, for as the rays of distant objects diverge less than those of near objects, the chrystalline must either be made less convex, or be set farther from the retina.

When dried, it appears to consist of a vast number of thin, round scales, one upon another, 2000 of which have been counted in one chrystalline. Each of these consists of a single fibre, wound this way and that, in a stupendous manner, so as to run several courses, and meet in as many centres, and yet not interfere or cross in any place.

The third, which is termed the vitreous humour is not unlike melted glass. It is covered with an exceeding thin coat. The forepart is concave, as receiving the chrystalline; the other side is convex.

The whole apparatus of the eye tends to this, that there be produced in the bottom of it, a distinct col. lection of all the rays, which proceeding from auy 


\section{8}

point of an object, penetrate the chrystalline humour, that so an image of that object may be painted there. In order to this, the rays striking on the cornea, are reflected toward the perpeniticular, and thus directed, through the pupil to the chrystalline. Mean time the iris, contracting or dilating the pupil, admits fewer or more rays, as the object is more or less vivid.

Now the flatter the cornea is, the fewer rays does it collect and transmit to the chrystalline, and those more diverging. The rounder is is, the more rays does it collect and transmit, and those more converging. It is too flat in old men; it is too round in them that are short-sighted. The rays transmitted through the pupil to the chrystalline humour, are there re. fracted anew, collected and rendered converging, and those that come from the same point, are thrown in one point on the botiom of the eye. But if the chrys. talline be too dense, the focus (or point wherein they unite) will be ton near: if that be not dense enough, it will be too remote. And this is another cause of short-sightedness or the contrary defect.

In all vision both the cyes are lised at once. And both together_(as any one will tind upon trial) behold an object in another situation than fither of them apart would do. Hence a gentleman who had one of his eyes struck out, for sonie months after was apt to pistake the situation of things, and when he attempted to pour liquors into phials, of ten poured them quite beside the neck of the phials.

Two eyes greatly contribute, if not to distinct, at least to extensire vision. When an object is placed at a moderate distance, by the means of both eyes we see a larger share of it than we possibly could with one; the right eye seeing a greater portion of its right side, and the left eye of its correspondent side. Thus bith cyes in some measure see round the object; and it is this that gives it in nature, that bold relievo, or swelung, with which it appears ; and which no painting, how exquisite soever, can attain to. The painter must be contented with shading on 
a flat surface; but the eyes in observing nature, do not behold the shading only, but a part of the figure also, that lies behind those very shadings, which gives it that swelling, which painters can never fully imitate.

'There is another defect, which either of the eyes, taken singly, would have, but which is corrected by haviug the organ double. In either eye there is a point, which has mo vision, so that if one of them only is employed in seeing, there is a part of the object to which it is always totally blind. This is that part of the optic nerve where its vein and artery run; that point of the object that is painted there, must continue unseen. To be convinced of this, we have only to try a very easy experiment. If we take three black patches, anil stick them upon a white wall, about a foot distant from each other, each about as high as the eye that is to observe them, then retiring six or seven feet back, and shutting one eyc, by trying for sometime, we shall find, that while we distinctly behold the black spots that are to the right and left, that which is in the middle remains totally unseen. When we bring that part of the eye, where the optic artery runs, to fall upon the object, it will become invisible. This defect, in either eye, is corrected by both, since the part of the object that is unseen by one, will be distinctly perceived by the other.

The form of the eye is the most commodious which can be imagiaed. It is fittest both to contain the humours within, and to receive the images of objects from without. Was it square, or of any multangular form, some of its parts would lie ton far off, and some too nigh those lenticular numours, which by their refractions cause vision. But by means of this form, the humours are fitly placed to perform their office of refraction, and the little iarkened cell neatly adapted to receive the image of the object.

Again. As it is necessary for the eye to move various ways, in order to adjust itself to various ob. jects; so by this figure it is well prepared for suct 
motione, and can with ease direct itself as occasion requires.

No less commodious is the situation of the eye : in the most eminent part of the body, and near the most sensible part, the brain. By its emincuce in the bndy, it can take in the more objects, and by its situation in the head, besides its nearness to the brain it is most conveniently placed for defence and secu. - rity. In the hand it might have been more ready for service : but to how many dangers would it have been exposed? The same may be said, as to its site in any other part but where it is. But the head is a part that scems contrived and made chiefly for the use of the principal scuses.

Some odd circumstances relative to the eyes, are related by a physician in the Philosophical Iransactions.

"6 A person had no visible disease in his eyes, yot could not see, unless he squeezed his nose with his fingers, or saddled it with narrow spectacles, and then he saw very well.

66 A maid, 23 years old, could see very well, but no colour besides white or black. She could some. times in the grealest dark riess, see to read almost a quarter of an hour.

6i A sarller's daughter had an imposthume, which broke in the corner of her eyes, and out of it there came about thirty stones, as big as small pearls.

"6 A young man in Suffolk, about twenty years of age, has all the day a clear and strong sight. But when twilight comes, he is quite blind, nor can he see any thing at all, either by fire-light or candlelight. No glasses give him any help. He has been thus, ever since he can remember. This cloudiness comes gradually upon him, like a mist, as day-light declines. It is just the same, both in summer and. winter, and at all times of the moon.

"6 When I was about sixty my sight was so decay. ed, that I could not rlistinguish nien from women. I 


\section{1}

received no help from any glasses, till I took specta. cles with the largest circles. Close to the upper semicircle on both sides, I cut the bone, and taking out the glasses, put black Spanish leather, taper-wise in to the emptied circles. These took in my whole eye at the wider end, and through the narrower end $I$ can read the smallest print. Into this end I can only put my little finger, not quite to the first joint. But they may be made wider or narrower, and longer or shorter, as best fits ciery eye.

"6 At first I could not bear them above two hours at a time : now I can use them abore twelve hours in four and twenty. And they prove a great help to those who are purblind, who have weak eyes or decayed with age. But for the purblind they must be made shorter, longer for eyes decayed with age.

" Instead of leather, they may be made of paper, coloured black, and pasted on, and with inner folds to be drawn out, from one inch to three."

In some men the iris has a faculty of darting out light. Dr. Willis mentions one, who after drinking wine plentifully, could see to read in the darkestnight. And Pliny records of 'Tiberius Cesar, that if he waked in the night, he could see every thing for awhile, as in the broad day-light. Dr. Briggs gives a parallel instance of a gentleman in Bedfordathire.

IN in sin various substitutes for the use of the eyes, in many blind persons. In some the defect has beer supplied, by an excellent gift of remembering what they had seen ; in some by a delicate sense of smelling; in others, by a fine sense of hearing. Su Richard Clutterbuck of Redborough in Gloucestershire, who was stone blivd, had so curious an ear, that he could hear the fine sand of an hour glass fall. In same it has been supplied by an exquisite sense of feeling, so that the same Richard Clutterbuck was able to perform all sorts of curious works. He could not only take a watch in pieces, and set it together again, but could also make all sorts of stringed instruments of music. He likewise played on them by notes cut in their. 


\section{2}

usual form, and set upon protuberant lines on the wood. Yet evcu this hardly came up to the skill of Van-Eyck, the organist of Utrecht, who, though he had been blind from two years old, played on all sorts of instruments.

Others have been able to take a face by the touch, and mould it in wax with the utmost exactness: as was the blind sculptor, who thus took the likeness of the Duke de Bracciano, and made a marble statue of King Charles the first extremely well.

26. But more than all this, some persons have been able even to distinguish colours by the touch. Peter of Maestricht, though perfectly blind, distinguished by his touch the different colours of cloth. John Vermansen of Utrecht did tho same; judging by the differcnt degrees of roughness which he felt.

Yet Elind persons, even though they distinguish them by the touch, bave no idea of visible objects. Thus the gentleman couched by Dr. Chesselden: he had sio jolea of distance, but imagined all the objects he saw, touched his eyes in the same manner as those he felt did his skin.

- An extract from Dr. Chesselden's account of this jerson, will not be unacceptable to the curious.

66 'This young getfemait cou!d in a strong light distinguish black, white, and scarlet. Yet the fatne ideas he had of them before he was couched, did not suffice to make him know then after. He now thought scarlet the most beautiful of all colours. Of others, the most gay, were the most pleasing. But the first time he saw black, he was very uneasy, yet after a while he was reconciled to it. When he first saw, no objects was so agreeable to him as those that were smooth and regular, although he knew not the shape of any thing, nor could distinguish one from another, either by its shape or size. Being told what those things were, whose forns he knew by feeling, he would carefully observe, that he might know thein again. Thus, having often forgot which was the cat 
and which the dog, he was ashamed to ask, but catching the cat, (which he knew by feeling) he looked at her stedfastly and said, "So puss, I shall know you another time." He was surprised that the things or per. sons he liked best, did not appear most agreeable to his sight, expecting that what was most pleasing to his other sense's, would be so to his sight also.

66 We thought he soon knew the nature of pictures, but found afterwards we were mistaken; for it was two months after the operation, before he discovered that they represented solid bodies. Even then be was no less surprised, oxpecting they would feel like tho things they represented. Ho was amazed, that thoso parts, which by their light and shade a ppeared round and uneven, should feel like the rest, and asked which was the lying sense feeling or seeing? Being shewn his father's picture drawn in miniature, and told, what it was, he acknowledged the likeness ; but asked, how it could be, that so large a face should be contained in so little room? Saying, it would have seemed as impossible to him, as to put a bushel of any thing into a pint. But eren blindness, he observed, had this advantage, that he could go any where in the dark, better than those that could see. And after he was couched, he did not lose it, but could go all about the house without a light. Every new object gave him new delight, such as he wanted words to express. He was particularly delighted, when he first saw a large prospect, and called it a new kind of see. ing. Being afterwards couched in his other eye, he said that objects appeared larger. to this eye, though not so large as they did to the other, when it was newly couched. But looking on them with both eyes, they seemed twice as large, as if helooked with that only."

27. I would beg leave to propose a few queries here to which I have not found a satisfactory answer. 1. Why do we see things false with one cye? Particularly with regard to their situation. 


\section{4}

2. How do the two eyes compound the rays of light, so as to see right?

3. Why do we not see all things double?

4. Since all things are painted upside down on the bottom of the eye, why do we not sce them so?

28. We now proceed to the ear, formed with exquisite wisdom, for the reception of sounds. The outward ear consisting of an oval cartilage, externally convex, concave within, leads by various windings to the meatus auditorius, which is first cartilaginous, and then bony. It is filled with a viscid matter, called the earwax, which is supplied from the ressels placed in the skin, surrounding the meatus, to hinder any hurtful animal from creeping into the ear. The meatus isclos. ed within by a thin, dry, transparent membrane, affixed to a bony circle, which is called the membrana tympani. Behind it is that cavity of the os petrosum, which is termed the drum.

The outward ear has two parts, that which stands out from the head, called the auricle, and the narrow passage which enters the skull, called mentus auditorius.

The auricie is furrowed with divers winding canals, which receive and collect the various undulations of the air. They trho have lost this, hear very confusedly, unless they use a trumpet, or form a cavity. round the hear, with their hands.

It is a wise provision that the substance of the auricle is cartilaginous. Had it been bone, it would have been troublesome, and might by many aceidents have been broken off. If flesh, it would neither have remained expanded, nor so well have received or canveyed the sounds. Rather it would have blunted them, and retarded their progress into the organ. But being hard, and curiously smooth and winding, sounds find an easy passage with a regular refraction, as in a well-built arch.

It is observable that in infants in the womb, and newly-born, the meatus auditorius is close shut np, partly by the construction of the passage, and partly 


\section{5}

by a glutinous substance, whereby the drum is guard. ed against the water in the secundine, and against the injuries of the air, as soon as the infant is born.

It is remarkable, that in the ear of most, if not all animals, where the meatus auditorius is long enough to afford harbour to ear wigs, or other insects, ear-wax is constantly to be found. But in birds, whose ears are covered with feathers, and where the drum lies but a little within the skull, no ear-wax is found, be. cause none is necessary to the ears so well guarded, and so little tunnelled.

29. In this, besides a little branch of nerves, there are four little bones, two passages, and two windows. Three of those bones, from some imagined resemblance, are stiled the hammer, the anvil, and the staple : the fourth is termed, the orbicular bone. These are fastened by strong ligaments to each other, and to the neighbouring parts. The passages go from the side of the drum : one of which, termed the labyrinth, by a very winding way, carries a part of the auditory nerve to the external muscles of the head. The other passes from the buttom of the drum to the palate; whereby not only air, if needful, may be received, but the defect of hearing, in some measure supplied by speaking to the mouth.

The labyrinth contains, besides the entrance, three bony, semicircular carities, and a bony canal, in the. form of a screw, divided into two parts, from the top to the bottom. The labyrinth is lined throughout with a thin membrane, furnished with reins, arteries and nerves. And this membrane may not improbably be the organ of hearing.

'The curious siructure of the labyriuth and screw, tend to make the weakest sounds audible. Those cauals, by their winding, contain large portions of the auditory nerve, upon every point of which, at once the sound being impressed, becomes audible; and by their narrowness the sounds are hindered from dilating; which must have weakened them proportionably. 


\section{6}

The strength of the impression is likewise increased, by the elasticity of the sides of the bony canal; which receiving the first impulses of the air, reverberate them oi the auditory neve.

The auditory nerves are distributed, one to the car, the other to the eye, tongue, and parts adjoining. By the distribution thereof to different parts, an admira. ble consent is established between them. Hence it is, that most animals hearing a strange sound, erect their cars to catch it, open their eyes, and are ready with their mouth to shriek or call for help. A farther use of this nervous communication between the ear and the mouth is, that the voice may corespond with the hearing, and be a kind of echo thereof : and that what is heard with one of these nerves, may readily be expressed by the help of the other.

And now what less than an infinitely wise God, could contrive so fine an organ, and such a medium, so susceptible of every impression, that the sense of hearing hath occasion for, to empower all animals to express their meaning to each other, with endless va. riety? Yea, what less could form such an œconomy as that of music is? So that the medium conveys the melodious vibration of every animal voice or well. tuned instrument, and the ear receives them, to allay the perturbations, and.calm and cheer the heart of man!

Though the ear be the ordinary organ of hearing, yet it is not the only orse. We may hear by the teeth. For if one end of a knife beapplied to a spinnet, and the other held between the teeth, the music will be distinctly heard, though the ears be ever so closely stopped. Yet this is not properly by the. teeth, but by the auditory nerre which passes from the drum to the palate.

In those who are born deaf, the eyes may in some measure serve in the place of ears. Some can understand what is said by nicely observing the lips and tongue of the spcaker : and may even accustom themselres to use their own, till they learn a kind of 
speech. Thus a physician at Amsterdam taught several children born deaf, to understand what was said and to give pertinent answers.

Mr. Goddy's daughter of Geneva lost her hearing. at two years old. Yet by observing the lips of others, she had acquired many words, whereby she would talk whole days with those that could understand her. But, she knew nothing of what was said, unless she saw the mouth of the speaker: so that if they wanted to speak, to her in the night they were obliged to light a candle. Only she knew what her sister said even in -the dark, by laying her hand on her mouth.

But many deaf persons can hear, if a loud noise be made while you speak. Dr. Willis mentions one, who, if a drum was beat in the room, could hear very clearyy. So that her husband hired a druinmer for his servant, and by that means conversed with her daily.

30. The nostrils are made not of flcsh or bone, but of cartilage, the better to be kept open, and as occasion requires, to be dilated or contracted ; for which purpose they are furnished with proper and curious muscles. The tub s therein growing narrower, and narrower, lead into several little cells and winding cavities, covered with a soft coat, and provided with arteries, veins, glands, and filaments of the olfactory nerves. This, therefore, is without all doubt the proper organ of smelling.

And forasmuch as it is by breathing, that the odo. rant particles are drawn in, the laminx with which the upper part of the nose is barricaded, serve two excellent purposas ; partly to prevent any thing hurtful from entering the breathing passages in our sleep (for which end likewise the hairs placed at the eutrance of the nostrils serve) anil partly to receive the divarications of the olfactory nerves, which are here, thick spread, and by this means meet the smells entering with the breath.

Each of the cartilaginous lamiux is divided into 
many others, folded into a spiral line. The os cibro. sum is made up of the extremities of these; the holes therein being the intervals between them. They are designed to uphold the inner tunic of the nose, which is folded round about together with these lamine, that by its great expansion it may receive a greater number of the odorant particles. For the same reason, it is furnished with many small glands, which open into it, and moisten it with a slimy exudication, fitted to entangle and detain the subtle efluvia that tonch it. And not only the number, but also the length of these laminx, is of great use for the strength of smelling. For this purpose most beasts, which either hunt, or distinguish their food by smell, have not their nose in the middle of their face, like a man, but prolonged to the very end.

31. The tongue has for its basis that forked bone, - called the os gutturis. It consists of various muscles in. terwoven together, that it may be fit for various kinds of motion. To these are added very many small branches of nerves, which pass through the middle of it to the outside, and being gathered into little bundles constitute those papilla. which makes its surface rough and uneven. Besides these, there appear also on the surface of the tongue, certain pointed fibres, not unlike the ends of birds claws, inclining towards the basis of it, with which are interspersed innumerable salival glands. And all these are in their several ways sub. servient to the sense of tasting.

It has been generally supposed, that the tongue is essentially necessary to the formation of speech. But as sure as we have been of this, it is an entire mis. take. A child in Essex, some years ago, had her torigue entirely cut out, by reason of an incurable canker. She was then three years old.' 'Twenty. years after, it was reported, that she was able to speak. 'To be satisfied hercof, Mr. Benjamin Boddington, Turkey merchant of Ipswich, with two other gen. 


\section{9}

themen, went to Wickham Market, where the young woman then lived, whose case they thus describe:

"We have this day been at Wickham Market, to satisfy ourselves concerning Margaret Cutting. We examined her mouth with the greatest exactness, but found no part of the tongue remaining ; nor was there any uvula. The passage down the throat is a circular open hole, large enough to admit a small nut. meg.

is Notwithstanding this she swallowed both solids and fluids as well as we could do, and in the same manner. Yea, and she talked as fluently as other persons do. She pronounced letters and syllables very articulately, even those which seem necessarily to require the help of the tongue, as $d, J, t, w$. She read to us in a book distinctly; she sings very prettily; nay, and she distinguishes tastes, and can tell the least difference either in taste or smell."

- But is it possible to teach any one to speak, who has been deaf and dumb from his birth ?-

It is. Dr. Wallis taught such an one to speak. Mr. Daniel Whaley of Northampton. He was pre. sent before the Royal Society, May 21, 1662, and did there pronounce, distinctly enough, such words as the company proposed to him : indeed not altogether with the usual tone, yet so as easily to be understood, In a year, which was the time he staid with $\mathrm{Dr}$. Wallis, he read over great part of the English bible, and learned to express himself intelligibly in common affairs, to understand letters written to him, and to answer them. And in the presence of many foreigaers, he has not only read English and Latin to them, but has pronounced the most difficult words in their lan. guages, which they could propose to him.

The doctor has since done the same for Mr. Alexander Popham, a gentleman of a fair estate.

But we have an instance of dumbness cured in a rol. I. 
shorter time. Henry Axford, son of Henry Axford, in the Devizes, at twenty-eight years of age, perceired a hoarseness, and in about six days became quite speechless; not only unable to speak articulately, but to utter the least sound with his tongue. His cold went off, but he remained absolutely speechless; and tho advice of all the neighbouring physicians did not help him.

He continued totally dumb for four years, till in July, 1741, being at Stoke, in returning homeward at night, he fell from his horse, and was taken up and put to bed in a house upon the road. He soun fell asleep, and dreamed, he was fallen into a ressel of boiling wort. Struggling with all his might to call for help, he actually did call aloud, and recovered the use of his tongue from that moment,as perfectly as ever he had it in his life.

Perhaps, therefore, there is truth in that ancient story, concerning the son of king Cressus, namely, having been dumb from his birth, he had never spoke at all, till in the battle, seeing a man ready to kill his father, his torigue wasloosed, and he cried out aloud, "Sol. dier, spare the king!"

The time of cutting the teeth is usually from the seventh to the seventeenth month. It is commonly preceded by an itching of the gums, and by convul. sions, fevers, and louseness : most of which symptoms happen to birds also, upon molting or casting their feathers. The seed of the teeth is a mucous matter, like the white of an $\mathrm{egg}$, contained in the cells of the jaw-bone, which grows harder and bigger till it breaks through the gun?.

That part of the tooth which stands out of the gum, is covered with a peculiar substance called enamel. It is composed of an infinity of little tubes, which grow on the bone by their root. If any part of this be broken off, so that the bone is left hare, it grows carious; there being no bone which will bear the air.

We may farther observe, 1. That the teeth only, 
of all the bones, grow in length during a man's whole - life : which is providently designted, to repair the waste that is continually made by attrition: 2. That the teeth are the only bones which are not covered with that exquisitely sensible membrane, the perio. steum : 3. That they are harder and firmer than any other bone, that they may be more durable and fit to chew the most solid aliments: 4. That for their nourishment, there is a cavity contrived in each side of the jaw-bone, in which are lodged an artery, a vein, and a nerve, which through smaller cavities send their twigs to every tonth : 5 . That as infants are designed to live on milk, for some months, they are so long without any teeth : whereas animals that need them, have them sooner, and some are even born with them. 6. The different shape of the teeth is remarkable. The fore-teeth are formed broad, and with a thin and sharp edge, like chissels, to cut off a morsel from any solit food. The next, one on each side, are stronger, deeper-rooted, and more pointed, to tear tougher aliments : the rest are made flat and broad at top, and withal, somewhat uneven, that thereby they may the better retain, grind and mix the aliment. 7. Because biting and chewing require much, strength, partly in the teeth themselves, partly in the instruments that move the lower jaw, which alone is moreable ; nature has given it strong muscles, which make it bear forcibly against the upper jaw : and has not only fixed each tooth in a distinct cavity, as in a close, strong and deep socket, but has given holdfasts to the several sorts of teeth, suitable to the stress that is to bc laill upon them. So whereas the cutters and eye-teeth have only one root, the grinders, lesigned for harder work, have three: in the upper jaw often four, because they are pendulous, and the substance of the jaw somewhat softer. 8 . The situation of the teeth is most convenient. The grinders are behind, near the centre of motion, because chewing requires a considerable force : the cutters before, ready for their easicr work. 


\section{2}

32. The Palate is of a bony substance, a little concave, and clothed with a thick membrane, which has the same kind of nervous papilla and small glands, that are seen in the surface of the tongue. And hence it is qualified to assist the taste, as well as the speech.

It would be endless to specify the curious mecha. nism of all the parts that concur to form the voice. However, let us note two things : 1 . There are thirteen muscles provided for moving the five cartilages of the wind-pipe. 2. It is amazing that the glottis, (the upper part of the wind-pipe) can so exquisitely contract or dilate itself, to form all notes. "Suppose (says Dr. Keil) the greatest distance of the two sides of the glottis to be one tenth of an inch,' in sounding $t$ welve notes (to which the voice easily reaches) this line must be divided in to twelve parts, each of which gives the aperture requisite for such a note. But if we consider the subdivision of notes into which the voice can run, the motion of the sides of the glottis is still vastly nicer : for if of two chords, sounding exactly unisons, one be shortened but the two thousandth part of its length, a just ear will perceive the disagreeinent, aud a good voice will sound the difference : and yet this is ouly the one hundredth and ninety-sixth part of a note. But suppose the voice can divide only into a hundred parts, it follows, that the different apertures of the glottis, actually divide the tenth part of an inch, into twelve hundred parts, the effect of each of which produces a sensible alteration upon a good ear."

33. The Urula is a round, oblong, fleshy substance, suspended near thi passage from the mouth into the nostrils, and probably designed to hinder the cold air, from rushing too fast into the lungs, as well as to prevent the food we swallow from regurgitating into the nostrils.

The Tonsils, or almonds of the ear, are two small 
glands, placed at the root of the tongue, which supply an humour, to keep the mouth and the tongue continually moist.

The Wind pipe is wonderful in its conformation : because continual respiration is necessary, it is made with annular cartilages, to keep it constantly open, that its sides may not fall together : and lest, when we. swallow, any particle of food should fall in, which might cause convulsions, or even death, it has a strong shutter, or lid, called the epiglottis, which, whenever we eat or drink, falls down of itself, and covers it close, so that no crumb or drop can enter. It is for the more convenient bending of our necks, that the wind-pipe is not made of one entire continued cartilage, but of many circular ones.

What is farther remarkable in these cartilages is, that all the way where they are contiguous to the gul. let, they are membranous, to give an easy passage to the food: but after that, they are, some completely round, some triangular. Another thing observable is, in the wind-pipe, the cartilages run parallel to each other: but, in the lungs, the lower parts of the su. perior cartilages receive the upper parts of the infe. rior: hereby enabling them to contract themselves in expiration, and to dilate in inspiration.

34. The Hairs are all hollow. The root of each hair is fixed in a mucous globule, of an oval figure, which often adheres to it, when it is pulled up by the root. They are jointed like a reed or cane, and shout out into small branches. They serve not only for a co. vering, but also for the excretion and expiration of af oily matter.

Livery hair does properly live, and receire nourishment like the other parts. The ruots do not tura white or grey in age, any sooner than the extremes. But the whole of each hair changes colour at once. Or (to speak more properly) the hairs of another colous fall off; and white ones grow in their place.

But extreme fear may turn the hair grey, or eqen D 3 


\section{4}

white in a short space. So it was in that famous in stance some years ago. A nobleman in Germany, was condemned to die, and ordered for cxecution in the morning. During the night, in ten or twelve hours time, all his hair turned white as flax. The emperor being informed of this, said, "he has suffered enough:" and pardoned him.

Since that time, there has been an instance of one of our own countrymen, who being shipwrecked, saved himself on a small rock, surrounded by the sea. A boat took him off after he had stayed there four hours. But in that space his hair was turned quite white.

Perhaps a still stranger instance of this kind is related in the duke of Sully's memoirs. "Henry IV. told the marquis de la Force, that the moment he was informed Henry 11I. had published an edict, (in July, 1585) ordering all the Hugonots cither 10 go to mass, or to abandon the kingdom in six months, his mustaches turned suddenly white on that side of his face, which he supported with his hand."

Its life is a pecutiar kind, and approaches to the nature of vegetation. Hairs grow much as plants grow out of the earth, or as some plants grow upon others: from which they draw their nourishment, and yet each has its life distinct from the other. So hair derives its food from some juices in the body; but not from the uutritious juices. Accordingly the hair may live and grow, while the body is starved to death.

That hair may grow merely as an excrescence of the vegetable kind, appears from that memorable case recited by Mr. Hook, of a budy which, having been buried forty-three years, was found in a manner wholly converted into hair. The woman was buried in a coffin of wood, and lay the lowest of three in the

- same grave. The others, being removed, and this coffin appearing; it was observed that much hair came through the clefts of it: on removing the lid, the whole appeared a rery surprizing sight. There wa? 
the whole figure of the corpse, exhibiting the eyes, mouth, ears, and every part. But from the very crown of the head, even to the sole of the foot, it was covered over with a very thick set hair; long, and much curled. The people, amazed at this appearance, went to touch the corpse. But the shape fell away, as it was handled, leaving only a quantity of shapeless hair; but neither flesh nor bones, only a small part of the great toe of the right foot.

Each hair consists of several smaller ones, wrapt up in one common covering. They send out branches at the joints. The root lies pretty deep in the skin : and by this they imbibe their proper nou rishment, from the adjacent humours. Their extremes also split into two or three branches, especially if they are very dry, or too long. So that what appears a single hair to the naked eye, to the microscope appears a brush. They are grey on the forepart of the head first, particularly about the temples: the back part affords them nourishment longer. For the same reason they fall from the crown of the head first. Their thickness depends on the size of the pores they issue from: if these are small, the hair is fine. If the pores be strait, the hairs are strait; if oblique or sinuous, the hairs are curled.

All hairs appear round. But the microscope dis. covers some of them to be square, others triangular ; which diversity of figures arise merely from the diversity of the pores. Their length depends on the quantity of humours proper to feed them, and their colour on the quality. And hence the colour usually differ in the different stages of life.

The hair of a mouse is a transparent tube, with a pith of small fibresconvolved, running in some hairs spirally, in some iransverscly, in others from top to bottom.

The Nails are of the nature and fabric of the cuticle, like which they are also insensible, and renewable, after being cut or fallen off. They are placed

D 4 
rpon the backs of the ends of the fingers and tous, which they support to make a due resistance in the apprehension of objects, having the nervous papillary bodies, that serve the organ of touch, placed under their lower surface. They arise with a square root, intermixed with the periosteum, a little before the last joints, from betwixt the outer and inner stratum of the skin, and passing on soft, go out by a lunar cleft in the external plate of the skin, where the cuticle returns back, and enters into a close adhesion with the root of the nail, together with which it is extended as an outer covering.

35. We proceed to the middle cavity of the body. Ilerein the princifal part is the Heart, consisting of a strong tendon, extended obliquely from the basis or broader part, to the cone, into which the fleshy fibres are inserted, in an elegant series, with a spiral bending one half opposite to, and crossing the other : by which means the grand muscle is admirably fitted both to re. ceive and to propel the blood. It has two great caritis, usually termed the ventricles of the heart. They are divided from each other by an intermediate part, called the septun, constituted by the same fibres, which is convex on the side next the right ventricle, and concave on the other. 'Phe vena cava is inserted in the right ventricle, and two inches from its insertion, divides into the upper and lower. The former brings the blood into it from the upper; the latter, from the lower parts of the body. The pulmonary artery carries the blool from that ventricle into the lungs, which the pulmonary vein brings from thence into the left ventricle. At the upper side of these veins, there is added to each ventricle, a kind of purse called the auricle, which is a hollow muscle of the same structure with the heart, in order to stay the blood, that it pour not too violently into the rentricle. Before the orifices of the veins of the heart, there are triangular valves, and sernilunar in the orifices of the arteries, to hinder the reflux of the blood from 
the rentricles into the veins, and from the arteries into the ventricles. In a healthy person, the heart contracts little less than five thousand times in an hour.

36. The Heart is covered with a fine membrane; and near the basc of it, on the outside, there is a little fat, probably designed to facilitate its motion. It is placed near the mildle of the breast; only its cone inclines a little to the left. It hangs by its base on veinsand arteries, communicating with all parts of the body. The other part of it is loose in the pericardium, that it may be the more commodiously constringed and dilated. The pericardium is a kind of mem, brane that like a kiud of purse, loosely incloses the heart. The shape of it is suited to that of the heart, and it contains a thin, saltish, reddish humour, exuding from the arteries.

The brain has an alternate contraction and dilation, answering those of the heart. It is highly probable, the weight of the atmusphere is the counterpoise to the contractile force af the heart. That of the brain, being not near so strong, does not need so strong a counterpoise.

Ii the basis of the heart, in some animals, there is a bone frequently found. Such an one was found in the heart of Pope U,bau. Probably it was only the tendons of the heart ossified.

Wounds of the heart are not always so immediately mortal as is generally supposed. A soldier was brought into one of the hospitals in Paris, with a wound in the upper part of the left breast. He seemed very well for three days : but on the fourth was taken with a fever and difficulty of breathing, and died on the tenth. On opening the body, it was found the sword had pierced the pericardium, traversed the right ventricle of the heart in its lower part, pierced the pericardium on the opposite side, and gone through the diaphragm, and an inch deep into the liver. 
37. The heartis placed in the middle of the lungs, which consist of two parts, the right and left lobe. Each of these is divided in to two other lubes; one of these frequently into three, sometimes into four, by fissures, sometimes deeper, sometimes shallower, running from the interior margin towards the back part. The lungs are divided into cells, which are no other than expansions of the small branches of the trachea or wind.pipe. And there is an easy passage from one branch into many cells, and again into it from them all. The upper part of the trachea opens into the mouth; the lower, divided into two branches, shoots out into various ramifications, which are termed bronchia. And these little canals running on, constitute the luags, whose cells are wonderfully connected together, and intermixed with numberless branches of veins and arteries.

The upper end of the trachea is called the larynx. At the fuurth vertebra of the back, it divides and en. ters the lungs. Its cartilages, ranged at small and equal distances, are smaller and smaller as they approach the lungs.

These cartilages have two membranes. The exterxal, composed of circular fibres, covers the whole trachea. That which lines it within, consists of three distinct membranes, the first woven of two orders of fibres, part longitudinal, to shorten it by drawing the cartilages together: part circular, to cuntract them. Both these, Ir gether with the external membrane, assist in breath.ing, coughing, and varying the tone of voice. The second membrane is glandulous; and its glands opening into the cavity of the trachea, separate a liquor which moistens and defends it from the acrimony of the air. The third is a net-work of nerves, veins, and arteries.

The organs which form the voice of man, have not been accurately ouserved by the ancients. As the trachea bears some resemblance to a flute, they considered the voice, according to the sounds of that in- 
strument, Mr. Dodart was the first who shewed the glottis to be the chief organ in producing it, and considered it $\mathbf{b}$ th as a string and wind instrument, far more perfect than any which art can produce.

The organs which form the various voices of other animals, are likewise worthy of our attention. Those of each species have peculiar sounds, whereby they understand each other.-Wherein do these organs resembie ours? and wherein do they differ?

'The human voice is almost wholly formed by the glottis, and various tunes are produced by the various modifications of it. But all these depend on one only; the separation and junction of its lips. This comprehends two circumstances, the one capital and prinitive, the other, a consequence of it. The first is, That the lips are more and mure bent, from the lowest to the highest note.' The second, That the more they bend, the nearer they draw to each other. It follows from the first, that their vibrations will be more frequent, as they come nearer the highest tone, and that the voice will be exact when they are equally bent, and the reverse when unequally : which corresponds perfectly well with the nature of stringed instruments. It follows from the second, that the higher the tone, the nearer they draw to each other. And this agrees perfectly with those wind-instruments which are governed by reeds. From these simple, and almost imperceptible variations, proceeds the infinite variety of sounds.

In most quadrupeds too the glottis is the principal organ of the voice. So it is in cats, sheep, and several others. But many have something more than a glot. tis. As horses, asses, mules, and swine. Some of these have also a tendinous membrane, which concurs in forming the voice. Others have several membranes: others a kind of bags, which in some are membra. nous and in others bony. Others have both membranes and bags. Others, lasily, have in their larynx a kind of cavity or drum, which assists them in uttering very strong and long continued notes. 
All sounds are produced by a swift suceession of vibrations, from the particles of sonorous bodies which agitate the air. But the vibrations of the lips of the glottis would not suffice to produce the neighing of a horse. This begins by more or less acute interrupted tones, accompanied by quarerings, and ends by tones more or less grave, which is performed by jirks. This second part is done by the lips of the glottis : the other chiefly by a snall, elastic membrane. This is tendinous, very thin, of a triangular figure, and lies flat on each extremity of the lips of the glottis. As it adheres but loosely to these, it can easily flutter up and down : and it is the play of the membrane up and down, which produces the acute sounds of neighing. These are more or less acute, as the membrane is more or less thin, and its adhesion more or less slack. The grave sounds that conclude the neighing, are excited by the flutterings of the thick strings, which form the lips of the glottis.

The hoarse sound of the ass's voice is not so much produced hy the lips of the glottis, as by a tendinous part $w$ hich adheres loosely on the aperture of a kind of drum, sitnate under the extremity of the lips of the: glottis : above which arealso found two large and -thick bags; one on the right, the other on the left. liach of these has a roundish aperture, cut much like the stopple of an organ.

Such are the organs which form this amazing sound.

$A$ kind of drum is the principal : and the two bags a bove the lips of the glottis, are the main auxilia. ries: while those lips, as pla in experiment shew, contributevery little thereto. The mule's voice mneh resem. bles that of his sire, and is formed by much the same organs; the dum of so singular a compusition, being found in mules also.

There is another animal which affords us a particular disposition of the vocal organs. This is the hog: - whose shrill cries are more insupportable than his usual grunting. Yet neither are these excited by the lips of the glottis, but by the futtering of two large mem. 
branous bags; situated on each side, abore the lips of the glottis. What is remarkable is, that each lid is cloven almost its whole length. By this cleft each lip has a communication with the bag belonging to it. And the motions of these bags produce most of the sounds peculiar to this animal.

Though the voice of birds bears a nearer resemblance to ours, than that of a quadruped's, yet their organs have far less resemblance to ours, and contain a greater number of singularities. They, like us, have a glottis at the top of the trachea ; but they have another at the bottom of it, which much contributes both to the strengthening and modifying of their voice. These have different membranes more or less fine, more or less bent, and in a variety of positions. In soine birds, as in gecse, there are four of these, figured and disposed like the reeds in hantboys.

With regard to the human voice, an ingenious man observes, "sitting in company, I chanced to take notice, that in ordinary discourse, all that is spoke, is spoken in perfect notes; and that some of the com. pany used eighths, some fifths, and others thirds. $\mathbf{I}$ oh. served likewise of him whose speech was the most pleasing, that all the tones he used, consisted either of concords, or of such discords as made up harmony."

Cutting the trachea was long reputed mortal; but it is now usual to open it in dangerous quinsies. This physicians were at first encouraged to do, from the case of a Cornish gentieman, who had his winil-pipe quitecut through, and yet was cured and lived several years after.

38. In order to the admission and expulsion of the air by the lings, it is necessary the breast shonld be contracted and dilated. This end is served by the bony part of the Thorax, the intercostal muscles, and the diaphragm, a broad, muscular part, reaching across the breast, and dividing the middle from the fower ca. vity. It runs obliquely from the sternou and ribs be fore to the vertebre of the loins behind. 
39. The whole thorax is covered on the inside with a firm, white membrane, called the pleura, It is dou. ble throughout, consisting of two folds : the innermost whereof has a smooth surface, that it may not hurt the tender substance of the lungs ; the surface of the outer is rongh and uneven. From the pleura rises the mediastinum, which is a double membrane, that divides the lungs and the cavity of the thorax lengthways into two parts.

40. On the slightest observation we cannot but acknowledge the consurnmate wisdom, wherewith the external parts of the middle cavity are formed, for beauty, as well as for the defence of the internal. This is commodiously connected with the head, by the neck. The breast, or fore part of the thorax, whicli begins at the throat, and enus at the sternon, or breastbone, is an admirable guard to the noblest parts. T'o the same end serve the shoulder-blades and the backbone, as well as to supiort the whole fabric.

The breasts consist of numberless oval glands, intermixel with globular vessels of fat. 'I'heir ducts, as they approach the nipple, unite together, till 'they form eight or more sinall pipes, communicating with each other by cross canals, which are of great use, when some of them happen to be obstructed. These tubes are in some parts narrower, in some wider, so as to form cells, which-hinder the efflux of the milk. The paps consist chiefly of the concurrence of these tubes, but with a glandulous substance intermixed. There are likewise joined herewith abundance of fibres, from the external teguments of the breasts, by mears of which the tubes are constringed, and the motion of the milk is modified.

In virgins, the glands of the breasts are so contract. ed, that no blood can enter them. But when the womb swells with the foetus, and compresses the descending trunk of the great artery, the blood forces its. way into them. They admit thicker and tinicker serum, till after the birth, they run with a thick milk. 


\section{3}

It is more difficult to account for the milk, which some men have in considerable plenty. Thus in the year 1684 , a countryman, called Billardino di Billo, living in a village near Nocæra, in Uinbria, when his wife was dead, took the child, and put the nipples of his breasts into its mouth, invited it to suck, which the infant did, and after several times drawing, fetched some milk. After awhile it brought down the milk so plentifully, as to nourish it for many months till it was weaned.

Almost as strange is the following account: One inforining me of an old woman that gave suck, I went to the house in Tottenham-court.road. Her name is Elizabeth Bryan. She is in the 68 th year of her agu, and tas not borne a child for many years : her face is withered, her cheeks and mouth sunk in : but her breasts are full, fair, and void of wrinkles. About four years ago, her daughter was obliged to leave' an infant she gave suck to, in the care of her mother. The old woman finding the child froward for want of the breast, applied it to her own. Having done this several times, her son thonght the child seemed to swallow, and begged his mother he might try, if she had nut milk. It soon appeared she had, and she then continued to suckle the child in earnest. Two years after, her daughter had another child, on which the grandmother weaned the first, and suckled the second. Both the children are healthy, plump, and firm in flesh, and as brisk and lively as can be desired."

41. In the lower cavity first occurs the Stomach, with the oesophagus or gullet, which reaches to it from the mouth. The right orifice, called the pylorus, transmits the digested food to the intestines. It is narrower than the other, as being designed to trans. mit nothing, till it is reduced to a kind of liquid. And it goes by a long and oblique descent into the duodenum, that the chyle may not pass out, either tooswiftly or too slowly. 
The upper opening of the stomach, is compressed in such a manner, by the lower muscle of the dia. phragm, in every inspiration, as to confine the food within the stomach, and direct it in every respiration, towards the pylorus. By this means this orifice of the stomach, is so closely shut, as to confine ever wind or vapours within the cavity of a healthy sto. mach, from whence they never escape but by a morbid affection.

The fabric of the stomach answers to that of the oesophagus, of which it is an expansion. (1) The outmost coat is from the peritoneum, of considerable strength, so as to limit the extension of the rest, and afford a support to the subjacent muscular fibres. (2) The cellular coat lies immediately under the fórmer, whence the outer and muscular tunic closely cohere together, in this substance the larger branches of the vessels are distributed. Next in order appears (3) the muscular coat. Here, the Jongiludinal fibres of the nesophagus, coming to the stomach are detach. ed one from another in all directions.

Immediately under the muscular fibres, follows (4) another cellular stratum, larger than the outermost, softer, more easy inflatible, and cunsisting of larger vesicles than what we usually obserie, even in the intestines. Within this cellular substance are spread the small vessels, which, coming from the larger branches of the stomach, enter through its muscular coat, and spread internally after the manner of a plexus. Under this lies, (5) the nerrous coat, which is thick, white, and firm, and makes up the true sub. stance of the stomach itself, and this is again lined. internally with a third cellular stratum, whose vascular net-work is much more minute than that of the former, from whence it is derived. Inmediately with. in this, lies (6) the villous or relvet-like coat, that lines the cavity of the stomach itself, contignous with the external cuticle, like which it is renewable, but of a soft nucous texture, and extended into a very short 
pile, like that of the tongue, only less conspicuous, and folded into large plates.

42. The Intestines are a continuation of the alimentary tube from the pylorus, wound together in various wreaths, yet without confusion, and to keep them in their situation, fastened together by the mesentery, a strong membrane, which fastens them also to the back. The intestinal duct is really but one; but because the parts of it differ in figure and use, the upper part of it, divided into the duodenum, jejunum and ileum, is termed the small-guts; the lower part, divided into the coecum, colon, and rectum, is called the great guts. All these are full of turnings and windings, especially the small, that the more subtle part of the chyle, loth through the length and narrowness of the passage, and the agitation of the in. testines, may enter the lacteal veins, and pass from thence into the receptacle of the chyle.

When the intestines are separated from the mesen. tery, they are usually six times as long as the mau. They have all a kind of vermicular motion, called the peristaltic motion from the stomach downwards; and are lubricated with much fat, especially the great ones, whose surface being more uneven, and their contents less fluid, they need somewhat more to make them slide easily.

Likewise from the exhaling arteries distils a thin, watry liquor into the cavity of the intestines not at all acid, but like the juice of the stomach; the quantity of which liquor may be computed from the large extent of all the excretory orifices, and from the section of the secretory artery, a larger than which we see no where in the body.

The Duodenum, (so called because it is usually ten or twelve inches long), receires the gall and pancreatic juice, which are here mixed with the chyle. The jejunum is so termed, because it is generally more empty than the rest. This may be occasioned partly by its capacity, which gives a free passage to its 


\section{6}

contents, partly to its irritation through the bile, which falls in a little above it. It takes up almost the whole umbilical region, and is usually twelve or thirteen hands long. The ileum, situate below the navel, fills the ilia with its numerous convolutions. It is much the longest of the intestines, generally one and twenty hands long. In both this and the jejunum the inner coat is much wrinkled, and lies in loose folds. They are formed (as the folds in the stomach) only by the inner coat being larger than the outer.

The first of the great guts, called the coecum, is li. terally inserted at the upper end of -the colon. It is not perforated at the other end, but hangs to it like the finger of a glove, and is three or four inches long. In new-burn children, and in beasts, it is found full of excrements, but in adults it frequently hangs like a worm. In a foetus it is doubtless a receptacle of the freces, during the time it.does not discharge by stool. And may it not occasionally serve the same end in adults? Perhaps in those animals wherein it is very large, it may likewise serve as a kind of second stomach. But it is not absolutely necessary. The coecum of a dog has been cut out, without any psrceivable prejudice.

The colon is the largest of the great guts. It runs into various circumrolutions from the coecum to the rectum. It has many cavities, formed by two liga. ments, runuing on each side of it, opposite to each other the whole length, and as it were guiding it at certain distances. 'The rectum, which reaches from the os sacrum to the anus, is usually about a hand and a half long.

43. The Lacteal Veins; which are of a whitish colour, are in all the intestines, small and great, and receive the chyle by imperceptible passages, throughout the whole canal. And for this end the food remains so long in the intestincs, and is carried through various windings, that whatsoever of nourishment it contains may be expressed before it learts the body. 
44. The Intestives are covered with the omentum or cawl, which is contained within the peritoneum, a very thin, soft, double membrane, and wholly consists of little bags of fat. Its use is to keep the intestines warm, to promote their peristaltic motion by lubricating them with its oily substance, by following them in their doublings and windings, to serve them as a bolster to slide upon, and by filling up their hollows, to prevent their being too much distended by flatulencics; yet giving way to them when filled with aliments.

Uuder the stomach behind lies the pancreas, (extended towards the spleen) which transmits to the intestines a liquor of the nature of spittle, helping to dissolve the food.

45. Under the diaphragm on the right side, lies the Liver, whence it extends over tie right part of the stomach, below the sternum, toward the left, growing gradually smaller, that it may not hinder the distention of the stomach. It consists partly of gall-ducts, partly of fine ramifications of the veua porta. The blood contained in these, deposits oily particles in the ducts, and then returns, chiefly through the vena cava, to the heart. It is thus the bile is secreted, for which purpose the gall.bladder also is designed. This both receives and retails the bile, by which delay the power of it is greatly heightened. Part of the bile is conreyed to the intestines by the hepatic duct which pours it into the ductus choledochus. Part goes first into the gall-bladder, thence into the ductus choledocus, and then in to the duodenum.

The principal use of the bile is to absterge and stimulate the intestines, to assimilate crude things to things concocted, to bruise and blunt sharp and saline particles, to divide those that are coagulated ; to ex. cite appetite, to open the passages for the chyle, and where need is, act the part of a ferment.

46. The Spleen is an elegant net-work of number- 


\section{8}

less ressels, enclosed in a double membrane; it is placed on the left side, between the short ribs and the stomach. Some suppose it to secrete a peculiar juice, which passes with the blood through the vena porta. Others imagine it to be a kind of reservoir, wherein on extraorlinary occasions, that blood may be received, which would otherwise oppress the viscera aud disturb the animal functions.

47. On the muscles of the loins on each side lie the Kidneys, to separate from the blood that part of the serum which is superfluous, and would be hurtful were it retained in the habit. 'This is carried by the ureters into the bladder, which is placed in the lowest part of the belly. What remains of the blood is conveyed to the heart by the reins and lymphatic vessels.

The bladder is composed of three coats, the first is an extension of the peritoneum; the second consists of muscular fibres; the third is both glandulous and nervous, and full of wrinkles, that it may be capable of contraction and dilatation. Its glands separate a slimy matter, which defends the bladder from the acrimony of the urine. The involuntary emission of this is prevented by a small ressel which goes round the neck of the bladder.

48. We proceed to the limbs. The hand (physically speaking) is divided into the arm, the cubit, and the hand, properly so called. In this there are twelve bones, besides tiftcen in the fingers, all oblong, sleuder, hollow, and so fitly joined together by ligaments, so wonderfully provided with various muscles, adapted to so nany different motions, that the hand alone gives us an abundant argument of the admirable wisdom of Grod.

Is there any pessibility that the want of so neces. sary an instrument as the arm should be supplied? One would think it impossible. But it is not: such is the amazing power of God! James Walker was born in 


\section{9}

1718 , in Ireland, in the parish of Hillsborough. His mother could not be delivered till the surgeon totally separated the arms of the child from the body. Nevertheless he lived, and in the room of his arms, had little protuberances that appeared as stumps. He grew to be six feet high, slender, and active. "6 $\mathrm{He}$ sits a saddle, says an eye-witness, upright and firm, will ride 40 miles a day to a fair, and deals in buying and selling horses, which he dresses and curries as well as any groom can do, holding the curry-comb between his chin and shoulders. The same way he holds the goad in driving the plow, and the spade when he digs. He throws a stone from the top of his foot with greater force than most men can with their hand, and seldom fails to hit his mark. He mounts a horse without any assistance, and shuffling the bridle over his head, till he gets it on his shoulders, guid. ing his horse with as little fear, and as much skill as any man."

49. The Thigh consisfs of one bone, the largest and longest in the whole bolly. It is a little crooked, bending forward before, that there may be more room for the muscles. 'The bones of the leg are two, distant from each other in the middle, but joined together at each end. They are nearly of the same length, but the inner is much thicker than the outer. The bones of the foot are twelve, beside fourteen in the toes; which like those in the hands, are most aptly connected by liganients, and fitted with muscles of various kinds, serving for equally various motions.

50. Thus far we have spoken concerning the solid parts of the body. Among the luid are usually reck. oned the animal spirits, supposed to be secreted in the brain, to flow through the nerves, and to be the in. struments of sense and motion.

"But are the uerves in general hollow canals, which contain a circulating fluid? Or are they solid threads, which being higbly elastic, vibrate variously 
to occasion various sensations ?" The latier suppo. sition is wholly orerthrown by the phenomena of wounded nerves. A nerve cut asunder, does not re. tract its divicled extremities, but becomes rather loriger,extruding its medulla into a round tubercle. Again, were it elastic, it should be composed of hard fibres, having their extremities fixed tn some firm bodies: since strings, otherwise constituted and disposed, have no elasticity. But it is evident all nerves are soft at their origin, as well as void of tension, and some soft in every part, as the olfactory nerve, and the soft portion, of the auditory nerve. Yea, they all grow soft in the viscera, the muscles, and the sensories, before they exert their functions. Besides, some nerves are so situate, that they cannot vibrate, as those of the heart, which are fastened to the great vessels and the pericardium. Further, the influence of an-irritated nerve is never propagated upwards; whereas an elastic chord communicates its tremors to both ends from the point of percussion. Hence it is plain the nerves do not act by their spring, but by the motion of their proper fluid. The extreme smallness of these canals, which no microscope can reach, is no valid objection to this, neither our inability to discern that fuid. This only proves the imperfection of our senses.

"6 But what is this fluid?" Who can tell? Wc may very probably conjecture, it cousists of some subtle fire or ether, diffused through the whole system of nature, and acting by laws unknown to us.

51. Of the other fluids, some scrve to prepare the chyle, some to thin the bloud and preserve it from putrefaction. Others only remain till they can be thrown ont of the body, as being useless and superfluous. All of these, but the chyle, arise from the blood, being secreted from it by proper glands. But as to the manner of secretion, after all the most accurate and laborious enquiries, it still remains abso. lutely uncertain, and every one abounds in his own 
sense. Some beliere it depends on the suitableness of the fluid secerned, to the shape of the secerning pores. Some lay the stress rather on the varions size and diameters of those pores: others on this, that the constituent particles, suppose of the bile, from their peculiar proportion, texture, and figure, may be more easily united to each other, than to the particles of Jymph, or any other fluid.

52. The chief of all the fluids in our body, and the fountain of life, is the Blood. It consists of a watry serum, fibrous particles, and red globules, which last are scarce a twelfth part of it. It is generated thus. The meat and drink being digested into chyle, pass from the intestines, through the lacteal reins and the thoracic duct, into the left subclavian vein, and thence into the vena cava, where it mixes with the blood, and then circulates with it, till it is wholly assimilated.

Blood, fresh drawn, appears to the naked eye, uniform and homogenous. But when cold, it separates into two parts; the one red and fibrous which clots together; the other thin and transparent, called the serum, in which theformer swims. The serum is in bulk three fourths of the blood; in weight fifteen seventeenths.

A red globule is computed to be 25,000 times smaller than the smallest grain of sand.

But whence arises the heat of the blood? This deserves a particular enquiry.

Fermentation is that spontaneous, intestine motion, which by the heat of subterraneous carerns, will in a few hours so change vegetable juices, (for fermentation is confined to the vegetable kingdom) as from a vapid wort quenching fire, to nourish fire, and to afford that inflammable liquor, commonly called spirits.

Eiffervescence arises from an intestine motion excited in various fluids, by the mixture of other tluids, or of salts or powders of a different nature. Acids 
and alcalis, when mixed, cause a great ebullition, but no great heat; whereas the solution of some metals in aqua-fortis, causes intense heat, and emits flame. Aromatic oils, mixed with acid mineral spirits, kindle and burn with violent explosions.

In these cases, as there is no adventitious fire, there must be fire lying hid in one or other of the bodies. And it is known, much air lies dormant in all bo. dies. It is known likewise, that fire cannot exert itself without the help of air. It being granted then, that fire and air lie dormant in all bodies, there is only required such an action as may set at liberty the particles of air and of fire. By this action the particles of air recorer their elasticity, and putting those of fire in motion, cause heat, but not incension, unless this fire meet a proper pabulum, which pabulum is sulphur only, though differently modified, whether in the appearance of brimstone, oil, spirits, metalline sulphur, or the most inflammable of all, animal sulphur, commonly called phosphorus.

In fermentation, the fire and air being let loose, produce warmth, but seldom kindle, because of the water predominating. But in the effervescence, produced by the solution of metalline sulphur, they kin. dle and sometimes cause explosions. Aronatic oils, containing little but the sulphureous parts of the regetables, immediately kindle and break out into flame. And phosphorus is so highly inflammable, that if it be only exposed to the air a few minutes, it kindles and flames.

Now all animals contain more or less phosphorus. Some insects constantly shine in the open air. Many sorts of fish are luminous: some quadrupeds emit light, on a very slight friction. These are proofs of phosphorus lying dormant in animal fluids : and as they all contain air likewise, let only the phosphoreal and aereal particles be brought into contact, and heat necessarily ensues.

This clearly explains the cause of animal heat : of which the heart and arteries are the occasion; not by friction, but by the intestine motion, which the cir- 


\section{3}

Culation gives to the several particles that constitute the mass of animal fluids. As the velocity of these fluids is increased, the particles of which tliey consist come oftener into contact, and the of tener the phosphoreal and acreal meet, the more heat they produce.

But to what cause is the colour of the blood owing? -

Burelli took some of the red part, and washing it frequently it water, found it separable into a viscous slippery substance, consisting of colourless fibres which rose and gathered into a scum on the top of the water, and a deep red powder, which precipitated plentifully to the bottom. Hence it appears that the redness of the blood springs from red tinging particles, as in the case of dying.

However, this red colour, though generally found in the blood of land-animals, is not absolutely necessary, there being some species, whose blood is white or limpid. Nay, Dr. Drake let out of the median vein of a man, a pure, white blood, like milk, which when cold, did not separate into two parts, as the red usually does. Nor yet did it yield any skim or cream, neither turn sour as milk uses to do. Dr. Beal gives an instance of the same kind; and Dr. Lower relates one as strange. A person bled at the nose, till 'at length the broth he drank flowed out very little altered.

It is amazing to see, how careful providence has been, to prevent the blood's running into concretions, which might destroy life, by the very dispositions of the vessels it is to run through. These are so contrived, so as to cause the giobules to come together with a brisk collision. The arteries which convey the blood from the heart to the extremitics, continually lissen as they recede from their source; in consequence of which the globules of blood must rush with force against one another, as they are driven on inpetuously. And the veins which bring it back from the extrenities to the heart, enlarging all the way as they go on, while the streams of several con. tinually run into one, each of these ingresses causes 


\section{4}

new commotions, capable, though not of dissolving that natural connexion of the red and serous particles, yet of preventing any preternatural concretions or coagulations.

53. These are the parts of which this wonderful machine is composed, which the chymists say, coll. sists of four sorts of matter, earth, water, salt, and sulphur, the particles of which being variously mixed constitute larger particles of different kinds; out of which, more luosely or closely connected, all the parts of the body, so id or fluid are composed.

But this is far from being an accurate account. For what are salt and sulphur but species of earth? May not we then much more properly say, with the an. cients, that the body is chiefly composed of earth and water, yet cannot enjoy even animal life, unless air and fire, also be wrought into its frame? So that at whatsoever time, it is deprived either of air or fire, it is an useless, lifeless clod. And yet the manner how these are so intimately mixed, both with our fluid and solid parts, as much exceeds our comprehension, as the manner how the soul is united to its house of clay.

That much air is wronght into the whole animal frame, appears by the following exjeriments. The bloud of a sheep, fresil drawn, was in a wide-mouthed glass put into a receiver, and the air drawn out. After awhile, the subile parts of the blood forced their way through the clamniy ones, and seemed to boil in large clusters, some as big as nutmegs; and sometimes the expansion was so vehement, that it boiled orer the glass. - Some milk buing put into a vessel four or fi.e inches hig!, when the air was drawn out, it boiled s inpetucusly, as to throw up several parts out of the glass tiat contained it.

Aud to shew that not only the blood, but the other parts of animals unclude air; the liver of an eel was fut into a receiver, and even this apparently swelled every way, as soon as the air was withdrawn.

The air as a uxed element in the composition of 
5otid and fluid bodies, has been generally orerlooked by philosophers, and even by the ehymists, who have above all sects, gloried in their knowledge of principles, or elements ; until Mr. Boyle, Sir Isaac Newn ton, and more especially Dr. Hales, by many experiments demonstrated that a great part of the sub. stance of most bodies, in several to half their weight, is a permanent or unelastic air, which being freed [either (1) slowly, by the air-punip, putrefaction, fermentation, distillation, \&c. or (2) suddenly by explo. sions, fulminations, ebullitions, mixtures, \&c.] from the other solid particles, assumes its elasticity, and fills an immense space, in comparison of the body from whence it came. Dr. Hales found a cubic inch of blood, in distillation, afforded above 30 times its bulk of elastic air; whose particles are in effect the wedges of nature, which pin and cement together the other elements, and particles of bodies for their growth of accretion, and under other circumstances, regaining their elasticity, serve to break again those parts for the dissolution of the compound, whose matter may be, by the same instrument, aga.n differently assembled and combined for the forming of other bodies.

54. It remains to add some reflections on the wis. dom of God, displayed in the structure of the human body. And how eminently is this displayed, first, in the situation of its several parts and members! They are situated most conveniently for use, for ornament, and for mutual assistance. 1. For use. The principal senses are placed in the head, as sentiuels in a watch-tower. How could the eyes have been more commodiously fixed, for the guidance of the whole body? The ears likewise, made for the reception of sounds, which naturally move upward, are rightly placed in the uppermost parts of the body; and so ure the nostrils, as all odours ascend. A gain: how could the hands have been mire convenientiy placed for all sorts of exercises? Or the heart, to

$$
\text { E } 2
$$


dispense life and heat to the whole body? Or the sinks of the body, than in the most remote parts of it? 2. For ornament. Not to descend to particu. Jars, what could be better contrived, than that those members which are pairs should be of equal length and just answer one anuther on each side? 3. For mutual assistance. So the eye stands most conveniently to guide the hand, and the hand to defend the eye. The same may be said of the other parts : they are all so placed, as to direct or help each other. This will clearly appear, if you suppose the position of any of them to be changed. Had our arms been bent backward, what direction could our eyes have afforded us in working? Or how could we even have fed ourselves? Nay, had one arm bent backward, and the other f.rward, half the use of them had been lost ; for one could not have assisted the other in any action.

How is his wisdom displayed, secondly, in the ample provision, made for the security of the pririci. pal parts! These are, 1 . The Heart, the fountain of Iife. This lies in the centre of the trunk of the body covered with its own membrale ; the pericardium, lodged within the soft bed of the Iungs. encompassed rourd with a double fence, both of thick muscles and skins, of firm ribs and bones; besides the arms, cons. veniently placed 10 ward off any violence? 2. The Brain, the pribcifle of all sense and motion, is surrounded with so strong a defence, that it must be a mighty furce indeed, which is able to injure it. The skull is so hard, thick and tough, that it is almost as firm as a heimet of iron. Th:s is covered with skin and hair, which both keep it warm, and soften the violence of a stroke. Yet more, a thick and tough membrane hatgs locse about it, which often saves it, eves when the skuil is broke. And lastly a fine mem. brane closely adheres, to keep it from quashing and shaking.

How is it displayed, thirdly, in the abendant pro-. yision that is waue against evil acciuents and iucon- 
Feniences! To this end, 1. The members which are of eminent use are in pairs. We have two eyes, ears, nustrils, hands ; two feet, two breasts, two kidneys, that if one should be rendered useless, the other might serve us tolerably well; whereas, had a man but onc hand or eye, if that were gone, all were gone. 2. All the ressels have many ramifications, which send forth twigs to the neighbouring vessels; so that if one branch be cut or obstructed, its want may bs supplied by the twigs from the neighbouring vessels. 3. Many ways are provided to evacuate whaterer might be hurtful to us. If any thing oppress the head, it cau free itself by sneezing, if the lungs, they can cast it off by coughing. If any thing burden the stomach, it can contract itself, and throw it up by romit. Be. sides th se evacuations, there are siege, urine, sweat, and haenorrnages of various kinds. 4. Whereas sleep in necessary for us in many respects, nature has provided, that though we lie long on one side, we should feel no uneasiness while we sleep, no, nor when we awake. One would think, the whole weight of the budy pressing the muscles on which we lie, would be very burdensome. And we find by experience so it is, when we lie long awake in the night. Probably this prorision is made, by an inflation of the zuuscles, making them soft, and yet renitent, like piliows. That they are inflated during sleep, appears to the very eye, in the faces of children; and from tile common exporiment, that if we sleep in o if clothes we must loosen our garters and other ligatures, otherwise we find uneasiness in those parts. 5. Because sleep is inconsistent with the sense of pain, therefore during rest, those nerves that convey the motions to the hrail, which excite the sense of pain are ob. structed, "This I nyself, says Mr. Ray, have often experienced, since I have had sores on my legs. Wak, ing suddenly, 1 find myself at perfect ease for awhile. Then the pail by degrees returns."

It is displayed, fourthly, in the multitude of in. teutions God hath in the formation of the several E 3 
parts, and the multitude of qualifications they require to fit them for their several uses. Galen observes, 66 that there are in a human body, ahove six hundred muscles. And there are at least ten several intentions in each, and as many qualifications needful: so that about the muscles alone, no Itss than 6000 ends are to be attended to. The bones are reckoned to be 284. The distinct intentions in each of these are above forty : in all about a hundred thousand. And thes it is, in proportion, with all the other parts : the skin, ligaments, veins, arteries, nerves, glands, humours : but more especially with the members of the body, which as to the multitude of intentions and qualifications, far exceed the similar parts. And should one of these qualifications fail, great inconvenience. would ensue."

It is displayed, fifthly, in the stature of man, so admirably well adapted to the circumstances of his existence. Had man been only a foot or two high, he had been quite disproportioned to every thing round about him. Had he been much larger he could not well have been supplied with food, all the edible animals would not have sufficed. And had they too been proportionably larger, the surface of the earth would not have sufficed to feed them.

It is however a common opinion, and has been so erer since old Homer's time, that the people in the early ages of the world, were much larger than us. And it is true, we read of some men of a surprising stature. But they were even then esteemed giants. The ordinary stature of men, is probably just the same now, as it was at the beginning. This may be gathered from the monuments still remaining, particularly the pyramids of Egypt. The cavities for bodies now visible herein, are little larger than our ordinary coffins : likewise from several embalmed bodies taken out of them it appears, that men are of the same stature.now, that they were when those pyramids were built, which is at least three thousand years ago. - Eighteen hundred years ago the emperor 
Augustus was five feet seven inches high: Queen Elizabeth was taller by two inches, being five feet nine.

But what a paradox is it, that all men are taller in the morning than in the evening ? I a young ma I the difference is near an inch, try the xperiment as often as you please. Does not the diff rence proceed from hence, that as long as the trunk of the body is in an erect posture, there is a constant pressure on the large cartilages connecting the vertebrie of the spine? So long they gradually contract, and consequently a man grows shorter. But they again gradually expand themselves, while we are in a reclining posture.

As to the art of embalming, it appears from a mummy not long siuce dug up in France, that this was more completely understood in the western world some nges since, than ever it was in Egypt. This, mummy which was dug up at Auvergie, was an amazing instance of their skill. As some peasants were digging in a field near Rion, within abut twenty-six paces of the highway, between that and the river Artier, they discovered a tomb, that was about a foot and a half beneath the surface. I $i$ was composed only of two stones ; one of which formed the b dy of a sepulchre, and the other the cover.

Tni : tomb was of free-stone; seven feet and a half long, three feet and a hall broad, and about three feet high. It was of rude workmanship; the cover had been polished, but was withoit figure or inscription : within this tomb was placed a lealen-corin, iour feet seven inches long, fourteen inches broad, aird fifteen uigh. It was oblong, hke a box, equally broad at bothends, and covered with a lid that fitted on like a snuff-box, withont a hinge. Within this coffiu was a mummy in the most perfect preservation. The internal sides of the colfin were filled with an aromatic substance, mingled with clay. Kound the mummy was wrapped a coarse cloth; under this were two shirts, or shrouds, of the most exquisite texE 4 
ture; beneath these a bandage, which covered all parts of the body, like an infant in swaddling clothes; under this general bandage there was another, which went particularly round the extremities, the hands and legs ; the head was covered with two caps; the feet and hands were without any particular bandages; and the whole body was covered with an aromatic substance an inch thick. When these were removed and the body exposed naked to view, nothing could be more astonishing than the exact resemblance it bore to a body that had been dead a day or two before. It appeared well proportioned, except the head was very Jarge, and the feet small. The skin had all the pliancy, and colour of a body lately dead ; the visage, however was of a brownish hue. The belly yielded to the touch; all the joints were flexible, except those of the legs and feet; the fingers stretched forth of themselves whon bent inwards. The nails still continued perfect; and all the marks of the joints, both in the fingers, the palms of the hands, and the soles of the feet, remained perfectly visible. The bones of the arms and legs were soft and pliant : those of the scul! preserved their rigidity ; the hair which only covered the back of the head, was of a chesuut colour, and about two inches long. The pericranium at top was separated from the scull, by an incision, in order to the introducing aromatics in the place of the brain, where they were found mixed with clay. The teeth, the tongue, and the ears, were all preserved in perfect form. The intestines were not taken out of the body, but remained pliant and entire, as in a fresh subject, and the breast was made to rise and fall like a pair of bellows. The embalming preparation had a very strong and pungent smell, which the body preserved for more than a month after it was exposed to the air. If one touched either the mummy or any part of the preparation, the hands smelt of it for several hours after. This mummy, having remained exposed for some months, began to suffer some mutilations. A part of the skin of the forehead was cut off; all its teeth 
not, like several of the reins, near the surface, but placed at a proper depth. And hereby they are more securefrom external injuries. In those parts which are most liable to pressure,-an admirable expedient takes place. The arteries inosculate with each other: breaking into a new track, they fetch a little circuit, and afterwarus return into the main road. So that if any thing bluck up or straiten the direct pasiage, the current, by diverting to this new channel, eludes the impediment, flows on, and soon regaius its wonted course.

The veins receive the blood from the arteries, and reconvey it to the heart. The pressure of the blood is not near so forcible in these as in the arteries. Therefore their texture is considerably slighter. Such an exact aconomist is nature, amidst all her liberality! In many of these canals, the current, though widening continually, is obliged to push its way against the perpendicular: hereby it is exposed to the danger of falling back and overloading the vessels. To prevent this, valves are interposed at prover distances, which are no hiudrance to the regular passage, but prevent the reflux, and facilitate the passage of the blood to the grand receptacle. But these valves are only where the blood is constrained to climb : where the ascent ceases, they cease also.

Here are glands to filtrate the passing fluids: each of which is an assemblage of vessels, complicated with seeming confusion, but with perfect regularity. Each forms a secretion far more curious than the most admired perations of chymistry : muscles, composed of the finest fibres, yet endued with incredible strength, fashioned after a variety of patterns, but all in the highest taste for elegance and conveniency. These are the instruments of motion, and at the command of the will, execute their functions as quick as light. ning: uerves snrprisingly minute; which set the muscles at work, diffuse the power of sensation through the bol'y, and upon any impression from with. out, give all needful intelligence to the soul : vesicles, 


\section{0}

siestined with an unctuous matter, in some places compose a soft cuishion : as in the calf of the leg, whose large muscles, mixed with fat are of singular service to those important bones, This flanks and fortifies them, like a strong bastion, supports and cherishes them, like a soft pillow. In other places they fill up the vacuities, and smooth the inequalities of the flesh. Inwardly, they supply the machine for motion ; outwardly, they render it smooth and gracelul.

The skin, like a curious surtout, covers the whole, formed of the most delicate net-work, whose meshes are minute, and whose threads are multiplied, even to a prodigy : the meshes are so minute, that nothing passes them, which is discernible by the eye; though they discharge, every moment, myriads and myriads of superfluous encumbrances. The threads are so multiplied, that nuither the point of t i e smallest needle, nor the infinitely finer laace of a guat, can pierce any part, without drawing blood, and causing an uneasy sensation. Consequently, without wounding, by so small a puncture, both a nerve and a vein!

But a course of incessant action must exhaust the solicis and waste the fluids, and unless both are properly recruited, in a shurt time destroy the machine. For this reason it is furnished with the organs, -and endued with the powers of nutrition: teeth, the foremost, thin and shurp, to bite asunder the food; the hindermost, bruad and strong, indented with smill cavities, the better to grind in pieces what is transmitted to them. But in chidren, the formation of teeth is postponed till they have accasion for them.

Were the teeth like other bones, covered with the periosteum, chewing would give much pain. Were they quite naked, they would soon decay and perish. Io guard against both, they are overiaid with a neat enainel, harder than the bone itself, which gives no pain in chewing, and yet secures then from various injuries.

The Lips prevent the food from slipping out of the mouth, and assisted by the tongue, return it to the 


\section{1}

were drawn out, and some attempts were made to pullaway the tongue. It was therefore put into a glass case, and trainsmitted to the king's cabinet, at Paris.

There are many reasons to believe this to be the body of a person of the highest distinction ; howerer no inarks remain to assire us either of the quality of the person, or the time of his decease. Thereare only to be seen some irregular figures on the cuffin : one of which represents a kind of star.

T ere were also some singular characters ipon the bandages, which were totally defaced by those who had tore them. Ii should seem that it had remained for several ages in this state, since the first years immediately succeeding the interment, are usually those in which the body is most liable to decay.

On this remarkable subject, I heg leave to add an extract from a iate author:

"I I always apprehended that human bodies after death, if interred, or exposed to the air withont any preparation to defend them from the attacks of it, would of necessity corrupt, become offensive, and putsify. The art of embalming is very ancient, and was invented to preserve them from this inevitable consequence of death; but that they may remain unputrified $f$ ir centuries without any sort of artificial aid, I have seen so incontestibly proved since my arrival at Biemen, that 1 imagine not the shadow of doubt can remain about it. Under the cathedral church is a vaulted apartinent, sipported on pillars; it is near sixty paces long, and half as many broad. The light and air are constantly admitted into it by three win. dows, though it is several feet beneath the level of the ground. Here are five large oak coffers, rather than collius, each containing a crarpse. I examined them severally for tivo hours. The most curious and per. fect, is that of a woman. 'Tradition says, she as an Huglish cuuntess, who dying here at Bremen, ondered.

$$
\text { E } 5
$$


her body to be placed in this vault uninterred, in the apprehension that her relations would cause it to be brought over to her native country. They say it has lain here two hundred and fifty years. Though the muscular skin is totally dried in every part, yet so little are the features of the face sunk or changed, that nothing is more certain than that she was young, and even beautiful. It in a small countenance, round in its contour : the cartilage of the nose and the nos. trils, have undergone no alteration : her teeth are all firm in the sockets, but the lips are drawn away from over them. The cheeks are shrunk in, but yet less than I ever remember to have set $n$ in embalmed bo. dies. The hair of her head is at this time more than eighteen inches long, very thick, and so fast, that $I$

- Beared the corpse out of the coffer by it : the colour is a light brown, and I cut off a small lock, which is as fresh and glossy as that of a living person. That this lady was of high rank seems evident from the extreme fineness of the linen which covers her body. The landlord of the inn, who was with me, said, he remembered it for forty years past ; during which time there is not the least perceptible alteration in it. In another coffer is the body of a workman, who is said to have tumbled off the church, and was killed by the fall. His features evince this most forcibly. Extreme agony is marked in them : his mouth is wide upen, and his eyelids the same; the eyes are dried up. His breast is unnaturally distended, and his whole frame betrays a violent death.-A little child who died in the snall pox is still more remarkable. The marks of the pustules, which have broken the skin on his hands and head, are very discernible; though one should suppose that a body which died of such a distemper, must contain in a high degree the seeds of putrefaction. - The two other corpses are not less extraordinary. There are in this vault likewise - turkeys, hawks, weasels, and other animals, which have been hung up here, some, time immemorial, sume sery lately, and are in the most complete preservation: 


\section{3}

the skin, bills, and feathers are all unaltered. The maristrates do not permit that any fresh bodies be brought here. The cause of these phenomenons are doubiless the dryness of the place where they are laid. It is in vain to seek for any other."

A repository of nearly the same kind, a late writer informs us is at a monastery, near Palermo, in Sicily. It is a long, subterranean gallery, having niches on every side, between six and seven feet high. In each of these is a human body standing erect, in its usual apparel. The face and the hands are uncovered, and preserve their shape, and natural colour, only a little biowner. They are fastened to the wall by the back. Some of them are believed to have been there two or three hundred years. - Sup ose they could remain there for ever, what would it profit their former inhabitants!

Another traveller gives a fuller account of them. "6 This morning we went to see a celebrated convent of Capuchins, about a mile without the city of Palermo; it contains nothing very remarkable, but the burial-place, which indeed is a great curiosity. This is a vast subterraneous apartment, divided into large coirmodious galleries, the walls on each side of which are hollowed into a variety of niches, as if intended for a great collection of statues : these niches, instead of statues, are all filled with dead bodies, set upright upon their legs, and fixed by the back to the inside of a nich. Their number is about three hun. dred; they are all dressed in the clothes they usually wore, and form a must respectable and venerable as. sembly. The skin and muscles, by a certain prepara. tion, become as dry and hard as a piece of stock. fish ; and although many of thein have been here upwards of two hundred and fity years, yet none are reduced to skeletons; though the muscles in some are more shrunk than in others; prubably becauge E 6 
these persons had been more exlenuated at the time of their death.

"Here the people of Palermopay daily visits to their deceased friends, and recal with pleasure and regret the scenes of the past life : here they familiarize them. selves with their future state, and choose the company they would wish to keep in the other world. It is a common thing to make choice of their nich, and to try if their body fits it, that no alterations may be neces. sary after they are dead; and sometimes by way of voluntary penance, they stand for hours in these niches.

"The bodies of the princes and first nobility are lodged in handsome chests or trunks, some of them richly adorned : these are not in the shape of coffins, but all of one width, and about a foot and a half, or two feet deep. The keys are kepi by the nearest relations of the family, who sometimes come and drop a tear over their departed friends.

"6 These visits must prove admirable lessons of humility ; and they are not such objects of horror as one would imagine: they are said, even for ages after death, to retain a strong likeness of what they were when alive: so that, as soon as you have conquered the first feelings excited by these venerable figures, you only consider this as a vast gallery of original portraits, drawn after the life, by the justest and most un prejudiced hand. It must be owned, that the colours are rather faded ; and the pencil does not appear to have been the most flattering in the world : but no matter; it is the pencil of truth, and not of a mercenary, who only wants to please.

"It might also be made of very considerable use to saciety : these dumb orators could give the most pathetic lectures upon pride and vanity. Whenever a fellow began to strut, or to affect the haughty, supercilious air, he should be sent to converse with his friends in the gallery : and if their arguments did not bring him to a proper way of thinking, I would give bim up as incorrigible.", 


\section{5}

I cannot better conclude this chapter than by as extract from the late pious and ingenious Mr. Herrey, which inay serve for a recapitulation of what has been said, as well as an improvement of it.

"6 Let us begin with the less adorned, but more solid parts, those which support, and which contain the rest. Fisst, you have a system of bones, cast in a variety of moulds, in a variety of sizes: all strong, that they may bear up the machine, yet light that they may not weigh us down: bored with an inward ca. vity to contain the moistening marrow, and perforated with fine ducts, to admit the nourishing vessels. Insensible themselves, they are corered with a mem. brane, exquisitely sensible, which warns them of, and secures them froin the annoyance of any hurtful fric. tion ; and also preserves the muscles from being fretted in their action, by the hard and rough substance of the bone. They are larger at the extremities, that they may be joined more firmly, and not so easily dislocated. The manner of their articulation is truly admirable, and remarkably various : yet never varied without demonstrating some wise design, and answer. ing some valuable end. Frequently when two are united, the one is nicely rounded and capped with a smooth substance; the other is scooped into a hollow of the sane dimensions to receive it; and both are:lubricated with an unctuous thid, to facilitate the rotation.

The feet compose the firmest pedestal, infinitely beyond all that statuary can accomplish, capable of altering its form, and extending its size, as different circumstances require. They likewise contain a set - of the nicest springs, which help to place the body in 2. variety of attitudes, and qualify it fo the multiplicity of motions. The undermost part of the heel; and the extremity of the sule, are shod with a tough insensible substance, a kind of natural sandal, which neter wears out, never wants repair: and which preverst? 
an urdue compression of the ressels by the weight of the body. The legs and thighs are like stately columus, so articulated that they are cuminodious for walking, and yet do not obstruct the easy posture of sitting. The legs swell out towards the top with a genteel projection, and are neatly wrought off toward the bottom : a variation which lessens their bulk, while it increases their beauty.

The ribs, turned into a regular arch, are gently moveable, for the act of respiration. They form a safe lodgment for the lungs and heart, some of the most important organs of li e. The back-bone is de. signed not only to strengtien the body, and-sustain its most capacious store rooms, but also to bring down the continuation of the brain, usually termed the spinal marrow. It both conveys and guards this silver cord, as Solomon terms it, and by commodious outlers transmits it to all paits. Hid it been only strait and hollow, it might have served these purposes. But then the loins must have been inflexible : to avoid which, it consists of very short bones, knit together by cartilages. This peculiarity of structure gives it the pliancy of an osier, with the firmmess of an oak. By this means it is capable of various inflections, with. out bruising the soft marrow, or diminishing that strength which is necessary to support all the upper stories. Such a formation in any other of the scilids, must have occasioned great inconrenience. Here it is unspeakably useful, a master-piece of creating skill.

The arms are exactly proportioned to each other, to preserve the equilibrium of the structure. These being the guards that defend, and the ministers that serve the whole body, are fitted for the most diversified and extensive operations: firm with bone, yet not weighty with flesh, aud capable of perforining all useful motions. They bend inwards and turn outwards; they move upward or downward; they wheel about is *hatercr direction we please. T.o these are added the 
hiands, terminated by the fingers, not of the same length, nor of equal bigness, but in ooth respects different, which gives the more beauty, and far greater usefulness. Were they all flesh, they would be weak: were they one entire bone, they would be utterly inflexible: but consisting of various little bones and miscles, what shape can they not assume? Being placed at the end of the arm the sphere of their action is exceedingly enlarged. Their extremities are an assemblage of fine tendinous fiures, acutely sensible: which notwith. standing are destined to almost incessant employ, and frequently among rugged objects. For this reason they are overlaid with nails, which preserve them from any painful impressions.

In the hand we have a case of the finest instruments. To these we owe those beautiful statues, this melodious trumpet. By the strength of the hand the tallest firs fall, and the largest oaks descend from the moun. tains. Fashioned by the hand they are a floating warehouse, and carry the productions of art and na. ture from Britain to Japan.

The hand is the original and universal sceptre, which not only represents, but ascertains our dumia. nion over all the elements, and over every creature. Though we have not the strength of the horse, the swiftness of the greyhound, or the quick scent of the spaniel, yet directed by the understanding, and cnabled by the haud, we can as it were make them all our own. These short hands have found a way to penetrate the bowels of the earth, to touch the bottom of the sea. 'These feeble hands can manage the wings of the wind, arm themselves - with the viulence of fire, and press into their service the forcible impetuosity of water. How greatly then are we indebted to our wise Creator, for this distinguishing, this invaluable member!

A bove all is the Head, for the residence of the brain; ample to receive, and firm to defend it. It has a communication with all, eren the remotest pars : has outlets, for dispatching couriers to all quarters, 
and avenues for receiving speedy intelligence, on all needful occasions. It has lodgments, wierein to post sentinels, for various offices : to expeclite whose operations the whoie turns on a curious pivot, nicely contrived to afford the largest and freest circumvo. Jut:ons.

This is screened from heat, defended from cold, and at the same time beautified by the hair: a decoration so delicate, as no art can supply: so perfectly light as no way to incumber the wearer.

While other animals are prone in their aspect, the attitude of man is erect, which is by far the most graceiul and bespcaks superiority. It is by far the most commodiuus, for prosecution of all our extensive designs. It is likew ise safest, less exposed to dangers, and better contrived to repel or avoid them. D ies it not also remind us of our noble original, and our sub. lime end ? Our original, which was the breath of the Almighty: our end, which was the enjoyment of him in glory.

Thus much for the rafters and beams of the house. Let us now survey the lotgings withili. Here are the ligzments, a touglı and strong arrangement of fiures, to unite the several parts, and render what would otherwise be an unwieldy jumble, a well compacted and sel-manageable system : membranes, thin and flexile tunicles, to enwrap the fleshy parts, to connect some, and form a separation betwcen others: arteries, the rivers of our little world, that striking out as they go, into numberless small cauals, visit every street, yea every apartment in the vital city. These being wide at first, and growing narrower and nare. rower, check the rapidity of the blood. This thrown from the heart dilates the arteries, and their own elastic force contracts them: by which means they vibrate against the finger, and much assist both in the discovery and cure of diseases. The larger arteries, wherever the blood is forced to bend, are situate on the bending side : lest being stretched $t$, an improper length, the circulatiou should be retarded. They are 
grinders. While they do this in concert with the cheeks, they squeeze a thin liquor from the adjacent glands. This inoistens the food and prepares it for digestion. When the mouth is inactive these are nearly closed: but when we speak or eat, their moisture being then necessary, is expressed as needs re. quire.

But the food could not descend merely by its own weight, through a narrow and clainmy passage into the stomach. Therefore to effect this, muscles both strait and circular are provided. The former enlarge the carity, and give an easy admittance. The latter, closing behind the descending aliment, press it downward. But before the food enters the gullet, it must of necessity pass over the orifice of the wind-pipe : whence it is in changer of faling upon the lungs, which might uccasion instant death. To obviate this, a moveable lid is placed, which when the smallest particle advances, is pulled down and shut close, but as snon as it is swallowed, is let loose and stands open. Thus the important pass is always made sure against any noxions approaches; yet always left free for the air, and open for respiration.

The food descending into the stomach, is not yet ready for the bowels. Therefore that great receiver is strong to bear, and proper to detain it, till it is wrought into the smoothest pulp imaginable. From hence it is discharged by a gentle force, and passes gradually into the intestines.

Near the entrance waits the gall-bladder, ready to pour its salutary juice upon the aliment; which dissolres any thing vicid, scours the ittestines, and keeps all the fine apertures clear. This bag, as the stomach fills, is pressed thereby, and then only discharges its coutents. It is also furnished with a valve of a very peculiar nature, namely of a spiral forin ; through which the detersive liquid cannot hastily ponr, but. must gently ooze. Admirable construction! which without any care of ours, gives the needful supply, and no more. 
The nutriment then pursues its way through the mazes of the intestines : which by a worm-like mo. tion protrude it and force its small paricles into the lacteal vessels. These are a series of the finest strainers, ranged in to countless multitudes all along the sides of the winding passage. Had this been strait or short, the food could not have resigned a sufficient quantity of its nourishing particles. Therefore it is artfuliy convolved and greatly extended, that whatever passes may besifted thoroughly. As the aliment pro. ceeds, it is more and more drained of its nutricious juices. In consequence of this, it would become hard, and pain the tender parts, but that glands are posted in proper places, to discharge a lubricated fluid. These are smaller or fewer, near the stomach, because there the aliment is moist enough: whereas in the bowels remote from the stomach, they are either multiplied or enlarged.

The Chyle drawn off by the lacteals is carried through millions of ducts, too fine eren for the microscrope to discover. To this it is owing, that nothing enters the blood, but what is capable of passing through the finest vessels. It is then lodged in seve. ral commodious cells (the glands of the mesentery) and there mixt with a thin diluting lymph, which makes it more apt to flow. Hence it is conveyed to the common receptacle, and mounts through a per. pendicular tube into the left subclavian vein. This tube lies contiguous to the great artery, whose strong pulsation drives on the fluid and enables it to ascend and unload its treasure, at the very door of the heart.

But the chyle is as yet in too crude a state, to be fit for the anim l functions. Thercfore it is throwa into the lungs. In ttie spungy cells of this amazing laboratory, it mixes with the external air, and its whole substance is made more smooth and uniform. Thus improsed it enters the left ventricle of the heart, a strong, active indefatigable muscle. The large muselez of the arm or of the thigh are soon wearied: a 


\section{3}

day's labour, or a day's journey exhausts their strengtho But the heart toils whole weeks, whole months, nay years, unwearied : is equaliy a stranger to intermission and fatigue. Impelled by this, part of the blood shoots upward to the head; part rolls thruugh the whole body.

Buthow shall a stream divided into myriads of channels, be brought back to its source? Should any portion of it be unable to return, putrelaction, if not death, must ensue. Therefore the ailwise creator has connected the extremities of the arteries with the begir. ning of the veins : so that the same force which darts the blood through the former, helps to drive it through the latter. Thus it is reconducted to the great cistern, and there played off afresh.

Where two opposite currents wold be in danger of clashing, where the streams from the rena cara and vena ascendens coincile, a fibrous excrecence interyoses, which like a projecting pier, breaks the stroke of each, and throws both into their proper receptacle. Where the motio:1 is to be speedy, the channels either forbear to wind (as in the great artery which descends to the feet) or to lessen in their dimensions, as in every interval between all the ramifications. When the pro. gress is to be retarled, the tubes are variously convolved, or their diameter contracted. Thus guarded, the living flond never discontinnes its course, but night and day, whether we sleep or wake, still perseveres to run briskly through the arteries, and return softly through the veins.

But farther, the great Creator has made us an invaluabie present of the senses, to be the inlets of innu. merable pleasures, and the mieans of the most valuable advantages:

The liye, in its elevated station, commands the most enlarged prospects ; cunsisting only of fluids, enclosed within coats, it shews us all the graces and glories of nature. How wonderiul, that an inage of the hingest mountains, and the widest landscapes, should enter 
the small pupil! that the rays of light should paint on the optic nerve, paint in an instant of time, paint in their truest colours and exactest lineaments, every species of external objects!

The eye is so tender, that the slightest touch might injure its delicate frame. It is guarded, therefore, with peculiar care, intrenched deep, and barricaded round with bones. As the smallest fly might incommode its polished surface, it is farther protected by two substantial curtains. In sleep, when there is no occasion for the sense, but a necessity to guard the organ, these curtains close of their own accord. At any time they fly together as quick as thought. They are lined with an extremely fine sponge, moist with its own dew. Its bristly palisades keep out the least mote, and moderate the tou strong impressions of the light.

- As in orr waking hours we have almost incessant need for these little orbs, they run upon the finest castors, rolling every way with the utmost ease; which circumistance, added to the flexibility of the neck, ren. ders our two eyes as useful as a thousand.

The Lar consists of an outward porch and inner rooms. The porch somewhat prominent from the head, is of a cartilaginous substance, covered with tight membranes, and wrought into sinuous cavities. These, like circling hills, collect the wandering undulations of the air, and transmit them with a vigorous inpulse to the finely stretched mombrane of the drum. This is expanded upon a circle of bones, over a po. lished reverberating cavity. It is furnished with braces that strain or relax, as the sound is faint or strong. The hammer and the anvil, the winding labyrinth, and the sunnding galleries, these and other pieces of mechanism, all instrumental to hearing, are inexpres. sibly curious.

Amazingly exact must be the tension of the auditory nerves, since they answer the smallest tremors of the atmosphere, and distinguish their most subtle rariz. 
tions. These living chords, turned by an Aimighty hand, and spread through the echoing isles, recerve all the impressions of sound, and propagate them to the brain. These give existence to the charms of music, and the still nobler charms of discourse.

'The eye is useless amidst the gloom of night; but the ear hears through the darkest medium. The eye is on duty only in our waking hours, but the ear is always accessible.

As there are concussions of the air which are discernible only by the instruments of hearing, so there are odoriferous particles wafted in the air, which are perceivable only by the smell. The nostrils are wide at the bottom, that more efluvia may enter; narrow at the top, that when entered they may act more strongly. The steams that exhale from fragrant bodies are fine beyond imagination. Microscopes that shew thousands of animals in a drop of water, cannot bring one of these to our sight; yet so judiciously are the olfactory nets set, that they catch the vanishing fugitives. They imbibe all the roaming perfumes of spring, and make us banquet eren on the invisible dainties of nature.

Another capacity for pleasure our bountiful Creator has bestowed, by granting us the powers of ta-te. This is circumstanced in a manner so.benign and wise, as to be a standing plea for temperance, which sets the finest edge on the taste, and adds the most poignant re. lish to its enjoyments.

And these senses are not only so many sources of delight, but a joint security to our health : they are the inspectors that examine our food, and enquire into the properties of it. For the discharge of this oflice they are excellently qualified, and olost coinmoliously situate, so that nothing can gain admission till it has past their scrutiny.

To all these, as a most necessary supplement, is added the sense of Feeling. And how happily is it tempered between the two extremes, neither too acute 


\section{6}

wor too obtuse. Indeed all the senses are exactly adapted to the exigences of our present state. Wero they strained much higher, they would be avenues of anguish ; were they much relaxed they would be well nigh useless.

The crowning gift which angments the benefits accruing from all the senses is Speech. Speech makes me a gainer by the eyes and ears of others, by their ideas and observations. And what an admirable in. strument $f, r$ articulating the voice, and modifying it intu speech, is the tongue? This little collection of muscular fibres, under the direction of the Creator, is the autificer of our words; by this we communicate the secrets of our breasts, and inake our very thoughts andible. This likewise is the efficient cause of music; it is suft as the lute, or shrill as the trumpet. As the tongue requires an easy play, it is lodged in an ample cavity ; it moves under a concave ruof, which gives ad. ditional vigour to the roice, as the shell of a violin to the sound of the strings.

Wonderfully wise is the regulation of voluntary and involuntary motions. The Will in some cases has no power : in others she is an absolute sovereign. If she commands, the arm is stretched, the hand is closed. How easily, how punctually are her orders abeyed!To turn the screw or work the lever is laburious and wearisome; but we work the vertebræ of the neck with all their appendant chambers ; we advance the leg with the whole encumbent body; we rise, we spring from the ground, and though so great a weight is raised, we mett with no dificulty or fatigue.

That all this should be effected without any toil by. a bare act of the Will is very surprising; but that it should be done eren while we are entirely ignorant of the manner in which it is performed is most astonishiug. Who can play a siingle tune upon the spinnet, without liarning the difference of the keys? Yet the mind touches every spring of the human machine with the most masterly skill, though she knows nothing at 
all of the nature of her instrument, or the process of her operations.

The eye of a rustic, who has no notion of optics, or any of it laws, shall lengthen and shorten its axis, dilate and contract its pupil, without the least hesitation, and with the utmost propriety, exactly adapting itself to the particular distance of objects, and the different degrees of light. By this means it performs some of the most curious experiments in the Newtonian philosophy, without the least knowledge of the scicuce, or consciousness of its own dexterity.

Which shall we admire most, the multitude of organs, their finished form and faultless order, or the power which the soul exercises over them? Ten thousand reins are put into her hands, and she manages all, conducts all, without the least perplexity or irregula. rity. Rather with a promptitude, a consistency and. speed, that nothing else can equal!

So fearfully and wonderfully are we made! made of such complicated parts, each so nicely fashioned, and all so exactly arranged, every one executing such cu. rious fuuctions, and many of them operating in so mysterious a manner! And since health depends on such a numerous assemblage of moving organs, sincea single secretion stopped may spoil, the temperature of the fluid, a single wheel clogged njay put an end to the solids ; with what holy fear shonld we pass the time of our sojourning here below. Trusting for conitinual preservation, not merely to our own care, but to the Almighty hand which formed the admirable machine, directs its agency, and swpports its being 


\section{8}

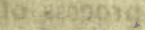

,

-

\section{CHAP. II.}

Of the Naturtil'stare of the Iruman Body.

1. What the natural State of the Body means.

2. Of the Circulation of the Blood.

3. Of Respiration.

4. Of Chylification.

5. Of Nutrition.

6. Of the Senses.

7. Of Sight.

8. Of Hearing.
9. Of Smelling.

10. Of Tasting.

11. Of Feeling.

12. Of Hunger and Thirst.

13. Of Sleep.

14. Of local Motion.

15. Of roluntary and involuntary Motions.

16. Of the Stature of Man. 17. Of the Age of Man.

1. THAT is the natural state of the human bolly wherein all parts of it duly perform their natural operations. The chief of these are, the circulation of the blood, respiration, chylification, nutrition, and motion.

5. 2. That the blood circulates through the whole body appears hence. Any of the arteries being tied with a thread will swell and beat between the bandage and the heart, but grow flaccid between the bandage and the extremities of the body. And if the artery be cut between the bandage and the heart, blood streams out even to death; but if it be cut between the bandage and extremities very little blood comes out. The vital blood, therefore, flows from the heart, through the arteries, toward the extremes of the body, and still out of a wider part into a narrower, out of the trunk into the branches. 
Any of the larger veins being tied with a thread, swells between the extremes and the bandage, but grows flaccid between the bandage and the heart; if opened in the former part it bleeds largely, if in the latter scarce at 711 . The blood therefure flows from all the extreme thrung ho veins into the heart, onu

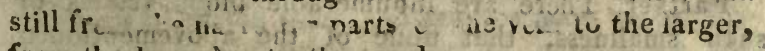
from the braiches to the trunk.

Upon the whole, it is evident that all the arteries are continually bringing the blood from the left ven. tricle of the heart, through the trunks of the arteries into their branches, and from thence to all parts of the body : and on the contrary, that all the veins (except the vena portæ) are continually bringing it back from all parts of the body, through the small branches into the larger, and thence through the trunks and vena cava into the right ventricle of the heart; so that the whole blood passes through the heart once in five or six. minutes.

It is certain that all the arteries and veins communicate or open one into the other, because often from one, and that a small artery, all the blood shall run even unto death, not only out of the wounded limb, but from the whole body. Of such fatal examples we have a number; from an inward artery of the nose, from the gums, a finger, a tooth, a cutaneous pore enlarged, from the lachrymal point, from the wound of cupping on the skin, and even the bite of a leach. There are, therefore, of course, open ways by which the blood speedily Hows from the venal into the arterial system, and the reverse.

Late writers have pursued the globules of blood to a great length, and found several orders of them. The large ones visible to the naked eye are globules of the first order. Each of these is composed of six smaller, joined together in a very regular way, but sometimes a red globule is seen loosening and breaking into these compounding spherules, and sometimes one may perceive these running together and beginning the composition of a new red globule. These smaller spherules 
they call globules of the second order. But we are not to stop here. There are in the blood a great many particles six times less than these. Globules of the se. cond order are compounded of these smaller ones, which therefore are globules of the third order.

Farther. There are innumerable blood vessels of such smallness, that none of the abovementioned globules can pass them; so that we cannot but suppose still smaller globules. The diameter of some vessels is less than the eighth part of the diameter of a red glo. bule, so that the particles passing through them must be above five hundred times less than those globules. Nay, on a careful examination, we perceive vessels narrower than the tenth part of the diameter of a red globule, which consequently can transmit spherules no greater than the thousandth part of a red globule.

On the whole then, each globule of the first order is made up of six of the secosd; these of six of the third, those of six of the fourth, these of six of the fifth, and so on. And accordingly we find the globules of the highest orders may be broken down into their compounding particles.

The diameter of a common red globule is about the 1938 th part of an inch. The diameter of a globule of the tenth oreler is less than the 400,000 th part of an inch.

Anatomists and physicians have generally determined the quantity of blood in the human body to be between fifteen and twenty-five pounds; but Dr. Keil shews from many instances of profuse hremorrhages, that a far greater quantity must be allowed, otherwise the patient could iever have furnished, or at least survived such evacuations, the least of which exceeded the whole quantity of blood supposed to be in the body.

In reality the quantity of blocd in a human hody is difficult to be determined. Blecding to death, the nsual method, can never shew what is its true quantity; because no animal can bleed longer than while the great artery is full, which will require a longer or a shorter time as the wounded artery is smaller or 


\section{1}

greater; and the great artery must always be the first ressel that empties.

The only certain way of calculating is, to find what proportion the cavities of the vessels, of which the whole body is composed, bear to the thickness of the coats. This in the veins and arteries may be exactly found; but in the other vessels we only know the quantity of fluid they contain by carefully evaporating as much as possible. Thus the Doctor found the fluids to be in the arteries as 17 to 1 ; in the veins as 15,6 to 1 ; in the bones as 1 to 1 . The least of these proportions shew's the liquors to be one half of the weight of the body; and if a calculation be made on the proportion of the blood in the arteries, also to their coats in a borly weighing 160 pounds, there will be found 100 pounds of blood or circulating fluid.

In a foetus the circulation is performed in a peculiar manner. The septum, which separates the two ventricles of the heart is piercel through with an aperture called the foramen ovale, and the pulmonary artery, a little after it has left the heart, sends out a tube into the descending aorta, called the communicating canal. When the foetus is born, the foramen ovale closes, and that canal dries up into a simple ligament.

The foetus while in the womb receives little air. Its lungs, therefore, cannot swell and subside, they con. tinue almost at rest; nor can they allow the blood to circulate either in abundance or with ease. Nature, therefore, has excused them from the passage of the greatest part of the blood, and has contrived the fora. men ovale, by which part of the blood of the vena cava passes through the right ventricle into the left, and by this means it is found as far on its journey as if it had passed the lungs: but this is not all, for that blood of the cava which, missing the foramen orale, passes from the right auricle into the right ventricle, being still too much to pass by the lungs, the commu. nicant canal intercepts part of it, and pours it iname. diately in to the descending aorta. 


\section{2}

3. Kespiration is performed by receiving the aif into the lunzs, and breathing it out alternately. In the former, the carity of the breast is enlarged by tlee sinking of the diaphragm, and the erection of the ribs, throught the force of the muscles placed between them. In the latter it is contracted, the diaphragm rising and the ribs falling again. Whenever the cavity of the breast is enlarged, the air by its weight naturally pres: ses into it, and mixing with the blood in the vesicle of the lungs, makes it more fluid, globular, and fit for motion. Air is likewise absolutely necessary in the borly, to counteract the pressure of the outward air.

But if the blood in the lungs of a fatus has not the advantage of respiration, it reccives a portion of air, transmitted with its mother's blood by the umbilical ressele, to be diffused through the body. This is quite wecessary, as appears hence; the the navel string very tight, and the child dies like a man strangled.

One use of respiration is, to push the blood from the right to the left ventricle of the heart: hence it is, that persons strangled so suddenly die, because with respisation the circulation of the blood ceases. And this is the true cause of the diastole of the heart; the weight of the incumbent atmosphere being the true an. tagonist to all the muscles that serve both for inspira. tion and the contraction of the beart. As in the elevation of tie ribs a passage is opened for the blood in. to the lungs, so in the depression thereof, by the sub. siding of the lungs and compression of the blood-ressels thereby, the blood is driven through the pulmonary vein into the left ventricle of the heart. And this, to. gether with the general compression of the body, by the weight of the atmosphere, is that power which causes the blood to mount in the reins, when the force impressed on it by the heart is nearly spent, and which forces the heart ftself from its natural state of contraction to that of dilatation.

- $W_{\text {siten }}$ in an ordinary expiration, the pressure on the larynx is two ounces, the pressure on the whole 


\section{To3}

internal substance of the lungs is 14412 pounds. So vast is the extent of the surface of the vesicles, on which it was necessary the blood should be spread in the finest capillary ressels, that each globule of blood might, as it were, immediately receive the whole force of the air, and thereby be broken into smaller parts, fit for secretion and circulation.

And hence we see the reason for the structure of the lungs. For since all the blood is to pass through them, in order to receive the effect of the air, and that this could not be done unless it were diffused in very small ressels; it was necessary the surface on which they were to be spread should be proportioned to their

w number, and this is admirably well provided for by the fabric of the lungs.

If the diameter of the trachea at the time of every expiration were the same in all, and the weight of the air always equal, the pressure on the lungs would be always the same. But as the difierence between its least and greatest gravity is $\mathrm{n}$ (less than a tenth part of the whole, that pressure is likewise greater by a tenth part at some times than it is at others.

This is a difference which the asthmatic must sen sibly fecl, especially as they breathe thicker, that is, every expiration is perfurmed in less time. In truth, these feel a diffurence in the air, upon the greatest rise and fall of the barometer, equal to above one third of its pressure in ordinary breathing.

The alternate rlilatatiun and contraction of the thorax are so necessary to animal life, that there is no anima! without this or something analugous to it. Fishes and insects have no dilatable thorax; but fishes have gills which receive and expel the water alternately, whereby the blood-vessels s.:ffer the same alterations of dimension as those in our lungs do; and insects have air-vessels distributed through the wholetrunk of their bodies. By these they communicate with the external air through sereral vent-boles, to which are fastened so many wind-pipes which send branches to all parts; and seem to accompany the blood-ressels all over the E. 4 


\section{4}

body, as they do in our lungs only. And hereby in every inspiration the whole body is dilated, and in every expiration compressed.

But may it sot be doubted whether the primary end of respiration be not to supply the whole animal machine with the ethereal fire, a particle of which is connected with every particle of air? Is not this detached from it by the action of the lungs, and thence commuzuicated to every part of the body? And is not this the true vital flame, the original source of life and motion.

4. Chylification is preceled by digestion, which is much illustrated by Mr. Papin's Digester. This is a vessel wherein meat is put, with just as much water as will fill it; then the lid is screwed on so close as to ad. mit of no external air. 'T'he meat herein is by the flame of a small lamp, in six or eight minutes, brought to a perfect pulp. In a few minutes more the hardest bones are reduced to a jelly. No air entering, the succes. sions caused by the air, enclosed in the flesh, resolve the whole into one homogeneous body : it is just so in digestion. In proportion to its heat the stomach does the very same thing as the digester.

Add to this, that the muscular coat of the stomach cpntinually contracting and pressing its contents by its peristaltic motion, occasions a more intimate mixture, and works the more fluid parts through the pylorus in to the duodenum. Along the sides of this and the other small intestines the lacteals are planted: into the minute orifices whereof the chyle or finer part of the mass is received. The lacteal veins of the first kind discharge themselves into the glands of the basis of the mesentery. The chyle is afterward received by the lacteals of the second kind, and conveyed into glands between the two tendons of the diaphragm, and hence it is carried to the heart, where it mixes with the blood.

5. By the perpetual motion of the fluids, (especialby in the minute ressels) as well as the constant cation of the muscles, small particles are continually 


\section{5}

worn off from the solids of the body. The fluids like. wise are continually diminishing; and hence every animal body, by the very condition of its frame, is liable to destruction. To prevent this, a restitution must be made to the juices and solids of the body, equal and similar to what is lost, and this we call nutrition.

It seems to be performed thus. The blood forcibly thrown by the heart into the arteries, endeavours to go out every way through the pores. But these are usually too small to give its particles a free passage : they can only pass where any of the pores are open. Here one will naturally follow another in a line, and constitute a fibre or part of a fibre. When as much is thus added to one end of the fibre, as is wasted at the other, the body is nourished; when more is added than is wasted, we are said to grow.

We see then how absolutely necessary food is to repair the constant decay of the body, so that few men or women can live without it above five or six days; and yet the abstaining from it for a season has its use. Indeed great is the efficacy of abstinence, both in prolonging life beyond its usual period, and in the cure of many stubborn disorders.

Lewis Cornaro, a nobleman of Venice, after all other means had failed, so that his life was despaired of at forty, recavered and lived to near a hundred, by mere dint of abstinence.

It is surprising to observe to what an age those an. cient ehristians lived, who retired from the fury of persêcution, in to the deserts of Arabia and Egypt. They drank only water, and took no other food than twelve ounces of bread in twenty.four hours. On this St. Anthony lived 105 years, Epiphanius 115, Simon Stylites 112, and Romuald 120.

Among animals we see surprising instances of long abstiaence. Several spẹcies pass four, five, or six months every year without eating or drinking. So tortoises and dormice regularly retire at the season to their respective cells. Some kinds get into ruins or the 
hollows of rocks; others into clefts of trees ; some sleep in holes under the earth, others bury themselves under water.

The serpent-kind bear abstinence to a miracle; rattle-snakes will subsist many months without food. Dr. Shaw saw two Egyptian serpents which had been kept in a bottle five years, (on a small quantity of sand wherein they coiled themselves up) without any sort of food. Yet when he saw them they had just cast their skins, and were as lively as if just taken.

There have been instances evén of men passing several months with scarce any sustenance. So Samuel Chilton, of Tinsbury, near Bath, in the year 1693 , 1694 , and 1695, slept sometimes four months and sometimes above six together, with very little food ; and six weeks without any but a little tent, conreyed with a quill through his teeth.

And since this, Juhn Ferguson, of Kilmelford, in Argyleshire, about eighteen years ago, overheated himself, drank largely of cold water, and fell asleep. He slept for four and twenty hours, and waked in a high fever; ever since his stomach loaths and can retain no kind of aliment but water. A neighbouring gentleman to whom his father is tenant, locked him up for twenty days, supplying him daily with water, and taking care that he should have no other food, but it made no difference either in his look or strength. He is now six and thirty years of age, of a fresh complex. ion, anil as strong as any common man.

Still more strange is the case of Gilbert Jackson. $\Lambda$ bout fiftecn years of age, in February 1716 , he was seized with a violent fever; it returned in $\Lambda$ pril for three wceks, and again on the 10th of June; he then lust his speech, his stomach, and the use of his limbs, and could not be persuaded either to eat or drink any thing. Nay the 17th, 1717, his fever left him, but still he was deprived of speech and of the use of his limbs, and took no food whatever. June $30 \mathrm{~h}$, he 


\section{8}

was seized with a ferer again, and the next day. recovered his speech, but without ening or drinking, or the use of his limbs. On the 11 th of October he recorered his health, with the use of one of his legs, but neither ate nor drank, only sometimes washed his month with water.

On the 18 th of $J$ une, 1718, the fever returned and lasted till September. He then recovered and continued in pretty good health, and was fresh coloured, but took no kind of meat or drink. On the 9 th of June, 1719, he was again seized with a severe fever: on the 10th, at night, his father prevailed on him to take a spoonful of milk, boiled with oatmeal. It stuck so long. in his throat, that his parents feared he had been choaked; but ever since that time he has taken food, though so little, that a half-penny loaf serves him for eight days. All the time he fasted he had no evacuation, either by stool or urine, and it was fourteen days after he began to eat before he had any. He is now. in pretty good health.

I suppose such another instance as this has scarce: been known in the memory of man.

It is not improbable that the air itself furnishes some nutritire particles. It is certain there are substances of alt kinds floating in the atmosphere, and that an animal body may be nourished hereby, is evident in the case of vipers. These, if taken when first brought forth, and kept from every thing but hir, will yet grow very considerably in a few days.

6. As without respiration and nutrition we cannot live at all, so without Sense, life would be like death. In every sensation there is, 1. An outward object. 2. Its action in the organ of sense. 3. A perception of it in the mind. The action of the object on the organ is by means of the nerves conmunicated to the brain ; and then, not otherwise, the perception follows: but how, none but He that made man can explain.

7. In Sight, the action on the oryan is performed. E. 6 , 
just in the manner of that in a camera obscura. The rays of light reaching from the surface of bodies to the eye, variously penetrate the coats and humours of it, - and paint on the bottom of the cye the images of the things which we see. This is communicated by the optic nerve to the brain, and then the perception, which is properly Sight, follows : but the eye has many advantages above a camera obscura; not only as it can be moved various ways by the help of its muscles, but also as the pupil by the help of the iris, is instantly either dilated or constringed according to the degree of light. The eye likewise accommodates itself to the various distances of the objects, the bottom of the eye approaching to or receding from the crystalline humour, as the object is nearer or farther off.:-

8. Sound is a tremulous motion of the air, produced by the stroke or collision of bodies. Hearing is performed in the following manner: the undulating air enters the outward cavity of the ear, and then strikes upon the drum, from which the motion is communicated to the little bones within, and the air contained in the inner cavity; this, by means of the nerve, con. veys it to the brain, and then follows the perception which we term Hearing.

9. The fine effuvia which spread every way from odorous bodies, ascending with the air into the nostrils, variously twitch the filaments of the olfactory nerves, according to the variety of their natures. When this motion is by those nerves communicated to the braill, the perception follows which is called Smelling.

10. It was observed before, that the surface of the Tongue is filled with small papillæ, which are no other than fine ramifications of the gustatory nerve. These are variously moved by the particles of meat and drink; and this motion being by that nerve transmitted to the brain, that perception arises which we stile dasting. 


\section{9}

11. The organ of Feeling is the skin in general, with which innumerable nervous papilla are interwoven, which being moved by the slightest touch of other bodies, convey that motion to the brain. But these papillæ abound in all the extremities, particularly the palms of the hand and the tips of the fingers. And. hence it is that the sense of feeling is far more exquisite in those than in other parts.

12. Nearly allied to the senses are the natural appetites, particularly Hunger and Thirst. The usual way of accounting for them is this : when the food, now reduced to a pulp, is expressed out of the stomach, it is of course contracted by its muscular coat, this causes the inner coat to lie in folds, which by means of the peristaltic motion, rubbing lightly on each other, occasion the uneasy sensation which we term hunger. This is felt first in the upper orifice which is first evacuated; but as by degrees the rest of the contents are expelled, this rubbing of the membranes on each other speads over the whole stomach, and renders our hunger more urgeut.

This uneasy sensation is increased by the acidity which the blood in the arteries of the stomach contracts through long abstinence, its soft balsamic parts having been all drawn off ; likewise its velocity is consilerably augmented, when we have not eaten for some time.

Hence it is, that hunger, if it continues long, will occasion a violent fever; that young persons, and those who labour hard, or are of a bitious constitution, are soonest hungry; whereas those whose humours are thick and riscid, are not so suon incommoded therewith.

13. Hot vapours ascending from the stomach, and drying the throat and mouth, are supposed to be the occasion of that uneasy sensation which we term 'Thirst.

I say, are supposed. For I apprehend nothing can be known with any certainty upon the head. In like 
manner it is supposed that we are then awake when the nerves are braced and filled with animal spirits, and that when they are unbraced and empty we sleep. But who can give any satisfactory account of sleep? Some ascribe it to the stoppage of the nerves, some to the quiescency, and others to a deficiency of the animal spirits. The truth is, we are ignorant of the whole affair; and no more understand sleep than we do death.

But this we know, that during sleep several functions are suspended, the organs of sense are at rest, the muscles are quiescent, so that hardly any spirits flow through them. The fibres of the nerves are little changed, and an equilibrium obtains throughout. There is no difference of pressure on the vessels, nor of velocity in the humours, which circulate equally; through all the canals. Mean time, all disturbing causes being at rest, the wasted humours are restored, and the particles supplied, which were worn off the solids.

We may observe farther, that when the head is hot and the feet cold, we camnot sleep; that perspiration. is twice as great while we sleep as while we are awake; that too much sleep makes the senses dull, the memory. weak, and the whole body listless; that sleep will for. a considerable time supply the place of męat and driuk; that a foetus sleeps always, children much, youths. more than adults, and they than old men.

To speak a little more particularly. While we are awake there is a continual motion of the voluntary: muscles, of the parts subservient to sense, and to the affections, all which stimulate the neryes, blood-vessels, and heart. Thus the finer parts of the blood are con.tinually wasted, whence weariness ensues; and if the vigilance be continued, a feverish heat and sensible loss of strength.

As the night advances, a weight falls on the large. muscles and their tendons, and the mind becomes heavy. The powers, that hold the body erect, begin to shrink from their office, the eye-lids close, the 


\section{1}

head nods, and we take less notice of outward ob. jects, till at length all the thoughts are in confusion, and a sort of delirium ensues, from whence there is a transition to sleep, not known to us. This is has. tened by darkness, composure of mind, and absence of irritation from all parts of the body.

Again, whatever weakens the natural powers, inclines to and increases sleep; such as loss of blood, cooling medicines, yea the cold of the external air. Add to these, whatever calls off the quantity of blood flowing to the heart, as warm bathing of the feet, a plentiful ingestion of food inta the stomach : likewise whatever lessens the motions of the spirits, whether in the brain or stomach, heart, or arterics -On the contrary, some hot medicines induce sleep, by causing a greater afflux of blood to the brain. The same effect have some fevers, as also fatness, and whatever else retards the venal blood. In all these cases, the blood collected in the head compresses the brain, so as to lessen the course of the spirits into the nerves.

Sleepiness is likewise produced by any compression of the brain, whether from extravasated blood, a depressed part of some bones, or a collection of se. rous water within the ventricles.

Sleep therefore sometimes rises from a defect of the spirits: always from a collapsing of the nervous fibres, through which the spirits pass from their foun. tain to all parts of the body.

It is hindered by intense thought, pain of body, and strong emotions of mind: all which urge the spirits on, and prevent the nervous fibres from col. lapsing.

In sleep, the heart is gradually restored from its quick and alnost feverish pulsation, to its slow and calm motion, the breathing is slower and smaller, the motion of the stomach and intestines, the digestion of the aliments, and the progression of the fieces are diminished. At the same time the thinner juices move more slowly, while the more gross are called 
together, the fat is accumulated in its cells, and the - nutritive particles adhere more plentifully to the inver surfaces of the small vessels, and the sides of the fibres. Thus while the spirits are secreted with a less consumption, they are by degrees accumulated in the brain, so as to distend and fill the collapsed nerves. And then we awake out of sleep.

Let us consider in another view these remarkable incidents of our frame, sleep and dreams; so remarkable, that they are a kind of experimental mystery, a standing miracle. Behold the most vigorous constitution, when resigned to the slumbers of the night. Its activity is oppressed with indolence, its strength suffers a temporary aunihilation. The nerves are like a bow unstrung, the whole aninfal like a motion. less log. Behold a person of the most delicate sensations and amiable disposition. His eyes, if wide open, discern no light, distinguish no objects. His ears, with the organs unimpaired, perceive not the sounds that are round about them. The exquisitely fine seuse of feeling is overwhelmed with an ulter stupefaction. Where are his social affections? He knows not the father that begat him, the friend that is as his own soul. Benold the most ingenious scho. lar, whose judgment traces the most intricate sciellces, whose taste relishes all the beauties of composition. The thinking faculties are unhinged, and instead of close connected reasonings, there is nothing but a disjointed hurdle of absurd ideas. Instead of well-digested principles, nothing but a disorderly jumble of crude conceptions.

Yet not sooner does he awake, than he is possessed of all his former endowments His sinews are braced and fit for action, his senses alert and keen. The frozen affections melt with tenderness : the romantic visionary is again the master of reason. And (what is beyond measure surprising) the intoxicated mind do's not work itself sober by slow degrees; but in the twinkling of an eye, is possessed of all its faculties ! Why does not the numbness, which seized the animal 
powers, chain the limbs perpetually? Why does not the stupor, that deadens all the senses, hold fast its possession? When the thoughts are once disadjusted why are they not always in confusion? How is it, that they are rallied in a moment, and reduced frop the wildest irregularity to the most orderly array? From an inactivity resembling death, and from extravagancies little differing from madness, how suddenly is the body restored to vigour and agility? How instantaneously is the mind re-established in sedateness and harmony? Surely this is the Lord's doing. And it is marvellous in our eyes.

14. That all motion is performed by means of the muscles, all men are now agreed. And it is supposed that the motions of the muscles proceed from the influx of the animal spirits; which, entering them by means of the nerves, swell and shorten the belly of the muscle, and thereby draw the extremities together and move the parts connected therewith. But a!l this likewise is mero conjecture. God only knows his own work.

15. That some motions are voluntary, and some are not, is another amazing proof of the Creator's wisdom. Those which are absolutely necessary for the conservation of the machine, as the beating of the pulse, and the circulation of the blood, go on by a kind of mechanic law, which no way depends upon our will; while a thousand other motions begin and end, by a single act of our will, when we please. But how this bodily motion is connected with that act of our mind, who is able to explain ?

16. There is a manifest congruity between the sta. ture of man, and his age, during the time of his growth. And as five feet and a half may be thought the ordinary height of man, so may seventy years the ordinary period of his life. Yet some vastly exceed in both respects. And as we know Thomas 


\section{4}

Parre and Henry Jenkins compleated double that usual term of life, so we have no reason to question that some have doubled the common stature of man. Wafter Parsons, King James the First's porter, was full seven feet, seven inches high. Mr. Ray saw a man at Bruges, who was eight fect and a half; all his limbs well shaped, and his strength proportionable. Becanus says he saw a youth almost nine feet high ; a man near ten, and a woman quite ten feet. Pliny mentions several-men of the same height in his age. Yea, Thevenot tells us that he met a Spanish merchant on the coast of Afric, who had in a coffer the skull and bones of an American giant, which he brought with him from that country, who was eleven feet, fire inches in height, and died in the year 1559.

From these warrantable accounts we learn that there have been men 11 or 12 feet high, which equals if not exceeds, the stature of the tallest giant menttioned in scripture. The height of Goliah was but six cubits and a span, which is only nine feet, nine inches. Indeed the bedstead of $\mathrm{Og}$, the king of $\mathrm{Ba}$. san is said to have been nine cubits in length. But his bed must have been longer than his body; we may fairly allow nine inches above his head, and as muck below his feet. And making this deduction, he was not abore twelve feet high : much of the same stature with t l giant, whose forehead bone, is still kept in the medicine-school at Leyden.

Is this deviation from the common stature of man by largeness, more remarkable than its opposite? The deviation from it by littleness, which has been observed in some instances? Such was the dwarf, wholived for several years in the palace of the king of Poland. His parents were healthy, strong peasants, who affirmed, that at his birth he weighed scarce a pound and a quarter, that he was presented on a plate to be baptized, and for a long time had a wooden shoe for his bed. When 18 months old, he could speak some words, when two years old, he could walk aldiost 


\section{5}

without help. His shoes were then just an inch and a half long. When he was six years of age, the king of Poland gave him the name of Bebe, and kept him in his palace. His height was then fifteen inches, and he weighed thirteen pounds.- He was in perfect health, his person was agreeable and well-proportioned; but there was little appearance of understanding. He had no sense of religion, was incapable of reasoning, and could learn neither music nor dancing. Yet he was susceptible of passions in a high degree, anger and jealousy in particular. When sixteen years old, he was 29 inches high, being still healthy and well proportioned, but from that time his health declined; yet he grew four inches in the four succeeding years. At 21 he was shrunk and decrepit; and at 22 it was with difficulty he could walk a hundred steps. In the $23 d$ year he fell into a kind of lethargy, and in a few days died, as if it were of old age.

17. The two most eminent instances of longevity in England were Thomas Parre and Henry Jenkins, 'Thomas Parre was a poor countryman of Shrop. shire; whence ho was brought up to London, by Thomas, Earl of Arundel. At the age of 120 he mar. ried a widow, at 130 he could do any husbandry-work, even threshing of corn, although soon after, his sight began to fail ; nor had he the use of his memory, or but in a small degree, for several years before he died: but he retained his hearing and apprehension to the last. He used to eat often, by day and by night, of milk, old cheese, with coarse bread, whey and small beer. He died at the age of a hundred and fifty. two years and nine months. He might have lived much longer, but coming out of a clear, thin, and free air to l,ondon, and from a plain country diet, to that of a splendid family, where he fed high, and drank the best wines, the natural functions were overcharged, and death could not but soon ensue.

"Henry Jenkins calling at my house I asked how 


\section{6}

old he was? "He paused and said, "about 162 or 163." I asked what was the first public transaction he remembered? He said", "the battle of Flowdenfield, being then 11 or 12 years old."

For many years he was a fisherman, and used to wade in the streams. After he was a hundred years old, he frequently swam in the rivers. The latter part of his life, he was obliged to beg. He died at lillerton upon Swale, in Yorkshire, Dec. 8, 1670: having lived (supposing him to have been 12 years old, at the battle of Flowden-field, which was fought Sept. the 9th, 1513) a hundred and sixty-nine years that is sixteen longer than Thomas Parre. 


\section{CHAP. III.}

Of the preternatural State of the Human Body.

1. What the preternatural state of the Body means.

2. The variety of Diseases.

3. Reduced to three classes : those of the Solids.

4. Those of the Fluids, particularly the Blood.

5. Those of the Animal Spirits.

6. The remote causes of Diseases.

7. Of Fevers.

8. The way to preserve Health.

9. Of Life and Death.

1. WhEN the structure or disposition of the parts of the body is so disturbed and disordered, that the natural operations are no longer performed, or not in the manner as they ought: this is a preterua. tural state of the body, otherwise termed a disease.

2. There cannot but be a great variety of diseases, whether we consider the manner, wherein that structure or disposition is disturbed, the part wherein each disease has its seat, or the various effects and circumstances of them. Some diseases only hurt the use of the parts; some wholly destroy it. Some affect this or that part; others the whole body. Some dis. order the body, some the mind; and others both mind and body.

3. But they are all reducible to three classes, those of the solids, of the fluids, and of both. The solid 
parts may be bruised, wounded, swelled, or remored out of their natural place.

It is a wonderful provision which nature makes in one of the most dreadful calamities incident to the solids. When a bone is broken, let it only be replaced and preserved in that situation, and nature does the rest, by supplying the divided parts with a callus.

This oozes out from the small arteries and bony fibres of the divided parts, in form of a jelly, and soon fills up the carities between them. It soon grows cartilaginous, afterwards bony, and joins the fractured parts so firmly, that the bone will be more easily broken in any other part than in tliat.

A callus of a different kind is formed on our hands and feet. This is composed of several layers of particles loosely connected. These, if stegped in fair water easily separate, and then are found, if riewed through a microscope, to be all of one shape, resembling that of a weaver's shuttle, broad in the middle, and pointed at each end. Being steeped again, they divide into a great number of smaller particles, all of the same figure with the first.

The thickness of the skin in the hands of those who labour hard, is wholly owing to vast numbers of these particles, which combine together, but so loosely that they are easily separated on moistening. That thick skin is composed of sereral layers of different thickness, which have been added from time to time, each of which layers is only a congeries of almost an infinity of these particles.

But people who labour ever so hard, will hare little callus on their hands if they wash them often. The washing the hands daily rubs off a great quantity of these scales. Indeed it is surprising to see how large a quantity of them is daily thrown off from our hands and feet, thongh from no other part of the body. We may learn from this, the great bounty of nature, in so carefully supplying the parts designed for walking or labour, with an additional matter for their de. fence, which is not in any other part of the body. 


\section{9}

4. The diseases of the fluids lie chiefly in the Wlood, when it is either too thick and sizy, whereby its motion becomes too languid and slow, whence spring the diseases owing to obstruction : or too thin. From the former cause arise leprosies, scirrhus, le. thargies, melancholy, hysteric affections: and if at the same time it abounds in acid salts, the sharp points of these tear the tender fibres, and occasion the scur$v y$, 'king's evil, consumption, with a whole train of painful distempers. - Fevers frequently arise from the too great thinness in the blood.

The plague is not an European disease. It is pro. perly a disease of Asia, where it is epidemical, and is never known elsewhere, but by importation from thence. The small-pox also is an exotic disease, and was not known in Europe, or even Asia-minor, till a spice-trade was opened by the later princes of Egypt, to the remotest part of the East Indies. Thence it originally came, and there it rages at this day.

5. As to the diseases ascribed to the animal spirits, some are thought to proceed from the suppression or diminution of their motion, as apoplexies and palsies, some from their excessive or irregular motion, as madness, convulsions, epilepsies.

I know not whether the gentlemen of the faculty would not term the following, " a disease of the animal spirits." Donald Monro, at Strathbogi, in Scotlant, imitates unawares all the motions of those he is with: be is a little slender, old man, and was subject to this infirmity from his infancy. He is loath to have it observed, and therefore casts down his eyes in the streets, and turns them aside when in company. We had made several trials before he perceived it, and af: terward had much a-do to make him stay. He imitated not only our scratching our heads, but the wring. ing our hands, and every other motion. We needed not to persuade him to be covered; for be still covered or uncovered as we did, and all so exactly, and 
Fet with such a natural and unaffected air, that none could suspect he did it designedly. When we held both his hands, and caused another to make such motions, he struggled to get free. But when we would hare known more particularly, how he found him. self affected, he would only give us this simple an. swer, That " it rexed his heart and his brain."

But to what class shall we refer the disease of Ann Jackson? She was born at Waterford, of English parents, both said to be sound and healthy, and from three years old, had horns growing on various parts of her body, she is now thirteen or fourteen, the horns grow chiefly about the joints ; they are fastened to the skin like warts, and about the roots resemBle them much in substance, but toward the end are much harder. At the end of each finger and toe is one, as long as the finger or toe itself, rising a little between the nail and flesh, and bending again like a turkey's claw. On the joints of each finger and toe - are smaller ones, which sometimes fall off, but others come in their place. Round her knees and elbows are many; two in particular at each elbow, which twist like rams-horns, at each ear grows one, yet she eats and drinks heartily, sleeps soundly, aod performs all the offices of nature, like other healthy per. sons.

6. Such are the proximate causes of diseases. As to the remote, the chief are these, 1. Intemperance in meat or drink, either with regard to the quantity or quality. 2. Want of exercise, or excess therein. 3. Immoderate sleep or watching. 4. Unwholesome air. 5. The diminution of some natural evacuation. 6. Irregular passions. All or any of these affect the temperature and motion of the blood and spirits.

7. But it can scarce be conceived, after all that has been said and wrote, on almost every subject, how very little is known to this day, concerning the causes 
of diseases. In most cases the most skilful physicians acknowledge they have nothing but conjectures to offer. We may give a specimen with regard to fevers, the most common of all distempers. These are of various kinds : at preseit we will speak of intermitting fevers ouly. Most of these agree in the following symptoms. During the approach of the fit, cold and shivering seize the body, with a small and slow pulse. Heat succeeds, with a quick, strong, hard pulse, followed by sweat and a softer pulse. These fits return at stated times.

It is supposed, that these changes in the blood arise from some foreign matter mixed with it, which it cannot readily assimilate, and which therefore mustin some measure hinder its motion: perhaps becanse the particles of it are too large, too long, or branching out. When the circulation is hindered or retarded, chilness naturally follows. And if these particles, sticking in the finer passages are pressed on by the afftuent blood, this will occasion both a shock and tremor of the muscles, and make the pulse more weak and slow. But when they are at length broken and commivuted by the continued afflux of the blood, it will flow more violently, and of course occasion heat, which, driving the blood to the surface of the body, mauy of its thinner particles will burst through the pores, in the form of sweat. $\boldsymbol{\Lambda}$ s to the fevers returning at stated times, it is supposed, the peccant matter is generated from time to time, and mingled with the blood afresh, whence the same symptoms of course return, and that with nore or less violence, as more or less of that matter is genierated. And as this is done more swiftly or slowly, the fever returns in one, two, or three days. But all this is mere conjecture. It may be so: and it may not. So that though we may guess much, we know nothing about it.

8. It is sufficient for us to know how we may aroid diseases, whether we can account for them or not. To this end, we should avoid whatever in meat, drink,

roL. 1. 
motion, or rest, is likely to produce any considerable change in the blood. The body likewise should be as far as possible accustomed to bear some change of food, air, and other externals, that if we should at any time be constrained to make such a change, no ill consequence may ensue. But no precise rule can be laid down, which will suit all constitutions. Every man must consult his own reason and experience, and carefully follow them.

A most unaccountable method of removing many diseases, was that of the famous Mr. Greatrix. "6I give you nothing concerning him, says Mr. Boyle, but from eye-witnesses. My own brother some time since was seized with a violent pain in his head and back. Mr. Greatrix coming by accident to our house, gave present ease to his head by stroking it. He then stroked his back, the pain immediately fled to his right thigh. He pursued it with his hand to the knee, ankle, foot, toe, then he stroked this, and it was gone.

" My uncle's daughter was seized with a pain in her knees, which occasioned a white swelling. She tried many remedies without effect, for six or seven years. Mr. Greatrix then coming to Dublin, my aunt brought her to him. Ife stroked her knees, and the pain fled downward from his hands till he drove it out of her toes. And in a little time the white swelling went away.

66 I had an acquaintance, who after a fever was very deaf, and had a violent pain in her ears. Mr. Greatrix put some spittle into her ears and rubbed them, which cured both the pain and deafness.

"Another told me, that when a child she was extrem ly troubled with the king's evil. She tried many remedies in vain ; but $M r$. Greatrix stroked and perfectly cured her. A smith near us had two daughters troubled with the same distemper. One of these had a running sore in the thigh, the other in the aris 


\section{3}

he cured them both. He cured all kinus of hysteric fits. He likewise cured the falling sickness, and without any relapse, provided he could see the paticnt is three or four fits."

9. As long as the soul and body are united, a man is said to be alive. But it is extremely difficult to determine the precise time at which life ceases, or what that is, which is absolutely necessary to the continuance of it. Is respiration ? But when this is entirely ceased, as is the case in a person strangled, blow strongly into the lungs, and they play again : which shews he was not dead before.-Is the beating of the heart? But when this also is ceased, in the foremen. tioned case, take the same method, and when the lungs begin to play, the heart begins to beat anew.Is the circulation of the blood? But persons drowned who hare been so long under water, as to have no pulse remaining in any artery, and consequently no circulation, have recovered by the use of proper means and lived many years after.-Is the fluidity of the blood? Nay, but it is a common thing in Sweden to recover to life one who has been twenty. four hours under water; and who not only has no pulse, but is as stiff all over, as any dead corpse can be. What then is death ? Undoubtedly it is the separation of the soul and body. But there are many cases wherein none but God can tell the moment wherein they separate.

Many who seem to be dead, may be recovered. - A person suffocated by the steam of coals, set on fire in the pit, fell down as dead. He lay be. tween half an hour and three quarters and was then drawn up, his eyes staring, his mouth gaping, his skin cold, not the least breathing being perceivable, nor the least pulse either in his heart or arteries.

A surgeon applied his mouth to that of the patient and by blowing strongly, holding the nostrils at tho same time, raised the chest by his breath. ImmediG 2 
ately he felt six or seven quick beats of the heart; the lungs began to play, and soon after the pulse was felt in the arteries. He then opened a vein, which at first bled drop by drop, but in a while bled freely. Mean time he caused him to be pulled and rubbed. In an hour he began to come to himself, in four hours walked home; and in four days returncd to his work.

Wherever the solids are whole, and their tone un. impaired, where the juices are not corrupted, where there is the least remains of animal heat, it would be wrong not to try this experiment. This takes in a few diseases, and many accidents. Among the first are many that cause sudden deaths, as apoplexies and fits of various kinds. In many of these it might be of use to apply this method, and in varions casual. ties, such as suffocations from the damps of mines and coal-pits; the condensed air of long unopened wells; the noxious vapours of fermenting liquors received from a narrow vent, the steam of burning charcoal, arsenical effluvia, or those of sulphureous mineral acids.-And perhaps those who seem to be struck dead by lightning, or any violent agitation of the passions, as joy, fear, anger, surprise, might frequently be recovered by this simple process.

The animal machine is like a clock: the wheels whereof may be in ever so goad order, the mechanism compleat in every part, and wound up to the full pitch, yet without some impulse communicated to the pendulum, the whole contiunes motionless.

Thus in these accidents, the solids are whale and elastic, and the juices no otherwise vitiated, than by a short stagnation, from the quiescence of that moving something, which enables matter in animated bodies, to overcome the resistance of the medium it acts in. Infating the lungs, and thus communicating motion to the heart, like giving the first vibration to a pendulum, enables this something to resume the govern. 


\section{2}

ment of the fabric, and actuate its organs afresh. It has been suggested, that " a pair of bellows might be apolied, batter than a man's mouth." But, 1. Bellows may not be at hand; 2. The dungs of oue man may safely bear as great a force, as the lungs of another can exert, which by the bellows cannot always be deterinined: 3 . The warmth and mois. ture of the breath may likewise be of use.

Bat what is properly a natural death? From the very birth, every vessel in the human body grows stiffer and stiffer by the adhesionof more and more earthy particles to its inner surface. Not only solid food sup. plies it with these, but every fluidthat circulates through it. Hereby more and more of the small vessels are so filled $u p$, as to be no longer pervious. In pro. portion, the coats of the larger vessels grow, harder, and their cavities narrower. Hence the dryness and stiffness of all the parts, which are observable in old age. By this means, more and more of the ressels are destroyed, the finer fluids seccrned in less quan. tity, the concoctions weakened, and the reparation of the decayed and injured parts prevented. So that only the coarser juices continue to run slowly through the larger vessels. Soon these also tiot only becone narrow, but stiff, bony, and unelastic, till eren the great artery - having lest its sprivig, can propel the blood no longer. And then follows death by rold age, which is a purely natural death. But this is a very rare case, it is seldom life is so long protracted, the lamp of life being easily blown ont, when it burns with so feeble a tlame. So that the a se of man, sel. dom exceeds three scoreyears and ten before dust re. turns to dust.

The term of life can be prolonged but a very little time, by any art we can use. A few only have lived beyond the ordinary duration of human existence ; such as Parre and Jenkins : yet these men used no particular arts to prolong life; on the contrary, they G 3 


\section{6}

were peasants, accustomed to the greatest fatigues, and who had no settled rules. Indeed, if we consider that the European, the Negro, the Chinese, and the American, the civilized man, and the savage, the rich and the poor, the inhabitant of the city, and of the country, though all so different in other respects, are yet entirely similar in the period allotted them for living; if we consider that neither the difference of race, of climate, of nourishment, of convenience, or of soil, makes any difference in the term of life: if we consider that those men, who live upon raw flesh, or dried fishes, upon sage or rice, upon cassava, or upon roots, nevertheless live as long as those who are fed upou bread and meat; we shall readily acknowledge, that the duration of life depends neither upon habit, customs, nor the quantity of food, and that nothing can change the laws of that mechanism, which regulates the number of our years.

If there be any difference in the different period of man's existence, it ought principally to be ascribed to the quality of the air. It has been observed, that in elerated situations there have been found more old people than in those that were low. The mountains of Scotland, Wales, Aurergne, and Switzerland, have furnished more instances of extreme old age, than the plains of IIolland, Flanders, Germany, or Poland. But, in gencral, the duration of life is nearly the same in most countries. Man, if not cut off by accidental diseases, is generally found to live ninety or a hundred ycars. Our ancestors did not lire beyoud that date; and since the time of Duvid this term has had but little alteration.

If we be asked how, in the beginning, men lived so much longer than at present, and by what means their lives were extended to nine hundred and thirty, or even uine hundred and sixty years, it, may be answered, that the productions of the earth, upon which they fed might be of a different nature at that time, than what they are at present. But perhaps it is better to say, that the term was abrilged by dirine command, in 


\section{7}

order to keep the earth from being over-stocked with human inhabitants; since, if every person were now to live and generate for nine hundred years, mankind would be increased to such a degree, that there would be no room for subsistence: so that the plan of providence would be altered; which is seen not to pro. duce life, without providing a proper supply!

But to whatever extent life may be prolonged, or however some may have delayed the effects of age, death is the certain goal to wh:ch we are all hastening. All the causes of decay, which have been mentioned, contribute to bring on this dreadful dissolution. However, nature approaches to this awful period, by slow and imperceptible degrees, life is consuming day after day, and some one of our fa. culties, or vital principles, is every hour dying before the rest: so that death is only the last shade io the picture : and it is probable, that man suffers a greater change ill going from youth to age, than from age into the grave. When we first begin to live, our lives may scarcely be said to be our own: as the child grows, life increases in the same proportion, and is at its height in the prime of manhood. But assoon as the body begins to decrease, life decreases also; for as the human frame diminishes, and its juices circulate in smaller quantity, life diminishes and circulates with less vigour; so that as we begin to lire by degrees, we begin to die in the same maniner.

Why then should we fear death, if our lives have been such as not to make eternity dreadful? Why should we fear that moment which is prepared by a thousand other moments of the same kind, the first pangs of sickness being probably greater than the last struggles of departure. Death, in most persons, is as calmly endured, as the disorder that brings it oll. If we enquire, from those, whose business it is to attend the sick, and the dying, we shall find, that, except in a very few acute cases, where the patient dies in agonies, the greatest number dio quietly, and seemingly without pain. And even the agonies of a 4 
the fortmer, rather terrify the speciators, than torment the patient, for how many have we seen, who have been accidentally relieved from this extremity, and $y$ et bad no memory of what they then endured? In fact, they had ceased to live, during that time when they ceased to have sensation; and their pains were only those of which they had an idea.

5o The greatest number of mankind die, therefore, without sensation : and of those few that still preserve their faculties to the last moment, there is scarce one that does not also preserve the hopes of still out-living hisdisorder. Nature, for the happiness of man, has rendered this sentiment stronger than his reason. A person dying of an incurable disorder, whicl he must know to be so by frequent examples of his case; which he perceives to be so, by the inquietude of all around him; by the tears of his firiends, and the departure, or the face of the physician, is, nevertheless, still in hopes of getting over it. His interest is so great, that he only attends to his own representations; the judgnent of others is considered as a hasty conclusion; and while death every moment makes new inroads upon his constitu. tion, and destroys life in some part; hope still seems to oscape the universal ruin, and is the last that sub. rsits to the blow.

Death, therefore, is not the terrible thing which we suppose it to be. It is a spectre which frights us at a distance, but which disappears when we come to approach it more closely. Our ideas of its terrors are conceived in prejuctice, and dressed up by fancy; we regard it not only as the greatest misfortune, but as also an evil accompanied with the most excruciating , tortures : we have even increased our apprehensions, tby reasoning on the extent of our sufferings. It must be dreadful, say some, since it is sufficient to separate the soul from the body ; it inust be long, since our sufferings are proportioned to the succession of our ideas; and these being painful, must succeed each other with extreme rapidity. In this manner false 
philosophy labours to augment the miseries of our nature, and to aggravate that period, which nature has kindly covered with insensibility. Neither the mind, nor the body, can suffer these calamities; the mind is, at that time, mostly without ideas, and the body too much enfecbled, to be capable of perceiving its pain. A very acute pain produces either death, or fainting, which is a state similar to death : the body can suffer but to a certain degree; if the torture be. comes excessive, it destroys itself ; and the mind ceases to perceive, when the body can no longer en. dure.

In this manner, excessive pain admits of no reflec. tion ; and wherever there are any signs of it, we may be sure, that the sufferings of the patientare no greater than what we ourselves may have remembered to endure.

But, in the article of death, we have many instances in which the dying person has shewn, that every refiection that pre-supposes an absence of great pain, and, consequently that pang which ends life, cannot eren be so great as those which have preceded. Thus, when Charles XII. was shot at the sicge of Frederickshal, he was seen to clap his hand on the hilt of his sword; and although the blow was great enough to terminate one of the boldest and bravest lives in the world, yet it was not painful enough to destroy re. flection. He perceived himself attacked, he reflected that he ought to defend himself, and his body obeyed the impulse of his mind, even in the last extremity. Thus it is the prejudice of persons in health, and not the body in pain, that makes us suffer from the approach of death : we have all our lives, contracted a habit of making oot excessive pleasures and pains; and nothing but repeated experience shews us, how seldom the one can be suffered, ar the other enjoyed to the utmost.

If there be any thing necessary to confirm what we havesaid, concerning the gradual cessation of life, or the insensible approaches of our end, nothing can G 5 
more effectually prove it, than the uncertainty of the signs of death. If we consult what Winslow or Bruhier have said upon this subject, we shall be convinced, that between life and death, the shade is so very un. distinguishable, that even all the powers of art can scarcely determine where the one ends, and the other begins. The colour of the visage, the warmth of the body, the suppleness of the joints, are but uncertain signs of life, still subsistiug; while, on the contrary, the paleness of the complexion, the coldness of the body, the stiffness of the extremities, the cessation of all motion, and the total insensibility of the parts, are but uncertain marks of death begun. In the same manner also, with regard to the pulse, and the breathing : these motions are often so kept under, that it is impossible to perceive them. By approach. ing a looking-glass to the moath of the person sup. posed to be dead, people often expect to find whether he breathes or not. But this is a very uncertain ex. periment. The glass is frequently sullied by the $\mathrm{va}$ pour of the dead man's body ; and often the person is still alive, although the glass is no way tarnished. In the same manner, neither burning, nor scarifying, neither noises in the ears, nor pungent spirits applied to the nostrils, give certain signs of the discontinuance of life; and there are many instances of persons who have endured them all, and afterwards recovered without any external assistance, to the astonishment of the spectators. How careful, therefore, should we be, before we commit those who are dearest to us to the grave, to be well assured of their departare. Ex. perience, justice, humanity, all persuade us not to hasten the funerals of our friends, but to keep their bodies unburied, until we have certain signs of their real decease.

Indeed, soon after the creation, when the earth was to be peopled by one man and one woman, the wise providence of God, prolonged the life of man to above 900 years. After the flood, when there was three men to people the earth, their age was cut shorter. 


\section{1}

And none of these patriarchs, except Shem, attained to five hundred years. In the next contiury, none reached 240. In the third, none but Terah lived 200: men being then so increased, that they built cities, and divided into different nations. As their number increased, the length of their lives diminished, till about the time of Moses it was reduced to 70 or 80 years, where it stands at this day. This is a good medium, so that the earth is neither orer-stocked, nor liept too thin of inhabitants. If men were now to live to Methuselah's age, of 969 years, or only to Abraham's of 175 , the earth would beover-peopled. If on the contrary, the age of man was limited (like that of divers other animals) to 10,20 , or 30 years, it would not be peopled enough. But at the present rate, the balance is nearly even, and life and death keep on an equal pace.

This is highlyremarkable, that wherever any account has been taken, there is a certain rate and proportion in the propagation of mankind. Such a number marry, and so many are born, in proportion to the number of persons in every town or nation. And as to births, two things are very observable.-One is, the proportion of males and females; fourteen males to thirteen females, which is exactly agreeable to all the bills of nortality. And this surplusage of males allows one man to one woman, notwithstanding the casualties to which men are exposed above women. The other is, that a few more are born, than appear to die in any platce. This is an admirable provision for extraordinary emergencies, to supply unhealthy places, to make up the rava. ges of epidemic distempers, and the depredations of war $_{i}$ and to afford a sufficient number for colonies, in the yet unpeopled parts of the earth. On the other hand, those extraordinary expences, are not only a just punishment of sin, but also a wise means, to keep the balance of mankind even. So one would be ready to conclude, by considering the Asiatic, and - other more fertile countries, where prodigious multiG 6 
tudes are swept away by wars and plagues; and still they remain full of people.

As to the length of life, it has been an ancient opinion, that men lived longer in cold countries than in hot. But the reverse is true. The inhabitants of the Caribbee islands, usually live a hundred and fifty years, In the Molucca islands, the ordinary life of the natives is a hundred and thirty years. In Sumatra, Java, and the neighbouring islands, the life of the inhabitants commonly extends to a hundred and forty years : in the realm of Cassuby, to 150. The Brasilians frequently live 160 years, and many, in Florida and Jucatan, still longer.

Nor is this at all improbable. For there being no such inequality of weather in those climates as in ours, the body is not shocked by sudden changes, but kept in a more equal temper. And sickly persons with us, when fixed to their beds, and kept in an equal degree of heat, are often found to hold out many years, who would otherwise scarce have survived one.

20 Before concluding this head, we máy observe one more eminent instance of the divine wisdom, in the great variety throughout the world of men's faces, voices, and hand-writing. Had men's faces been cast in the same mould, their organis of speech given the same sound; and had the same structure of muscles and nerves, given the hand the same direction in writ. ing: what confusion, what numberless inconveniencies must we have been exposed to ? No security could have been to our persons, no certainty of our possessions. Our courts of justice abundantly testify the effects of mistaking men's faces or hand-writing. But this, the wise Creator has taken care to prevent from being a general case. A man's face distinguishes him in the light, as his voice does in the dark : and his hand-writing can speak for him when absent, and secure his contracts to future generations.

Lastly, how admirably has God secured the execttion of his original sentence, upon erery child of man, 


\section{3}

Dust thou art, and unto dust shalt thou return? From the moment we live, we prepare for death, by the adhesion of dust, mixed with all our aliments, to our native dust; so that whatever we eat or drink, to prolong life, must sap the foundation of it. Thus in spite of all the wisdom of man and all the precautions which can be used, every morsel we take, poisons while it feeds, and brings us vearer to the dust from whence we came. - 


\section{CHAP. IV.}

\section{Of the Soul, and of the Origin of Man.}

1. There is something in Man which perceives the various Motions of the Body.

2. This Perception is sometimes continued, and recalled.

3. We know some Things in a more sublime Manner.

B. There is something in us which has an Appetite to sensible Things.

5. And another Appetite, which is often contrary to this.

6. How Philosophers account for the direction of our bodily Mo. tions.

7. For the External Senses.

8. The Imagination and Memory.

9. The Understanding, Will, and Affections.

10. This may be so, or may not.

11. Of the Immortality of the Soul.

12. Of the Union of the Soul and Body.

13. Reason cannot discover the Origin of Man.

14. The Scriptural account of it.

15. Of the production of the Soul.

16. Of the Generation of the Body.

1. WVERY one finds there is something in himself which perceives the motions raised in his body by outward ohjects. For when we see, hear, taste, smell, or feel, while the objects affect our bodily organs, we find also various perceptions in our mind, according to the variety of those objects.

2. We observe, likewise, that after the objects are removed, those perceptions often continue, yca, and are variously mixed and compounded together, which 


\section{5}

we term imagination. And a long time after, when those objects are not only removed, but even cease to exist, those perceptions return into our mind. And this we call inemory.

3. And as we perceive these outward objects, so we know that we do perceive them. The mind can look inward upon itself, and reflect upon its own perceptions. Over and above this, we seem to find in ourselves, a knowledge of things abstracted from mat. ter. But the more we labour to penetrate into the nature of this divine principle, the more it seems to retire and withdraw itself from our most studious re. searches.

4. In like manner we find in ourselves various ap. petites for good things, and aversions to evil things : yea, the very involuntary motions of the body tend to 2roid the evil and attain the good. And the things which are perceived by our senses, or represented by our ima. gination, so necessarily affect us, that we can by no means hinder ourselves from having an appetite for some, and an aversion to others.

5. Yet frequently a more hidden and sublime appe. tite exerts itself in our minds : one that checks, controls, and exercises anthority over all the rest. For if we are convinced, that the things which are plea. sant, are nevertheless hurtful, the appetite for them is over-ruled, and we find a desire, not to enjoy, but to aroid them.

6. In order to explain these things, philosophic men suppose, that all the involuntary motions of the body are performed in a mechanical manner, by matter so and so modified: and that such effects spring of course from such causes, according to the stated laws of motion.

7. As to the senses, they suppose, that when the 
organs of sense are struck by any of the bodies that surround us, and the motion caused thereby continued through the nerves to the brain, the soul, residing there, is suitably affected : Grod having so closely connected the soul and the body, that un certain mo. tions of the body, (if conveyed to the brain by means of the nerves) certain perceptions of the mind always follow : as, on the other hand, on certain perceptions of the mind, certain bodily motions follow.

8. They suppose, if these motions, which are by the nerves communicated to the brain, continue there after the objects are removed, the perception of these is imagination : which, if it occurs after it has ceased, is then stiled memory. Others suppose, that imagination results from the motion of the animal spirits, through those traces which were made in the brain, while the outward objects were present ; and memory, from the spirits moving through them afresh, after some intermission.

9. Once more. They suppose there are two facul. ties in the soul ; one that is passive, the Understanding, by which it perceives all the motions of the body, and knows and reflects on its own operations : the other active; the Will, by which we incline to good, and are averse to evil. The affections are only the Will exerting itself variously on various objects.

10. To speak freely upon the matter. I know the body of man is contrived with such exquisite wisdom, that he is able, by means of the organs of sense, to perceive outward objects ; to continue those perceptions, to recal them after they are gone, and by a reflex act, to know what passes in his mind or body. But I know not how to account for any of these things.

11. That the soul is immaterial, is clear from lience that it is a thinking substance. If it be said, "God 


\section{7}

can endue matter with a faculty of thinking :" we answer, no otherwise than he can endue a spirit with solidity and extension; that is, he can change spirit into matter: and he can change matter into spirit. But even the Almighty cannot make it think while it remains matter; because this implies a con. tradiction.

12. The union of the soul and body is another of those things which human understanding cannot ap. prehend. That body and spirit cannot, be implicated or twisted together like two bodily substances, we know. But how two substances of so widely dif. ferent natures, can be joined at all, we know not. All we can tell is this; God has ordered that certain perceptious in the soul, should constantly follow certain motions of the body, and certaiu motions of the body, such perceptions in the soul.

13. How mankind began, is another point, which is too hard for our reason to determine. That men always existed, is no way probable, were it only on this account, the late invention of arts. For since it appears, at what time the must necessary arts were invented, we cannot reasonably suppose, that men began to exist long before that period : seeing, if they had always existed no reason can be given, why these and many more arts, were not invented long before. And yet the accounts given of the origin of mankind, by the wisest of the heathen philosophers, are so above meastire ridiculous, that they serve as a melancholy proof of the weakness of barely natural reason.

14. The scriptural account is this: God made the body of man out of the earth, and breathed into him the breath of life : not only an animal life. but a spiritual principle, created to live for ever. Even his body was then perfect in its kind; neither liable to death nor pain. But what the difference was, be. 


\section{8}

tween the original and the present body, we cannot determine.

But to form it even as it is now, no less than a divine power was requisite. No less could mix earth, water, air, and fire, in so exact a proportion, and then frame so many different parts, of so various figure, texture and magnitude. God alone was able to forn the original fibres; to weare those fibres into hollow tubes ; to dispose these tubs, filled with their several humours and variously interwoven with each other, into different organs; and of those organs connected together in a continued series and due situation, to finish so complicated and wonderful a machine as the human body.

15. Nothing was wanting now, but that the immortal spirit should be sent into its habitation, to bear the image of its Creator, and enjoy his glory. But the manner wherein this was done we cannot tell ; this knowledge is too wonderful for us. And it is of no use to indulge mere conjecture, whero knowledge is unattainable.

16. Eren the present production of the body by generation is what no man can fully explain. But this we know : the female ovaries, which hang on each side the womb, contain abundance of small vesicles, filled with a transparent liquor. Some suppose, that each of these contains, in miniature, ail the parts of a human body : that when one of them is penetrated by the male seed, it is rarified and explanded thereby, till it breaks the membrauous shell, and by the fallopian tube, falls down into the womb. Here, being slightly fastened to the sides of the womb, it receires nourishment from the mother, till the heart is formed and begins to propel the blood to the extremities of the still increasing body. When it is come to its full size, by rolling to and fro, it tears asunder the enclosing 


\section{9}

membranes, and having burst as it were the prison. bars, emerges into light.

The first thing that appears of a folus is the placenta, like a little cloud on one side of the outer coat of the egg. A bout the same time, the spine becomes visible; and alittle after, the brain and cercbellum appear like two small bladders. Next the eyes stand prominent in the head: then the puncturn saliens, the heart beating is plainly to be seen; and last of all, the extremities. When formed, the foetuslying in the womb, is almost of an oval figure. For the head hangs down with the chin upon the breast. Its back is round. With its arms it embraces the knees, which are drawn up to the belly, and its heels are close to the buttocks. Its head is upwards and its face to the mother's belly. About the ninth month, the head, which till then was lighter, becomes heavier than any other part. In con. sequence of this the head falls down, in the liquor that contains it ; the feet get loose, and the face turns toward the mother's back. But being now in an uneasy posture, it struggles and brings on the mother's throes.

Mr. Dodart, nicely observing an embryo, one and twenty days old, found the placenta more than half of the whole; and thence concludes the younger the embryo is, the larger is the placenta in proportion to it: a plain reason, why miscarriages, though the fortus is less, wre more dangerous than regular delive. ries. For though the embryo in a miscarriage makes a way sufficient for itself, it does not make a way for so large a placenta as is to follow it.

'The embryo itself was only seren lines long, from the top of the head to the bottum of the spine, where it terminated. The thighs were not unfolded : they only appeared like two warts at the bottom of the trunk. The arms made the same appearance on the shoulders. The head was one third of the whole length. On this were two small black points, which would have been eyes. The mouth was very big ; a 


\section{0}

plain indication that it fed thereby. There was no eminence for the nose; but two little, almost insperceptible pits for the nostrils. Always the younger the embryo, the bigger the head is, in proportion to the body. The parts nearer the head are likewise bigger, in proportion to the rest.

It weighed less than seven grains, which is an extraordinary lightness, for a body seven lines long. It was so soft that no part of it conld be touched, with. out making a change in its figure. Upon opening it, Mr. Dodart discovered the heart and the right auricle. All the other parts in the thorax an I the lower belly, were simple outlines, (all vesicular) except a part on the left side, probably the spleen.

Some suppose, that millions of animalcula swim in the seed of male animals, which are so many embryos, for which a receptacle only is provided in the eggs of the female. But all agree, that either the male seed, or the fernale egg, contains all the parts of the body; so that generation is no more than the growth or un. folding of the parts there delineated. But how those seeds, whether male or female, are elaborated and prepared, abundantly transcends the highest reach of human understanding.

If the animalcula, of which all animals are formed, are originally in the male, yet they never can be formed into animals, without the egg of the female.

'That all animals'spring from animalcula, secms probable from the following consideratious :

1. That something may be observed in the tread of an egg, even before incubation, tike the rudiments of an animal, in form of a taduole.

2. That after incubation, all the parts of the animal suddenly appear, the stamina, which existed before, being thell expanded. After three days incubation, the punctum-saliens of a chick is discovered by the naked eye. On the fifth day, the rudiments of the head and body appear, which were beforo discernablo 


\section{1}

by glasses. After thirty hours, we sec the head, the eyes, the heart, and the carina, with the vertebra distinct. And by glasses we see all those parts, after forty hours, which the naked eye canuot disceru till the fifth day. Whence it is prabable, that even the first discovery of them by the microscope, is not the discovery of the parts newly formed, but of those that existed before incubation, though not then dilated enough to be visible.

3. That there is a near analogy between animals and plants. Now we know, the seeds of these are only little plants, folded up in membranes. Hence we may easily infer, that animals proceed from animal: cula folded up, till they are gradually enlarged and un. folded.

And that these animalcula are originally in the seed of the male, is probable. For 1. Numberless animal. cula are observed in the seed of animals. 2. We observe the rudiments of a fotus in eggs fecundated by the male, but not in others. 3. The rudiments in the egg, both before and after incubation, exactly resem. ble the animalcula in the seed. 4 . This gives a rational account of many foetuses at one birth, especially that of the Countess of Holland. It accounts also for a whole chuster of eggs in a ben, being fecundated at once. 5. This best suits the analogy between animals and plants. Every herb and tree bears its own seed; and a little plant of the same kind, which being throw in in to the womb of the earth, spreads forth its roat and receives its nourishment from the earth, but has its form within itself.

Yet, that no animal can be formed without the egg of the temale, is evinced by the following considerations :

1. No animalcula can come forward, if it do not fall into a proper nidus. So thongh a thousand should fall into one egg, none of them would come forward, 
but that which was in the very centre of the cicatricu. la, or tread. And perhaps the nidus necessary for their formation is so proportioned to their bulk, that it can hardly contain more than one animalcula. 'This is certainly the case in oviparous kinds. And all the difference between the viviparous and the oviparous is, that in the former, the egg is nothing but the cicatricula with its yolk: so that the foetus must draw its nourishment from the womb. Whereas, in the oviparous, the egg itself is a kind of womb, containing all that is needful for the animal, till it is hatched.

2. It is acknowledged, that the foetus in the womb, is not connected with it, for a considerable time after conception : that it is wholly loose from it, and is only a little round egg, with the embryo in the midst, which sends forth its umbilical vessels by degrees, and at last lays hold on the womb. Hence it is plain,that the cicatricula, which nourishes the animaleula, does not spring from the womb, but only falls into it, as a fit soil, whence it may draw nourishment for the foctus.

Yet there is a difficulty which presses equally on those, who suppose the animal to spring either from the male or female parent. It is the case of monsters. In a mule, forinstance: the body is of the form of the mare: whereas the feet, the tail, and the ears, resemble thove of its sire. If the male supplied the artimalcula, one would imagine the foetus should always be of the same species with the male. If the female, it should be of her kind: whereas monsters are of both : as if the main part of the animal lay in the egg, and the im. pregnation only conveyed or changed the extremities.

Yet, that some animals first exist, not in the seed of the male, but wholly in the egg of the female, unde. - niably appears from the case of frogs and toads. (And why may it not be the same thing with other animals?) The eggs of these are not impregnated by the male, till they issue from the womb. It is while they are ejected, that he fecundates them with his seminal li- 


\section{3}

quor. And there is no circumstance, by which the fecundated egg can be known from the unfecundated. It appears that tadpoles exist before fecundation. For the unfecundated eggs do not differ in the least from those that are fecundated. But these are only tadpoles coiled up. Such, therefore, are the unfecundated tad. poles : they exist before fecundation ; only they cannot unfold themselves without the liquid of the male. Frogs then should not be placed among oviparous animals, but among viviparous : if they do not rather constitute a class between both. Thus nature seems to delight in diversifying the modes of animal genera. tion.

This may be the case with regard to one, or perhaps a few species of animals. But, in general, where to place the pre-existent animal or embryo, in the animalcula or the egg, is still the question. A division of vital, essential, and original stamina, is impossible. Yet innumerable instances in monsters, mules, and many natural subjecis, concur to prove, that the young partakes of the nature and qualities of both the parents, even to their defects and diseases, which are often hereditary. How then can we suppose unal. terable stamina? Can the visible species of any pro. duction be determined by them, if every sensible quality may be influenced indiscriminately by either parent ?

If they are placed in the animalcula or the egg, how are they transmitted? If in the animalcula, why is the process attended with so vast an expence, so great a waste of millions of entities, each containing a series of the most perfect, and most wouderful productions, when one only of those millions is to take place? And how are these auimals genera. ted? If in the common way, not only the process will be boundless, (these in their seed will have others, and so on in an endless series ;) but they can. not then be unalterable, because they are capable of being generated. Further, if they loat in the air, 
or lie hid in food, how is it that the stamina of one species does not sometimes insinuate themselves into a parent of another species ? Or if they are excluded, by proper strainers, in distant species, they cannot be so in those that are near akin. For if the sper. matic animal, which in the matrix of a mare, produces a horse, is yet so fitted to that of an ass, that it can possess a cellule there, exclusive of every other, which shews an exact co-aptiturle; certainly the same animat, if contained in food or air, common to botk horse and ass, might pass indiscriminately the strainers of either: and so we might have mules without the promiscuous congress of the two species.

In another view, if we consider the extreme te. nuity of one of these stamina, in its first origin at the distance of many ages, compared to the smallest fibre of the animal it is said to constitute : can so minute a filament serve as a substratum for a cylinder, com. paratively immense? Can the terraqueous globe derive its present dimensions from the dilatation of an atom? Such is a muscular fibre in its present state, compared to what it was in its origin. Consequently, what must have been the increase of extraneous matter, either by apposition or incorporation, which is now as much a part of the fibre, as the original stamen? And if thus much can be mechanically assimilated, why not the whole formed by mechanical causes? Or why must so insignificant a part of it, be supposed to be concreated with the universe?

The difficulty still increases immeusely, if we look into the vegetation of plants, and the wonderful repro. duction of the parts of the polypus, lobsters, and many other animals. The original stamina, how miuute soever, questionless, are diffused through the whole production : since in this system all animal and vegetable growth is made by developement only: But if diffused, then some or all may be lost by suecessive 


\section{5}

bisection. And if lost, how can they be reproduced? If reproduced, how were they concreated with the universe? These and a thousand other difficulties can in nowise be evaded, but by multiplying supposition on supposition, which renders the hypothesis so complex, as utterly coutradicts the ordinary process of nature.

It is more reasonable to say, that so many secretory ducts, so many strainers, so many preparatory vessels in animals, and such a curious disposition in plants, for the continuation of every species, imply a digestion, secretion, and preparation of principles, invariably productive of every individual, when they fall in to their respective matrixes, and fund aliment proper to assimilate. Are not these principles contained in the nourishment taken by the parent plant or animal, the same that continually vegetate in it, and increase it till it is adult, then exuberate, while it is by new preparations, fitted, invariably to propagate its kind? Else why this digestion? Why this secretion? Why so many strainers, receivers, lucts and valves? And why is some food more productive of these principles than others?

And if every mixed body is made up by the combination of certain principles; we cannot doubt, but God may have established forces in natiure, by which such principles may in certain circumstances, be in. variably united, without any danger of deviating, su as to render generation equivocal. Apd if every production in question is a mixed body, we know that hor various soever they are, a smal! number of principles differently combined, will yield variety enough to produce them all. Thus we reduce nature to what it is ever found to be, simple in the beginning of its course, but afterwards, when it is discributed, wagnificent beyond expression.

Moderu naturalists all agree, that every plant proceeds from its specific seed ; every animal from an egg. or something analogous, fre-existing in its parcut.

Vo) $I_{2}, 1$. 
But what do we mean by seeds and eggs? These in the common sense of the words, are certain mixed bo. dies, that immediately furnish those productions. They are said to contain not only the pre-existent germ, but the fit nidus also and aliment to be assimilated in proper circumstances. 'They are therefore heterogeneous bodies, that coalesce in a known time; and their principles are so far from being united at the creation, that they sensibly come together from distant places, in all hermaphrodite plants, and from different indiriduals in all those species, where the male and female are distinct.

But it is in vain for us to lay down any certain rule, and to say to nature, "this is thy scheme; from this thou shalt not deviate." If she makes it a law in many species, that every individual requires the co-operation of a male and female parent; she has, at the same time, her hermaphrodites, both in plants and animals. And if in some hermaphrodites, the sexes are so distinct, that she seems not to deviate far from her primitive law ; she will, in another instance, that of the puccrons, act either with or without the co.operation of a male. Again : in some species, the female may be so impregnated, that the impregnation shall diffuse itself to five or six generations. Yet again : in many kinds of polypes, generation pro. ceeds without male or female, egg or seed. And far. ther still; there are some species of polypes, where a whole family, (after branching out by real vegetation, as far as nature designs) jointly concur to furnish one egg, as the source of a future progeny. If at last youresolve to stand by this, that at least every individual proceeds from a parent like itself; even this is overthrown by late experiments. For we have now a cloud of instances, of a class of beings hitherto unknown, wherein animals grow upon, are produced by, and in the strictest sense of the word, brought forth from plants. Then, by a strange vicissitude, they become plants of another kind. These again become 


\section{7}

animals of another, and thus on, for a series farther than the utmost power of glasses can carry the most inquisitire observer.

And as to the animalcula supposed to be discovered in the male seed, the microscope discorers the same in the seminal liquor of females. Probably neither the one, nor the other are real animals, but only inani. mate particles in strong fermentation. 


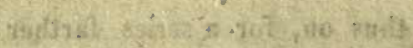

Jourin gils

\section{PART THE SECOND.}

\section{OF BRUTES.}

\section{CHAPTER I. \\ OF BEASTS.}

1. The general Difference of Men and Beasts, as to the Structure and Posture of the Body.

2. Their Agreement.

3. Their Agreement and Disagreement as to the Head and Brain,

4. The Heart and Lungs.

5. The Eyes.

6. The Ears, Nose, Teeth.

7. The Windpipe.

8. The Vegetative and Sensitire Motions in Brutes.

9. Of the Soul of Brutes.

10. Of some particular Sorts of Beasts.

11. Some general Refections.

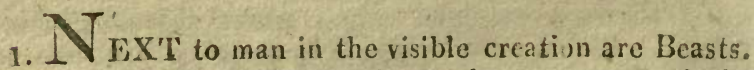
And certainly, with regard to the structure of the body, the difference is not extremely great between man and other animals, only in this, that the stature of man is erect, and his form more elegant; that no beast has the feet of a man, much less a hand so admirably fitted for crery purpose : and lastly, that no 


\section{9}

other animal has a brain so large in proportion to its bulk as mall. Concerning the prone posture of their body we may observe two things; the parts ministering thereto, and the use thereof.

I. As to the parts, it is observable that in all these creatures; the legs are made exactly conformable to their posture, as those of man are to his posture; and farther, that the legs and feet are always admirably suited to the motion and exercise of each animal. In some they are made for strength, to support a rast unwicldy body; as in the elephant, which being a creature of such prodigious weight, has its legs accordingly made like pillars. In others, they are made for agility and swiftness. So deers, hares, and several other creatures, have their legs very slender, but strong withal, and every way adapted for quick motion. In some, they are formed only for walking and running, in others for swimming too. Thus in the feet of the otter, the toes are all conjoined with membranes, as they are in geese and ducks. And in swim. ming it is observable, that when the foot goes forward in the water the toes are close, but when backward they are spread out; whereby they more forcibly strike the water, and drive themselves forward. In others, as moles, they are made for walking and digging, and in others for walking and flying.* In some they are made more woak for the plainer lands, in others, stiff and less flexible, f fur traversing ice and dangerous precipices. In some they are shod with rough and hard hoofs, in others with only a callons skin. $f$ In the latter, the feet are composed of toes;

* The membranous wings of a bat are a prodiginis deriation froun nature's ordinary way; and so is the Virginian flying squirrel, whose skin is extended in the nature of wings between its fure-legs and body.

+ The Elk has legs so stiff and inflexible, that they run on ice without slipping. And this is the way they take in winter to save themselves fiom the wolves.

- ₹ The Goat, which generally dwells on mountains and rocks, and delights to walk on narrow ridyes, and to take great and seemingly

II 3 


\section{0}

some short, barely for going; some long to supply the place of a hand; some armed with long and strong talons to catch hold and tear the prey; and some fenced only with short nails to confirm the steps in running and walking.

11. 1. As the posture of man's body is the fittest for a rational animal, so is the prone posture of beasts, the most useful to themselves, and the most fit for the service they perform to man.

2. But there is a wonderful agreement between the bodies of men and beasts, not only with regard to the structure, but also the use of the several parts. How they differ, will be mentioned hereafter.

3. The brain in them is of nearly the same structure and consistence as in man, and undoubtedly performs the same office, secreting the animal spirits (if such there he) in order to sensation and muscular motion in every part of the body. The cerebellum is nearly of the same shape in all; but the shape of the brain ne. ccssarily varics according to that of the head.

It is remarkable that in man the head is of one singlo form; whereas in the four-footed race it is as rarious as their species. It is in some square and large, suit. able to their food, abode, and slow motion : in others, it is small, slender, and sharp, agreeable to their swifter motion, or to make way to their food or habi. tation under ground. And as to the brain contained therein, how small is it in beasts in proportion to what it is in nian! Another thing no less remarkable is, the situation of the brain and the cerebellum. As God has given to man a lofty countenance, and has lodged in his brain an immortal soul, to behold and contemplate heavenly things, so as his face is erect, his brain is set in a higher place, above tne cerebellum and

dangerous leaps, has the joints of the legs remarkably stiff and strong; likewise the hoof is hollow underneath, and its edger sharp. 
all the sensories; but in brutes; whose face is prone to the earth, and who are not capable of speculation, the corebellum, which ministers merely to animal life, is placed above the brain, also some of the organs of sense are placed, if not above the brain, at least on a level therewith.

A nother very great convenience in this position of the brain and cercbellum is, in the head of man, the base of the brain and cerebellum, yea of the whole skull, is set parallel to the horizon, by which means there is the less danger of the two brains joggling or slipping out of the place; but in beasts, whose heads hang down, the base of the skull makes a right angle with the horizon, by which means the brain is bencath and the cerebellum above. And lest the cerebellune should hereby be liable to frequent concussions, an ad. mirable provision is made by that strang membrane the dura mater, closely encompassing it. Buside this, it is guarded in some species with a strong bony fence. In the hare, the coney and several others, a part of the cerebellum is on each side within tho os petrosum, so that its whole mass is, by this double stay, firmly con. tained within the skull.

4. The heart and lungs in beasts are of the same structure, with the same apparatus of veins and arteries as in men. We cannot therefore doubt but the blood circulates in them, and nutrition is performed as in us. Their food also being dissolved in the stoma $\mathrm{h}$, is conveyed by the lacteals to the receptacle of the chyle. To the fore-part of this (in men the upper part) joins the thoracic duct, which extending through the length of the thorax ends in the vein called in beasts cruralis anterior. The remaining. part of the circulation is performed in them as in men.

But some beasts have more stomachs than one; and some have the peculiar property of chewing the cud. The food, after it has been swallowed, is returned to the mouth, where it is chewed over again at leisure.

Not that this is altogether peculiar to beasts. There u 4 
have been instances of men who had this property. Dr. Slare gives us a particular account of one whom he knew at Bristol. "He begins," says he, "to chew his meat over again, within a quarter of an hour after meals. This chewing, after a full meal, lasts an hour and a half. If he goes to bed soon after a meal, he cannot sleep till the usual time of chewing be over. The vicluals returned, taste morc pleasantly than they did at first. Bread, flesh, cheese, and drink, are of much such a colour as they would be if mixed together in a mortar. Ilis victuals lie heary on his stomach till they lave passed this second chewing. He was thus ever since he can remember. His father does the same, but in small quantities." - What a mercy is it that we have not more such instances! For how much of our precious time would it consume!

5. The situation, number, and conformation of the eyes in various animals, is wonderfully adapted to their various circumstances. In several the eye looks chiefly forward, but so as to take in nearly the he. misphere before it. In others, the eyes are so placed as to take in nearly a whole sphere. In some, they are so fixed as to look chiefly behind, so that they see their eneny following them; so in rabbits and hares : whereas in dugs they are more forward, to look after their prey.

Generally the head is moveable for the sake of the eyes, and the eyes themselres moveable every way. Where it is not so, other expedients are found to au. swer the same end. Thus in some creatures the eyes are set at a distance from the head, to be moved this way or that: as in snails, whose eyes are fixed to the end of their horns, or rather of the optic nerves which are sheathed therein. In other creatures, whose heads and eyes are immoveable, this is made up by the num. ber of eyes. So spiders, which cannot move their head, have four, six, or eight syes, all placed in the front of the head (which is round) like a locket of diamonds. 


\section{3}

Minny animals have muscles to move the eye, and obvert it tis the object. Fishes have none; but for amends they have many litte protuberances finely ranged on their large bulging eyes, by which numberless rays of light are deflected from objects above, beneath, and on either side. Yea, some hundrels of these protuberances are curiously ranged on the conrex eye of a Flesh-fly.

- Scorpions have above a hundred eyes; an Epheme. ron fly futl two thousand.

In other creatures which have only two eyes, the want of motion therein is supplied by their eyes pro. tuberating into hemispheres, each being a vast number of segiments of a sphere.

The eyes of a Cameleon resemble a conrex glass set in a round socket, which he turns backward and for ward without stirring the head, and cominonly one a contrary way to the other.

Lastiy, Moles living under ground, have not sa much need of eyes as other creatures; yet they have eyes, but exceeding small, far in the head, and $\mathrm{co}_{\text {. }}$ vered with strong hair. When they are above ground they can put then forth beyond the skin, and draw. them back at pleasure.

Another circumstance relative to the eye is highly remarkable. As we use varions a pertures to our optic glasses, so nature has made a far more compleat provision to admit enough, and not too much light into the eyes of animals, by the dilatation and contraction of the pupil. And this, in divers animals of divers forms, is according to their peculiar occasions. In some it is round, particularly in man, that being the most proper figure for the position of our eyes, and the use we make of them both by day and night. In some animals it is of a lougish form, in some transverse, with its aperture large (an admirable provision for their seeing side-ways) and thereby avoiding many inconveniencies, as if ell as a help for gathering their food on the ground, whether by day or night. In otiners, that aperture is erect, and also capable of opening wide II, 5 : 
and shutting close. The latter serves to exclude the bright light of the day, the former to take in the faint rays of the night, thereby enabling them to see and catch their prey when there is no light discernable to us.

Thus cats can so cluse their pupil as to admit but a single ray of light; and again, by throwing all open, they can take in all the faintest rays; which is an incomparable provision for creatures that have occasion to watch their prey both by day and night.

But beside this, in cats and other nocturnal animals, there is a sort of carpet at the bottom of the eye, which gives a kind of radiation on the pupil, thereby enabling them to see in the dark.

To preserve this tender organ, many creatures have a membrane, which is not commonly perceived, where. with they can at pleasure cover the eye, without too much hindering the sight, being both transparent and strong, so that it is a kind of moveable cornea.

Providence is conspicuous in furnishing frogs with this; for as they live in watry places which generally abound in plants that have sharp edges or points, and as the frog goes on, not by walking but by leaping, if he were not so furnished, he must either shut his eyes, and so leap blindfold, or run many risques by leaving them open; but this membrane guards the eyes without blinding him, and as soon as the occasion for it is over, he draws it back into a little cell. Many birds also, as they must fly between trees and bushes, are provided with the same membrane, and so is the rein. deer.

6. The comparative anatomy of the Ear, yields abundant instances of the Creator's wisdom. In birds the outward ear is close and covered, not protuberant, as that would obstruct their flight. In beasts, its form is agreeable to the posture and motion of the body, but admirably varied in the several species according to their various occasions. In some, as the hare, it is large, open, and erect, by which means 


\section{5}

that timorous helpless creature is warned of the least approach of danger. In others, it is covered to keep out noxious bodies. In those which are forced to mine and dig for their habitation, it is short, and lodged deep and backward in the head. Thus moles have no auricle at all, but only a round hole between the neek and shoulder, and this is closed with a little skin, which opens and shuts like an eye-lid. The sea-calf also, as well as lizards and serpents, have no outward ear, and the tortoise, with most kind of fishes, have the passage quite covered over.

But among all the varieties in the structure of this organ, none are more remarkable than those of the passage into the os petrosum. In an owl, which perches upon a tree or beam, and hearkens after the prey beneath her, it comes farther out above than below, for the better reception of sounds from beneath. In a fox, which scouts under the prey at roost, it comes farther out below than above. In a pole-cat, which hearkens straight forward, it is produced be. hind, for the taking a forward sound. Whereas a hare, whose enemy comes behind, is supplied with a bony circle directed backward, by means of which she receives distinctly the smallest sound which comes that way.

The more accurate the sense of Smelling is in any creature, the longer are the lamina in the nostrils, and the more in number, folded up and crowded together, to contain more nervous filaments, and to de. tain the odoriferous particles in their windings and turnings. An admirable provision this for the good of many creatures, the chief acts of whose lives are per. formed by the ministry of this sense. In insects and many other creatures it is of great use, in helping them to proper places for hatching their eggs, and breeding up their young: and most irrational animals, beusis, birds, and reptiles, do by their smell find out their food. With what sagacity do some of them discover it, in the midst of mud and dirt. How curiously do others pick and chuse such plants as afford them wholesome 
fool (perhaps medicine too) aroiding such as tend to hurt or destroy them. And all this principally by the smell, together with its near ally, the taste.

The various forms of the Teeth in various creatures, is another instance of the Divine wisdom. How curiously are they adapted to the peculiar food and occasion of each species! Thus in the rapacious, they are fitted to catch ard hold their prey ; in the herbaceous, to gather and chew regetables. In those which have no teeth, as birds, the bill supplies that defect, to. gether with their additional stomach. And it is a remark which hardly fails, alt such animals as hare four stomachs have no teeth at all.

There are great varieties in the teeth of other ani. mals : trout have teeth upon their tongues; cod-fish at the bottom of their gullet. Crocodiles have three rows of teeth on the same jaw ; sharks four or five : sea-devils, so called, have several rows of moveable teeth.

7. The variation of the Wind-pipe in variotis creaiures is likewise observable, as it is necessary for that of the roice. In a hedge-hog, which has a very small woice, it is hardly more than membranons. In a pigeon, which has a low soft note, it is partly membraneous, partly cartilaginous. In an owl, which has a good audible note, it is more cartilaginous: but that of a jay (as of a linnet) has bones instead of cartilages.

The rings of the wind-pipe likewise are fitted for the modulation of the voice; for in $\log$ s and cats, which use a great many notes, they are (as in man) open and flexible, whereby all or any of thesn is mose or less dilated ur contracted, in order to a deeper or shriller note. But they are one entire ring in the Japan peacock, which uses one single note.

8. As to the Motions of brutes it is not easy to conceive that even those of the regetative kind, can be the mere mechanical effects of matter, however modified; much less can we coticeive this of their sensitive 


\section{7}

motion, for we have not the least reason to doubt but the same impressions of external objects raise the same perceptions in them as in us. No question, they sec, and hear, and smell, and taste, and feel in the same. manner as men!.

9. We cannot therefore deny, that there is something in brutes which perceives the impressions madey by outward objects; and that they perform a thousand actions which can never be explained by mere mechab nism, those in particular which spring from what we call instinct, as the feeding and tending their young, the building their nests and preparing their habitation, upon or in the earth.

It is true, some things in brutes as well as in men may be mechanically accounted for, but others cannot; so that we are constraiued to own there is in them also some superior prineiple, of whatever kind it be, which is endued with sense, perception, and various appe. tites : for from their outward actions we may as easily learn, as we conld from those of a man born deafand dumb, that there are in this principle or soul two different faculties-that of perceiring or knowing, answerable to our understanding, and that of desiring and shunning, answerable to our will. That this principle is immaterial appears from this single consideration, it has a power of self-motion, which no matter can have, being wholly anr essentially passive.

10. It is not my design to enumerate the scveral spe. cies of beasts, but it may illustrate the wisdon of the great Creator to give some account of a few, several of which are not so commonly linown...

The largest land animal in the world is an Elephant, which seems rather to belong to the hog-kind than any other; they are found only in the south of Afric, and in the Last.Indies, and are generally of a dark colour. Their eyes are like those of a hog: at the corners of their mouth grow two large teeth, six or seven feet 
Jong in the male, but not above one in the female. They feed on grass, nuts, and other vegetables.

Of all quadrupeds the elephant is the strongest as well as the largest; and yet in a state of nature it is neither fierce nor formidable. Mild, peaceful, and brave, it never abuses its strength, and only uses it for its own protection. In its native deserts the elephant is a social friendly creature. The oldest of the company conducts the band, that which is next in seniority lirings up the rear. The young, the weak, and the sickly, fall into the centre, while the females carry their young. They maintain this order only in dangerous marches, or when they desire to feed in cultivated ground : they muve with less precaution in the forests and solitudes, but without ever removing far asunder.

Nothing can be more formidable than a drove of elephants, as they appear at a distance in an African landscape : wherever they march, the forest seems to fall before them : in their passage they bear down the branches on which they feed; and if they enter into an enclosure, they destroy all the labours of the husbandman in a very short time. 'Their invasions are the more di agreeable because there is no means of repelling them: since it would reqnire a smatl army to attack the whule drove when unitud. It now and then happens that one or two is found lingering behind the rest, and it is against these that the art and force of the hunters are united; but an attempt to molest the whole body would certainly prove fatal. They go forward directly against him who offers the insult, strike him with their tusk, scize him with their trunks, fling him into the air, and chen trample him to pieces under their feet. But they are thus dreadful only when they are offended, and do no mauner of personal injury, when suffered to feed without interruption.

The elephant has very small eyes when compared to the enormous bulk of its body; but though their mivuteness may at first sight appear deformed, yet, when 
we come to examine them, they are seen to exhibit a variety of expression. It turns them with attention and friendship to its master; it seems to reflect and deliberate; and as its passions slowly succeed each other, their various workings are distinetly seen. It is remarkable for the excellence of its hearing : its ears are extremely large, they are usually dependent, but it can readily raise and move them : they serve also to wipe its eyes, and to protect them against the dust and flies. It appears delighted with music, and readily learns to beat time, to move in measure, and even to join its voice with the drum and trumpet.

This animal's sense of smelling is not only exquisite, but it is pleased with the same odours that delight mankind. The elephant gathers flowers with great pleasure; it picks them up one by one, unites them in a nosegay, and seems charmed with the perfume. The orange flower is particularly grateful, both to its taste and smell; it strips the tree of all its verdure, and eats every part of it, even to the branches thernselves. It seeks in the meadows the most odoriferous plants to feed upon, and in the woods it prefers the coco, the banana, the palm, and the sage tree to all others.

But it is in the sense of feeling that this animal excels all others of the brute creation, and perhaps man himself. The organ of this sense is wholly in the trunk, which is an instrument peculiar to this animal, and that serves it for all the purposes of a hand. The trunk ends in two openings, or nostrils, like those of a hog. An elephant of fourteen feet high has the trunk about three feet long, and five feet and a half in ciroumference, at the mouth. It is hollow all along, but with a partition running from one end of it to the other. This tube is composed of nerves and muscles covered with a skin like that of the rest of the body. It is capable of being mored in every direction, of being lengthened and shortened, of being bent or straightened; so pliant as to embrace any body it is applied to, and yet so strong that nothing can be torn from its gripe. To aid the force of this grasp, there are 
several very little eminences like a caterpillar's fect on the under.side of this instrument, which without doubt contributes to the sensibility of the touch as well as the firmness of the hold. Through this trunk the animal breathes, drinks, and smells; and at the very point. of it, just above the nostrils, there is an extension of the skill, above five inches long, in the form of a finger, and which, in fact, answers all the purposes of one; for with the rest of the extremity of the frunk it is capable of assuming different forms at will, and consequently of being adajted to the minutest objects. By means of this, the elephant can untie the knots of a rope, unlock a door, and even write with a pen. It sometimes happens, that the object is too large for the trunk to grasp, in such a case the elephant makes use of another expedient, it applies the extremity of the trunk to the surface of the object, and, sucking up its breath, lifts and sustains such a weight as the air in that case is capable of keeping susyended. In this manner this instrument is useful in most of the purposes of life; it is an organ of smelling, of touching, and of suction; it not only provides for the animal's necessities, but it also serves for ornament and defence.

The legs are not so inflexible as the neck, yct they are very stiff, and bend not without difliculty. Thoses before seem to be longer than the hinder, but, upon being measured, are found to be something shorter. The joints by which they bend are nearly in the midWle, fike the knee of a man, and the large bulk which they are to support makes their flexure ungain. Yet while the elephant is young it bends the legs to lie down or rise, but when it grows old or sickly this becomes so inconvenient that the animal chuses to sleep. standing.

It is one of the striking peculiarities of this animal, that his generative powers totally fail when he cumes under the dominion of man; as if he seemed unwilling. to propagate a race of slaves to increase the pride of his: conqueror.

the elephant, when once tamed, becomes the most 


\section{1}

gentle and obedient of all animals. It soon conceives an attachment for the person that attends it, caresses him, obeys him, and seems to auticipate his desires.

In a short time it begins to comprehend the signs made to it, and even the different sounds of the roice; it perfectly distinguishes the tone of command from that of anger or approbation, and acts accordingly. It receives its orders with attention, eagerly, yet with. out precipitation. $\Lambda l l$ its motions are regulated, and its actions seem to partake of -its maguitude, being grave and majestic. It is quickly taught to kneel down to receive its rider; it caresses those it knows with its trunk; with this salutes such as it is ordered to distinguish, and with this, as with a hand, helps to take up part of its load. It suffers itself to be arrayed in harness, and seems to take a pleasure in the finery of its trappings. It draws either chariots, cannons, or shipping, with surprising strength and perseverance; and this with a seeming satisfaction, provided its master appears pleased with its exertions : and he fre. quently takes such an affection for his keeper that he will obey no other; and it has been known to die for grief, when in some sudden fit of madness it has killed its conductor.

In Deli, an elephant passing the streets, put his trunk into a taylur's shop, where several people were at work. One of the persons of the shop, desirous of amusement, pricked the animal's trunk with his needle. the elephant passed on without any signs of resentment, but coming to a puddle of dirty water, filled his trunk, returued to the shop, and spurted it over all their finery.

Some of them are twenty feet in compass, and near fourteen high. They seem to have more sense than any other brute, and are capable of fidelity and strong affection, particularly to their companion, so that neither the male nor female is ever known to make a second choice.

The female goes seventeen months with her young: they are fifty orisixty years before they have their fult 


\section{2}

strength, are in full vigour at about a hundred, and lire two or three hundred years.

A Rhinoccros, next to the elephant, is the most extraordinary animal in the Indies. It is usually twelve feet long, from the tip of the nose to the insertion of the tail, from six to seven feet high, and the circumference of its body is nearly equal to its length. It is therefore equal to the elephant in bulk, and if it appears much smalier to the eye, the reason is, the legs are much shorter. In other respects it is shaped like a wild.boar.

It is said to have a very rough tongue, but this is so far from the truth, that no animal of near its size has so soft a one. It is smooth arid small like that of a dog; and to the feel, it appears as if one passed the hand over velvet. It has a peculiar cry, a mixture be. tween the gruating of a hog and the bellowing of the calf. The age of these animals is not well known: it is said by some that they bring forth at three years old, and if we may reasun from aualogy, it is probable they seldom live above twenty.

That which was shewn iu London, was said by its keeper to be eighteen years old, and even at that age he pretended to co sider it as a young one; howerer it died shortly after, and that probably in the course of nature. It is a native of Asia and Africa, and is usually found in those extensive forests that are fre. quented by the elephant and lion. As it subsists en. tirely upon vegetable food, it is peaceful and harmlcss among its fellows of the brute creation; but though it never provoles to combat, it equally disdains to fly. It is every way fitted for war, but rests contented in the consciousness of its security.

His skin is without hair, and so full of scratches and scabs, that at a distance they may well be taken for scales. On his nose he has a liorn of a dark brown colour, which bends backward, and is often two feet long. He has often another horn a little above this, which never exceeds six inches. His eyes are exceed. 


\section{3}

Ing small, and he only sees strait forward; thereforehe always runs in a strait line, tearing up whatever stands in his way. With his horn he throws stones over his head to a great distance, and even tears up trees by the roots.

The outer skin of the Rhinoceros, which consists of many folds, is thick and impenetrable. In running one's fingers under one of the folds, it feels like a piece of hoard half an inch thick; but between the folds the skin is as smooth and soft as silk, and easily penetrated.- See here the wisdom of the great Creator! If the outer skin, which is quite inflexible, was continued all over him without any fold, he could not perform any action whatever; but the suppleness of skin in other beasts, is compensated in this by these folds. It was necessary his skin should be hard for his defence: mean time, it was a noble contrivance that it should be so soft and smooth underneath, that when he bends himself any way, one part of this board-like skin, should slide over the other. And these folds are placed in such parts of his hody as to facilitato the performance of every voluntary motion.

Another native of the East Indies is the Camel, one of the most serviceable animals in the world. He kneels down to receive his burden, and rises when he hath his accustomed load. If he feels himself orer-burdened, he will not rise, but cry till part of it is taken off. One of them will carry a thousand or twelve hundred weight, forty miles a day, for thirty or furty days to. gether. 'Ihey have no teeth in the upper jaw. They will travel forty hours without either meat or drink, and nine days without drink : they have two stomachs admirably contrived for this purpose. The gentleman who dissected one at Paris, found in his second stomach several square holes, which were the orifices of about twenty cavities, made like sacks, placed between the two membranes, which compose the substance of the stomach. And in these reservoirs he contains water enough to serre him for so many days. 


\section{4}

The bunch on his back is not flesh, much less bone; but mere hair; and when this is pressed close down, he is no more lunch-backed than a swine. They subsise on very little, which enables them to travel throighi those vast and barren deserts.-How wise is he who caused these to be natives-of those countries where such creatures are absolutely necessary ! $\AA$ farther instance of this is, that the African camel, which has still greater and more uncouth journeys to take, is larger and stronger, and capable of carrying heavier burdens than those of Asia.

Another wonderful property of camels is, that of foreseeing the poisonous winds, which kill in a mo. ment. A little before these come, they run togethen and cry, and hide their noses in the earth; and as soon as they are past, they lift up their heads, and continue their journey.

The Dromedary in most respects resemiles the camel, only it is of a slighter make, and instead of one bunch on its back has two, about six inches in height. It goes frequently forty leagues a clay; so that although it caunot carry above six hundred weight, yet its swiftuess atones for its weakness. Its feet are soft as a sponge, and are not hurt either by stones or sand. And (what is an excellent providence) they travel best and have the greatest spirits in the hottest weather.

The Lamas, in Peru, have small heads, resembling in some mcasure both a horse and a sheep. The upper lip is cleft like that of a hare, throngh which, when they are enraged, they spit, even to ten paces distance, a sort of juice, which when it falls upon the skin, causes a red spot and great itching. The neck is long like that of a camel, the budy like that of a sheep, but with much longer legs. It yields strong and fine wool, and is also a beast of burden, and kept at an casy expence. It carries a burden a rast way without tiring; cats vory little, aud never drinks. A't 
night he lies down, and no blows can make him rise; or move one foot till morning.

A creature no less remarkable, but in a quite different way, is the Castor or Beaver. This creature is about four feet long, and fifteen inches broad: he is covered with two sorts of hair, one long, the other a soft down. The down, an inch long, is properly his cloathing, being extremely fine, and close laid upon theskin. The long hair is spread over all, to preserve it from dirt and wet.

Whether male or female, it has two bags under its belly, which contain a liquid substance that congeals in air, and aftords an excellent medicine, which we call Castoreum.

He Kas strong teeth rivetted fast in his jaws, to cut. wood, as well as chew his foud. His fore-feet are like those of an ape or squirrel, to hold what he eats in his paw, and with these he digs, softens and works the clay or loam for his habitation. His feet are remark. ably formed, more proper to swim than to walk with, the fire toes being joined together by a strong membrane. His tail is long, flattish, covered with scales, and constantly lubricated'with oil ; because, being an architect from his birth, he uses his tail as a hod, to carry his clay or mortar, and as a trowel to spread it. into an incrustation. Mean time the scales preserve it from being hurt by the burden; and the oil which he squeezes from his bags, and rubs on with his snout, from the noxious air and water.

As they like to live together, they chuse a sitnation near some rivulet. They first build a causeway, in which the water may rise level with the first story of their habitation. 'I'his is built of wood and clay, twelve feet thick at the bottom, lescending in a slope on the side next the water. The other side is perpen. dicular: the top of this is about two fect broad. They cut their wood, though as thick as one's thigh, into pieces, from two to six feet long, drive them into the earth with their tecth, and lace them together with 
boughs, closing all the opening within and without with a strong plaister made of clay. If the water in. crease upon them, they raise their wall higher. Know. ing their materials are more easily brought by water than by land, they watch its increase, to swim with mortar on their tails, and stakes between their teeth, to the place where they build. When the causeway is fiuished, they begin their apartments, which are oval, and divided into three partitions, one above another; but the walls of these are perpendicular, and only two feet thick. All the wood that projects, they cut of with their teeth, and rough-cast both the out and in. side of their work, with a mixture of clay and dry grass. The first partition being below the level of the dyke, is full of water, for they love to have their hinder part hanging in the water. The other two are above it, so that if the water ascend, they may ascend proportionably.

At the bottom of their building, they strike out two openings to the stream; one leads to the place where they bathe, the other to that where they ease nature.

They associate ten or twelve together, and propor. tion their house to their number. When all is finished below, they vault the top or roof in an aral form.

In summer they feed on fruits and plants, in winter on willow, ash, or other wood. This they collect and store up in time. They cut boughs from three to six feet long: the large piecesare brought to the magazine by several beavers, the smaller by one alone; but they take different ways, each having his path assigned, to prevent the labour being interrupted. They build up their pile with much art, which is proportioned to their number. A square pile of thirty feet, about ten feet deep, serves for ten beavers; but the wood is not piled up in one continued heap, the pieces are laid across one another, with cavities between for the con. reniency of drawing out what they want. They al. ways use first the parcel at bottom which lies in the water, and when it is taken up for use, they cut this wood into small pieces, and conrey it to their apart. 


\section{7}

ment, where the whole fanily come and receive their shares.

The feet of a female beaver, which a gentleman kept in England some years since, were webbed like those of a goose. The tail was scaly, and shaped like the blade of an oar; this she used as a rudder to steer herself, especially when she swam under water, which she would do for two or three minutes, and then come up to taise breath, sometimes raising only her nostrils above water. She swam swifter than any water fowl; and under water as swift as a carp. The hind legs being longer than the fore, make her walk slow on dry land, or rather waddle like a duck. If drove along fast, she could not run, but went by jumps, flapping her tail against the ground. She never made any noise except a little sort of a grunting, when angry or driven fast. As the beaver frequen/s the water like waterfowls, may not the castor be provided for him by nature to anoint his fur with, and to prevent the water from soaking to his skin ; and as it is impregnated with penetrating pungent particles, it may likewise contribute to keep off the chill, which the water might otherwise strike to his body when he remains long therein.

The Shamnoy, though a wild animal, is easily tamed, and is to be found only in rocky and muntainous places. It is about the size of a domestic goat; it is agreeably lively and actire beyond expression. The Shammoy's hair is short like that of the doe. In spring it is of an ash-colour, in autumu, a dun colour, inclining to black, and in winter, of a blackish brown. This animal is found in great plenty in the mountains of Dauphiny, of Piedmont, Saroy, Switzerland, and Germany. They are peaceful gentle creatures, and live in society with each other. They are found in flocks of froin four to fourscore, dispersed upon the crags of the mountains. The large males are seen feeding detached from the rest, except in rutting time, 
when they approach the females, and drive away the young.

It is to be observed, that this creature is extremely vigilant, and has an eye the most piercing in nature. Its smell also is not less distinguishing. When it sees its enemy distinctly, it stops for a moment, and then, if the person be near, in an instant flies off. In the same manner it can by its smell discover a man at a great distance, and gives the earliest notice. Upon any alarm, the shammoy begins his hissing note with such force, that the rocks and the forests re-echo to. the sound. The animal having reposed a moment, again looks round, and perceiving the reality of its fears, continues to hiss by intervals. During this time it seems in the most violent agitation; it strikes the ground with its fore-foot, and sometimes with both: it bounds from rock to rock; it turns and looks round; it runs to the edge of the precipice, and still flies with all its speed.

Its head is furnished with two small horns of about half a foot long; of a beautiful black. The ears are placed in a very elegant manner, near the horns, and there are two stripes of black on each side of the face, the rest being of a whitish yellow, which nerer changes. 'They run along the rocks with great ease and indifference, and leap from one to another, so that no dogs are able to pursue them. . They always mount or de. scend in an oblique direction, and throw themselves down a rock of thirty feet, and light with great secu. rity upon some excrescence or fragment on the side of the precipice, which is just large enough to place their, feet upon. The more craggy and uneven the forest, the more this animal is pleased with the abode, which thus adds to its security.

The Roe-Buck is the smallest of the deer-kind in our climate, and is now almost cxtinct, except in the IIighlands of Sectland. It is generally about three feetlong, and about two feet high. The horns are 


\section{9}

from eight to nine inches long, upright, round, and divided into three branches. The body is covered with very long hair, well adapted to the rigour of its mountainous abode.

As the stag frequents the thickest forests, and the sides of the highest mountains, the roebuck courts the shady thicket, and the rising slope. Although far inferior in strength to the stag, it is more active, and even more courageous. Its hair is always smooth clean, and glossy; and it frequents only the dryest places, and of the purest air. Though but a very little animal; yet, when its young are attacked, it: faces the stag himself, and often comes off victorious. All its motions are elegant and easy; it bounds without effort, and continnes the course with little fatigue. It is also possessed of more cunning in avoiding the hunter : and, although its scent is much stronger than that of the stag, it is more frequently found to make good a retreat. The stag never offers to use art until his strength is beginning to decline; this more cumung animal, when it finds that its first eiforts to escape are without success, returns upon its former track, again goes forward, aud again returns, until by its various windings, it has entirely destroyed the scent, and joined the last emanations to those of its former course. It then by a bound, goes to one side, lies flat upon its belly, and perinits the pack to pass by very near, without offering to stir.

The roe-buck differs from the stag also, in its natural appetites, its inclinations, and its whole habit of living. Instead of herding together, these animals live in separate families, the sire, the dam, and the young ones associate together, and never admit a stranger into their little community. All others of the deer-kind are incoustant in their affection; but the roe-buck never leaves its mate: and as they have been generally bred up together, from their first fawn. ing, the male and female never alter separate.

They drive away their fawus upon these occasions, the buck forcing them to retire in order to make 


\section{0}

room for a succeding progeny. However, when the season is over, the fawns return to their does, and remain with them some time longer; after which, they quit them entirely, in order to begin an independent family of their own.

When the female is ready to bring forth, she seeks a retreat in the thickest woods, being not less ap. prehensive of the buck, from whom she then separates, than of the wolf, the wild cat, and almost every ravening animal of the forest. She generally produces two at a time. In about ten or twelve days these are able to follow their dam, except in cases of warm pursuit, when their strength is not equal to the fatigue. Upon such occasions the tendermess of the dam is very extranrdinary, leaving them in the deepest thicket she offers herself to the danger, flies before the hounds and does all in her power to lead them from the retreat where she has lodged her little ones. Such animals as are nearly upon her own level she boldly encounters; attacks the stag, the wild cat, and even the wolf; and while she has life, continues her efforts to protect her young.

Of all animals of the deer kind, the rein-deer is the most useful. It is-a native of the icy-regions of the North, and cannot live in a more southern cli. mate. Nature seems to have fitted it entirely for that hardy race of mankiud that live near the pole. As these would find it impossible to subsist among their barren, snowy mountains, without its aid, so this animal can live only there. From it alone, the natives of Lapland and Greenland supply most of their wants. It answers the purposes of a horse, to convey them and their scanty furniture, from one moun. tain to another; it answers the purposes of a cow, in giving milk; and of the sheep, in furnishing them with a warm, though a homely kind of clothing. From this alone, therefore, they receive as many advantages, as we derive from three of our most useful creatures. It is lower and stronger built than the stag; its legs are shorter and thicker, and its hoofs 


\section{1}

much broader; its hair is much thicker and warmer, its horns much larger in proportion, and branch. ing forward over its eyes, its ears are much larger; its pace is rather a trot than a bounding, and this it can continue for a whole day; its hoofs are cloren and moveable, so that it spreads them abroad, as it goes, to prevent its sinking in the snow.

Lapland is divided into two districts, the mountainous, and the woody. The mountainous part is barren and bleak, excessively cold, and uninhabitable, during the winter. Still, however, it is the most desirable part of this frightful region, and is most thick. ly peopled, during the summer. The natives generally reside on the declivity of the monntains, three or four cottages together. Upon the appruach of winter, they migrate into the plains below, each bringing down his whole herd, which often amounts to more than a thousand, and leading them where the pasture is in greatest plenty. The woody part of the country is much more hideous: a frightful scene of trees without fruit, and plains without verdure. As far as the eye can reach, nothing is to be seen even in the midst of summer, but barren fields, covered only with moss, no grass, no flowery landscapes, only here and there a pine tree, which may have escaped the frequent conflagrations, by which the natives burn down their forests. This moss, however, which deforms the coun. try, serves for its only support, as upon it alone the rein deer can subsist. The inhabitants, who, during the summer, lived among the mountains, drive down their herds in winter, and people the plains and woods below.

There is something worthy our notice even in that despised animal, an ass. There is a much greater resemblance between the horse and the ass, than between the sheep and the goat. And yet the latter produce an animal, that is not barren; whereas the mule always is.

The She-ass is not less fond of her young, tian the 1 2 
male is of her. She will rush either through fire or water, to protect or rejoin it. An ass is often no less attached to his owner. He scents him at a con. siderable dislance, he distinguishes him from others, in a crowd. He knows the way wherein he has passed and the places where he inhabits.

When over-loaded he shews it by hanging down his head, and lowering his ears. If his eyes are co. vered, he will not stir a step; and if he is laid down in such a manner that one eye is corered with the grass, while the other is hidden with a stone, or whatever is next at hand, he will continue fixed in the same situation, and will not so much as attempt to rise, to free himself from those slight impediments. He walks, trots, and gallops like a horse, but is soon tired, and then no beating will mend his pace. It is in vain that his unmerciful rider exerts his whip or his cudgel : the poor little animal bears it all with patience, and does not offer eren to morc.

The Spaniards, of all people in Europe, seem to be acquainted with the value of the ass. They take allpre. cautions to improve the breel, and a jack-ass in Spain is above fifteen hands high. This animal, however, seems originally a natire of Arabia. A warm climate is known to produce the largest and the best, their size and spirit decline, in proportion as they ad. vance into colder regions.

In Guinea, they are larger and more beautiful, than even the horses of the same country.

In Persia, they liave two kinds; one of which is used for burthens, being slow and heary, the other is kept for the saddle, being smooth, stately, and nimble. An ass will live above sixty years. He sleeps much less than the horse; and never lies down for that purpose, unless very much tired. The sheass goes above gleven months with young, and never brings forth more than one at a time.

The mule may be engendered, either between a horse 
and a she-ass, or between a jack-ass and a mare. The latter bred is every way preferable, being larger, stronger, and better shaped. The common mule is found very serviceable in carrying burthens, particularly in mountains aud stony places. Their manner of going down the precipices of the Alps is very extraordinary. In these passages, on one side, are steep eminences, and on the other, frightful abysses; and, as they generally follow the direction of the mountain, the road, instead of lying in a level, forms at every little distance steep declivities, of several hundred yards downward. These can only be de. scended by mules, and the animal itself seems sensible of the danger. When they come to the edge of one of these descents, they stop of themselves without being checked by the rider; and, if he inadrertently attempts to spur them on, they continue immorable. They seem ruminating and preparing themselves for the encounter. They not only attentively view the road, but tremble and snort. Having prepared for the descent, they place their fore-feet in a posture, as if they were stopping themselves; they then put their hiuder feet together, but a little forward, as if they were going to lie down. In this attitude, having taken as it were a survey of the road, they slide down with the swiftuess of a meteor. In the mean time, all the rider has to do, is to keep himself fast. on the saddle, without checking the rein, for the least. motion is sufficient to disorder the mule; in which case they both unavoidably perish. But their ad. dress in this rapid descent, is truly wouderful; for in their swiftest motion, when they seem to have lost all government of themselves, they follow exactly the different windings of the ruad, as if they had previously settled in their minds the route they were to follow. In this journey, the natives who are placed along the sides of the mountains, and hold by the roots of the trees, animate the beast with shouts, and - encourage him to perseverance. 
There are but three animals of the horse kind. The Horse, which is the most stately and courageous, the $\triangle$ ss which is the most patient, and the Z'ebra which is the most beautiful, but at the same time the wildest animal in vature. Nothing can exceed the delicate regularity of this creature's colour or the stnoothness of its skin; but on the other hand, nothing can be wore timid, or more untaméable.

The Zebra, or wild ass, is chiefly a natire of the sonthern paris of Africa, and there are whole herds of them often seen feeding in the extensire plains near the Cape of Good Hope. However, their watchfulness is such, that they suffer nothing to come near them; and thcir swiftness so great, that they readily Jeave every pursuer far behind. The zebra, in shape, rather resembles the mule than the ass. Its ears are not so long as those of the ass, and yet not so small as in the horse-kind. Like the ass its head is large; its back straight, and its tail tufted at the end; like the horse, its skin is smooth and close, and its hind quarters round and fleshy. But its great beanty lies in the amazing elegance of its colours. In the male, they are white and brown; in the female white and black. These colours are disposed in alternate stripes orer the whole boly, and with such exactness and symmetry, that one would think nature had employed the rule and compass to paint them. These stripes which, like so many ribbons are laid all over its body, are narrow, parallel, and exactly separated from each other.

It is now not known, what were the pains and the dangers which were first undergone to reclaim the breed of horses from savage ferocity, these no doubt made an equal opposition; but by biing opposed by an industrious and enterprising race of mankind, their spirit was at last subdued, and their freedom re. strained.

It is otherwise with regard to the zebra : it is the 


\section{5}

native of countries where the human inhabitants are but little raised above the quadruped. The natives of Angola or Cafraria, have no other idea of advantage from horses, but as they are good for food; neither the fine stature of the Arabian courser, nox the delicate colourings of the zebra, have any allurements to a race of people who only consider the quantity of flesh, and not its conformation. The delicacy of the zebra's shape, or tho painted elegance of $\mathrm{fts}$ form, aro 110 more regarded by such, than by the lion that makes it his prey. Perhaps the zebra may have hitherto continued wild, because it is the native of a country where there have been no efforts made to reclaim it. All pursuits then were rather against its life than its liberty; the animal has thus been long taught to consider man as its mortal enemy: and it is not to be wondered, that it refuses to yield obedience where it has 80 seldom experienced mercy.

All animals secm perfectly to know their enemies, and to aroid them at the same time; which we can. not account for. Instinct, indeed, may teach the deer to fly from the lion; or the mouse to avoid the cat :-but what is the principle that teaches the dog to attack the dog-butcher wherever he sces him ? In China, where the killing and dressing dogs is a trade, whenever one of these move out, all the dogs in the village, or the street, are sure to be after him.

I have seen, (says Dr. G-) more than one instanca of the same kind among oursclves. I have seen a poor fellow, who made a practice of stealing and killing dogs for their skins, pursued hue and cry for three or four streets together, by all the bolder breed of dogs, while the weaker flew from his presence with affright.

How these animals could thus find out their enemy and pursue him, is unacconutable; but such is the fact; and it not only obtains in dogs, but in several other animals, though perhaps to a less degree.

The noise of the zebra is neither like that of a. 
horse or ass, bet nore resembling the confused bark. ing of a mastiff dog. In the two, which I saw, there was a circumstance, that seem to have escaped naturalists, which is, that the skin hangs loose below the jaw, upon the neck, in a kind of dewlap, which takes away muck from the general beauty.

The Squirrel is a beautiful little animal; which from the gentleness of its manners, deserves our pro. tection. It is not hurtful. Its usual food is fruits, nuts, and acorns ; it is cleanly, nimble, active, and industriqus; its cyes are sparkling, and its physiog. nomy marked with meaning. It generally like the bare and rabit', sits upon its hinder legs, and uses the fore paws as hauds; these have five claws as they are called, and onc of them is separated from the rest like a thumb. This animal secins to approach the nature of a bird, from its lightness and surprising agility. It seldom descends to the ground, except in case of storms, but jumps from one branch to another; feeds in spring, on the buds and young shoots, in summer, on the ripening fruits; and particularly the young coves of the pine tree. In autumn it has an exten. sive variety, the acorn, the filbert, the chesuut, and the wilding. This season of plenty, however, is not spent in idle enjoyment; the provident little animal gathers at that time its provisions for the winter, and cautiously foresees the season when the forest shall be stripped of its leaves and fruitage.

Its nest is generally formed among the larre branches of a great tree, where they begiil to fork off into small ones. After chusing the place where the timber begins to decay, and a hollow may easily be formed, the squirrel begins by making a kind of level between the forks; and then bringing moss, twigs, and dry leares, it binds them together with great art, so as to resist the most violent storm. This is corered on all sides, and has but a siugie opening at top, which is just large enough to almit the little animal; and this opening is itself defended from the weather 
by a kind of canopy that throws off the rain, though never so heavy. The nest thus formed with a very little opening above, is nevertheless, very commodious and roomy below : soft, weil knit together, and every way convenient and warm. In this retreat the little animal brings forth its young, shelters itself from the heat of the sun, which it seems to fear, and from the storms and inclemency of the winter, which it is still less capable of supporting. Its provision of nuts and acorns is seldom in its nest, but in the hollows of the tree, laid up carefully together, and never touched but in cases of necessity. Thus one single tree serves for a retreat and a store-house, and without leaving it during the winter, the squirrel possesses all those enjoymen's that its nature is capable of receiving.

The Marmot is almost as big as a hare, but is more corpulent than a cat, and has shorter legs. Its head pretiy nearly resembles that of a hare, except that its ears are much shorter. It is clothed all orer with very long bair, and a shorter fur below. These are of different culours, black and greý.

The length of the hair gives the body the appearance of grcater corpulenec than it really has, and at the same time shortens the feet so that its be!ly secms to touch the ground. Its tail is tufted and well furnished with hair, and it is carried in a straight direction with its body. It has five claws: behind, and only four before. These it uses as the squirrel does, to carry its food to its month, and it usually sits upon its hinder parts, to feed in the manner of that little animal. It is readily taught to dance, to wicld a cud. gel, and to obey the voice of its master. Like the cat, it has an antipathy to the dog, and when it becomes familiar to the family, and is sure of being supported by his master, it attacks and bites even the largest mastiff. From its squat muscular make, it has great strength joined to great agility. However, it is in general a very inoffensive animal; and, except its enmity to dogs, seems to live in friendship with is. 
crery creature, unless when provoked. As its legs are very short, and made somewhat like those of a bear, it is often seen sitting up, and even walking on its hind legs. Like all the hare kind, it runs much swifter up hill than down; it climbs trees with great ease, and runs $1 p$ the clefts of rocks, or the contiguous walls of houses with great facility.

Those arms which the Hedge-hog possess in minia. ture, the Porcupine has in an enlarged degree.

In the one, the spines are but an inch long; in the other, a foot. The Porcupine is about two feet long, and fiftcen inches high. It is covered with quills from ten to fourteen inches long, resembling the barrel of a goosequill in thickness; but tapering and sharp at both ends. Each quill is thickest in the middle : and inserted into the animal's skiu, in the same manner as feathers in birds. The biggest are often fifteen inches long, and a quarter of an inch in diametex, extremely sharp, and capable of inflicting a mortal wound. They are harder than common quills, and solid at the end which is not fixed in the skin. All these quills incline backwards, like the bristles of a hog; but when the animal is irritated, rise and stand upright.

Such is the formation of this quadruped, in those parts in which it differs from most others. As to the rest of its figure, the muzzle bears some resemblance to that of a hare, but black; the legs are very short and the fcet have fire toes, both before and behind, and these, as well as the belly, the head, and all other parts of the body, are covered with a sort of short air, like prickles; there being no part, except the ears and the sole of the foot that is free from them: the ears are thinly covered with very fine hair, and are in shape like those of mankind: the ejes are small like those of a hog, being only one third of an inch from one corner to the other. After the skin is taken off there appears a kind of paps oin thuse farts of the body from whence the large 


\section{I79}

quills proceed; these are about the size of a small pea, each answering to as many holes as appear on the outward surface of the skin, and which are about half an inch deep, like as many hollow pipes, wherein the quills are fixed, as in so inany sheaths.

This animal partakes much of the nature of the hodge-hog; having this formidable apparatus rather to defend itself, than annoy the enemy. Indeed many have supposed that it was capable of discharging at its foes, its quills. But, it is now well known that its quills remain fixed in the skin, and are then only shed, when the animal moults them, as birds do their feathers.

The Pangolin, a native of the tarrid climates of the ancient continent is, of all animals, the best pro. tected from external injury. It is three or four feet long, or taking in the tail, from six to eight. It has a small heal, a very long nose, a short thick neck, a long boily, legs very short, and a tail extraordinary long. It has no teeth, but is armed with five toes on each foot, with long white claws. But what it is chiefly distinguished by, is its scaly covering. These scales defend the animal on all parts, except the under part of the head and neck, under the shoulders, the breast, the belly, and the inner side of the legs; all which parts are covered with a smooth, soft skin, without hair. The scales of this extraordinary creature are of different sizes, and different forms, and stuck upon the body somewhat like the leares of an artichoke. The largest are near the tail, which is covered with them like the rest of the body. These are above three inches broad, and about-two inches long; thick in the middle, and sharp at the edges. They are extremely hard, like horn. They are convex on the uutside, and a little concave on the inner, one edge sticks in the skin, while the other laps over that immedrately behind it. Those that cover the tail are so hard, when the animal has acquired its full growth, as to turn a musquet-ball. 
This lapped round the rest of the body, and being efended with shells even more cutting than any other art, the creature continues in perfect security. Its hiclls are so large, so thick, and so pointed, that they repel every animal of prey, they make a coat of armour that wounds while it resists, and at once protects and threatens. The most cruel beasts of the forest, the tiger, the panther, and hyæna, make vain attempts to force it. They roll it about, but all to no purpose ; the pangolin remains safe while its in. vader feels the reward of its rashness.

The Armadillo is chicfly an inhabitant of South America; a harsless creature, incapable of offending any other, and furnished with a peculiar covering for its own defence.

This animal being corered like a tortoise, with a shell, or rather a number of shells, its other propor. tions are not easily diecerned. It appears at first view a round mishapen mass, with a long head, and a vcry large tail sticking out at either end.

It is of different sizes, from a foot to three feet long, and covered with a shell, divided into several pieces, that lap over each other, like the plates in the tail of a lobster. This covers the head, the neck, the back, the sides, the rump, and the tail to the very point. The only parts to which it does not extend are the throat, the breast, and the belly, which are covered with a white soft skin. By this means the animal has a motion in its back, and the armour gires way to its necessary inflexions. These shells are differently coloured in different kinds. But most usually they are of a dirty grey. This colour in all arises from another peculiar circumstance in their conformation; for the shell itself is covered with a softish skin, which is smooth and transparent.

Beasts may be considered as a numerous groupe, terminated on every side by some, that but in part deserve the name. On one quarter wo see a tribe 


\section{1}

covered with quills, or furnished with wings, that lift them among the inhabitants of the air, on ano. ther, we behold a diversity clothed with scales and shells, to rank with insects; and still on a third, we see them desceuding into the waters, to live among the mute tenants of that element. We now come to a numerous tribe, that seem to make approaches even to humanity, that bear an aukward resemblance of the human form, and discover the same faint efforts at intellectual sagacity.

Animals of the monkey class are furnished with hands instead of paws, their ears, eyes, eye-lids, lips, and breasts, are like those of mankiud: their internal conformation also bears some distant likeness; and the whole ofiers a picture that may mortify the pride of such as make their persons the principal objects of their admirations.

These approaches, however, are gradual, and some bear the marks of our form, more strongly than others.

In the Ape-kind we see the whole external machine strongly impressed with the human likeness; these walk upright; want a tail, have fleshy posteriors, have calves to their legs, and feet nearly like ours.

In the Baboon-kind, we perceive a more distant approach; the beast mixing in every part of the animal's figure, these generally go upon all fours; but some, when upright, are as tall as a man: they have short tails, long smouts, and are possessed of brutal fierceness.

The Monkey-kind are remored a step further: these are much less; with tails as long as their bo. dies, and flattish faces.

Lastly, the Opossum.kind, seem to lose all resem. blance of the human figure, except in having hands, their noses are lengthened out, and every part of 
their bodies totally different from the haman; how. ever, as they grasp their food, with one hand, which beasts cannotdo, this single similitude gives them an air of sagacity, to which they have scarce any other pretensions.

The Baboon, is from three to four feethigh, very strong built, with a thick body and limbs, and caninr teeth, much longer than those of men. It walks more commonly upon all fours than upright, and its hands as well as its feet are armed with long, sharp claws, instead of the broad, round nails of the apekind.

At the Cape of Good Hope, they are under a sort of natural discipline, and go about whatever they undertake with surprising skill and regularity. When they set about robbing an orchard or vineyard, (for they are extremely fond of grapes, and apples) they go in large companies, and with pre-concerted delibe. ration; part of them enter the enclosure, while one is set to watch. The rest stand without the fence, and furm a line reaching all the way fom their fellows within to the rendezvous without, which is generally in some craggy mountain. Every thing lieing thus disposed, the plunderers within the orchard throw the fruit to those that are without as fast as they can gather it; or, if the wall or hedge be high, to those that sit on the top; and these hand the plunder to those next them on the other side. Thus the fruit is pitched from one to another all along the line, till it is safely deposited at their head quarters. They catch it as readily as the most skilful tennis-player can a ball; and while the business is going forward, a profound silence is observed. Their sentinel, during this whole time, continues upon the watch, and if he perceives any ône coming, instantly sets up a loud cry, on which signal, the whole company scamper off. Nor yet are they willing to go empty handed ; for if they be phundering a bed of melons, for instance, they go off with one in their mouths, one in their hands, and one under their arm. If the pursuit is hot, they c'rop first that from under their arm, then that from their hand; 


\section{3}

and, if it be continued, they at last let fall that which they had kept in their mouths.

The Chimpanaze is an animal found in Angola, nearly approaching to the human figure; but of a fierce disposition, and remarkably mischievous. In the year 1738, one of these creatures was brought over to England. It was about twenty months old. ['The parent had it in her arms, when she was killed; she was five feet high.] It was of the female sex, naturally walked erect, was hairy on some part of the body and limbs, and of a strong, muscular make. It would eat any coarse food, but was very fond of tea, which it drank out of a cup, with milk and sugar, as we do. It slept in the manner of the buman species, and its voice resembled the human, when people speak very hastily; but without any articulate sounds. The males of this species are very bold, and will fight a nian, though he is armed. It is said they often assault and ravish the negro women, when they meet thein in the woods.

There is another strange species of monkey found in the West Indies, of the size of a Fox. Its face is raised high, its eyes black and shining, and its ears small aud round. His hairs are so nicely disposed all orer the borly, that he appears "perfectly. smooth : and they are much longer under the chin, so that they form a kind of beard there.

These are found in great numbers in the woots, and make a loud and frightful noise. But it is very common for one only to make a noise, and the rest to form a mute assembly round him.

Marcgrave says, "I have frequently seen great numbers of them, meeting about woon : at which time they formed a large circle, and one placing himself above the rest, began to make a loud noise. When he had sung thus by himself, for some time, the rest all remaining silent, he lifted up his hand, and they a!l instantly joined in a sort of chorus. 


\section{4}

This into!erable yell continued, till the same mon. key, who gave the signal for their beginning, lifted up his haud a second time. On this they were all silent again, and so finished the business of the assembly.

The Opossum, is about the size of a Cat, only more corpulent, and its legs more robust. It is of a kind of Chesnut colour, very bright and glossy. Its licad is long, and terminates in a snout, somewhat like a Fox's. The tail is long, and much resembles that of a rat, which it twists abont with a surprising facility. The legs being short, the body is carricd at no great distance from the ground. On the belly of the female, a bang is formed by the skin being doubled. It is not very deep, the closest part being toward the upper part of the body, and the open part toward the lower. This is covered with fur, like the rest of the body, so that it is not very obvious to the sight.

It is a harmiess, but likewise a defenceless animal : and the young of no creature, are produced so snall and tender, in respect of the parent animal. Therefore that bag is exiremely useful to them. They are cherished by the warmth of the parent's body, till toward noon : then they go abroad till at the first warning by the evening cold, they retire into their lodging again. Nor is this all the help which it affords. For as the tender young of the opossum are delicate morsels, they would be exposed to the rage of many animals, both by day and night. But the body of the parent is a safe and ready receptacle for them. I By day she is as watchful over her brood as a hen over her chickens. She is alarmed at the slightest appearance of danger, and by a noise which they well understand, instantly calls them into her bag. At night she constantly takes them in, and consults for herself and them in a very uncommon manner. There are those among the devourers of her young, who will climb a tree after her. Therefore when she 


\section{5}

has climbed, to secure herself and her young still far. ther, she twists her tail twice round some small bough, and then drops from it. There she hangs with her hoad downward : and whenever she pleases, she reco. vers the branch with her feet by a swing, and loosen. ing her tail, walks about as usual.

To cnable her thus to hang, there are spikes or hooks in the under side of the vertebre of the tail. Indsed, in the first three vertebre there are none; for they would be of no use. But they are found in all the rest. They are placed just at the articulation of each joint, and in the middle from the sides. No. thing could be more advantagcously contrived. For when the tail is twisted round a bough, these hooks easily sustain the weight. And there is no more la. bour of the muscles required, than just to bow or crook the tail.

Another animal of a very peculiar kind is an Ich. neumon. It is of the weasel-kind, with a longer and narrower body than a cat, something approaching to the shape and colour of a badger. Its nose is black and sharp, like that of a ferret. Its colour is a yellowish grey. Its legs are short, and each of its feet hasfive toes. Its tail is very long; its tecth and tongue much like those of a cat. It is a very cleanly animal, very brisk and nimble, and of great courage. It will engage a dog, and will destroy a cat, by three bites on the throat. But it is quite inoffensive to mankind, and is kept tame in Egypt, running about tho house, destroying all vermin, and playing tricks, like spaniels.

When wild, he cannot orertake any nimble animal. But he makes this up by assiduity. His legs being short, he is not much seen; but he has a way of concealing himself yet more, by crawling with his belly close to the ground, which he does all day long. But on the least noise (for his hearing is exceeding quick) he starts up erect on his hinder legs. If the noise is made by any reptile, bird, or small beast, he observes 


\section{6}

where abouts it is, places his nose direclly in a line with it, and begins to move toward it. He is silent and slow, but constant in his approach ; often stôp. ping to liear or look forward, and knows exactly. where the creature is : when he is got within about five feet, he stops. Nature, which has denied him speed, has given him strength to leap, beyond most other creatures. Having taken good sim, he springs from the place, and falls directly on his prey. Thus he deals with beasts and biris. But to serpents he gives chace, and to aroid their bite, always scizes them by the neck.

Gesner tells, that the Ichnenmon is not only an enemy to serpents themselves, but to their eggs also : which he hunts after continually and destroys, though he does not feed upon them.-How mercifully has God given this animal in the countries where those terrible reptiles most abound! And which, without this provision, would be so over-run with them, as to be uninhabitable.

The Jackal is of the carnirorous kind. They hunt byscent and go in packs. They pursue with patience, rather than swiftness, and excite each other by a spirit of enulation.

It goes for current that the Jackal discovers the lion's prey; that each of these retains one of them, and having satisfied himself, lets his deperident feed on the offals of his repast.

But the truth is, there are great numbers of jackals in some woods, and when one of these sees a stag, or otherlarge beast, which is not a beast of prey, he sets uphis cry, which is like that of a hound and follows it. As he cuntinues his cry, the other Jack. als that are within hearing follow likewise. And could the creature oustrun those that began the chace, there is a continual supply; so that it cannot escape. When they have run it down, they worry it at once, and it is devoured almost in an instant. After this the jackals disperse, till another cry invites them. 


\section{7}

They hunt generally in the night, and in the parts of the East where they are most frequent, there never is a night but they are heard, in one part or other of the woods. The other beasts of prey understand the sound : and frequently profit by it. If a lion, tyger, or leopard happens to be near, he hears the cry, and stands upon the watch. These large animals are all very swift, but they are lazy, and never make long pursuits. If the creature pursued be far off, and runs another way, they never trouble themselves about it. But if it be near, or if it runs toward the place where the lion is, he will dart out upon it as it goes by. And the little animals that hunted it down must stand by, and be content with what their master leaves.

The Sable-mice, (which were first observed in Lapland, in 1697) are near as big as a small squirrel. Their skin is streaked and spotted with black and light brown. They have two teeth above, and two under, very sharp and pointed. Their feet are like a squirrel's. They are so fierce, that if a stick be held out to them, they will bite it, and hold so fast, that they may be swinged about in the air. In their march they keep a direct line, generally from north. east to south-west. Innumerable thousands are in each troop, which is usually a square. They lie still by day, and march by night. The distance of the lines they go in, parallel to each other, is of some ells. Whaterer they meet in their way, though it were a fire, a dcep well, a torrent, lake, or morass, they avoid it not, but rush forward. By this means many thousands of them are destroyed. If they are met swimming over a lake, and are forced out of their course, they quickly return into it again. If they are met in woods or fields and stopt, they raise them. selves on their hinder legs, like a dog, and make a kind of barking noise, leaping up as high as a man's knee, and defending their line as long as they can. If at last they are forced out of it, they creep into 


\section{8}

holcs, and set up a cry, sounding like biab, biab. If a house stands in their way, they never come into it, but stop there till they die. But they will eat their way through a stack of corn or hay. When they march through a meadow, they eat the roots of the grass : and if they encamp there by day, they utterly spoil it, and make it look just as if it had been burnt. They are exceeding fruitful; but their breeding does not hinder their march. For some of them have been observed to carry one young in their mouth, and another upon their back. In winter they live under the snow, having their breathing-holes, as hares and other creatures have.

I would mention only two creatures more, very ex. traordinary, and yet but little known.

The Glution is frequent in the forests of Germany. It is rarely seen twice of the same figure. It is of the weasel-kind, and is in its middle state, about the size of a turn-spit dog. Its body is long, its legs short. Its colour is brown, with a reddish tinge; but its breast and belly are whice. The tail is long and bushy: the head small and sharp at the nose. The tceth are excceding sharp, and the claws sharper than almost in any creature.

This is the most hungry animal in the world, but is ill provided for catching its prey. Most creatures can out-run it, and itself can scarce run away from any thing. But what he wants in swiftness, he has in climbing, which he performs to admiration : its sharp claws enabling it to run up a tree as fast as on the ground. Its usual place is some large and spreading oak, chose both for safety and for catching its prey. He squats all day on some large branch; and if nothing offers below, he preys in the night on whatever creatures he can find on the tree above. Many birds roost on such trees, which he climbs softly to, and devours. But his farourite food is larger animals. Ile will lie many days on a slanting bough; and 
when any which he likes comes underneath, he drops down upon them. Hares and rabbits seldum escape him; but he chooses rather a goat, or any creature of that size. When one of these comes under. the tree, he creeps from bough to bough, till he comes just over it, and then drops down upon it. He always contrives to fasten on the neck. In an instant he fixes both his teeth and claws, and lies across the neck, near the shoulders. Here he is secure; and while the poor creature runs with all its speed, he is feed. ing on its tlesh. At length it drops, and be continues eating in the same ravenous manner, till from a mere skeleton, his back becomes round, and his sides swelled out like a ton. Still he continues to eat, till he can eat no longer. He too drops down, and lics panting for breath. He resembles a dead carcase, swelled and ready to burst with lying in the sun: and being unable to move for a long time, is frequently destroyed, and sometimes perishes without an enemy.

The God of nature seems to have formed the Sloth, to represent to us in a strong light, that odious and despicable vice, from which it takes its name. Its body is short, its head small, and it has scarce any tail. Its fur is long, thick, and of a greyish green, so that when seen on the bough of a tree, it appears only like an excrescence or a cluster of moss. It is about the size of a cat, but the legs are short, as is the neck : and its long and thick covering, renders it so shapeless, that it secms only an irregular Jump of liring matter. Its little and remarkably ugly head stands close between the shoulders. The face has much of the monkey aspect. Its small and heary eyes, are always half shut, and it has no appearance at all of any cars. Its feet are flat and very narrow, but armed with sharp claws, for laying hold on the bark of a tree, by striking deep into it.

He rarely changes his place; and never, but when compelled by absolute necessity. As upon the ground 
190.

it would be a prey to every other animal, so its con. stant residence is on a tree. Here it is safe from all animals, but those who climb these trees for the birds that roost on them. The leaves and tender part of the tree are itsfood, and serve it for drink as well as meat. It never moves to another branch, till it has devoured all the nourishment upon that where it is stationed : nor from one tree to another, till the first is wholly withered and wasted.

It is observable, the Sloth always ascends to the top of a tree, only baiting as he goes, before he begins his devastations. And this is doubtless from the in. stinctive guidance of nature. For was it to begin eating upward, when it had levoured all, it would have to climb down from the top of a dead tree, and would be half starved in its journey. But this is not all. The havoc which one sloth makes on the largest tree is easily seen. For he eats not only the leares, but all the buds and bark, leaving only a dead branch : so that unless the same thing might happen by accident this would betray the creature. It does so happen; and trees then put on the same form, as when they are left by the sloth. But they always die at the top first, and so gradually downward. This animal therefore, wonderfully taught, begins its havoc at the top. As it feeds, the tree decays; but its decay is in the course of nature. The decay spreads down. ward; and when he has eaten the last of his pro. vision, he is near the ground, and has only to walk away to another tree. But if it is at any distance, his motion is so slow, that he grows quite lean in the expedition.

$\Lambda$ s the Sloth brings forth her young in the hollow of a tree, so is she led by the same wouderful in. stinct to conduct them to the topmost branches, as soon as they crawl out. When she is big with young, she climbs some old, hollow tree; and having fixed on a convenient spot for her young, she climbs to the very highest bough, and there feeds faster than usual. When she is full, she descends with unaccustomed 
haste, and brings forth one, two, or three young ones. It is well she is full fed ; for she is to support these with her milk, till they can crawl out, without having any supply herself. She is round and fleshy when she retires for this purpose, but a mere skeleton when she comes out. She crawls as well as she can, to the part where she left off feeding, and her young follow her. Nor will she touch any thing in the way, howerer both her hunger and laziness may prompt her to it.

It is the most timorous of all creatures. And with reason: for it can neither fight nor fly. While it is journeying on the ground, the tread of a human foot shakes the earth enough to put it into terrors. It trembles: the hear is turned about every way, and the mouth is open to cry like a young kitten.

Insignificant as this creature is, there is a special Providence in the formation and care of it. Not designed for walking, its claws enable it to climb, and then to hold fast in its station. Helpless as it is, the universal Provider has assigued it a place of safety, where it finds plenty of food; and as it cannot easily scek for drink, it has no need of any. To render it the less obnoxious to pursuit, its colour secures it even from view : and its amazing instinct of feeding from the top to the bottom, proves a designing and directing Hand.

Before I proceed to some general reflections upon beasts, I beg leare to take notice of one circumstance, relating to several species of them, which is very strange, though very common.- - The horns of many animals fall off every year, and new ones come in theirplace. Our deer drop them in March, and the new horns are full grown by the July following. We may justly rank this, among the most wonderful phenomena of nature, which yields nothing analogous to the growth of such hard solid bodies, of so great a bulk, in so short a time. Many idle opinions have been maintained, concerning the cause of their falling 
off. The fruth secms to be this : they are a sort of vegetables, growing on animals, as the uails and hair on man, and feathers on birds. And there is some analogy between the growth of them, and that of branches and leaves on trees. Trees commonly drop their leaves in autumn, because the nourishing juice flows into them no longer. And at certain periods, these parts of the animal drop off, because the blood and juices cease to flow in them. At this time, the hollow part at the root of the horn grows hard, and the pores through which the juices passed, grows up. And as no more nourishment can then be carried to the horn, it decays and falls off. It is probable this stoppage of the pores happens, as soon as the horns are at their full growth. But they are so fixed to the head, that it takes a long time for them to loosen and fall. Whercas in leaves, their stalks are so tender, that when the juice ceases to flow, they presently wither and fall.

The analogy between the falling off of deers horns and the falling of leaves and ripe fruit from the tree, will receive light from observing the process of nature in the latter case. If the stalk from which a ripe orange has fallen, be compared with that part of a deer's forehead, frow which a horn is just fallen, it will plainly appear that nature has operated by the samelaws in both. The young horns, while yet soft, are full of blood-vessels; and if cut off, especially near the head, bleed violently. By these vessels they are supplied with nourishment for their growth. But these dry up, when there is no farther occasion for them. And hence it is, that no ill symptoms attend the falling off of these parts, when full grown.

So far we may give a probable account:- - But who can account for this, that if a stag be castrated, while be is so young as not to have horns, he will never have any : and if castrated afterward, while his horns are on, he will never cast them? 


\section{3}

10. It remains only to add a few reflections. And first, what admirable wisclom is displayed, in the motion of various animals, suited to their various occa. sions ! In some, their motion is swift; in others, slow; and both dirersified a thousand ways.

And first, for swift or slow motion. 'This is exactly proportioned to the occasion of each animal. Rep. tiles, whose food, habitation, and nests lie in the next clod, plant, tree, or hole, or which can bear long hunger, need neither legs, nor wings, but their vermicular motion answers all their purposes.

Beasts, whose occasions require a larger room, have accordingly a swifter motion : and this in various de. grees, answerable to their range for food, and the enemies they are to escape from.

But as for birds who are to traverse vast tracts of land and water, for their food, habitation, breeding their young, and for places of retreat and security, from various inconveniences : they are endned with the faculty of flying; and that swiftly or slowly, a long or short time, according to their occasions. In all this, the wisdom of .God appears, ordering all things well.

Again. How admirahle in the motion of all creatures, is the neat, geometrical performance of it! The most accurate mathematician cannot prescribe a nicer motion than that they perform, to the legs and wings of those that fly or walk, or to the bodies of those that creep. Neither can the body be more completely poised, for the motion it is to have in every creature. From the largest elephant to the smallest mite, the body is exactly balanced. The head is not too heary, nor too light for the rest of the body, nor the rest of the body for it. The bowels are not too loyse, or so placed as to swag, overbalance, or overset the body : but well braced, and accurately distributed to maintain the equipoise of it. The motive parts also are admirably well fixed, in respect to the centre of gravity, placed in the very point which best serves to support and convey the borly, Every leg bears its 
true share of the weight. Aud the wings are so exactly placed, that even in the fluid medium, the air, the body is as truly balanced, as we could have balanced it with the nicest scales.

Yet again. What an admirable provision is made for the motion of some creatures, by temporary parts! Frogs, for instance, have tails in their tad. pole state, which fall off when their legs are grown out. The water-newt also, when young, has four fins, two on a side, to poise and keep the body up. right. But as soon as the legs are fully grown, these presently drop off.

Secondly, the bore of the gullet in all creatures, is answerable to their occasions. In a fox, which feeds on bones, (as in all ossivorous beasts) it is very large. But in a squirrel it is exceeding small, lest he should disgorge his meat in his descending leaps : and so in ratsand mice, which often run along a wall with their heads downward.

Thirdly, In all animals the strength and size of their stomach are proportioned to their food. Those whose food is more tender and nutritive, have it smaller, thinner, and weaker. Whereas it is large and strong in those whose food is less nutritive, and whose bodies require large supplies.

All carnirorous beasts have the smallest stomachs, as flesh gocs the farthest. Those that feed on fruits and roots hare them of a middre size. Sheep and oxen, which feed on grass, have the greatest. Yet the horse, hare, and rabbit, though granivorous, have comparatively small ones. For a horse is made for la. bour, and both this and the bare for quick and continued motion : for which the most easy respiration and so the freest motion of the diaphragm is requisite. But this could not be, did the stomach lie big and cumbersome upon it, as it does in sheep and oxen.

Another very remarkable circumistance is, that those animals which have teeth on both jaws, have but one stomach; whereas most of those which have 


\section{5}

no upper-teeth, or no teeth at all, have three sto. machs. For the meat which is first chewed, is easily digested; but that which is swallowed whole, requires a stronger concoctive power.

Fourthly, All the parts of the same animal are adlapted one to the other. So for instance, the length of the neck is always proportioned to that of the legs. Only the elephant has a short neck : for the weight of his head and teeth, would to a long neck, have been insupportable. But then he is provided with a trunk, which abundantly supplies the defect. In other beasts and birds, the neck is always commensurate to the legs : so that they which have long legs, have long necks, and they that have short legs, short ones ; as may be observed in lizards of all kinds and the king of them, the crocodile. And creatures that have no legs, as they want no necks, so they have none, as fishes. This equality between the length of the neck and legs, is peculiarly seen in beasts that feed on grass. Their legs and necks are very near equal. Very near, I say, because the neck must necessarily bave some advantage; for it cannot hang serpendicular, but must incline a little.

Moreover, as these creatures must hold their heads down, for a considerable time together, which would be very laborious and painful for the muscles, therefore on each side of the neck, nature has placed a thick and strong ligament, capable of stretching and shrinking again as need requires : this, which is vulgarly called white leather, extends from the head (to which, and the next vertebre of the neck it is fasten. ed at that end) to the middle vertebre of the back, to which it is knit at the other. And by the assistance of this, they are able to hold the head in that posture all day long.

Fifthly, The parts of all animals are exactly fitted to their manner of living. A notable instance of this <2 2 


\section{6}

is in the Swine. - His natural food being chiefly the roots of plants, he is provided with a long and strong snout; long, that he may thrust it to a convenient depth in the ground, without offence to his eyes; strong and conreniently formed, for rooting and turning up the ground. And besides, he has an extremely quick scent, for finding out such roots as are fit for him. Hence in Italy, the usual way of finding truffles, or subterraneous mushrooms, is by tying a cord to the hind.leg of a pig, and driving him before them into their pastures. They then observe where he stops and begins to root: and digging there they are sure to find a truffle. So in pastures where there are earth-nuts, though the roots are deep in the ground, and the leaves are quite gone, the swine will find them by their scent, and root only in the places where they grow.

Another instance of like nature we hare in the porpus (anciently written porc-pesce, that is, Swinefish) which rescinbles the hog, both in the strength of his snout and in the manner of getting his food. For the stomach of one of these when dissected, was found full of sand.eels, which lie deep in the sand, and cannot be gotten, but by rooting and digging there.

That very action, for which we look upon swine as unclean creatures, namely, wallowing in the mire, is designed by nature for a good end ; not only to cool their bodies (which fair water would do as well) but also to suffocate and destroy fleas, lice, and other insects, which are troublesome and hurtful to them. For the same reason, poultry and divers other birds bask themselves in the dust, in hot summer weather.

The variety of shape and colour observable in beasts, prevents any two from being exactly alike, as much as the human features distinguish mankind one from another. Wherefore then was this variety bestowed upon brutes? Are they at all sensible of 


\section{7}

such diversity? Are they the more happy, or more useful to one another for it ? No. This variety then is doubtless intended for the sake of man, to prevent confusion, and decide and ascertain his pro. perty. 


\section{8}

\section{CHAP. II. \\ OF BIRDS.}

1. Some general Remarks:

2. Of their Motion:

3. Brain:

4. Organs of Sensel

5. Iungs :
6. Stom ach and Bladder

7. Generation.

8. Of some particular Sorts of Bird:.

9. Reflections,

1. No part of nature is destitute of inhabitants. The woods, the waters, the depths of the earth, have their respective tenants; while the yielding air, and those tracts where man never can ascend, are also passed through by multitudes of the most beautiful beings of the creation.

Every order of animals is fitted for its situation in life: but none more apparently than birds. Though they fall below beasts in the scale of nature, yet they hold the next rank, and far surpass fishes and insects, both in the structure of their bodies and in their sagacity.

The body of man presents the greatest variety: beasts, less perfectly formed, discover their defects in the sim. plicity of their conformation : the mechanism of birds is yet less complex : fishes are furnished with fewer organs still; while insects, more imperfect than all, fill up the chasm between animal and vegetable nature. Of man, the most perfect animal, there are but three or four species; the kinds of beasts are more nume. rous; birds are more various still; "fishes yet more; but insects affurd an immense variety. 
In all birds, except nocturnal ones, the head is smaller, and bears less proportion to the body than in beasts, that it may the more readily divide the air in flying. Their eyes also are more flat and depressed, and a circle of small plates of bone, placed scale-wise under the outer coat of the organ, encompasses the pupil on each side to strengthen and defend it from in. juries. Besides this, birds have a kind of skin called the nictitating membrane, with which, like a veil, they can at pleasure cover their eyes, though their eyelids continue open. This membrane serves also to wipe, cleause, and probably to moisten its surface. The oyes, though they, outwarily appear but small, yet each almost equals the brain; whereas in man the brain is more than twenty times larger than the eye.

Hence it follows that the sense of secing in birds is infinitely superior to that of other animals. Indeed this piercing sight seems necessary to the creature's support and safety. Were it not sn, from the rapidity of the bird's motion, it would he apt to strike against every object in its way, and it conld scarcely find sub. sistence unless it could discern its food from above with astonishing sagacity. A hawk, for instance, perceires a lark at a distance, which neither men nor dogs could spy ; and a kite, from an almost imperceptible height darts down on its prey with the most unerring aim.

Granirorous birds, or such as live upon vegetables, have their intestines differently formed from those of the rapacious kind. Their gullet dilates just above the breast-bone, and forms itself into a pouch or bag called the crop. 'This is replete with salival glands, which moisten and soften the food it contains. After the dry food of the bird has been macerated, it passes into the belly, where, instead of a soft moist stomach, as in the rapacious kiucs, it is ground between two pair of muscles, cominonly called the gizzard, covered on the inside with a streng ridgy coat. These coats rubbing against each wher, are capable of attenuating the hardest substances; their action being often comparK 4 
ed to that of the grinding tecth in man and other animals.

Thus the organs of digestion are in a manner revers. ed in birds. Beasts grind their food with their teeth, and then it passes into the stomach, where it is softened and digested. On the contrary, birds of this sort first soften it in the crop, and then it is ground and comminuted in the stomach or gizzard. Birds are all careful to pick sand, gravel, and other hard substances, not to grind their food, as has been supposed, but to prevent the too violent action of the coats of the stomach against each other.

To birds, the return of spring is the beginning of pleasure. Those vital spirits which seemed locked up during winter, then begin to expand; regetables and insects supply abundance of food; and the bird having more than a sufficiency for its own subsistence, is im. pelled to transfuse life as well as to maintain it. Those warblings which had been hushed during the colder sea. sons, now begin to animate the fields; every grove and bush resounds with the challenge of anger, or the call of allurement. The delightful concert of the grove, which is so much admired by man, is no way studied for his amusement : it is the call of the male to the fe. male; his efforts to sooth her during the time of incubation, or a challenge between two males for the affections of some common favourite.

It is by this call that birus begin to pair at the ap. proach of spring, and provide for the support of a fu. ture progeny. The loudest notes are usually from the male; the hen expresses her consent in a short inter. rupted twittering. 'Their compact holds with unbroken faith : most birds live with inviolable fidelity together, and when one dies the other is always seen to share the same fate soon after. We must look for it in our fields and in our forests, where nature continues in unadulterated simplicity; where the number of males is generally equal to that of females: but the male of all wild birds is as happy in the young brood as the 


\section{1}

female. They both seem, at this season, transported with pleasure; every action testifies their tender solicitude.

But previous to laying, the work of nestling becomes the common care, and this is performed with no small degree of assiduity. It has been asserted that birds of one kind always make their nests in the same manner, and of the same materials ; but the truth is, they vary this as the materials, places, or climates differ. The red-breast, in some parts of England, makes its nest with oak leares, where they are in plenty, and in other parts with moss and hair. Some birds that with us make a very warm nest, are less solicitous in the warm climates. In general, however, every species of birds has a peculiar architecture of its own, and this adapted to the number of eggs, the tem. perature of the climate, or the heat of the animal's body. Where the egys are numerous, the nest is warm, that the animal's heat may be equally diffused to them all. Thus the wren, and all the small birds, make their nests very warm, for having many eggs, it is re. quisite to distribute warmth to then all; on the contrary, the plover, that has bat two eggs, the eagle, and the crow, are not so solicitous in this respect as their bodies are capable of being applied to the small number upon which th:y sit.

Nothing can exceed the patience of birds while hatching; neither hunger nor-danger can drive them from the nest. They are fat upon beginning to sit, yet hefore incubation is over, are usually wasted to skin and bone. Indeed ravens and crows, while the females are sitting, take care to provide them with food in abundance. But it is different with most of the smaller kinds; during the whole time the male sits near his mate upon some tree, and sooths her by his singing; and often when she is tired takes her place, and patiently coutinues on the nest till she returns.

So great is the power of instinct in these animals, that they cuntinue almost passive under its influence, is 5 


\section{2}

Yet, at the same time, the hen that has all this seeming ingenuity, in other respects, is without the least glimmerings of common sense; she mistakes a piece of chalk for an egg, and sets upon it in the same manner : she is insensible of any increase or diminution in the number of those she lays : she does not distinguish be. tween her own and those of another species; and when the birth appears of never so different a bird, will cherish it for her uwn.

As the principle which acts in these animals cannot be termed reason, so when we call it instinct, we mean something we have no knowledge of. It appears to me the immediate direction of Providence; and such an operation of the supreme Being as that which determines all the portions of matter to their proper centres.

While the young are yet unfledged, the old one takes care to provide them with a regular supply; when the family is fully plumed, and capable of avoiding danger by flight, they are then led forth when the weather is fine, and taught the paternal art of providing for their subsistence. They are led to the places where their food lies; they are shewn the method of discovering or carrying it away; and then led back to the nest for a day or two longer. At lengih, when they are qualified to shift for themselves, the old one takes them abroad, and leading them to the accustom. ed places, fursakes them for the last time, and all convection is at an end.

Birds in general, though they have so much to fear from man and each other, are seldom scared from their usual haunts. The greatest number remain contented where they have been bred. The rook, if undisturbed, never desires to leave his native grove; the black-bird still frequents its accustomed hedge; and the red. breast, though seemingly mild, claims a certain dis. trict, from whence he seldom moves, but drives out every one of the same species from thence without pity. They are excited to migrations by no other motixes but those of fear, climate, or huager. It is 


\section{3}

from one of these motives that birds of passage, every year, forsake us for some time, and make their regular returins. The canse of their retreat is, either scarcity of food, or the want of an asylum from man, during the time of courtship and bringing up their young. Thus the starling, at Sweden, at the approach of winter, finding subsistence no longer, descends into Germany; and the hen chaffinches of the same country are seen to fly every year through Holland, to pass their winter in a milder climate. Others prepare for longer journeys. Thus the quails, in spring, forsake the heats of Africa for the milder sun of Lurope; and when they have passerl the summer with us, steer their flight to enjoy, in Egypt, the temperate air. This with them seems a precuncerted underlaking. They unite together in some open place, for some days before their departure, and, by an odd kind of chattering, seem to debate on the method to proceed; then they all take flight together, and often in such numbers, that to marivers at sea, they seem like a cloud upon the horizon. The strongest, and by far the greatest number, make good their intention; but many there are, who grow weary in the way, and drop down into the sea, aud sometimes upon the decks of ships.

Of the vast quantity of water fowl that frequent onr shores, few are known to breed here. The cause that urges them to leave us seems to be, not mercly the want of food, but the desire of a secure retreat. Our country is too populous for birds so shy, as the greata est number of these are. When great part of our island was an uncultivated tract of woods and marshes, many species of birds, which now migrate, remained with us the whole year. The great Heron and the Crane, that have now forsaken this country, in former times bred familiarly in our marshes. Their nests, like those of most cloven-footed water-fowl, were built on the ground, and exposed to every iuvader; but as zural œconomy increased, thesceanimals were more and \& 6 


\section{4}

more disturbed. Once they had little to fear, as the surrounding marsh defended them from all the carnivorous surrounding quadrupeds, and their own strength from birds of prey; but by a long series of alarms, they have, at length, been obliged to seek, during the sunimer, some lanely habitation, at a safe distance from every destroyer.

Of the numerous tribes of the Duck-kind, we know of no more than five that breed here. The rest con. tribute to form that amazing multitude of water-fowl which annually repair to the dreary lakes and deseris of Lapland, from the more southern countries of Europe. In those solitary retreats, they perform the duties of incubation and nutrition in full security. There are few of this kind that may not be traced to the northern deserts, ta countries of lakes, rivers, swamps, and mountains, covered with thick and gloomy forests. In those regions, from the thickness of the foreste, the ground remains moist and penetrable during the summer -season; the woodcock, the suipe, and other slender-billed birds, can there feed at ease, while the web-footed birds find more than sufficient food from the number of insects which swarm to an incredible degree. The days there are long, and the beautiful nights afford them every opportunity of collecting so minute a food.

2. Birds have feathers which they expand in order to fly, the fine branches of which lie sa close together, that little air can insinua!e itself between them. Now when the column of air on which a body rests is specifically heavier than the body, it remains suspended in the atr; if it be lighter, the body sinks. Hence the Jarger space a body circumscribes, the more easily does the air sustain it: consequently the same birl which sinks when the wings are clos:d, is sustained when they are expanded. To this also the motion of the wings contribute: (as a body while moving swiftly nill swim in water, which immediafely sinks if that 


\section{5}

motion ceases.) And so do the feathers with which their bodies are clothed, which increase their bulk, but not their wcight in the same proportion.

The parts of birds chiefly concerned in flying, are the wings and the tail. By the first, the bird sustains and wafts himself along: by the second he is enabled to keep his body steady and upright, particularly in ascending and descending. It is by the largeness and strength of the pectoral muscles that they are qualified for flying. In men these are scarce a seventeenth part of the muscles of the body. In birds they considerably outweigh all the other muscles together. And this circumstance alone, the want of suitable muscles, makes all human attempts to fly void and vain.

Nevertheless the art of flying has been seriously at. tempted by many, in various ages, particularly in the time of our famous Friar Bacon, who lived about 500 years since, and whom his excellent works shew to have been a rare chymist, an excellent mathematician, a knowing mechanic, and a most accomplished experimental philosopher. Yet even he believed the art of flying possible, and says, he himself knew how to make an engine, in which a man sitting might be able to convey himself through the air like a bird. Nay, he alfirms, that there was then another person who had actually tried it with suecess.

In flying, the bird first bends his legs and leaps from the ground; then opens the juint of his $w$ ings so as to make a right line, perpendicular to the sides of his body. Being now raised and strongly vibrating his wings, the air re-acts as much as it is acted upon, and so protrudes his whole body; but in recovering his wing for fresh strokes, it has a great resistance to overcome. To elude this, the bony part of the wing, into which the feathers are inserted, moves sideways with its sharp end foremost, and the feathers follow it like a flag.

All birds have near their tail a little bag, which con. tains oil to moisten their feathers. Geese have two glands for the secretion of this; other birds only one. 
In this are divers little cells ending in two or three large ones, lying under the nipple of the oil-bag. This nipple is perforated, and being prest by the bird's bill, emits its oil.

In all birds that fly much, the wings are placed in the very best manner to balance their bodies in the air, and to give as swift a progression as they are severally capable of. Otherwise they would reel and fly unsteadily, as we see they do if we destroy the equipoise by cutting one of their wings.

And what nicety may we obserre, in a part no more considerable, than the vanes of the flag-feathers of the wing!-1. The edges of the exterior or narrow vanes bend downward, but the interior, wider vanes upward. By this means they catch hold and lie close to each other, when the wing is spread, that not one feather may miss its full force and impulse upon the air. 2. Equal nicety is observed in the very sloping the tips of the flas-feathers; the interior vanes are neatly sloped away to a point toward the outward part of the wing. The exterior (at least in many biris) are sloped toward the body, and in the middle of the wing, the vanes being equal, are but little sloped; so that the wing, whether open or shut, is as neatly sloped as if constantly trimmed with a pair of scissars.

The vane consists not of ove continued membrane, because if once broken, it would not easily be repaired; but of many laminæ, which are thin, stiff, and something resembling a thin quill. Toward the shaft of the feather (especially in the flag-feathers of the wing) these lasninze are broad and of a senicircular form, which serves for strength and for shutting them close together, when impulses are made on the air. Toward the outer part of the vane, they grow slender and taper, on their under side they are thin and smooth, but their upper outer edge is parted into two hairy edges.

As curiously made are the feathers in the wing, and no less curiously placed, exactly according to their se. veral lengths and strength; and thesc again are lined, 


\section{7}

faced, and guarded with covers and secondary feathers, to keep the air from passing through and so eluding the impulse.

How admirably wrought are the bones of the wing ! very strong, but light withal ; the joints, which open, shut, and move every way, as occasion is, and the various muscles, all suited to the motions which they minister to.

Next to the parts for flight, let us view the legs and feet which minister to their other motions, both made light for their easier passage through the air, and the latter, some with membranes for swimming, some without, for steady going, for perching, for catching, and holding their prey, or for hanging by the heels to gather their food : the legs, all curved, for their easy perching or roosting, as also to help them upon their wings in taking their flight. In some they are long, for wading and searching the waters, in others, if need be, remarkably short. And how wisely are they placed! In all somewhat out of the centre of the body's gravity; but in such as swim, more than in others, for the better rowing their bodies, as also to help them in diving.

Creese and Ducks, their bodies being made for swimming, have their wings too placed out of the centre of gravity, nearer the head; lut the extending the neck and head in flight, balances the body upon the wings, which is another excellent use (beside searching for food) of the long necks of these birds.

But in the Heron, whose head and long neck (al. though tucked up in flight) overbalances the hinder part of the body; the long legs are extended both to counterpoise the body and to supply what is wanting in the tail.

It has been supposed that the flying of birds is ana. logous to the rowing of ressels; but it is a motion of quite another kind. Oars are struck toward the stern; whereas birds do not vibrate their wings toward the tail, but waft them downward. Nor does the tail cut 


\section{8}

the air (as the rudder does the water) at right angles, but horizontally. It likewise keeps the same situation which way soever the bird turns.

It is not therefore by the tail that most birds turn to the right hand or the left, but by the wings. They turn to the right by beating the air with the left wing alone toward the tail : to the left, by beating it with the right wing. Thus Pigeons changing thcir course toward the left, labour with the right wing, scarce stirring the other.

Birds with long necks have another way of altering their course, by only inclining their head and neck this or that way.

Birds rarely fly up or down perpendicularly, but rather in a crooked line. In ascending direclly, the natural and artificial tendency would counteract each other. In descending directly, both would concur, and endanger too précipitate a motion.

Only the Hawk stoops directly to seize its prey: whereas other birds in descending reiard the motion by keeping their wings expanderl, and at the same time stretching out their feet and legs.

There is no flying animal but has fect as well as wings, because there is no food or at least not food suffieient for them, to be had always in the air : but if there were, yet such birds could take no rest; for haring no feet, they could not perch upon trees, and if they alighted on the ground they could not raise themselves again : which birds that have short feet can

\footnotetext{
* It is a remarkable use which is made of pigeons in the Eastern countries. They are trained up in Turky and Persia to carry expresses : being filst used to short dights, afterwards to longer, tiil at length they will return from the farthest part of the kingdom. Yea, if they are brought hood-winked twenty or thirty miles, nay, sixty or a hundred, they will find their way in a very little time to the place where they were bred. Every bashaw has a basket of these pigeons bred at the seraglio; one of which he dispatches. thither on any emergent eccasion, with letters braced under her wings. This proves a more speedy method, as well as safer, than any other. For cne of these lirds will ca ry a letter from Babylon to Aleppo, which is thirty days journey, in forty-eight hours.
} 


\section{9}

hardly do. Beside, they would want means of breed. ing, having no way to lay their eggs, to sit, hatch, or brood their young.

Before we conclude this head, it may be obserred, that all the parts of birds are fitted for the use of $t \mathrm{y}$. ing. First, as the muscles of the wings are peculiarly strong, so the under side of them is made concave, and the upper convex, that they may be the more easily lifted up, and the more strongly strike the air. Then the trunk of their body somewhat resembles the hull of a ship; the head the prow, which is generally small, that it may the more readily cut the air, and make way for the body. Add to this, that the bodies of birds are small in comparison of beasts, that they may be more easily supported by the air : and they are not only small, but of a broad figure, that they may be buoyed up the better. They are also hollow and light, yea, their very ones are light. For even those of the legs and wings have ample cavities: by this means also they become rigid and stiff, it being demonstrable that a hollow body is more stiff and inflexible than a solid one of equal substance. The shafts also of the feathers are either empty or filled with a light and spungy matter; and their webs consist of two rows of contiguous filaments furnished all along with hooks on each side, whereby catching hold of one another they stick fast together.

As to their tails, although it is true as was obserred, that all birds whose tails are pointed and end in a right line, turu themselves by their wings and not their tails, yet in those that have forked tails it is otherwise. Thus it is manifest to sight, that the forked-tailed Kite, by turning her train sideways, raising one horn, and de. pressing the other, turns her whole body. And doubtless the tail has the same use in swallows, who a have all forked tails, and make more sudden turns in the air than any other bird. 


\section{0}

To lighten birds still farther, they have large membranes extending to the bottom of their bellies, into which the air is received, where, by the heat of the body it is expanded into twice or thrice the dimensious of the external air; and this they can either compress by the muscles of the abdomen, or expire more or less, in order to their desceuding swifter or slower, in what. degree they please.

3. As to the brain of birds, whereas in men the cortical part of the brain is outermost, in lirds it is in. nermost, and the membrane that covers tho upper ven. tricle is medullary. The ventricles likewise are situated above, near the upper part of the skull.

Perhaps before we proceed, it may be well to prea mise one general observation, that the structure of birds is in many respects different from those both of men and beasts, having sereral parts which these want, and wanting others which they have. Besides, there are great variations in the contrivance of parts which are common to both, all wisely adapted to their different conditions and manner of life.

Parts peculiar to birds are, 1. The bill.-2. The membrane to draw over the eyes, -3 . Feathers and wings. The parts wanting in birds are, 1 . Teeth and lips.<2. The bladder, which they do not need, as they drink nu more than just to moisten their food. Variations in the parts of birds from those of men and beasts are, 1. In the ear, which is of a very peculiar make. -2. In the division of the aorta.-3. In the spinal marrow, which is divided into two in the middle of the back.-4. In the bones, which are all hollow.5. In the heart, which has a fleshy valve at the month of the vena cava.- 6 . In the lungs, which are strougly joined to the back, for the greater conveniency of tlight. -7 . In the stomach; birds have two or more, to supply the want of chewing. -8 . In the legs and 
fuet. -9 . In their tails. - 10. In their pectoral muscles, which are the strongest of all; whereas in man, the crural muscles are the strongest. -11 . In the brain, as was before observed.-12. In the bronchia, which extends to the very bottom of the abdomen, so as to contain a large quantity of air.-13. In the ovaries, which in birds are single, and fastened on their back.

4. The ears of birds differ much from those both of men and beasts. There is almost a direct passagefrom ear to ear, so that if the drum be pricked in either ear, water poured in at one ear will run out at the other; and what is still inore remarkable, they have a small winding passage that opens in to a large cavity, running betwixt two skulls, and passes all round the head : the upper of these skulls is supported by many linndreds of small, thread-like pillars, which hare another use also, to break their sound, and hinder its making a con. fused echo.

This passage between the two skulls is much larger in singing-birds than in others. So that a person who has been shewn this may hereby know them from all others.

The other organs of sense are nearly the same in birds as in other animals. Only there is a difference in the organ of smell: the nostrils lie on each side of the beak, in the inner part whereof, beside the tube which reaches to the lungs there are little tubes continued from the membranes and substance of the brain, and these seem to be the organ of smell. Only two nerves pass through the os cribrosum to the beak, lest if there were more perforations, as in other animals, too much air might flow into the brain.

The bill of-birds is peculiarly remarkable. In the first place, it is neatly shaped for piercing the air. In the next it is hard and horny, to supply the want of teeth, and also in some measure, of a hand. Its hooked form is of great use to rapacious bircts, in 
catching and holding their prey; and to others, in climbing, and in taking and comminuting their food.* Its extraurdinary length and slenderness is of use to some, to search for their food in moorish places : $t$ as its length and breadth is to others, to hunt and search in muddy places. \pm The contrary form, a thick, short, and sharp-edged bill is as useful to all other birds, who must husk the grain they swallow. But it would be endless to reckon up all the shapes and commodious mechanism of all : the sharpness and strength of those that have occasion to perforate woods and shells, $\$$ the slenderness and neatness of such as pick up small insects : the cross form of such as break up fruits;

Parrots have their bills nicely adapted to thesé services, being hooked, for climbing and reaching what they want, and the lower jaw so exactly fitted to the hook of the upper that it will break the food, as other creatures do with their teeth.

+ As to Woodcocks and Snipes, who hunt for worms in moorish ground, and likewise suck the unctuous humour out of the earth. So also the bills of Curlews, and other Sea-fowl, are very long, to enable them to hunt for worms, \&c. in the sands.

‡ Ducks, Geese, and divers other species of birds, have bills both lous and broad, whereby they are enabled to quaffer in the water or inid, till they find their food.

STe green woodspite, and all woodpeckers have strong and sharp bills, curiously made for digging wood. An even rilge runs along to the top of the green woodpecker's bill, as if an artist had designed it at once for strength and neatness.

Woodpeckers have also a tongue, ending in a sharp, bony rib, dented on each side, which they can at pleasure shoot out to a great length, and thrust into the holes, clefts and crannies of trees. They strike them likewise into ant-hills, and fetch out the ants and their eggs. Moreover they have short, but strong legs, and their toes stand, two forward, two backward; a disposition which is particularly convenient for the climbing of trees. In this they are likewise assisted by the uncommon stiffness of the feathers of their tails, and by their bending downward, whereby they are fitted to serve them as props to lean on.

\|I The cross-bill, whose bill is thick and strong, with the tips crossing each other, readily breaks open fir-cones aid other fruits, to come at and feed on the kernels. And undoubtedly the crossing of the bill was designed for this very service.

** The sea-pye has a long, sharp, narrow bill, compressed sideways, and every way adapted to the raising limpets from the rocks, which are its chief, if not only, fuod. 


\section{3}

with many other curious forms, all suited to the occa. sions of the several species.

In the flat-billed birds, as ducks, there are three pair of nerves, which come down between the eyes in the upper bill, whereby they are enabled to smell and find out their food in the mire or water. The like have been observed in several round-billed birds, but so small as to be scarce discernible. Only in the rook they are discernible enough : and it is remarkable that these, more than any other round. billed birds, grope for their meat in cow-dung, and the like.

5. Of their lungs it is observable, that they are not only larger in proportion than those of beasts, but they admit the air, both above and beneath, by which means they become far lighter.

A duck is furnished with a peculiar structure of vessels, which enables it to live some time under water. Yet she cannot live without air. One that was put into the air-pump, and the air exhausted, seemed to bear it better for a few moments than any other fowl. But in less than two minutes her head fell down, and she appeared dying, till revived by letting in the air.

A young callow duck being tried in the same man. ner, was near death in less than two minutes. It is observable both of them swelled extremely, on pumping out the air. It not being intended that water-fowl should live in an exceeding rarified air, but only con. tinue under water, they are qualified for this, but not at all for the other.

Yet that ducks can live almost any where, we may learn from the blind ducks of the Zerchintzer lake in Carniola, a territory of Austria. This communicates with another lake under ground in the mountainSavor. nick, and fills or empties itself accurding to the ful- 


\section{4}

fiess or emptiness of that. The waters of the upper lake, when it empties, run off by large holes in the bottorn. The dacks which are very plentiful in the water, are often carried down with it into the subter. raneous lake. In this many of them undeubtedly perish; yet some remain alive. But they lose their sight and their feathers : and at the next filling of the upper lake, both they and vast numbers of fish are thrown up with the water. They make a strange appearance in their naked state; and for want of sight are easily caught. In about a fortnight they recover their sight and their feathers, and are then as big as common wild-ducks. At their first coming up, their stomachs are full of small fishes, and something resembling weeds. It seems therefore, they were not quite blind, when in their dark habitation, but could see by that small quantity of light, to search for and find their food.

Nor is it in this lake only that these ducks are found. They are frequently thrown up, after great rains, at a hole in a mountain, near the town of Laon, in the Isle of France. The water then gushing out with great violence, brings these blind and bald creatures with it. And their frequency and cheapness, from the vast quantities which are thrown out, make them esteemed no variety.

The bodies of duckers or loons are admirably fitted for diving: being covered with a thick plumage, and the surface of it so smooth, that the water cannot penetrate it. Hereby their bodies are defended from the cold, the water being kept at a distance; and are - so poised, that by a light impulse, they easily ascend in it. Again, their feet are situate in the hindmost part of their body, so that shooting them backward and striking the water upwards, they plunge themselves down with great ease, and move forward therein. Their legs also are made flat and broad, and their fect cloven into toes, with appendant membranes on 
each side. By this configuration they easily cat the water, and are drawn forward, to take their stroke backward : and by this, their feet being moved to the right or left, serve them as a rudder to turn under water. How they rise above water is not determined: whether by their natural lightness, or by striking against the bottom, in the manner of a leap, or by some peculiar motion of the legs. That they dive to the hottom is undeniable. For in the sto. machs, both of the greater and lesser kind, we find much grass and other weeds; and in the lesser kind, little else. Yet both prey upon fish; and their bills are straight and sharp, for the easier striking their prey.

It is likewise remarkable, that whereas in other animals the lungs are loose and have much play, in all birds they adhere to the thorax, and have little play. This is a good provision for their steady flight. Also they want the diaphragm, and instead there of have divers large bladders, made of thin trans. pareut membranes, with pretty large holes, out of one into the other. These membranes serve for braces to the viscera, as well as to contain air. Toward the upper part, each lobe of the lungs is perforated in two places, with large perforations; whercof one is toward the outer, the other toward the inner part of the lobe. Through these perforations the air has a passage into the fore-mentioned bladders; so that by blowing into the windpipe, the lungs are raised, and the whole belly blown up. This doubtless is a meatis to make them more or less buoyant, as they take in more or less air : and so auswers the design of the air-bladder in fishes.

In general we may observe, whatever is poculiar in the wings, bills, and every other part of birds, on a close inspection will be found exactly suited to their wants. They are a set of implements nicely proportioned to their manner of life. To instance in a few, 
sparrows and most small birds, are supported by the little grains they find up and down.- They have wo effort to make, to obtain their food, or break it in pieces, and therefore have a small bill, as well as short necks and legs, which are sufficient for their purposes. But the woodcock, snipe, curlew, and many other birds, seek their food deep in the earth or slime. Therefore they are provided with a long neck and bill, and with these they dig and search and want for nothing. The woodpecker, who lives in a quite different manner, is as differently formed. His bill is very long, solid, and strong : his tongue is sharp and extremely long; beside which, it is armed with little points, and covered with glue toward the extremity. He has short legs, two talons before, two behind, and all very crooked. All this equipage suits his manner of living. His food is worms or insects, that lire in the heart of branches of trees, or under the bark of old wood; frequently they are sunk very deep, under the bark of large billets. The woodpecker has hooked claws, to grasp these branches; and a strong and pointed bill, to find out by darting it up and down, what parts of them are rotten. When he has found out these, he with his bill, shatters the bark and wood. He then sends forth a loud whistling cry, into the cavity, to alarm the insects and put thein in motion. Next he darts in his tongue, and by the small points which arise out of it, and the glue that covers it,draws out whatever lodged there.

The Heron, on the contrary, mounts aloft. His legs and thighs are very long, and bare of feathers. He has a great length of neck, and an enormous bill, very sharp and jagged at the end. What reason can be assigned for a figure, which at first sight seems so extravagant? He feeds on frogs and small shell-fish, as well as other fish, which he finds in fens, or bogs, or near the shores of rivers. He wants no feathers on his thighs, to walk tl rough water and slime ; but he seeds very long legs, to run in the water, along the 


\section{7}

shores, whither the fishes resort for their foorl. A long neck and bill qualify him for pursuing and seizing his prey at sume distance: and the jaggs of his bill enable him to hold the fish, which would otherwise slide away. In fine, his large wings, which seem incommodious to a bird of so small a body, are absolutely needful for his making so great movements in the air and conveying such burdens to his nest, which is frequently two or three leagues distant from the place where he fishes.

The imperfections therefore which we imagine we discover in this (as in many other animals) in reality belong only to our own understanding; and all our censures of the works of nature, are in truth, only so many indications of our own ignorance.

6. The Stomach (especially of granivurous birds), is of a peculiar structure. First, there is a glandulous receptacle, wherein the grains are kept for some time. They are then received into another stomach, consisting of two muscles, and a callous membrane. One of these moves obliquely downward, and the other up. ward. Hereby the shell of the grain is broke, and the meal expressed and mixed with proper juices. The aliments thus, prepared, fall into the bottom of the stomach, where they are purged again from the refuse : to which end that part is a little raised, that the corn may not pass out too soon. There is also a partition, which divides what is already digested from the rest.

As birds have no bladder, in the room of urine, a whitish excrement is discharged from the kidneys into the rectum.

7. The generation of birds is not well known in the ovary, placed between the liver and the backbone, a great number of yolks are contained; one of which when impregnated, passes through the oviduct into the womb, where it reccives the white and vol. I. 


\section{8}

the shell, and remains till it comes to its full size. The parent then broods over it, till the young being gradually formed, perfected, and quickened, bursts the shell.

Under the shell of an egg lies the common membrane, adhering closely to it, except at the bigger end, where a little space is left between them. This mernbrane contains two whites, each enclosed in its own membrane. In the middle of the inner white is the yolk, enclosed likewise in a separate cover. The outer white is oral, the inner round, (as is the yolk) and of a more viscid substance.

At each end is a chalasa, a white, dense body consisting of three little globules, like grains of hail, (so the word signifes) all joined together. These serve voth to knit the several membranes together, and to keep the liquors in their proper places and position.

About the middle of the small end of the yolk, is a little yellowish bladder, like a vetch, called the cicatricula, or eye of the egg. This contains a humour, in and out of which the young bird is generated. The white serves it for food, till it becomes big : then the yolk, and likewise after it is hatched. For even then a good part of the yolk is lodged in its belly, as in a store-house, and being conveyed thence by the intestinal duct into the bowels, serres it instead of milk.

An egg, improperly so called, is that, of the whole whereof the animal is formed. Such are the eggs of flies. Proper eggs, when excluded need no external vutriment. Of proper eggs, some are perfect, that is, have all the parts above described, while in the ovary or womb: some imperfect, which have them not, till after they are excluded, as those of fishes, which assume a white in the water. 


\section{9}

An egg not impregnated by the male, will never breed young, but always putrify. One impregnated contains the rudiments of the bird, even before incubation. By the microscope we see the plain carina or spine of it swimming in the middle of the cicatricula, consisting of fine white threads, which incuba. tion gradually perfects.

The air-bag is very small in a new laid egg, but becomes larger, when the egg is kept. The yolk is specifically heavier than the white. Hence its smal. ler end is always uppermost in all positions of the egg.

After incubation, the air-bag gradually extends, till near the hatching, it takes up a third of the egg. By incubation the white becomes thinner and more tur. bid, especially near the air-bag where it is first consumed. Then it lessens towards the sharp end of the egg, till nothing is left, but a white,chalky substance. The white of an impreguated egg is as sweet all the time of incubation as that of a new laid-egg. They are only unimpregnated eggs, vulgarly called wind. eggs, which putrify and stink.

The yolk also remains fresh and uncorrupted all the time of the incubation. It is depressed in the middle, as the chick grows, and is soon brought into a form, not much unlike that of a horse shoe, in the middle of which the chick lies.

Not long before the chick is hatched, the wholcyolk is taken into the abdomen.

The eye or tread, in which the chick lies, is soon enlarged by incubation, and rises to the upper part of the egg. The heart and umbilical vessels, are some of the first parts, which we are able to dis tinguish. 


\section{0}

The embryo is seen at first like a small worm. Then its carina or spine appears, with the large pro. minences that afterwards sliew themselves to be the brain and eyes. The other bowels seem hanging from the spine. Then the chasm of the mouth is dis. covered. The extremities sprout out. The bowels are gradually covered with the teguments. At last the beak, nails, and feathers are seen. When all its parts are formed, the chick is always found lying on its side, with its neck bent forward, the hearl co. vered with the upper wing, and the beak placed be. tween the thighs.

The birds which nourish their young, have commonly very few. On the contrary, thiose whose young feed themselves, when they first see the day, have sometimes eighteen or twenty at a brood. This prudence could only spring from Him, who regulates all things to the best advantage. Were those who provide for their young to have so numerous a brood, both the parents would be slaves, and yet the young but ill accommodated. Whereas the mother, who only marches at their head, without nourishing them, can conduct twenty as well as four.

But when they first make their appearance, what care do the parents take, till their young can subsist without them? Of those that feed their young, the liunet and the nightingale then labour like the rest. Sometimes one parent goes in quest of pro. visions, sometimes the other, and sometimes both. They are up before the sun. And the food they have procured, they distribute with great equality, giving each a portion in its turn, before ever they feed one bird twice:

And this tenderness for their offspring, is so strong, as even to change their natural disposition. Follow the hen when she is the parent of a family, and she is no longer the same creature. She is no longer ra. 


\section{1}

renous and insatiable. If she finds but a grain of corn or a crum of bread, she -never touches it herself but calls her troop by a note they well understand, and divides it among them. She is no longer timorous, but at the head of her young, will spring even at the stoutest dog.

When the turkey hen appears at the head of her young, she sometimes utters a mournful cry, and they immediately run under bushes, furz or whatever presents itself. She looks upward and repeats her cry: which is occasioned by her seeing a bird of prey, though so distant, that he appears unto us, only as a dark point under the clouds. But he no sooner disappears, than she utters another cry, which revives all her brood. They run to her, flutter their wings, and shew all the tokens of joy. Now, who apprizes her'of an enemy, that never yet committed any act of hostility in the country? And how is she able to discover him, when at so great a distance? II ow are her family instructed to understand her different cries, and regulate their behariour accordingly? What wonders. nie these which are daily obvious to our view, though we treat them with inattention?

An amazing degree of natural instinct, or understanding, Gud has imparted to birds of passage. They fly in truops, often in the form of a wedge, with the point foremost. They steer their course through unknown regions, without either guide or compass. Ani they are peculiarly accommodated for their flight by the structure of their parts.

In the act of nigration, it is highly remarkable, 1. That they know, (as the scripture speaks) their appointed times, when to come and when to g o. Ap. pointed by whom? Surely by the great Creator, who has imprinted on their nature an inclination, atsuch a time to fly from a place that would obstruct their. generation, or not afford food for them and their r. 3 
young, and betake themselves to another piace, which will afford all that is wanting.

It is highly remarkable, 2. That they know whi. ther to go, and which way to steer their course! That they should be directed yearly to the same place, perhaps to a little island, as the Basse in Edinburgh Frith. How come land-birds to venture over a vast ocean, of which they can see no end? And how do they steer their course aright to their several quarters, which before the compass was invented, man himself was not able' to do? They could not possibly see them at that distance. Or if they could, what should frach or persuade them that that land is more proper for their purpose than this? That Britain, for instance, should afford them better accommodations than Egypt, than the Canaries, than Spain, or any uthes of the intermediate places?

But it has been commonly supposed that several birc's are of this number, because they disappear in winter, which really are not; cuckoos for instance, and swallows : for neither of these erer cross the seas. Cuckoos lodge all the winter in hollow trees, or other warm and convenient cavities. And swallows have bren found in rast quantities, clung together in a lump, like swarms of bees, but utterly cold and senseless, even in ponds that have been cleaned out, hanging under the water.

1 know not how we can doubt of this fact, that swallows have been found in winter, under water, clung together, attested by men of unquestionable ve. racity. And yet others affirm, that they have seen flights of swallows crossing the sea in autumn. The truth seems to be this. There are some species of swallows, which seek a warmer climate at the approach of winter, while others remain here in a temporary death, like the flies on which they feed.

They have in Virginia, a martin like ours, only larger, which builds in the same manner. Col, Bacon observed for several years, that they constantly came 
thither upon the I0th of March. Two of them always appeared a day or two before, hovering in the air, then they went away, and speedily returned, with the whole flock.

The following seems to be a very rational account of most of those that are really birds of passage.

When by the approach of our winter their food fails, birds of passage are taught by instinct to seek it elsewhere. Want of food seems to be the chief rea. son of their migration. The length of their wings enables them to cateh the flying insects, with which the air is stored during the warm months. And most summer bircls of passage, feed on the wing upon such insects, as are seen no more when winter comes. If it be cousidered, how much of the globe still remains unknown, it is no wonder we are not yet acquainted with the places to which they retire. Probably they lie nearly in the same latitude in the southern hemisphere, as those from whence they depart.

As swallows cannot bear so much cold, as some other birds of passage, they are constrained to visit us somewhat later, and to depart somewhat sooner. Some stay a month after them. Probably many of them perform their long journies chiefly in the night. Lying on the deck of a sloop en the north-side of Cuba, I and the company with me heard three nights succest sively, flights of rice-birds (their notes being plainly distinguishable) passing over our lieads northerly, which is their direct way from the suuthern con. tinent of America, from whence they go yeariy when. the rice begins to ripen, and after growing fat, return back.

There are also winter birds of passage, which ar. rive here in autumn and go away in spring, namely the fieldlare, relwing, woodcock, and snipe. But the two latter sometimes spend the whole year here. Whereas the two former, constantly at the

$$
24
$$


approach of summer, retire to more northern climates where they breed, and remain till at the return of winter, they return to us again.

The winter fuod of these birds being berries and haws, which are far more plentiful here than in more northern regions, this is one reason of their coming over: but the principal is, the severity of the weather in those climates, which nature teaches them to exchange, for such as are more temperate. But why do they depart from us in spring: This still remains among the secrets of nature.

Besire these summer and winter birds, there are others which come periodically to certain places, for the sake of some sort of food, which their own coun. try is destitute of. These quickly depart, and are seen no more till that time twelvemonth. Such are the rice-bird and blue-wing of Carolina.

But abore half a century passed from the time of cultivating rice and wheat in Carolina, and Virginia, before these foreign birds made their appearance there. The wheat birds now come annually to Virginia, when the wheat ripens, and hare come every year, since their fiist appearance, in numerous flights.

The species of birds already known, amount to about eight hundred. Linnæus divides them into six classes ; namely, into birds of the rapacious kinds, birds of the pie-kind, birds of the poultry kind, birds of the sparrow-kind, birds of the duck-kind, and birds of the crane-kind. The four first comprehend the kituds of land birds, the two last, those that belong to the water.

In beginning with the feathered tribe, the Ostrich seems to unite the class of beasts and of birds in itself. While it has the general outlines and pro. perties of a bird, it retains many of the marks of a beast. In appearance it resembles the carnel, and is almost as tall; it is coveren with a plumage that resembles hair much more than feathers, and its internal parts bear as near a similitude to those of the beast, 
as of the bird creation. It may be consilered, therefore, as an animal made to fill up that chasm in nature which separates one class of beings from another. It is usually seven feet high from the top of the head to the ground. The external eye is like that of a man, the upper eye lid being adorned with eye-lashes which are longer than those on the lid bel:sw.

They inhabit the most solitary desarts, where there a fe few vegetables, and where the rain never comes. The Arabians assert, that the ostrich never drinks; and the place of its habitation confirms the assertion. In these regions, ostriches are seen in large flocks, which to the distant spectator appear like a regiment of cavalry. The ostrich is of all other animals the most voracious. It will devour leather, hair, grass, iron, stones, or any thing that is given. But those substances, which the coats of the stomach cannot soften, pass whole; so that hair, stones, and iron, are excluded in the forn in which they were devoured.

In their native desarts, however, they live chiefly upon vegetables, where they lead an inoffensive and social life ; the male, as Thevenot assures us, assorting with the female with connubial fidelity. They lay generally from forty to fifty eggs. It has been commonly reported, that the fernale deposits them in the sand, leaves them to be hatched by the heat of the climate, and then permits the young to shift for themselves. Very little, however, of this is true : no bird has a stronger allection for her young: none watches her eggs with greater assiduity. Indeed in those hot climates, there is no necessity for the continual incubation of the female; but though the female forsakes her eggs by day, she carefully broods over them by night. Then they sit on their eggs like other birds, and the male and female take this office by lurns. Nor do they forsake their young after they are excluded the shell. On the contrary, the young oncs are not even able to walk for several L 5 
days after they are hatched. During this time, the old ones are very assiduous in supplying them with grass, and very careful to defend them from danger : nay, they encounter. every danger in their defence.

All land-birds of the rapacious kind, are furnished with a large head, and strong crooked beak, notched at the end, for the purpose of tearing their prey. They have strong -short legs, and sharp crooked talons for the purpose of seizing it. Their bodies are formed for war, heing fibrous and muscular; and their wings for swiftness of flight, being well feathered and expansive. The sight of such as prey by day is astonishingly quick : and such as ravage by night, have their sight so fitted as to see objects in darkness. 'Thus formed for war, they lead a life of solitude, they inhabit by choice, the most lonely pla. ces. They make their nests in the clefts of rocks, and in the highest and most inaccessible trees of the forest. Whencrer they appear in the cultivated plain it is only, for the purposes of depredation, aml they spread terror wherever they approach : all the variety of music, which but a moment before enlivened the grove, at their approach is at an end : Jesser birds seek for safety, either by concealment or flight, and some are eren driven to take protection with man, to a void their less merciful pursuers.

It would indeed be fatal to all the sualler race of birds, if as they are weaker than all, they were also pursued by all : but it is contrived wisely, that every order of carnivorous birds seck only for such as are of a size approaching their own. The eagle flies at the bustard or the pheasant, the sparrow-hawk at the thrush and the linnet. And nature has provided that each species should make war ouly on such as are furnished with adequate means of escape. The smallest birds avoid their pursuers by the extreme agility, rather than the swiftness of their flight; for every order would soon be at an end, if the eagle, to its swifuess of wing, added the versatility of the sparrow. 


\section{7}

Another circumstance which tends to render the tyranny of these animals more supportable, is, that they are less fruitful than other birds. Thuse of the larger kind seldom produce above four eggs, of ten but two; those of the smaller kinds, never above six or seven. Likewise the carnivorous kinds only breed annually, and of consequence their fecundity is small.

8. The largest of birds is the Cuntur of Peru. The body is as big as that of a sheep. Its wings extended are fifteen or sixteen feet from point to point It is never seen in forests, because it would not have room to $8 y$, but frequents the sea-shore and the banks of rivers. Nature, to allay their fierceness, has denied them the talons given to eagles, though they are of the eagle-kind. However, their beak is strong enough to tear off the lide, and rip up the bowels of an ox.

What a blessing is it to mankind, that there are but few (just enough to keep up the species) of this monster in the feathered creation! And into what can we resolve this, but the wise and overruling care of an adorable Providence?

In beasts the smallest animals are noxious, and loathsome ; the smallest of birds are the most beautiful, innocent, and sportive. Of all those that flut. ter in the garden, or paint the landscape, the bum. ming-bird is the most delightful to look upor, and. the most inoffensire.

Of this there are six or seven varieties, from the size of a small wren, down to that of an humble bee. An European could wever have supposed a bird ex jsting so very small, and yet completely furnished with a bill, feathers, wings, and intestines, exactly resembling those of the largest kind. A bird not so hig as the end of one's little finger, would probably be supposed but a creature of imagination, were it not seen in infinite numbers, and as frequent as L. 6. 
butterflies in a summer's day, sporting in the fields of America, from flower to flower.

The smallest is about the size of a hazle-nut. The feathers on its wings and tail are black; but those on its body, and under its wings, are of a greenish brown, with a fine red cast or gloss, which no silk or velvet can imitate. It has a small crest on its head, green at the bottom, and as it were gilded at the top, and which sparkles in the sun like a little star in the middle of its forehead. The bill is black, straight, slender, and of the length of a sinall pin.

As soon as the sun is risen, the humming-birds, of different kinds, are seen fluttering about the flowers, without ever lighting upon them. Their wings are in such rapid motion that it is impossible to discern their colours, except by their gittering. They are never still, but continually in motion, visiting flower after flower : they are furnished with a forky tongue, that enters the cup of the flower, and extracts its nectared tribute. Upon this alone they subsist. The rapid motion of their wings bring out an humming sound from whence they have their names.

The nests of these birds are not less curious than the rest : they are suspended in the air, at the points of twigs of an orange, a promegranate, or a citrontree. The female is the architect, while the male goes in quest of materials, such as cotton, fine moss, and the fibres of regetables. Of these inaterials a nest is composed, of about the size of a hen's egg cut in two, admirably contrived, and warmly lined with cotton. They lay two eggs at a time, ahout the size of small peas, and as white as snow, with here and there a yellow speck. The male and female sit npon the nest by turns; but the female takes to herself the greatest share. She seldom quits the nest, except a few minutes in the morning and evening when the dew is apon the flowers. The time of incubation continues twelre days; at the end of which the young ones anpear, much about the size of a bluebottle Aly. 


\section{9}

Father Labat's companion, in the mission to Ame. rica, found the nest of a humming-bird, and took it in, at a time when the young ones were about fifteen or twenty days old; he placed them in a cage at his chamber window: but he was soon surprised to see the old ones, that came and fed their brood regularly every hour in the day. By these means they themselves soon grew so tame, that they seldom quitted the chamber; but without any constraint, came to live with their young ones.

All four hare frequently come to perch upon their master's hand, chirruping as if they had been at liberty. He fed them with a fine clear paste, made of wine, biscuit, and sugar. They thrust their tongues into this paste, till they were satisfied, and then fluttered and chirruped about the room. I never bebeld any thing more agrceable, continues he, than this lovely little family, that had taken possession of my companion's chamber, and that flew out and in just as they thought proper; but were ever attentive to the voice of their master when he called them. In this inanner they lived with him for above six months. but, at a time when he expected to see a new colony, he unforlunately forgot to tie up their cage to the cciling at night, to preserve them from the rats, and he found they were devoured in the morning.

Eren Vultures are in Egypt of singular service. There are great llocks of them in the neighbourhood of Grand Cairo, which no person is permitted to de. stroy. The service they render the inhabitants, is the devouring the carrion and filth of that gieat city, which might otherwise corrupt and putrify the air. They are commouly seen in company with the wild dogs of the country, tearing a carcase very deliberately together. This odd association produces no quarrels; the beasts and birds live amicably, and nothing but harmony subsists between them.

The wonder is still the greater, as both are extremcly rapacious, and both leas and bony to a very 
great degree, having no great plenty even of the wretched food on which they subsist.

In America wherever the hunters go, who pursue beasts for their skins, these birds pursue them. They still keep hovering at a little distance ; and when they see the beast head and abandoned, they call out to each other, pour down upon the carcase, and in an instant, pick its bones as clean as if they had been scraped, by a knife.

Rooks keep together in pairs; and when the offices of courtship are over, prepare for making their nests and laying. The old inhabitants of the place are already provided; the nest which served them for years before, with a little dressing will serve again; the difficulty of nestling lies only upan the young ones who hare no rest. And not only the materials are wanting, but also the place in which to fix it. Every part of a tree will not do for this purpose, as some branches may not be sufficiently forked; others may not be sufficiently strong; and others may be too much exposed to the rockings of the wind.

The male and female upon this occasion are, for some days, seen exantining all the trees of the grove very attentisely, and when they have fixed rpon a. branch fit for that purpose, they continue to sit upon. and observe it very sedulously for two or three days longer.

The place being determined, they begin to gather the materials; such as sticks and fibrous roots, which they regularly dispose in the most substantial manner. But here a new and unexpected obstacle arises, it often happens that the young couple have made choice of a place too near the mansion of an older. pair, who do not chuse to be incommoded by neigh. bours. A quarrel therefore instantly ensues, in which the old ones are always victorious.

The young couple thus expelled, are obliged again. to go through the fatigues of examining, and chus. 
ing; and having taken care to keep their due dis. tance, the nest begins again. But they grow weary of bringing materials from distant places; and perceive that sticks may be provided nearer home. Away they go, therefore, to pilfer as fast as they can; and wherever they see a nest unguarded, they rob it of the choicest sticks of which it is composed. But these thefts never go unpunished. Eight or tem rooks come, and setting upon the new nest of the young couple at once, tear it in pieces in a moment.

At length, therefore, the young pair find the necessity of going more honestly to work. While one flies to fetch the materials, the other sits upon the tree to guard it; and thus in the space of three or four days, with a skirmish now and then between, the pair have fitted up a commodious nest, composed of sticks without, and fibrous roots and long grass with. in. From the instant the female begins to lay, all hostilities are at an end; not one of the whole grove that a little before treated her so rudely, will now molest her; so that she brings forth her brood with patient tranquillity. Such is the sererity with which even native rooks are treated by each other; but if a foreign rook should attempt to make himself a denizen of their society, the whole grove would at once be up in arms against him, and expel him without mercy.

In all its habits the Magpie discovers a degree of instinct unusual to other birds. Its nest is not less remarkable for the manner in which it is composed, than for the place it is built in : either in the mid. dle of some hawthorn bush, or on the top of some high tree.

It is always chifficult of access; for the tree or bush pitched upon, usually grows in some thick hedge-row fenced by brambles at the root.

When the place is chosen as inaccessible as possible to men, the next care is to fence the nest abore from various enemies. 


\section{2}

The kite, the crow, and the sparrow-hawk, are to be guarded against; as their nests have been sometimes plundered by the magpie, so it may be, they will take an opportunity to retaliate. To prevent this, the magpic's nest is built with surprising labour and ingenuity.

The body of the nest is composed of haw-thorn branches; the thorns sticking outward, but well uni. ted together by their mutual insertion. It is lined with fibrous roots, wool, and long grass, and nicely plaistered round with mud and clay. The body of the nest being thus made firm and commodious, the next work is to make the canopy which is to defend it above.

This is composed of the sharpest thorns, so wove together; as to deny all eutrance except at the door which is just large enough to permit egress and regress to the owners. In this fortress the male and female hatch and bring up their brood with security, sheltered from all attacks but those of the climbing school boy, who often finds his torn and bloody hands too dear a price for the eggs or the young ones.

As the Wood-pecker is obliged to make holes in trees to procure food, so is it also to make cavities still larger to form its nest and to lay in. This is performed as usual with the bill. He chuses for this purpose, trees that are decayed, or wood that is soft, like beech, elm, and poplar. In these, with very little trouble, it can make holes as exactly round as a mathematician could with compasses. Une of these holes the bird generally chuses for its own use, to nestle, and bring up its young in, but as they are easily made, it is delicate in its choice, and often makes twenty before one gives entire satisfaction:

In our climate, wood-peckers are contented with a wainscoat habitation for their young, but in Guinea and Brazil, they take a very different method. A traveller who walks into the forests of these countries among the first strange ubjects, is struck with the 


\section{3}

multitude of birds nest hanging at the extremity of almost every branch. Many other kinds of birds build in this manner, but the chief of them are of the wood. pecker kind.

In cultivated countries a great part of the caution of the feathered tribe, is to lide their nests from the invasion of man. But in the depths of those remote and solitary forests, the little bird having nothing to apprehend from man, is careless how much the nest is exposed to general notice : satisfied if it be ost of the reach of those rapacious creatures that live by robbery, and surprise. If the monkey or the snake can be guarded against, the bird has no other enemies to fear : for this purpose, its nest is built upon the depending points of the most outward branches of a tall tree. On one of those immense trees, is seen the most various assemblage of creatures that can be imagined. The top is inhabited by monkies of some particular tribe, that drive off all others : lower down twine about the trunk numbers of snakes, waiting till some unwary animal comes within their reach, and at the edges of the tree hang these artificial nests, inhabited by birds of the most delightful plumage.

The nests are usually formed in this manner: when the time of incubation approaches, they fly beautifully about, in quest of a kind of moss, called by the Linglish, old mau's bard. It is a fibrous sub. stance, not unlike hair, which bears being moulded into any form. This the little wood-pecker first glues by some viscous substance, to the extreme branch of a tree ; then building downward, a uest is formed, that descends like a pouch, from the point of the branch : the hole to enter at, is on the side; and all the interior parts are lined with the finer parts of the same substance, which compose the whole.

Such is the general contrivance of these hanging nests ; made by some other birds, with still superior art. A little bird in the Phillippine islands, make 


\section{4}

its nest in such a manner that there is no opening but from the bottom. At the bottom the bird enters, and gaes up through a funnel, like a chimney, till it comes to the real door of the nest, which lies on ane side.

Some birds glue their uests to the leaf of the banana sree, which makes two sides of their little habita. tion; while the other two are artificially composed by their own industry. But these, and all of the kind, are built with the same precautions, to guard their young against the depredations of monkies and serpents. The nest hangs there, before the spoilers, a tempting object, which they can only gaze upon, while the bird goes in and out without danger and molestation.

The Bird of Paradise appears to be as large as at pigeon, though in reality not much greater than a thrush. The tail is about six inches long, the wings are large, compared with the birl's other dimensions. The liead, the throat and the neck are of a pale goldcolour. The base of the bill is surrounded by black feathers, as also the side of the head and throat, as soft as velvet, and changeable like those on the neck of a mallard. The hinder part of the head is of a shining green, mixed with gold. The body and wings are chiefly covered with brown, purple, and gold feathers. The uppermest part of the tail-feathers are of a pale yellow, and those under them white and longer than the former; for which reason the hinder part of the tail appeass to be all white. But what chiefly excites curiosity, are, two long naked feathers, which spring from the upper part of the rump above the tail, and are usually about three feet long. These are bearded only at the beginning and the end, the whole shaft, for above two feet nine inches, being of a deep black, the feathered extremity of a changeable colour.

This bird is a native of the Molucca islands. There, in the delightful and spicy woods, do these beautiful 


\section{5}

creatures fly in large flocks, so that the groves which jroduce the richest spices, produce the finest birds 2/so. They are called by some, the swallows of Ternate frum their rapid flight, and from their being continually upon the wing, in pursuit of insects, their usual prey.

The American Mock-bird does not vie with the feathered inhabitants of that country in the beauty of his plumage. It is a plain bird about the size of a thrush, of a white and grey colour, and a reddish bill. It is possessed not only of its own natural notes, which are musical and solemn, but can assume the tone of every other animal in the wood, from the wolf to the raven. It seems even to sport itself in leading them astray. It will at one time allure the lesser birds with the call of their males, and terrify them when they come ncar with the screams of the engle. There is no bird in the forest, but it can mimic; and there is none that it has not at times deceired by its call. But it is surest to please, when it is most itself.

At those times it frequents the houses of the Ame. rican planters, and sitting all night on the chimneytop, pours forth the sweetest and the most various notes of any bird whatever.

The Crane, is above three feet from the tip of the beak to the tail, and four feet from the head to the toe. It is a tall, slender bird, with a long neck and long legs. The top of the head is covered with black bristles, and the back of it is bald and red, which sufficiently distinguishes this bird from the stork, to which it is very nearly allied in size and figure.

Cranes were formerly known in this island, and held in great estimation for the delicacy of their flesh: there was even a penalty upon such as destroyed their eggs; but at present, they never go so far out of their.way. 


\section{- 236}

Cultivation and populousness go hand in hand; and though our fields may offer them a greater plenty, yet they find the venture greater than the enjoyment, and we are better off by their absence than their company.

The Crane spends the autumn in Europe; then flies off to some more southern climate, returns to Europe in spring, crosses up to the north in summer, visits those lakes that are nerer dry, and then comes down again to Italy in autumn.

In these journies it is amazing to conceive the heights to which they ascend. Their note is the londest of all birds, and that is often heard in the clouds, when the bird itself is entirely unseen. But though unseen themselves, they have the distinct vision of every ob. ject below. They govern and direct their flight by their cries, and exhort each other to proceed or descend when a fit opportunity offers.

Their loud clangorous sound is, when near, almost deafening: however it is particularly servictable to the animal itself, either during its migrations or stay: by it the flock is encouraged in their journies; and if while they are feeding, which is performed in profound silence, they are invaded on any side, the bird that first perceives it sounds the alarm, and all are speedily upon the wing.

The Stork also is a bird of passage, and goes away toward winter to the southern countries. It has a very long beak, and long red legs. It feeds on seipents, frogs, and insects. As it seeks for these in watry places, nature has provided it with long legs. And as it flies to the nest with its prey, its bill is strong and jagged to hold fast what it has taken : she likewise digs with her bill into the earth for snakes or adders, which she carries to her young. Most of her feathers are white. She lays but four eggs, and sits for thirty days.

But what renders this bird most remarkable is, its 


\section{7}

steady love to its parents. It nover forsakes them when they are old, but tenderly feeds and defends them as long as they live.

The following adventure of a tame stork some years ago in the University of Tubingen, seems to shew a degree of understanding which one would scarce expect in the brute-creation. This bird lived quietly in the court-yard, till Count Victor Gravenitz, then a student there, shot at a stork's nest adjacent to the college, and probably wounded the stork then in it. This happened in autumn, when foreign storks usually leave Germany. The next spring a stork was observ. ed on the roof of the college, which after a time came down to the upper gallery, the next day something lower, and at last, by degrees quite into the court. The tame stork went to meet him with a soft cheerful note, when the other fell upon him with the utmost fury. The spectators drove him away, but he came again the next day, and during the whole summer there were continual skirmishes between them. The spring following, instead of one stork came four, and attacked him all at once. A surprising event followed. All the turkies, ducks, and geese, that were brought up in the court, ran together, and formed a kind of rampart round him, agaiust so unequal a combat. This secured him for the present : but in the beginning of the third spring, about twenty storks suddenly alighted in the court, and before the poor stork's life-guards could form themselves, or the people come to his as. sistance, they left him dead on the spot, which none could impute to any thing but the shot fired by Count Victor at the strange stork's nest.

The Pelican somewhat resembles a swan. The body is as large, the neck nearly as long, the legs are short, and the feet are black, broad, and webbed, in the same manner. It is also of a whitish colour, only the tips of some of his feathers are black. It is much in the waters: it has a most horrid roice, like that of a man grievously lamenting. 


\section{8}

Its beak is abore a foot in length, and the point is very sharp: the upper part is formed as in other birds, but the lower is unlike every thing in nature. It is made of two long flat ribs, with a tough membrane connected to one and the other; this reaches also to the throat, and is very broad and loose, so that it can contain a vast quantity of provision.

Its eyes are very small; there is a sadness it its countenance; and its whole air is melancholy. They are torpid and inactive to the last degree, so that nothing can exceel their indolence, but their gluttony: it is only from hunger that they labour, otherwise they would contiuue in a fixed repose. When they have raised themselves thirty or forty feet above the sea, they turn their head with one eye downwards, and continue to fly in that posture. As soon as they perceive a fish near the surface, they dart upon it with the swiftness of an arrow, seize it with unerring cer. tainty, and store it up in their pouch. They then rise again, and continue hovering and fishing with their head on one side as before.

This work they continue till their bag is full, and then fly to land to devour and digest it. This they are not long performing; for towards night they have another hungry call, and they again reluctantly go to labour. At night fishing is over, and they retire a little way from the shore; and though with the webbed feet and clumsy figure of a goose, they will be contented to perch nowhere but upon trees among the light and airy tenants of the forest. There they repose for the vight, and often spend great part of the day, sitting in dismal solemnity as it were half asleep. Their attitude is with the head resting upon their great bag, and that resting upon their breast: there they re. main without motion till the calls of hunger break their repose.

The same indolence attends them even in preparing for incubation, and defending their young. The female makes wo preparation for her nest, nor seems to chuse any place to lay in, but drops her eggs on the 


\section{9}

bare ground, to the number of fire or six, and there continues to hatch them. Without any desire of defending her eggs or her young, she tamely sits and suffers them to be taken from under her. Now and - then she just ventures to peck or to cry out when a person offers to beat her off. She feeds her young with fish macerated in her bag, and when they cry flies off for a new supply.

They are but disagreeable and useless domestics; their gluttony can scarcely be satisfied; their flesh smells very rancid, and tastes a thousand times worse than it smells. The native Americans kill vast num. bers; not to eat, for they are not fit even for the banquet of a savage, but to convert their large bags into purses and tobacco-pouches. They bestow no small pains in dressing it with salt and ashes, rubbing it well with oil, and then forming it to their purpose. It thus becomes so soft and pliant, that the Spanish women sometimes adorn it with gold and embroidery to make work-bags of.

Yet with all the hebetude of this bird; it is not entirely incapable of instruction. The emperor Maxi. milian had a tame pelican which lived for above eighty years, and always attended his army on the march.

The Albatross is one of the largest and most formidable birds of Africa and America. It is as large as a goose, of a brown colour, and is one of the most fierce of the aquatic tribe, not only living upon fish, but also such sinall water-fowl as it can take by surprise. It preys, as all the gull kind do, upon the wing, and chiefly pursues the flying-fish. These are every mo. ment rising to escape from their pursuers of the ileep, only to encounter equal dangers in the air. Just as they rise, the dolphin is seen to dart after them, but generally in vain. The gull has more success, and often takes them at their rise, while the albatross pur. sues the gull, so that the whole horizon presents but one living picture of rapacity and evasions.

But though this bird be one of the tyrants of the 


\section{0}

deep, there are some associations which eren tyrants form, either by caprice or necessity. The albatross has a peculiar affection for the penguin. They chuse the same places for breeding, some distant uninhabited island, where the ground slants to the sea, as the penguin is not formed either for flying or climbing. In such places their nests are seen together, as if they stood in need of mitual assistance. Our men upon Falk land islands were often amazed at the union preserved between those birds. In that bleak and desolate spot, where they no way dreaded the encroachments of men, they seemed to make their abode as comfortable as they expected it to be lasting. They built with an amaxing degree of uniformity; their nests covering fields by thousands, and resembling a regular planta. tion. In the middle on high, the albatross raised its nest, built of heath, sticks, and long grass, about two feet above the surface; round this the penguins made their lower settlements, rather in holes in the ground, and most usually eight penguins to one albatross.

Nothing is a stronger proof that the presence of man not only destroys the society of meaner animals, but their instincts also. These nests are now totally de. stroyed, the society is broke up, and albatross and penguins have gone to breed upon more desert shores in greater security.

The Swan is as delicate in its appetite, as elegant in is form. Its chief food is corn, bread, herbs growing in the water, and roots and seeds, which are found near the margin. It prepares a nest in some retired part of the bank, and chiefly where there is an islet in the stream. This is composed of water-plants, long grass, and sticks; and the male and female assist in forming it with great assiduity. The swan lays seven or eight eggs, white, much larger than those of a goose. It sits near two months befere its young are excluded, which are ash-coloured, for some months. It is dangerous to approach the old ones, when their little family is feeding round them. They soon take the 


\section{1}

alarm, and they sometimes give a blow with their pinion that breaks a man's leg or arm.

It is not till they are a twelvemonth old that the young swans change their colour with their plumage. All the stages of this bird's approach to maturity are slow, and mark its longevity. A goose has been known to live a hundred years, and the swan is sup. posed to live still longer.

The Gonse, in its domestic state, exhibits a variety of colours. The wild goose always retains the same marks; the whole upper part is ash-coloured, the breast and belly are of a dirty white, the bill is narrow at the base, and at the tip it is black. These marks are seldom found in the tame, whose bill is entirely red, and whose legs are entirely brown. The wild goose is rather less than the tanie; but both invariably retain a white ring round the tail, which shews that they are both descended from the same original.

The wild goose breeds in the northern parts of Ev. rope, and in the beginning of winter descends into more temperate regions. They are of ten seen flying at very great heights, in flocks from fifty to a hundred. Their cry is frequently heard when they are at an imperceptible distance above us: and this seems landed from one to the other, as among hounds in the pursuit.

Upon their coming to the ground by day, they range themselves in a line, and seem rather to descend for rest than refreshment. When they have sat in this manuer for an hour or two, one of them, with a loud long note, sounds a kind of charge, to which the rest attend, and pursue their journey with renewed alacrity.

The wild goose seldom lays above eight eggs, the tame goose oiten above twenty. The female hatches her eggs with great assiduity, while the gander visits her twice on thrice a day, and sometime's drives her off to take her place, where he sits with great state and composure.

vol. I. 
But beyond that of all animals, is his pride when the young areexcluded: he seems then to consider himself as a champion: he pursues dogs and men that never attempt to molest him; and though the most harmless thing alive, is then the most petulant and provoking. When, in this manner, he has pursued the calf or the mastiff, to whose contempt alone he is indebted for safety, he returns to his female and her brood in tri$u m p h$, clapping his wings, screaming, and shewing all the marks of conscious superiority.

The Soland.Goose, somew hat less than a land goose, is white; only the tips of its wings are black, and the top of the head yellow. The bill is long, and so sharp pointed, that it pierces an inch deep into a board, when they stoop at fish which are laid thereon: this is one way of catching thein. When they sleep they put their head under their wings ; but one keeps watch. If that be surprised by the fowler, which frequently happens, a!I the rest are easily caughit by the neck one after another. But if the sentincl cries and gives them warning, the whole flock escapes. When they fish for herrings, which come in shoals, they fly rear sixty yards high, and stoop perpendicularly: but when they aim at a single fish, they descend aslant.

'There is always one tribe anong them which is barren: these kcep together, and never mix with them that bivild and hatch. (Is it not probable that these are the males, like the drones among the bees?) The soland grese come to the Western Isles in Scotland in March, taking the advantage of a south-west wind. They send a few before them who make a towr round the isles, and then return to their company. In a few days after, the whole flock comes together, and stays till September. All this time they are daily making up their nests in the shelres of high rocks. Itrey fish, hatch, and make their nests by turns. In order to this, they amass together not only heaps of grass, but whatever else they find floating on the water. In a nest 


\section{3}

on St. Kilda, was found a soldier's red coat, and some Molucca beans in another.

They are thought the sharpest sighted of all sea. fowls. They have a large gorget somewhat like a pelican, in which one of them will preserve five or six herrings entire, and carry them to her nest, where they empty them out for food to their young. Nay, they have been observed to go a fishing to some isles which are thirty leagnes distant, and bring the fish in their gorget all that way.

In the isle of Rona (one of the Scotch Western isles) there are a couple of eagles, which the natires say, not only drive away their young as soon as they are able to fly, but keep pussession of the island, not suffering any of their kind to live there but them. selves:

There are also a couple of ravens in this island, which beat away all ravenous fowls. And when their own young are able to fly, they beat away them likewise.

That which in Iceland they call the Down.bird, is very remarkable : it is a species of duck, but covered with fine soft downy feathers. The drake is full as large as a goose, but the duck considerably smaller: They abound all over lceland, but particularly the western part, on account of the islands off the coast, where chiefly they build their nests : they build them with the down they pull from their breast. They lay four green eggs as large as a goose. The inhabitants then trke away both the eggs and the nest. The ducks go to work again, pull more down from th.tir breasts, and lay four eggs more, which are again inken away by the inhabitants. This does not however discourage the duck : she builds a third nest, and lays four more eggs : but the drake is now obliged to supply the down, the duck having none left. They now let her hatch her young: for if they disturb her a third time, she builds 


\section{4}

no more that year, nor ever returns to the same plase. When the young have left the nest, they take it a third time, and so have two sets of eggs, aud three parcels of down from the same nest.

The Bat seems a medium between bird and beast; but it comes nearer to the latter. They lay themselve's up and sleep for the winter montlis, in the dryest parts of caves. There fixing their talons in the roof, they cover their bodies with their wings, and hang perpendicularly in great numbers, but so as not to touch each other.

Who can account for another matter of fact which is particularly observed on the Western Islands? The Western ocean throws up on their shores great quantities of weather-beaten tinuber, on which hang multitudes of little shells fastened to one another, much as muscle-shells are. In every one of these shells is a perfect fowl : the little bill is like that of a goose, the eye marked, the head, neck, breast, wings, tail, and feet formed. The feathers are perfectly shaped, and of a blackish colour, and the feet like those of other water fowl: but we caunot hear of any person that ever saw any of them alive.

Now as bats are a kind of medium between beasts and birds, are not barnacles a kind of medium between birds and fishes.

1.will conclude this account of birds with one that seems to unite in itself somewhat of every class preced. ing. It is at once possessed of appetites for prey like the rapacious kinds, and an attachment to water like the birds of that element. It exhibits in its form the beautiful plumage of the peacock, the shadings of the humming bird, the bill of the crane, and the short ligs of the swallow. The bird I mean is the King Fisher: it is not much larger than a swallow; its shape is elumsy, the legs very small, and the bill very long; 


\section{$2+5$}

it is two inches from the base to the tip, but the colours of this bird atone for its inelegant form. The crown of the head and the edges of the wings are of a deep blackish green, spotted with bright azure; the back and tail are of the most resplendeut azure; the whole under-side of the body is orange-coloured; a broad mark of the same passes from the bill beyond the eyes, beyond that is a large white spot; the tail is short, and consists of twelve feathers of a rich deep blue; the feet are of a reddish yellow.

From the dininutive size, and the beautiful colours of this bird, no person would be led to suppose it so rapacious an animal. It is ever on the wing, and feeds on fish, which it takes in surprising quantities, balancing itself at a certain distance above the water for a considerable space, then darting down and seizing the fish with inevitable certainty.

The king fisher, with which we are acquainted, has none of those supposed powers of allaying the storm, or building upon the waves. It is contented to make its nests on the banks of rivers, in such situations as not to be affected by the rising of the stream. When it has found a place for its purpose, it hollows out with its bill a hole about a yard deep ; or if it fuds the deserted hole of a rat, it takes quiet possession. This hole it enlarges at the bottom, and lining it with the down of the willow, lays its eggs there without any further preparation.

The female begins to lay early in the season, and excludes her first brood about the beginning of April. The male brings her large provisions of fish, while she is thus employed, and she, contrary to most other birds, is fund fat at the season of hatching.

9. I have now only to add a few reflections.

And 1. That birds should all lay eggs, and odt bring M 3 
forth live young, is a clear argument of Divine Providence, designing their preservation thereby. For if they had been viviparóus, had they brought any num. ber at a time, the burden of their wnmb must have beetr so great and heavy, that their wings would have failed, and they become an easy prey to their enemies. And had they borne but one at a time, they would have been bearing all the year.

2. Since it would have been many ways inconvenient to birds to give suck, and yet inconvenient if not de. structive to the new-born chick, to pass suddenly from liquid to hard food, before the stomach was strengthened and able to digest it, and before the bird was ac. customed to use its bill, and gather it up, which it docs at first very slowly and imperfectly; therefore nature has provided in every egg a large yolk, which serv's the chicken a considerable time instead of milk. Mean time it feeds by the mouth a little at a time, and that more and more, till the stomach is strengthened to digest it.

3. Birds that feed their young in the nest, though they bring but one morsel at a time, and have perhaps seven or eight, which all at once, with equal greediness, hold up their heads and gape for it; yet never mistake, never omit one, but feed them all by turns.

4. Though birds cannot number, yet they are able to distinguish many from few ; and when they have laid as many eggs as they can cover, they give over, and begin to sit. Yet they are not determined to such a number: they can go on and lay more at their plea. sure. Hens, for instance, if you let their eggs alone, lay fourteen or fifteen, and give over; but if you with. draw their eggs daily, they will go on to lay five times that number. This holds not only in domestic birds, but also in the wiid. A swallow, when her eggs were withdrawu daily, proceeded to lay nineteen. 
5. It is remarkable that birds, and such other or to parous creatures as are long lived, hare eggs enonght conceived in them at first to serve laying for many years, allowing such a proportion for every year as will suffice for one or two incubations. Thereas insects, which are to breed but once, lay all their eggs at unce, be they ever so manyy

6. How exceeding speedy is the growth of hirds that are fed by the old ones in the nest. 1 Most of them come to near the full binness, within the short term of a fortnight : an admirable provision that they may not lie long in that helpless condition, exposed to the ravine of any vermin, and utterly unable to shift for themselves.

7. What amazing care do the parents take for the hatching and rearing of their young? First, they seek qut a secrel and equiet place, where they may be un. disturbed in their incubation. Then they make their nests, every one after his kind, that their eg $\tilde{5}^{s}$ and yourig may be soft and warm ; and those so elegant and artificial, as no art of man can imitate.

After they have daid their eggs, how diligently da: thog sit upon them, scarce giving themselves time to go off to get them meat? When the young are hatched, huw diligently do they brood over them, lest the cold should hurt them? All the while labouring hard to get them food, and almost starriig themselves, lest thry should want. Murcover, with what courage are they incpired, so as to venture their own lives in de. feure of them ? The most timorous, as hens and geese, daring then even to lly in the face of a man. Aad all the pains are bestowed upon those that will render them no thanks fur it! And they are bestowed just so. long as is necressary ; for when the young is able, to shift for itself, the old retains no stich alfection for it, but will beat it indifferently with others.

8. It is auother proof of a superiutending Providence, M 4 


\section{8}

that all animals are produced at the most convenient time of the year, just when there is food and entertainmint ready for them. So lambs, kids, and many other living creatures, are brought into the world in the spring, when tender grass and nutritive plants are provided for their foud. The like may be observed cuncerning sills-worms, whose eggs are hatched just when the leaves of the mulberry tree appear; the aliment being soft and tender, while the worms them. selves areso, and growing more strong and substantial as the insects increase in bulk and vigour.

9. A still farther proof hereof we have in the various instincts of animals, directed to ends which they know not, as, 1. All creatures know how to defond them. selves, and ofiend thelr enemies; all know what their natural weapons are, and how to make use of them. A boar knows the use of his tusks, a horse of his hoofs, a cock of his spurs, a bee of her sting. Yea a calf will make a push with his head, even before any horns appear. " $\because$. Thuse creatures which have not strength to fight, are usually swift of foot or wing, and are naturally inclined to make use of that swiftness, and save themselves by llight. 3. Every creature knows and shuns its natural enemy, as a lamb dows the wolf, and partridge or poultry birds of prey; and they make use of a peculiar note to warn their young of their approach, who thereupon immediately run to shelter. 4. As soon as ever it is brought forth, every animal knows its food. Such as are nourished with milk, inmediately find their way to the payss, and suck; whereas those which are desigued for other nourishment, never make any such attempt. 5. Birds that are fin-toed, or whole-footed, are naturally directed to go into the water. So ducklings, though hatched and led by a ben, if she brings them to the brink of a river or pond, presuntly leave her and go in, though they never saw any such thing before, and thongh the hen clucks and calls, and does all she can to keep them out. 6 . Birds of the same kinds make 


\section{9}

their nests of the same materials, laid in the same or. der, and exactly of the same figure, so that by the sight of the nest one may certainly know what bird it belongs to. And thi, though living in distant coun. tries, and though they never saw any nest made; that is, although they were taken out of the nest, and brought up by hand. Nor were any of the same kind ever known to make a different nest, either for matter or fashion, unless where the usual matter was not to be had; in, that case, some birds use what they can get.

I would add a little farther improvement of some particulars-mentioned before.

What master has taught birds that they have any need of nests? Who has warned them to prepare them. in time, and not to suffur thenselves to be prevented by necessity?: Who hath shewi them how to build? What mathematician has given the figure of them? What architect, has taught them to choose a firm place, and to build a solid foundation? What tender mother has alvised them to corer the bott m with a soft and delicate substance, such as cotto.1 or down, and when these fail, who has suggested to them that ingenious charity, to pluck offas inany feathers from their own: breast, as will prepare a soft cradle for their young?

Again. What wislum thas pointed out to each kind a peculiar manner, of building? Wino has comn inded the swallow, to instance in one, to draw near tomit, and make choice of this house fur the bulling her nent, within his view, withuat fear of his knuwny it, but secming rather to iuvite him to a consideration of her labour? Nor dies sho bund like other sirds, wrh birs or sticks and stubble, but emplays cim nt aid mortar, and tirat in so firm a manner, that it requines sme faitls (1) demulish her work. And yet su all t is, it has no other i.sstrument to wakse use of out a little beak.

Yot ugain. Who bas made th li, ds comprehend tha is 5 , 
they must hatch their eggs by sitting upon them : that this necessity is indispensible; that the father and mother could not leave them at the same time; and that if one went abroad to seck for food, the other must wait till it returns? Who has told them the precise number of days this painful diligence is to cost? Who has taught them to assist the young in coming out of the egg, by breaking the shell for them? Yea, and advertised them of the very moment before which they never come?

Who has taught several of the birds that marvellous industry of retaining food and water in their gullet, without swallowing either, and preserving them for their young, to whom this preparation serves instead of milk?

Is it for the birds, O Lord, who have no knowledge thereof, that thou hast joined together so many miracles? Is it for the men who give no attention to them? Is it for those who admire them, without thinking of thee? Rather is it not thy design, by all these wonders, to cail us to thyself? To make us sensible of thy wistiom, and fill us with confidence in thy bounty, who watchest so carefully over those inconsiderable creatures, two of which are sold for a farthing ?

But pass we from the industry of birds to hearken for a moment to their music: the first song of thanks. giving which was offered on earth before man was form. ed. All their sounds are different, but all harmonious, and altogether compose a choir which we cannot imirate. One voice however more strong and melodious I distinguish above the rest. On enquiry, I find it comes from a very small bird. This leads me to considcr the rest of tle singing birds : they likewise are all small; the grcat ones having a harsh and disagrceable voice. Such an amends is made to these weak little creatures for their defect of strength! 


\section{6}

Some of these little birds are extremely beautiful, nor can any thing be more rich or varicgated than their feathers : but it must be owned, that all ornament must give place to the finery of the peacock; upon which God has plentifully bestowed all the riches which set off the rest, and lavished upon it with gold and azure all the shades of every other colour. This bird seems sensible of its advantage, and looks is if it designed to display all its beauties to onr eyes, when it stalks along and expands that splendid circumference which sets them all in open view.

But this pompous bird has of all others that are kept tame, the most disagreeable cry, and is a proof that there may be a shining ontside, when there is little substance within.

In examining the feathers of the rest, I find one more circumstance very observable. That feathers of 5.wans and other water fowl are proof ajainst the water, and accordingly they continue dry, though the creature swims or dives ever so long; and yet neither our eyes nor all our art cau discover wherein they differ from others.

I know not how to conclude this chapter without adding a few more rellections.

All the universe is replenished with life, and every part of it with its properasimals : but would wice expect to see them in the air? Nothing seems more natural to our eyes; but nothing is more astonishing to our reasou. The fact is certain, and jet might seem to be altogether impossible. A bird in tlight is a nass raised aloft, in spite of the gravity of the air, aud the tendency of all bodies to the earth: lhis mass is raised not by any forcign force, but by a movement suited to the purpose of the creature, and which sustaiued it it the ail, for a considerable lime, with a peaceful vigour. 


\section{2}

Again. In the thole kingdom of bir's, none have more than two wings, and yet they all fly in a different manner. Some launch away by repeated springs.; others glide through the air with an even motion: these always skim orer the earth; those soar up to the clouds. Some know how to diversify their llight by a straight oblique, or circular motion : to suspend their bodics and cuntinue motionless in an element lighter than themsives : after this, to start into a horizontal notion, and then dart either to the right or left, wheel into a contrary tract, remount, and then precipitate themselves like a descending stone: in a word, they transport themselves without opposition or hazard wherever their necessities or pleasures call them.

'The structure of their nests, the care with which they attend their eggs, the mechanism of the egg itself, and the birth and education of their young, are equal. Jy astonishing. See the perfect similitude that appears in all the nists of birds of the same species, the con. stant difference between the nests of one species and another; together with the neatness and precaution which all of them observe. One species builds its uest on the top of trees, another on the sround, under a canopy of grass, but alirays with a shelter, either of herbs or a branch, or a dunble roof of leaves, down which the rain slides, without entering the opening which lies conceald below. The outward parts of the nest is made of solid materials, thorns, reeds, chay, or compact moss; the inner of softer materials clusely interwoven, so as to keep out both winds and insects. But each species has a peculiar taste. When the building is completed some hang the inside with a tapestry of feathers, or quilt it with wool or silk.

How admirably does this display the wisdom of Him who furmished man with reason, which extends to every thing around him, and inspired aninals with an imitalion of it, limited inded to a few points, but ad. 
inirable in that limitation? For who informed the bird that she should lay eggs, and want a nest tolodge and nourish them with genial heat? That this heat would not be concentered round the eggs, if the n:st. were too large, and that were it smaller it would not be capable of containing all the young? Who has taught her not to mis-calculate the time, or lay her eggs before she has completed her nest?

The same wisdom will more fully appear, if swe ob. serve what the egg contains, with the manner how the young is there formed, and how it issues from its cons. finement.

The yolk lics in the heart of the egg, inclosel ia the first membrane, which is surrounded by the second. Near the centre of the egg are the ligaments that sustain the yolk, which is contained in a peculiar -membrane. A second membrane incloses the first white, a third and fourth encompasses the whole. The shell is furmed last of all out of the salts evacuated from all the humours of the bolly, which the heat gradually fixes and consolidates, to serve a double purpose, first that it inay be excluded without crush. ing the contents; secondly, to defend their youig, till it is thoroughly formed, and ready to forsake the egg.

Under the membrane which surrounds the yolk is a white speck, which is the seed of the chick in ininia. ture. If the smallest portion of the vital spirit be ine fused into it from the male, by a process of wach we have no idea, in the instant the chick receires life, and the whole substance is in motion. 1 it is not infused, the egg may indeed be laid, but it never comes to a living creature.

The pulsation of the heart bears some analogy to the pendulum of a clock, from wiose viorations the whole machine derives all its motions : the mument the heart begins to beat, the animal is alive, and rectives by the umbilic duct, the nourishment which it trans. 


\section{4}

mits to the other ressels, whose branches distribute it to the whole body. All those little canals which were flat before, are now swelled and enlarged : the whole substance imbibes a proper aliment, and the chick begins to grow.

In this situation of the speck out of which it is formed, one circuinstance is highly remarkable. This minute particle which is lodged on the film that includes the yolk is always near the centre of the egg, and toward the body of the dam, in order to be im. pregnated with a necessary warmth; but in how admirable a manner is this effected? The yolk is sustained by tro ligaments, which fasten it on each side

- to the common membrane, that is glued on the shell. $A$ line drawn from one ligament to the other woulh not pass through the middle of the yolk, but above the centre, and cut the yolk in two unequal parts, so that the smaller part which contains the seed, is of necessity raised towards the belly of birds that sit: the other part as necessarily subsides, so that let the egg turn as it will, the young receives no hurt, bat still enjoys a warmth that puts all about it in motion. So it feeds at case, first on the white, which is more thin and delicate, and afterwards on the yolk, which af. fords more substantial oourishment. When his bill is hardezed, and he grows uneasy at his confinement, he pecks and breaks the shell, and issues out fully replenished with the yolk, which nourishes him a little longer, till he is strong enough to raise nimself upon his feet, and can march about to look for provisions. 


\section{5}

\section{CHAPTER III.}

\section{OF FISHES,}

1. The number of Fishes.

2. Their Covering.

3. Their Brain.

4. Organs of Sense:

5. Gills or Lungs :

6. Heart:

7. Air-Bladcler:

8. Stomach:
9. Fins:

10. Experiments on Fish.

11. Of Shell-Fish.

12. Of the Generation of Fishes.

13. Of some particular Sorts of Fishes.

14. General Reflections.

IIE ocean is the great receptacle of fishes. It has been thought by some, that all fishes are naturally of the salt element, and that they have mounted up into fresh water by some accidental migrations. A few still swim up rivers fto deposit their spawn; but the great body of fishes, of which the size is enormous, and the shoals endless, keep to the sea, and would expire in fresh water. In that extensive and undiscovered abode, millions reside, whose manners are a secret to us, and whose very form is unknown. The curiosity of mankind, indeed, has Jrawn some from their depths, and his wants many more. With the figure of these at least he is acquainted: but for their pursuits, societies, antipathies, pleasures, times of gestation, and manner of bri!ging forth these, all are hidden in the turbu'ent element that protects them. 
1. The number of fish to which we have given names, and of the figure, at least, of which we know something, are above four hundred. Thus to appearance the history of fish is tolerably copious, but when we come to examine, it will be found the greatest part of these, we know very little of.

2. As most animals that live upon land have a covering to keep off the injuries of the weather, so all that live in the water are covered with a slimy glutinuus matter, that, like a sheath, defends their bodies from the surrounding fluid. 'This substavce, secreted from the pores of the animal's body, serves not only to defead but to assist the fish's casy progress through the water. Beneath this, in many kines, is found a strorig covering of scales, that, like a coat of mail, defends it still more powerfully, and under that, before we come to the muscular parts of the body, an oily substance, which supplies the requisite warmth and rigour.

3. It is observable in all, that thongh their heads are much larger in proportion to their budies, yet their brain is considerably less than that of other animals. It consists of only two small rentricles placed in the fore-part of the head.

4. Their organs of sense do not much differ from those of other animals; but in their eyes this is peculiar, that they are quite spherical, and that the optic nerves, in cuming from the brain, cross each other: whereas in other animals they incline a little to cach other, bat du not meet. A protuberant eye would have been inconrenient for fishes, by hindering their motion in so dense a medium, and their continually brushing through the water would have been apt to wear their eyes; therefore their cornea is flat : but to make amends for this, and for the refraction of water, different from that of air, the wise Creator has made their crystalline spherical, which in other animals is 


\section{7}

more fat. It was formerly believed they did not hear at all; but from later experiments, there is reason to beliove that several species of them do hear, thongh but in a low degree. Over the two holes in their head, which serve for stielling, a fine inembrane is spread, by which means they can open and shut them at pleasure; a contrivance higbly necessary for creatures that live in the water.

The sense of smelling which in beasts is so exquisite, and among birds is not wholly unknown, seems given to fishes in a very moderate proportion. It is true that all fishes have one or more riostrils, and even those that have not the holes perceptible without, yet have the proper formation of the bones for smelling within. But as air is the only medium we know, for the distribution of odours, it cannot be supposed that these animals residing in water can be possessed of any power of being affected by them. If they have any perception of smells, it must be in the saine manner as we distinguish by our taste; and it 1 s probable, the ol. factory membrane in fishes, serve them instead of a distinguishing palate: by this they judge of substances that first tincturing the water with their vapours, are thus sent to the nostrils of the fish, and no doubt produce some kind of sensation. 'This most probably must be the use of that organ in those animals, as otherwise there would be the instrument of a sense provided for them, without any power in them of enjcyment.

Hearing in fishes is found still more imperfect, if it be found at all. Certain it is, that anatomists have rot been able to discover, except in the whale kind, the smallest traces of an organ of hearing, either within or without the head. Indeed, of what advantage would this sense be to animals that are incapable of making themselves heard? They have no voice to communicate with each other, and consequently have no need of an organ for hearing. 


\section{8}

Seeing seems to be the sense which fishes are possessed of in the greatest digree. And yet even this is obscure, if we compare it to that of other animals. The eye, in almost all fish, is covered with the same transparent skin that cuvers the rest of the hearl, and which probably serves to defend it from the water, as they are without eye-lids. The globe of the eye is depressed before, and is furnished behind with a muscle which serves to strengthen or flatten it, ac. cording to the necessities of the animal. The crystalline humour, which in beasts is flat, and of the shape of a button mould, in fishes is as round as a pea, or sometimes oblong like an egg.

From all this, it appears that fishes are extremeiy near-sighted, and that even in the water they can see objects only at a very small distance.

Thus nature seems to hare fitted these animals with appetites and powers of an inferior / lsind, and formed them for a sort of passive existence in the obscure and heavy element to which they are consigned: to preserve their own existence, and to continue it to their posterity, fill up the whole circle of their pursuits and enjoyments.

5. Some fishes have lungs, but in the greater part the place of them is supplicd by gills. As we take in and throw out the air by our lungs, so they take in the air, mixed with the water, by their mouth, and throw it out by their gills.

1. There is always much air enclosed in water. This the gills separate from it, and present to the blcod; as it is presented in the lungs of other animals. Each gill contains a great number of bony laminæ, consist. ing of an infinity of bony fibres, that sustain the in. numerable ramifications of the veins and arteries, which present the blood extremely sub-dividcd, and as it were, each glosule by itself to the water: betw een the lamina, through the wholecontexture of the gills, 


\section{9}

are an infinity of very narrow passages, which receire and diride the water taken in by the mouth, into minute particles. Then the air, its prison-doors being in some measure opened, escapes and joins the blood of all the little arteries.

The gills have an alternate motion of dilatation and compression. When they dilate, the water is taken in ; when they contract, it is driven out. It seems that in the instant of contraction, the air expressed from the water is forced into the blood-vessels. It is the same, as to our lungs. The air euters them at the time of inspiration, but is received into the blood at the time of expiration only. So that the water which is taken in by the mouth of fishes, when stripped of its air, is carried off by the gills. Meantime the air which is thus gained is distributed first to those fine ramifications of the arteries, which are ex. panded upon the gill throughout, and then to the veins inosculated therewith. And fishes can no more live without a constant supply of this, than land ani. mals can.

The gills in ull fishes are eight, four on each side. The lower gill is always smaller than the rest. The other three on each side are gradually larger to the top one, which is always the largest. Each of these is formed of a bony substance, bent into the shape either of a semicircle or a bow. On the convex side of this, there is a sort of plumes or leaves, each of which consists of a double row of bony lamella, formed like so many sickles, and fixed to the convex side of the bow by means of the membrane wherewith it is coverel.

These lamella have one part convex, and the other concare. The concave part of each lamella is applied to the convex part of the next opposite lamella. Every lamella is invested with a fine membrane, which receives the ramifications of the blood-vessels. Every gill has an artery, a vein and a nerve. The gills receive the blood which is thrown from the heart into the aorta, and derive it to the utmost parts of the 
lamella, from whence it returns by veins which dis. tribute it throughout the body.

6. In most tishes the heart is like that in other animals. But in some it has only one ventricle; which necessarily occasions a difference in the manner wherein the blood circulates. In some also the blood is not red, but clear and transparent. In others, especially shell-fish, besides the arteries and veins, there are open tubes, which convey the water to the farthest part of them: probably that they may find no want of water, when they continue some time on shore.

7. The air-bladder is described as a bag filled with air, sometimes composed of one, sometimes of two, and sometimes of three divisions, situated towards the back of the fish, and opening into the maw or the gullet. It is commonly supposed, by its swelling at the will of the animal, to increase the surface of the fish's boily, and so to enable it to rise to the top of the water, and keep there at pleasure. On the contrary when the fish wants to descend, it is supposed to empty this bladder of its air, and to sink to the bottom.

But many fishes have an air bladder, that continually cravl at the bottom; such as the eel and the flounder: and many more are entirely without it, that swim in every depth; such as the anchovy and the fresh-water gudgeon. Indeed, the number of fishes that want this organ is alone a sufficient proof that it is not uecessiry for the purposes of swimming ; and the ventral fins, which in all fishes lie flat upon the water, are fully sufficient to keep them at all depths.

8. The stomach is, in general, placed pext the mouth, and though not sensibly hot, is endued with a surprising faculty of digestion. Its digestive power seems in some measure to increase with the quantity 


\section{1}

of food it is supplied with; a single pike haring been known to devour a hundred roaches in three days. Its faculties also are as extraordinary, for it digests not only soft fish, but prawns, crabs and lobsters, shells, and all. These the cod or the sturgeon will not only devour, but dissolve, though their shells are so much harder than the sides of the stomach which contains them. This amazing faculty in the cold stomach of fishes has justly excited the curiosity of philosophers : and has effectually overturned the system of those who suppose the heat of the stomach is alone a sufficient instrument for digestion. 'I'he truth seems to be, that there is a power of animal assimulation lodged in the stomach of all creatures, which we can neither describe nor define, converting the substances they swallow into a fluid, fitted for their own peculiar support. This is done neither by trituration, nor by warmth, nor by motion, nor by a dissolving fluid; but by some principle yet unknown, which acts in a different manner from all kinds of artificial maceration.

Yet though fish are thus hungry, and for ever prowling, no animal can suffer the want of food for so long a time. The gold and silver fish which we keep in vases, seem never to want any nourish. ment at all; whether it be that they feed on the water-insects, too minute for our observation, or that water alone is a sufficient supply. Even the pike, the most voracions of fishes, will live in a pond where there is none but himself, and what is more extraordinary, will be often found to thrive there.

Air however is so necessary to all fish, that they can live but a few minutes without it : yet nothing is more difficult to be accounted for, than the manner in which thay obtain this necessary supply. Those who have seen a fish in the water, imust remember the motion of its lips and its gills, or at least of the bones on each side that cover them. This motion in 
the animal is without doubt, analogous to our breath. ing, but it is not air, but water, that the fish actually takes in and throws out through the gills at every motion.

The manner of its breathing seems to be this. The fish first takrs a quantity of water by the mouth, which is driven to the gills, these close and keep the water so swallowed from returning by the mouth, while the bony covering of the gills prevents it from going through them, until the animal has drawn the proper quantity of air from the body of water thus imprisoned : then the bony covers open and give it a free passage; by which means also the gills again are opened, and admit a fresh quantity of water. Should the fish be prevented from the free play of its gills, or should the bony covers be kept from moving, by a string tied round them, the animal would soon fall into courulsions and die in a few miuntes.

9. The chief instruments in a fish's motion are the fins, which in some are much more numerous than in others. A fish completely fitted for sailing is furnished with two pair; also three single fins, two above and one below. Thus equipped it migrates vith the utmost rapidity, and takes royages of a thousand leagues in a season. But such fish as have the greatest number of fins have not al ways the swiftest motion. The shark is one of the swiftest swim. mers, yet it wants the ventral fins; the haddock does not move so swift, though it has them.

The fins not only assist the animal in progression, but in rising or sinking, in turning, or even leaping out of the water. 'To answer these purposes, the pectoral fins serve like oars, to push the animal forward. They are placed behind the opening of the gills; they are generally large and strong, and answer the same purposes to the fish as wings do to a bird. Those also balance the fish's head, when it is too 


\section{3}

large for the body, and keep it from timbling prone to the bottom, as is seen in large headed fishes, when the pectoral fins are cut off. Next these are the ven. tral fins, placed under the belly. These are always seen to lie flat on the water, in whatever situation the fish may be; and they serve rather to raise or depress the fish, than to assist its progressive motion. The dorsal fin is situate along the ridge of the back; and serves to keep it in equilibrio. In many fishes this is wanting ; but in all flat fishes it is very large, as the pectoral fins are proportionably small. Lastly, the tail, which in some fishes is flat, and upright in others, seems the grand instrument of motion; the fins are subservient toit, and gire directions to its impetus, by which the fish darts forward with so much velocity. To explain all this, by experiment, a carp is taken, and pat into a large vessel. The fish, in a state of repose, spreads all its fins, and seems to rest upon its pectoral and venfral fins near the bottom : if the fish folds up either of its pertoral fins, it inclines to the lane side; folding the right pectoral fin, the fish in. clines to the right side; folding the left fin, it incliries to that side. When the fish desires to have a retrograde motion, striking with the pectural fins, in a contrary direction produces it. If the fish de. sires to turn, a blow from the tail sends it abont; but if the tail strikes both ways, then the motion is progressive.

10. There is something extremely odd in the experiments of an ingenious man, on some of our common ishes.

"I put a banstickle, says he, in a glass jar filled with water : at first it refused to eat any thing, which is common with all fishes; birt afterward it grew so tame as to take small worms out of my hand. Nay, it was so bold at last, that when its belly was full, it wuuld set up its prickles, and with all its strength, make a stroke at my fingers, if put them near it. 
66 This fishwas so unsociable, that it would suffer no other fish to live in the jar with it, and so auda. cious as to attack whatever $I$ put in, though ten times its own size. One day I put in a small ruff; the ban. stickle instantly assaulted it, and tore off part of its tail, and I am persuaded would have killed it, had I not separated them.

In 6 The abilities they use to get from place to place, are likewise extraordinary. Thongh they are scarce two inches long, I have seen them leap out of the water a foot high perpendicularly, and much farther obliquely, when they wanted to get over some obstacle in their way.

"6 Nature has furnished them with a kind of breast. plate, to be a deferuce against outward injury, and with prickles upon their sides and back, which they erect on the least appearance of danger.

"6 I have always olasived among the fish I keep in jars, that such as I keep awhile together, con. tract so great an affection for each other, that if they are separated, they grow melancholy and sullen. $A$ bout Christmas I put two ruffs into a jar, where they lired together till A pril. I then gave one of them to a friend, the other was so affected, that for three weeks it would eat nothing. Fearing it would pine to death, I sent it to its companion : being put to this, it ate immediately, and presently recovered its former briskness."

"In the beginning of September," says the same gentleman, "6s I procured a small dace, which 1 kepit in a glass jar till the latter end of May following. All this while it ate nothing except the small animalcules, which happened to be in the water:I gave it, once a day in winter, twice or thrice in the spring, as the weather grew warmer. When the water was fresh, it cane up to the top-about once an hour, to blow out some small bubbles of air. Then putting its niose near the surface, it took in fresh, and retired to the bottom again. But as the water became less 


\section{5}

pure by its use, its returns to the surface were more frequent, and at last it would remain there continually, till I gave it a fresh quantity. I believe I might have kept it for years, but business one day prevented me from giving it clean water in due time, which put a period to the life of my little companion.

"At first it would not suffer me to come nigh the glass, without the utmost confusion and surprise; but at last it grew so tame, that if 1 came but in sight, it would be sure to be at the same sicle of the glass, and lie gazing at me, until I was weary of observing it. I often took the opportunity of looking at it by candle-light, which it seemed to take great pleasure in.

"In the above-mentioned month, I put into another glass, a ruff about three inches long. At first he too appeared mighty reserved, and would not eat, nor suffer me to come nigh him; but in a short time all. powerful hunger tamed him : for he could not like the dace, live on the small inliabitants of the water, and so was quickly forced to take whatever I provided for him. In awhile it grew so tame that it would not only eat small worms which I threw in to the glass, but would take them out of my hands. Nay, it would eyen rise out above the water for them ; which is contrary to the way wherein this kind of fish uses to take its food. At last it would come to my hand, whenever I put it in to the glass, and suffer me to handle it. When I had made all the observations I thought proper, after eight months I gave him his li. berty."

11. It has long been supposed that all shells, as well as the animals in them, arose wholly from the egg. But it is now found by various experimerits, that the shells of snails (and probably of all other animals) are formed of a matter which perspires from their bodies, and then condenses round them. - havos? 


\section{6}

It is certain all animals perspire and are encem. passed with an atmosphere which exhales from them. Suails have nothing peculiar in this respect, unless that their atmosphere condenses and hardens about them, and forms a visible cover for the body, while that of other animals evaporates. This difference may arise from the different substance perspired; that from snails being viscous and stony. This is no sup. position, but a matter of fact, proved by numerous experiments.

But the re-production of the shells of some fish, yes, and of the parts contained therein, is far more strange and unaccountable, than their first production. This is particularly observed in crabs and lobsters. Lobsters cast their shell yearly, some time after midsummer. In the rocm of the old, a new, thin shell is immediately prepared by nature, which in less than eight days, acquires alniost the same degree of hardpess as the other.

The legs of a lobster consist of five articulationg. When any of these legs break, which frequently happens, the fracture is always near the fourth joint, and what they lose is precisely reproduced in some time after: four joints shooting out, the first wheroof has two claws, as before.

If a leg be broken off purposely at the fourth or fifth joint, it is constanily reproduced : but very rarely, if at the first, second, or third joint. What is still more supprising is, that upon visiting the lobster, which is maimid in these barren articulations, at the end of two or three days, all the other joints are found broken off at the fourth, which he has uitdoubtedly done nimself.

Thie part re-produced is perfectly like that broke off, and in a certain time grows equal to it. Hence it is, that lobsters have often their two big legs unequal. This shews the smaller leg to be a new one. If a part thus re-produced is broken off, there is a second reproduction. The suramer, which is the 


\section{7}

only, time whon lobsters eat, is the most farourable time for this. It is then performed in four or five days; otherwisc it takes op eight or vine months.

The common crab-fish has its abode from twenty to forty fathom water. They herd together in distinct tribes, and have their separate haunts for feeding and breeding, and will not associate with their neighbours. This has been tried by marking a crab, car. rying it two or three miles, and leaving it among other crabs. This crab has afterward found its way home, and been caught in its old abode.

This creature too can break off its own limbs. If when it is laid on its back, one of the outer joints of a small leg be bruised, he -shews uneasiness, by moving it about. Afterward he holds it quite still, in a direct and natural position, without touching any part of the body, or of the other legs with it. Then on a sudden with a gentle crack, the wounded part of the leg drops off. If a hole be pierced in the great leg, the elfect will be the same; and the large limb is thrown off in the same manner, only with greater violence. A mucus then overspreads the wound, which presently stops the bleeding; and a small leg is by degrees produced, which gradually attains the size of the former. Nature has given this singular power to these creatures, for the preservation of their lives in their frequent quarrels. In these, one crab lays hold of the claw of another, and crushes it in such a manner, that it would bleed to death, had it not the power of giviug up the limb, and healing the wound.

However different in figure the lobster and the crab may seem, their manners are nearly the same. Though without any warmth in their bodies, or even red blood, they are wonderfully voracious. What. ever they seize upon that has life, is sure to perish, though pever so well defended: they even derour each 


\section{8}

other: and, to increase our surprise, they may in some measure, be said to eat themselves, as they change their shell and their stomach erery year, and their old stomach is generally the first morsel that serves to glut the new.

What this animal differs in from all others, is, that the spinal marrow is in the breast-bone. It is furnished with two long feelers or horns, that issue on each side of the head, to correct the dimness of its sight, and apprize the animal of its danger, or of its prey. The tail is the grand instrument of motion; and with this it can raise itself in the water.

When the young lobsters leave the parent, they seek for refuge in the smallest clefts of rocks, and in crevices at the bottom of the sea. There they grow larger in a few weeks, from the accidental substances which the water washes to their retreats. By this time also they acquire a hard firm shell, which furnishes them with both offensire and defensive armour. They then issue from their fortresses, and creep along the bottom, in hopes of meeting with plunder. The spawn of fish, the smaller animals of their own kind, but chiefly the worms that keep at the bottom of the sea, supply them with plenty. They keep in this manner close among the rocks, busily employed in scratching up the sand with their claws for worms, or surprising such heedless animals as fall withiu their grasp: th us they have little to apprehend, except from each other, for in them, as among fishes, the large are the most formidable of all enenies to the small.

But the body of the lobster still continuing to increase, the animal soon becomes too large for its habitation. In general all aumals change their shell once a year; and this is a most painf season is gerierally about the beginning of summer; at which time their food is plenty, and their strength and vigour in the highest perfection. But soon all their activity ceases : they seck some retired situation among the rocks, where they remain in safety from 


\section{9}

the attacks of their various enemies. For some days before their change, the animal discontinues its ysual voraciousness; it is no longer seen harrowing up the sand at the bottom, or fighting with others of its kind, or hunting its prey : it lies torpid and motionless. Just before casting its shell, it throws itself, upon its back, strikes its claws against each other, and every limb seems to tremble; its feelers are agitated, and the whole body is in violent mation. It then swells itself in an unusual manner, and at last the shell begins to divide at its junctures; particularly at the junctures of the belly, where like a pair of jumps, it was before but seemingly united. It also seems turned inside out; and its stomach comes away with its shell. After this it disengages itself of the claws, which burst at the joints ; the animal, with a tremulous motion, cast. ing them off, as a man would kick of a boot that was too big for him.

'Ihus this wonderful creature is at liberty; but so weak that it continues for several hours inotionless. Indeed, so violent and painful is the operation, that many of them die under it ; and those which survive, for some time neither take food, nor venture from their retreats. Immediately after this change, they have not only the softness, but the timidity of a worm. Every animal of the deep is then a powerful enemy, which they can neither escape, nor opposes and this is the time when the $\log$-fish, the cod, and the ray devour them by hundreds. But this state continues for a very short time : in less than two days, the skin that covered its body is grown almost as hard as before.

When the lobster is completely equipped in its net shell, it appears how much it has grown in the space of a very few days. The old shell being compared with those of the new, it is increased above a third in its size ; and, like a boy that has outgrown his clothes, it seems wonlerful how the deserted shell was able to contain so great an animal as entirely fills up the Dew. 


\section{0}

It may be worth observing, that lobsters use their tails as fins, wherewith they commonly swim back. ward, by jerks or springs, reaching sometimes ten yards at a spring. For this purpose, as the gill-fins of uther fishes, which are their oars, are a little concave backward, these have the plates of their tails, when they bend them down as they use to do, a little concave forward.

Different from all these are the land crabs of the Caribbee islands; which live in a kind of orderly society, within their retreats in the mountains; and regularly once a year march down to the sea side in a body of some millions. They chuse the months of April and May to begin their expedition : and then sally out from the stumps of hollow trees, from the clefts of rocks, and from the holes which they dig for themselves under the surface of the earth. At that time the whole ground is covered with this band of adventurers. The sea is their place of destination, and to that they direct their march. No geometrician could send them to their destined station, by a shorter course. They never turn to the right or left, whatever obstacles interveue. And even if they meet with a house, they will attempt to scale the walls, to keep the unbroken tenor of their way. But upon some oe. casions they are compelled to conform to the face of the country; and if it be intersected by rivers, they wind along the course of the stream. They are com. monly dirided into three battalions; of which, the first consists of the strongest and boldest males, that like pioneers, march forward to clear the route, and face the greatest dangers. These are often obliged to halt for want of rain, and wait till the weather changes. The main body of the army is composed of females, which never leave the mountains till the rain is set in, and then descend in regular battalia, in columns of fifty paces broad, and three miles deep, and so close, that they almost cover the ground. Three or four days after this, the rear-guardfollows; a straggling undis. 
ciplined tribe, consisting of males and females, but neither so robust, nor so numerous as the former. The night is their chief time of proceeding; but if it rains by day, they do not fail to profit by the occasion. And they continue to move forward in their slow, uniform manner. When the sun shines hot, they make an universal halt, and wait till the coos of the evening. When they are terrified they march back in a disorderly manner, holding up their nippers with which they sometimes tear off a piece of the flesh of an assailant, and leave the weapon where they inflicted the wound. They often clatter their nippers together, as if it were to threaten those that come to disturb them. But though they thus strive to be formidable to man, they are much more so to each other; lor if any of them by accident is maimed in such a manner, as to be incapable of proceeding, the rest fall upon and devour it on the spot, and then pursue their journey.

When after a fatiguing march, perhaps of three months, they arrive at their destined purt, they prepare to cast their spawn. The peas are as yet with. in their bodies, and not as is usual in animals of this kind, under the tail. And the creature waits for the benefit of the sea.water, to help the delivery. For this purpose, the crab has no sooner reached the shore, than it eagerly goes to the edge of the water, and lets the waves wash over its body, two or three times. Then they withdraw to seek a lodging upon land : in the mean time, the spawn grows larger, is excluded out of the body, and sticks to the baibs under the tail. In this state of pregnancy, they once more seek the shore, and shaking off the spawn into the water, leave it there. At this time whole shoals of hungry tish are in expectation of this annual supply. The sea to a great distance is black with them ; and about two thirds of the crabs eggs are im. mediately devoured. The eggs that escape are hatched. under the sand; and soon aiter millions at a time of at 4 


\section{2}

these little crabs are seen quitting the shore, and slowly travelling up to the mountains.

The old ones however are not so active to return; they are become so feeble, that they can hardly creep along. Most of them therefore, are obliged to continue in the flat parts of the country till they recover, making holes in the earth, which they cover at the mouth with leares and dirt. There they throw off their old shells. At that time they are quite naked, and almost without motion for six days. They have then under their stomachs four large white stones, which gradually decrease in proportion as the shell hardens, and when they como to perfection, are not to be found. It is at that time the animal is seen slowly making its way back, and all this is commonly performed in six weeks.

There is likewise an animal of the lobster-kind that annually descends from its mountains, not only to produce an offspring, but to provide itself a covering ; not only to secure a family, but to furnish a house. I mean the Soldier Crab. It is about four inches long, has no shell behind, but is covered down to the tail with a rough skin, terminating in a point. But what nature has denied this animal, it takes care to supply by art; and taking possession of the deserted shell of some other animal, it resides in it, till, by growing too large for its habitation, it is under the necessity of a change. It is a native of the West India Islands, and every year descends from the mountains to the seashore, to deposit its spawn, and to provide itself with a new shell. Its first care is to provide for its offspring, and it is thought, from the number of little shells which it is seen examining, that it deposits its spawn in them, which thus is placed in perfect secisrity till the time of exclusion.

It is then mintful of itself. It is still seen in its old shell, which it has considerably outgrown : a part of the naked body is seen at the mouth of it, which 
the habitation is too small to hide. A shell therefore, is to be found large enough to cover the whole body; and yet not solarge as to be unmanageable. To an. swer both these ends is no easy matter, nor the attainment of a slight enquiry. The little soldier is seen "busily parading the shore along that line of pebbles and shells that is formed by the waves; still, however, dragging its old habitation at his tail; unwilling to part with one shell, till it can find another more con. venient. It is seen stopping at one shell, turning it and passing it by, going on to another, contemplating that for awhile, and then slipping its tail from its old habitation to try on the new. This also is found to be inconvenient, and it quickly returns to its old shell again. In this masner it frequently changes, till at last it finds one, light, roomy, and commodious. To this it adheres, though the shell be sometimes so large as to hide the body of the animal, claws and all.

Yet it is not till after many trials, and many combats also, that the soldier is thus completely equipped. For there is often a contest between two of them, for some well-looking shell. They hoth elldeavour to take purstssion: they strike with their claws; they bite each other, till the weakest is obliged to yield. It is then that the victor takes possession, and para les in his new conquest three or font times backward and forward upon the strand, before his envius antagonist.

Crabs-cyes, so callel, are found in the bodies of cray-fish. Kach fish produces two yearly, ont on each side of the stomach, between the coats of it. Here it grows, coat upon coat, and is supplied with petrifying juic s, oy vissels opening on the uner surface of the outwa d coat. The first scale, whereof all the others are formed, may be perceived in the centre; the bims or circumferences of many of the rost b ing likewise apparent It is lo li, red, that they cast these stonez with their shells yenty; but this is iv 5 


\section{4}

not the case. For about the time of casting their shell, the stones break through the internal coat of the stomach, and being thrown by the three serrated teeth therein, become dissolved in the space of a few days, which makes it difficult to find them just at this time.

They eat their old shells immediately after shed. ding them. Perhaps these stones may be designed to furnish new petrescent juices to its fluids, for the re-production of their annual dress.

As to turbinated shell-fish of the snail-kind, we may first observe the snail itself. This is surprisingly fitted for the life it is to lead. It has the organs of life in a manner almost as complete as the largest ani$\mathrm{mal}$; a tongue, brain, salival duets, glands, nerves, stomach, and intestines; liver, hrart, and blood ves. oels : besides this it has a purple bag that furnishes a red matter to different parts of the body, together with strong muscles, that hold it to the shell, and which are hardened like tendons at their insertion.

But theseit possesses in common with other animals. - We must now see what it has peculiar to itself. The first striking peculiarify is, it has got its eyes on the points of its largest horns. When the snail is in mo. tion, four horms are seen distinctly:' but the two longest deserve peculiar considerarion, both on account of the various motions with which they are endued, and of their having eyes at the extreme ends of them. These appear like two blackish points. The animal can direct them to different objects at pleasure, by a regular motion out of the budy; and sometimes it hides them by a very swift contracion into the belly. Under the small horns is the animul's mouth; and though it ray appear too soft a substance to be furmished with teerh, yet it has no less than eight of them, with which it devours leaves and other substances seemingly harder than itself. 


\section{5}

It may seem whimsical to make a distinction be tween the animal perfections of turbinated and bivalve shell-fish, or to grant a degree of superiority to the snail above the oyster. Yet this distinction apparently obtains in nature; and we shall find the bivalved tribe of animals in every respect inferior to the other. Inferior in all their sensations; inferior in all their motions; but peculiarly i.ferior in their systen of animal generation. The snail tribe are hermaphrodit." ; but require the assistance of eack other for fecundation; all the bivalre tribe are hermaphrodite in like manner, but they require no assistance from each other towards impregnation; and a single muscle or oyster, if there were no other in the world, would quickly replenish the ocean.

The multitude of muscles is in some places very great; but irom their defenceless state, the number of their destroyers are in equal proportion. The crab, the cray-fish, and many other animals are seen to devour them ; but the tochus is their most formidable enemy. When their shells are found deserted, if we then observe clogely, it is most probable we shall find that the tochus has been at work in piercing them. There is scarce one of them without a hole in it; and this probably was the ave. nue by which the enemy entered to destroy the inhabitant.

But notwithstanding the number of this creature's animated enemies, it seems still more fearful of the agitations of the element in which it resides; for if dashed against rocks, or thrown far on the beach, it is destroyed without a power of redress. In order to guard against these, which are to this animal the commovest and the moit fatal accidents, although it has a power of sluw motionwhich I shalt presently describe, yet it endeavours to become stationary, and to at tach itself to any fixed object it happens to be near. For this purpose it is furnished with a very singalar capa. city of binding inclf by a number of threads to what. ever object it approaches; And these Reaumus sup. s 6 
poses it spins artifieially, as spiders their webs, which they fasten against a wall. Be this as it will, nothing is more certain than that the muscle is found attached by these threads to every fixed object; sometimes, indeed, for want of such an object, these animals are found united to each other, and though thrown into a lake separately, they are taken out in bunches of many together.

To have some fixed resting place where the muscle can continue, and take in its accidental food, scems the seat that this animal chiefly desires. Its instrument of motion by which it contrives to reach the object it wants to bind itself to, is that muscular substance resembling a tongue, which is found long in proportion to the size of the muscle. This the animal has a power of thrusting out of its shell ; and with this it is capable of making a slit in the sand at the bottom. By means of this furrow it can erect itself upon the elge of its shell: and thus continuing to make the furrow in proportion as it goes forward, it reaches out its tongne, that answers the purposeof an arm, and thus carries its shell edge-ways, as in a groove, until it reaches the point intended. Then where it determines to take up its residence, it fixes the ends of its beard, which are glutinots, to the rock, or the object whatever it be; and thus like a ship at anchor, braves all the agitations of the waters. Sometimes the animal is attached by a large number of threads; sometimes but by tñree or four, that seem scarce able to retain it. When the muscle is fixed in this manner, it lives upon the little earthy particles that the water transports to its shells, and perhaps the flesh of the most diminutive animals. However, it does not fail to grow considerably; and sume of thiskind have been found a foot long I have seen the beards of a foot and a half; and of this substance the natives of Palermo make gloves and stocking.

Oysters usually cast their spawn in May, which at first appears like drops of candle-grease, and stick to 


\section{7}

any hard substance they fall upon. These are covered with a shell in two or three days, and in three years the animal is large enough to be brought to the market.

The Scallop is particularly remarkable for its method of moving forward upon land, or swimming upon the water. When it finds itself deserted by the tide, it moves towards the sea in a most singular manner. It first gapes!with its shell as widely as it can, the edges being of ten an inch asunder; then it shuts them with a jerk, and by this the whole animal rises five or six inches from the ground. It thus tumbles any how forward, and renews the operation until it has attained its journey's end. When in the water it is capable of supporting itself on the surface; and there opening and shutting its shells, it tumbles over and over, and makes its way with some celerity.

The Razor-shell has a very different kind of motion. As the former moves laboriously forward, so the razor. shell has only a power of sinking downward. The shells of this animal resemble nothing so much as the haft of a razor ; and by this form it is enabled to dire into the soft sand. All its motions are confined to sinking or rising a footdownwards or upwards inthe sand, for it never leaves the spot where first itwas planted. From time to time it raises about half way out of its hole: but if any way disturbed sinks perpendicularly down again. Just over the place where the razor buries itself, there is a small hole like a chimney, through which the animal breathes or inbibes the sea water. Ujion the desertion of the tide, these holes are easily distinguished by the fishermen; and their method of enticing the razor up is by sprinkling a little sea-salt upon the fiole. This melting, no sooner reaches the razor below, than it rises instantly, and shews above half its length alsore the surface. This appearance is instantaneons; and if the fisher does not seize the oppertunity, the razor buries itself 


\section{8}

to its former depth. There it continues secure; no salt can allure it a second time; but it remains unmolested unless the fisher will be at the trouble of digging it out, sometimes two feet below the surface.

Multivalve shell-fish may be considered as animals shut up in round boxes. To view their habitations externally. one would be little apt to consider them as the retreats of living creatures; and still less, to suppose that some of them carry thiir boxes with a tolerable share of swiftness, so as to escape their pursuers. Of these there are principally two kinds; such as move, and such as are stationary : the first are usually known in our cabinets by the name of sea-eggs; the others are often admired for the cavities which they sroop out for their habitation in the hardest marble. The first are valled, by naturalists, Echini, or urchins: the latter are called Pholades, or filefish. Of both these are several surts; but by describing these two, we shall have a competent idea of all the rest.

To a slight view, the Sea-urchin may be compared to the husk of a chesnut; being like it, round and with a number of bony prickles standing out on every side. If we could conceive a turnip stuck full of pins on erery side, and running upon these pins with some degree of swiftness, we should have some idea of this ex.raurduary creature. The mouth is placed downwarjs; the vent is abuve; the shell is a hollow vase, rese bling a scooped apple; and this fited with a soft muscular substance, through which the intestines wind Irom the bottom to the top. The mouth, which is placed undermost, is large and red, furnished with fi ie silarp teeth, which are easily discerned. The jaws are strengthened by fine sinall bones, in the centre of which is a small tleshy tongue : and from this the intestines make a winding of fire spires, round the internal sides of the shell, ending at the top, 


\section{9}

where the excrements are excluded. But what malces the most extraordinary part of this animal's confirma. tion, are its horns, and its spines, that point from every part of the body, like the horns of a snail, and that serve at once as legs to move upon, as arms to feel with, and as instruments of capture and defence. Between their horns it has also spines that are not en. dued with such a share of motion. The spines and the horns issue from every part of the body, the spines being hard and prickly, the horns being softer, longer than the spines, and never seen except in tho water. They are put forward and withdrawn like the horns of a snail, and are hid at the base of the spine, serving as was saill before, for procuring food and motion. All this apparatus, however, is only seen when the animal is hunting his pry at the bottom of the wafer; for a few minutes after it is taken, all the horns are withdrawn into the body, and most of the spines drop off.

It is generally said of insects, that those which have the great'st number of legs, always move the slowest: but this aninal seems to be an exception to the rule; for though furnished with two thousand spines, and twelve hunired horns, all servirg for legs, and which from their uumber seem to impede each other's motion, jet it runs with some share of swiftness at the bottom, and it is sometimes no easy matter to overtake it.

Very different in motion, though not much different in shape from them, are the Acorn Shell-fish, the Thumb.footed Shell-fish, and the Imaginary Barnacle. These are fixed to one spot, and appear to regetate from a stalk. Indeed, to an inattentive spectator, each actually seems to be a kind of fungus that grows in the deep, destitute of animal life, as well as motion. But the enquirer will soon change his opinion, when he comes to observe this mushroom.like figure more ninutely. He will then see that the animal residing within the shell, has not ouly life, but some degree of 


\section{0}

Poraciousness; that it has a cover, by which it opens and shuts its shell at pleasure; that it has twelve large crooked arms, furnishcd with air, which it thrusts forth for its prey; and eight smaller, which are ge. nerally kept in the shell. They are seen adhering to every substance that is to be met with in the ocean; rucks, roots of trees, ships buttoms, whales, lobsters, and even crabs; like bunches of grapes clung to each other. It is amusing enough to behold their operations. They for some time remain motionless within their shell; but when the sea is calm, they are ssen opening the lid, and peeping about them. 'They then thrust out their long neck, look round them for some time, and then abruptly retreat back into their box, shut the lid, and lurk in darkness and security.

Among the shell-fish on the Waterford coast, is the Murex, which gare the Tyrian parple. - It is in great plenty there, and is by the English called a horse-winkle. The sho!l is about an inch long, and half an inch broad, and turns spirally like a suailshell. Each fish has a peculiar reservoir, which contains a large drop of liquor: if this is pressed out on linen, the linen first appears of a dirty yellow, inclining to green, afterward it changes to a lemon- colour, then to a deep green; then it turns to a deep blue, and at last to a charming purple.

The shells of the ancient purple-fish, are still common in the Tyrian shore. The fish itself is fuund in great abundance in the seas of the Spanish West. Indies, near Panama and Niccya, exactly agrecing with Pliny's acconnt of the ancient Murex. Clith of Segovia, died with this purpley is sold for twenty crowns an ell, and is very rarely worn by any, but the greatest noblemen in Span. The Caribbe islands have also the same sort of fish, which we may likewise find nearer hume, namely on the coasts of Somerset. shire, as well as of South-Wales. 
The pearl nuscles lie partly open : the inside of the shell is of a pearly colour. The pearl lies in the smaller end of it, at the extremity of the gut, and out of the body of the fish, between the two films that line the shell. This answers to the stone in other animals, increasing by crusts growing over one another. Accordingly if a pearl be pinched in a vice, the upper coat will crack and leap away. And as it is now known, that the shells of fishes are formed of stony matter oozing out of their body, it is no wonder if that matter when it chances to overflow, bursts forth in any cavity of the body, and forms a little mass, which hardening, becomes a pearl of the same colour with the shell.

Whereas all other animals take in untriment by the mouth, the muscle takes it in by the anus. The part called the head though without eyes, ears, or tongue, is immovably fastened to one of the shells, so that it cannot receive any thing. The food of a muscle is water, which as the shell opens, enters in at the anus, and passing on by certain canals running between the shell and the animal, is thence conveyed in to the mouth.

We have lately discovered a progressive motion in those shell-fish, which were supposed to be quite fixed. Even oysters, which one would think wholly iminovable, if they are thrown irregularly into a vessel of water, will in a while turn themselves till the smooth shell becomes uppermost: otherwise they could hold no water in the concave shell for their sustenance.

Muscles can walk on the ground, which they do in this manner. Lying on the flat side of their shell, they thrust ont a part, in form of a tongue, wherewith - they make little motions to the right and left, and thereby dig a passage in the sand. In this digging they drop' gradually on one side, and so get the shell mousted on its edge ; then they stretch ont the tongue as far as they can, and rest for a minute or fwo on 


\section{2}

its extremity to draw the shell after them, as water. snails do. This motion is repeated as long as they please : thus they form a sort of groove in the sand, which sustains the shell on either side, and leaves behind then a sort of irregular tract, three or four yards long. In rivers abounding with muscles one may see many of them, with a muscle at the end of each.

That called the arm or a leg in a sea-muscle, which in its natural state is uot above two lines long, may reach out of the shell two inches : and the muscle having laid hold on a fixed point therewith, bends and shortens it and so drags itself on. The beard serves for an anchor to fasten it to some heary body, that it may not be carried away with the motion of the waves.

When a pond muscle walks, it thrusts out its whole belly, in form of the keel of a ship, and creeps on the belly as the serpent dues. So true it is, that mature is not confined in her manner of operation, but is evcry varying, though nerer confused.

In Port-Mahon harbour, there are stones from half a hundred to five hundred weight each, lying at all depths, full of shells, each containing a single fish of the muscle-kind. The holes in the surface are far narrower than the hole in which is the fish, which it seems is capabie of enlarging its room as it grows bigger, by abraiding the sizes of its cells. And this is apparent, from the sandy matter found in the bottum of those cells, whenever the orifice is higher than the bottom; for then the fish cannot throw it out.

The Bollani likewise in the Adriatic sea, live in large stonts. Tneir stiell is rough and oblung, nit unlike a date. They are found in several kinds of porous stones. In the pores of these the spawil is deposited. Fr quently the aperture, through which it was injected, is nolonger perceivable; but the fish thrives 


\section{3}

notwithstanding. On breaking some of these stones, one finds near thirty live fish, though no opening can be perceived on the outside. Each has just room to open its shell, the inside of which is white, the outside ash-colour ; the largest is four or five inches long. Both the fish itself and its juices are so luminous, one may see to read by it; and even water in which it has been squeezed, put into a glass, will shine ten or twelve hours.

Likew ise in Toulon harbour are found solid stones containing in separate cells, seciuded from all communication with the air, several living shell.fish. The same are found along the coast of Alcona, in stones weighing fifty pounds and upwards. The outside of which is soft, but the inside so hard as to require an iron mall, and a strong arm to break them.

Pholades Bullani, when divested of their shells, resemble a roundish, soft pidding, with no instrument that seems in the least fitted for boring into stones, or even penetrating the soitest substance. A pholas is furnished with two teeth indecl; but these are placed in such a situation as to be incaplable of touching the hollow surface of its stony dwelling. It has also two covers to its shell that open and shut at either end; but these are totally unserviceable to it as a miner. The instrument with which it performs all its operations, and buries itself in the hardest rocks, is onily a broad flesiy substance, somew hat resembling a tongue, that is seen issuing from the bottom of its shell. With this soft yielding instrument, it perforates the most solid marbles; and having, while little and young, made its way, by a very narrow passage into the substance of the stone, it then begins to grow bigger, and thus to enlarge its apartment. While yet naked and very small, it has effected an entrance, and has buried its body in the stune : it there continues for life at its ease ; the sea-water that enters at its apertures supplyivg it with luxurious plenty. Wher 


\section{4}

the animal has taken too great a quantity of water, it is seen to spurt it out of its hole with some violence. Upon this seemingly thin diet, it quickly grows larger, and soon finds itself under a necessity of enlarging its habitation and its shell. The motion of the pholas is slow beyond conception; its progress kecps pace with the growth of its body ; and in proportion as it grows larger, it makes its way farther into the rock. When it has got a certain way in, it then turns from a certain direction, and hollows downward; till at last when its habitation is completed, the whole apartment resembles the bowl of a tobacco-pipe: the hole is the shank, being that by which the animal entered.

- Thus immured, the pholas lives in darkness, indoJence, and plenty; it never removes from the narrow mansion into which it has penetrated; and seems perfectly content with being enclosed in its own sepulchre. The influx of the sea-water, that enters by its little gallery, satisfies all its wants; and with. out any other food, it is found to grow from seven to eightinches long, and thick in proportion.

Yet the pholas thus shut up is not so solitary an animal as it would at first appear; for though it is immured in its hole without egress; though it is impossible for the animal, grown to a great size, to get out by the way it made in, yet many of this kind meet in the heart of the rock, and like miners in a siege, who sometimes cross each others galleries, they frequently break in upon each others retreats : whether their thus meeting be the, work of accident or of choice, few can take upon them to determine; certain it is they are most commonly found in numbers in the same rock ; and sometimes above twenty aro discovered within a few inches of each other.

As to the nest, this animal is found in greatest num. ber at Ancona in Italy; it is found along the shores of Normandy and Poitou, in France ; it is found also upon same of the cuasts of Scatlat, and in ge. 


\section{5}

neral is considered as a very great delicacy at the ta. bles of the luxurious.

One of the most extraordinary kinds of shell-fish is the Animal-flower, in Barbadoes. In the parish of St. Lucy, on the north-side of the island, there is a high rocky cliff fronting the sea, near the bottom of which is a large cave. This opens into another cave, the bottom of which is a bason of water. In the midst of this bason is a rock, always covered with water : on the sides of which, a few inches below the water, are seen at all times of the year, issuing out of little holes, what have the appearance of finely ra. diated flowers, in size, colour and shape greatly resembling a common marygold.

If you attempt to pluck one of these, as soon as your fingers come within two or three inches of it, it contracts, closes up its border,and shrinks back in. to the hole of the rock. But if left undisturbed for a few minutes, it issues again and soon appears in full bloom. This might induce one to believe, that it was no other than an aquatic sensitive plant.

But on a nearer inspection we may discern four dark-coloured filaments, rising from the centre, moving with a quick and spontaneous motion, and frequently closing, to seize its prey, much like the claws of a lobster. So that the seeming flower is really an animal; and its body, which appeared to be the stalk of the flower is black, about as big as a raven's quill.

It seems the vivid yellow colour of its feelers, is ab. solutely necessary to procure its food. The water in the cave having no motion, cannot bring any food to them. Therefore the Creator has endued this creaturewitha qualitywhich may allure its prey. For bright colours invite many aquatic animals, as the flame of a candle does flies. 

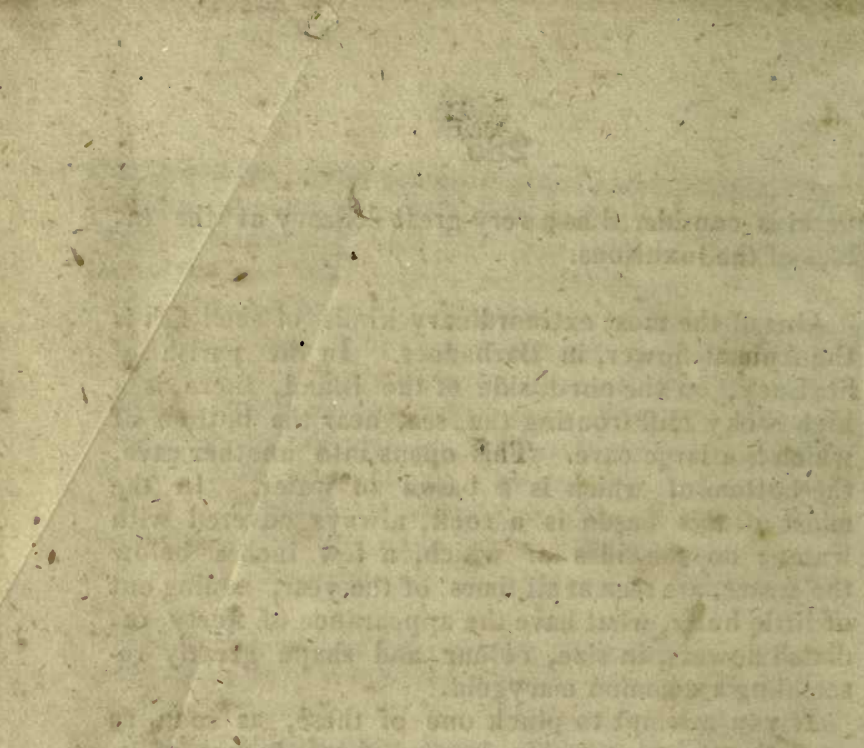

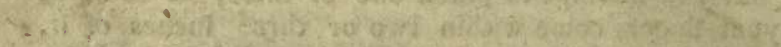

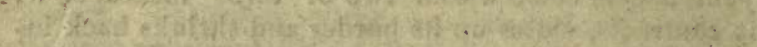

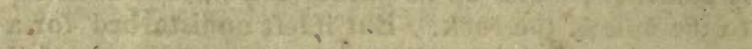

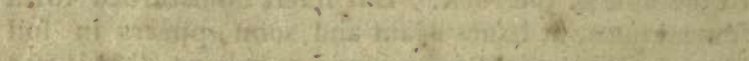

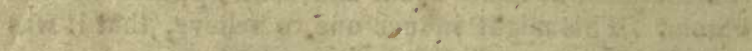

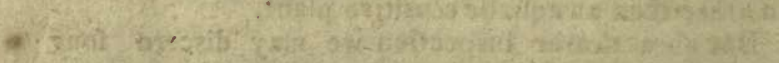

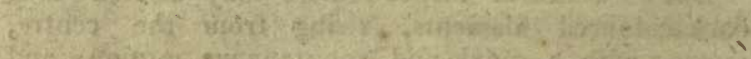

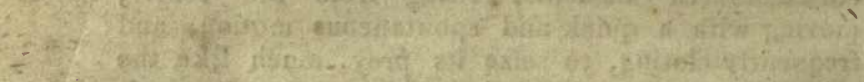

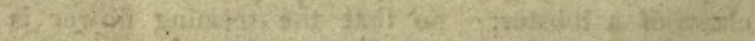

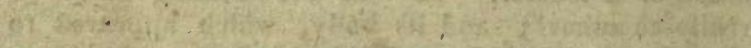

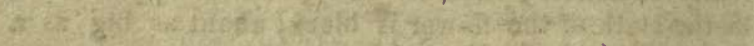

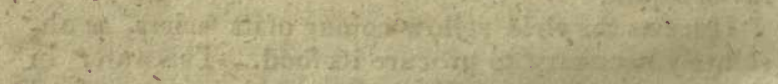
-

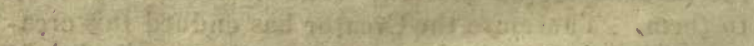

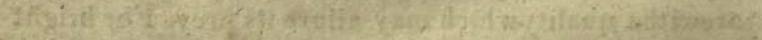
If Al. 303 




\section{U. C. BERKELEY LIBRARIES}

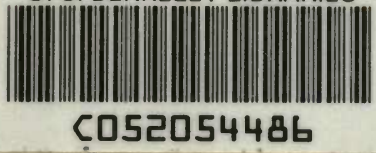




\section{mes \\ 2.}

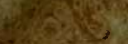

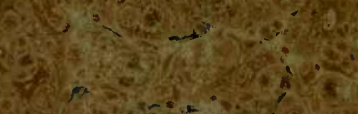

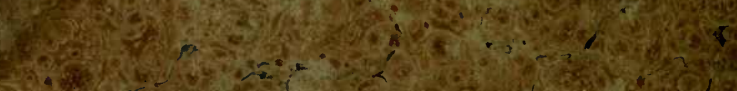

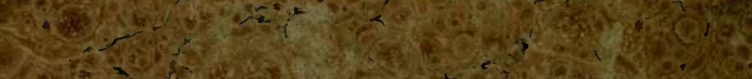
5.

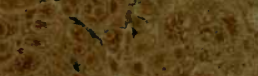
4. $9 x^{2}+2$

ces

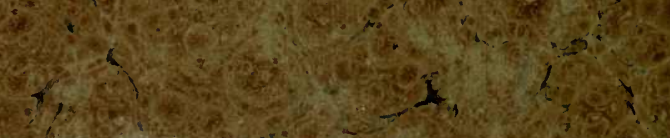

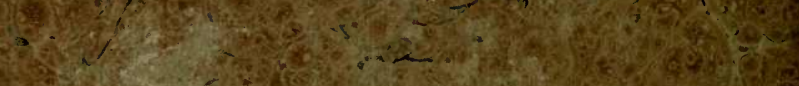
1.

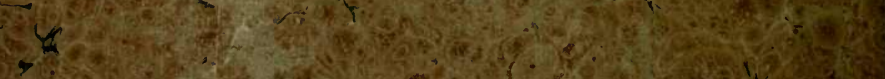

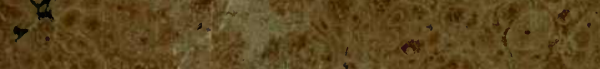

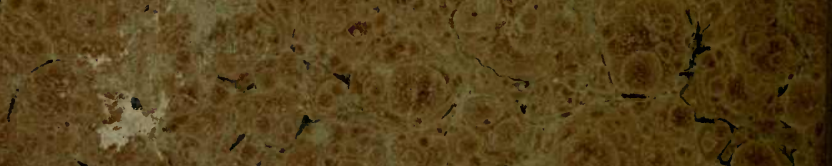

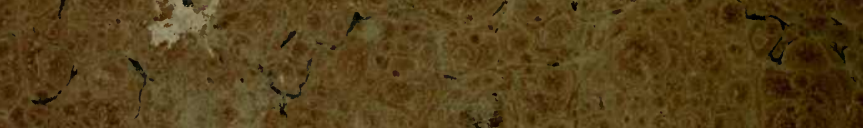

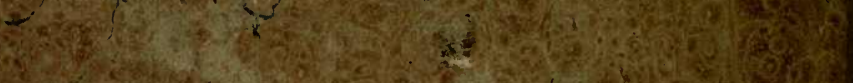
4.

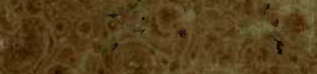

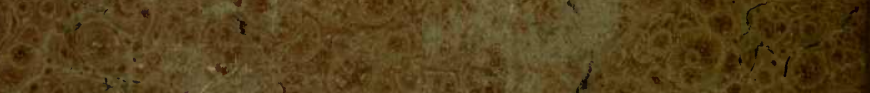

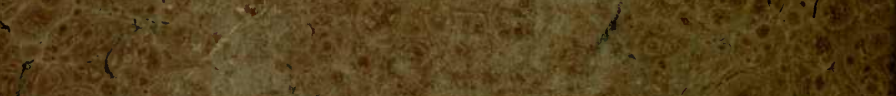

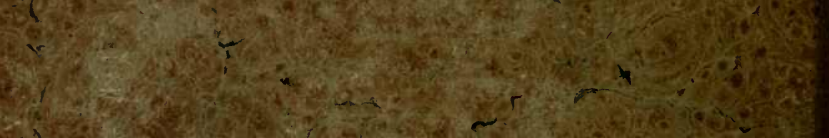

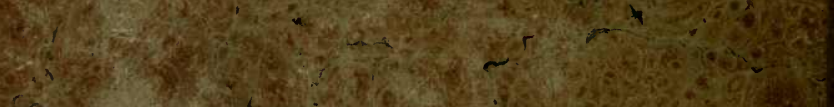

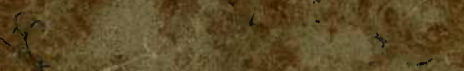

Sintion

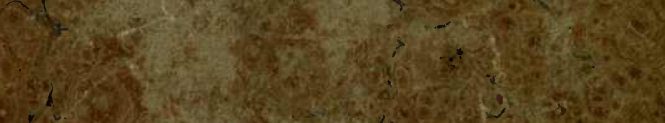

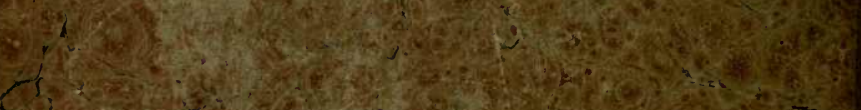

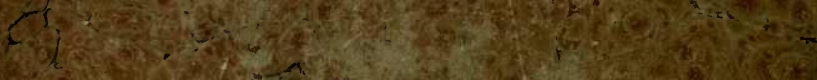

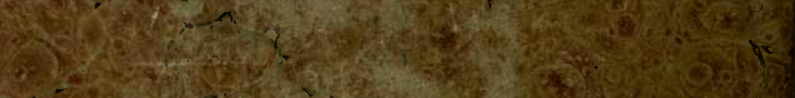

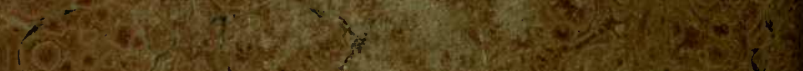

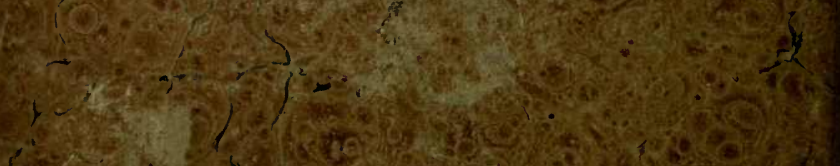

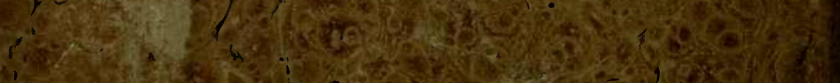

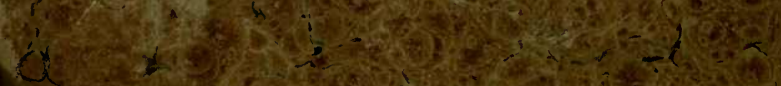

